\author{
Economics Working Paper Series
}

\author{
2018/017
}

\title{
Imperfect mobility of labor across sectors and fiscal transmission
}

Olivier Cardi, Romain Restout and Peter Claeys

The Department of Economics

Lancaster University Management School

Lancaster LA1 4YX

UK

All rights reserved. Short sections of text, not to exceed two paragraphs, may be quoted without explicit permission, provided that full acknowledgement is given. 


\title{
IMPERFECT MOBILITY OF LABOR ACROSS SECTORS AND FISCAL TRANSMISSION*
}

\author{
Olivier $\mathrm{CARDI}^{\dagger}$ \\ Lancaster University Management School \\ Romain RESTOUT ${ }^{\ddagger}$ \\ Université de Lorraine BETA (CNRS UMR 7522) \\ Peter CLAEYS ${ }^{\S}$ \\ Vrije Universiteit Brussel
}

\begin{abstract}
Our paper investigates the impact of government spending shocks on relative sector size and contrasts the effects across countries. Using a panel of sixteen OECD countries over the period 1970-2007, our VAR evidence shows that a rise in government consumption i) increases the share of non tradables in labor and real GDP while lowering the share of tradables, and ii) causes a significant increase in non traded wages relative to traded wages. While the first finding reveals that the non traded sector is more intensive in the government spending shock and experiences a labor inflow that increases its relative size, the second finding suggests the presence of labor mobility costs preventing wage equalization across sectors. These labor mobility costs appear to play a key role in determining changes in relative sector size across time and space. Whilst the responses of intersectoral labor reallocation and sectoral shares are found empirically to decline over time, the share of non tradables increases more in countries where the degree of labor mobility across sectors is higher. To account for our evidence, we develop an open economy version of the neoclassical model with tradables and non tradables. Our quantitative analysis shows that the open economy model is successful in replicating the responses of sectoral output shares to a fiscal shock, as long as we allow for a difficulty in reallocating labor across sectors along with adjustment costs to capital accumulation. Finally, calibrating the model to country-specific data, we are able to generate a cross-country relationship between the degree of labor mobility and the responses of sectoral output shares which is similar to that in the data.
\end{abstract}

Keywords: Fiscal policy; Labor mobility; Investment; Current account; Non tradables; Sectoral wages.

JEL Classification: E22; E62; F11; F41; J31.

\footnotetext{
${ }^{*}$ We are grateful to Agustin Benetrix for sharing RATS codes and to Luisito Bertinelli who provided invaluable help at different stages of the paper. We thank Benjamin Born, Falko Juessen, Gernot Müller for providing us with the dataset they constructed containing forecasts for government spending and Laura González Cabanillas for the dataset covering time series for the budget balance-GDP ratio forecast. We are grateful to Francisco Alvarez-Cuadrado, Christophe Hurlin, Stefan Schubert, Stephen Turnovsky for very helpful comments. We have also benefited from suggestions by participants at seminars and conferences. Obviously, any remaining shortcomings are our own.

${ }^{\dagger}$ Corresponding author: Olivier Cardi. Correspondence address: Lancaster University Management School, Bailrigg, Lancaster LA1 4YX. E-mail: o.cardi@lancaster.ac.uk.

${ }^{\ddagger}$ Correspondence address: Université de Lorraine, Université de Strasbourg, CNRS, BETA, 54000, Nancy, France. Phone: +3303545043 72. Fax: +3303545043 51. E-mail: romain.restout@univ-lorraine.fr.

${ }^{\S}$ Correspondence address: Vrije Universiteit Brussel, Faculteit Economische en Sociale Wetenschappen, Pleinlaan 2, B-1050 Brussel. E-mail: peter.claeys@vub.ac.be.
} 


\section{Introduction}

Does a government spending shock affect the production sectors in an open economy uniformly? If not, how can we explain the heterogeneity in the sectoral effects of a rise in government consumption? Does the magnitude of the sectoral effects vary across time and across countries and what factors cause such variations? Our paper provides an attempt to answer these questions by exploring the sectoral effects of a government spending shock empirically and calibrating an open economy version of the neoclassical model with tradables and non tradables.

The motivation for the analysis of the sectoral effects of a rise in government consumption is based on our panel VAR evidence for 16 OECD countries over the period 1970-2007. First, our evidence reveals that a government spending shock has a strong expansionary effect on hours worked and output in the non traded sector relative to the traded sector. Such a finding suggests that the rise in government consumption is biased toward non traded goods. Second, we also find empirically that a government spending shock leads to a shift of labor toward the non traded sector, increasing its relative size. Such a reallocation of labor toward the non traded sector is costly, however, as we detect empirically a significant increase in non traded wages relative to traded wages. Third, when we turn to cross-country differences, these labor mobility costs are found to play a pivotal role in explaining international differences in the sectoral impact of fiscal policy. More precisely, we find that both the increase in the share of non tradables and the decline in the share of tradables are more pronounced in countries where the degree of labor mobility across sectors is higher.

Estimates of the responses of sectoral output shares to a government spending shock allow us to evaluate the contribution of the reallocation of resources to sectoral fiscal multipliers empirically. More specifically, our evidence reveals that a rise in government spending by one percentage point of GDP increases non traded output by $0.7 \%$ of GDP on impact while the output share of non tradables rises initially by $0.35 \%$ of GDP. Since the latter result indicates that non traded output would increase by $0.35 \%$ if GDP remained constant, the reallocation of resources toward the non traded sector thus contributes to $50 \%$ of non traded output growth. The rise in the share of non tradables in real GDP also suggests that the non traded sector receives a disproportionate share of the shock to government spending. In this regard, our estimates show that government consumption of non tradables contributes $90 \%$ on average to increases in government spending.

While government spending shocks are biased toward non tradables and generate a substantial reallocation of resources which significantly affects the relative size of sectors, our evidence suggests some difficulty in reallocating labor between sectors. By hampering the shift of hours worked between sectors, the presence of labor mobility costs should 
mitigate the changes in relative size of sectors following a rise in government consumption. A first way to gauge the role of labor mobility costs is to investigate how impact responses of relative sector size vary over time and whether their movements are positively related to labor reallocation following our identified government spending shock. Our estimates reveal that the responses of sectoral shares are reduced over time by about $40 \%$ and that this reduction is concomitant and highly correlated with the decline in the rate of workers shifting from one sector to another. While changes in relative sector size vary over time, our estimates also reveal large variations across space. Importantly, we empirically detect a positive cross-country relationship between the change in relative sector size following a government spending shock and the degree of labor mobility, the latter being measured by estimating the elasticity of labor supply across sectors.

To account for our evidence on fiscal transmission, we put forward an open economy version of the neoclassical model with tradables and non tradables. In calibrating the model to a representative OECD economy, we allow for the fraction of higher government consumption expenditure on non tradables to be larger than the share of non tradables in real GDP, in line with our evidence, so that the government shock is biased toward non tradables. Our quantitative results show that the model is successful in replicating the sectoral effects of government spending shocks as long as we allow for imperfect mobility of labor across sectors and capital adjustment costs. ${ }^{1}$ With these two features, the model produces a rise in the share of non tradables by 0.38 percentage point of GDP, close to our empirical findings. ${ }^{2}$ If we remove both or either one of these ingredients, the model fails to account quantitatively for our evidence on fiscal transmission, in particular the responses of sectoral output shares which we estimate empirically. Intuitively, if we do not allow for capital adjustment costs, a government spending shock leads to a dramatic fall in investment which offsets the rise in government consumption. As a result, the excess demand in the non traded goods market is low or even nil. Due to low incentives to shift resources toward the non traded sector, the open economy experiences a trade balance surplus resulting in the model substantially understating the rise in the share of non tradables. Conversely, if we allow for capital adjustment costs, the decline in investment is mitigated, which leads to significant excess demand in the non traded goods market. However, if we impose perfect mobility of labor across sectors, high incentives to shift resources toward the non traded sector result in a large trade balance deficit which leads the model to overstate the rise in the share of non tradables considerably.

\footnotetext{
${ }^{1}$ To generate imperfect mobility of labor, we consider limited substitutability in hours worked across sectors along the lines of Horvath [2000]. See e.g., Bouakez et al. [2011], Cardi and Restout [2015] who assume that sectoral hours worked are aggregated by means of a CES function in order to account for the evidence related to monetary policy shocks or the long-run effects of productivity shocks biased toward the traded sector.

${ }^{2}$ Whereas our study differs greatly from that by Phelan and Trejos [2000] in terms of both objective and modelling strategy, like the authors, we show that the combined effect of sectoral intensity in the government spending shock and imperfect mobility of labor across sectors matter for fiscal transmission.
} 
The final exercise we perform is to investigate whether the model can account for crosscountry differences in the responses of sectoral output shares to a fiscal shock. We thus calibrate the model to match data from the 16 OECD countries regarding dimensions such as the non tradable content of labor, consumption, investment, government spending, and the elasticity of labor supply across sectors capturing the degree of labor mobility. In line with the evidence, the decline in the output share of tradables and the rise in the output share of non tradables are more pronounced in countries with a higher degree of labor mobility. We find quantitatively that impact responses of sectoral output shares to a government spending shock are sensitive to the degree of labor mobility, as they vary between $0.26 \%$ and $0.49 \%$ of GDP for non tradables when we move from the lowest to the highest value of elasticity of labor supply across sectors. Although the model tends to understate changes in the relative size of sectors, it is able to generate a cross-country relationship between the responses of sectoral output shares and the degree of labor mobility that is similar to that in the data.

We contribute to the extensive literature investigating fiscal transmission both empirically and theoretically by focusing on the reallocation effect of government spending shocks. Like Ramey and Shapiro [1998], we emphasize the importance of the composition of government spending in understanding the sectoral effects of a fiscal shock. Whilst the authors consider three episodes of expansionary defense spending in the United States driven by foreign policy, we identify exogenous increases in government consumption by assuming that discretionary government spending is subject to certain decision and/or implementation lags, as proposed by Blanchard and Perotti [2002]. Putting aside the advantages and disadvantages inherent to the narrative and SVAR approaches, the identification scheme does matter, as the identified government spending shock can be intensive either in tradables or non tradables. ${ }^{3}$ While the Ramey-Shapiro narrative approach suggests that military shocks, which are heavily concentrated in the manufacturing sector, are intensive in traded goods, our study reveals that government spending shocks, identified on the basis of Blanchard-Perotti assumption, lead to a sharp increase in non traded output relative to traded output.

This finding is in line with estimates documented by Monacelli and Perotti [2008] and Benetrix and Lane [2010], which show that an increase in government spending disproportionately benefits the non traded sector. In contrast to the authors who restrict their attention to sectoral output effects, we highlight the changes in sectoral shares in labor and real GDP. In this regard, one major finding is that the share of non tradables in employment and real GDP increases significantly, while the share of tradables declines. These

\footnotetext{
${ }^{3}$ To deal with the potential endogeneity problem inherent to the SVAR approach, in a robustness exercise, we augmented each VAR model with the 'spending-based' events variable constructed by Guajardo, Leigh, and Pescatori [2014]. Overall, our results show low sensitivity to the identifying assumption. We thank one referee for having drawn our attention to this dataset.
} 
findings reveal that government spending shocks are strongly biased toward non tradables and generate a reallocation of labor across sectors that affects their relative size. ${ }^{4}$ Like Perotti [2008], we find that the sector which is relatively more intensive in the government spending shock experiences an increase in real wages. In contrast to Perotti who considers Ramey-Shapiro episodes (i.e., Vietnam War and the Carter-Reagan buildup) and finds empirically higher increases in the real wage in industries that are defense related, we detect empirically a significant increase in wages paid by non traded industries which are relatively more intensive in government spending shocks identified by adopting the SVAR approach.

One additional key finding with respect to the papers mentioned above is that international differences in workers' costs of switching sectors can account for the cross-country dispersion in the responses of sectoral shares, as we uncover a positive cross-country relationship between the degree of labor mobility and the changes in relative sector size. In this regard, our study can be viewed as complementary to three papers which contrast the effects of fiscal policy on output across a number of country characteristics. In particular, Ilzetzki, Mendoza, and Vegh [2013] perform a split-sample analysis on the basis of the level of development, the level of public debt, trade openness, and exchange rate regimes, Born, Juessen and Müller [2013] further explore the implications of exchange rate regimes by investigating the role of anticipations, and Brinca et al. [2016] document a strong positive relationship across countries between the magnitude of fiscal multipliers and wealth inequality. While these papers focus mainly on the aggregate fiscal multiplier, we explore the size of sectoral fiscal multipliers resulting from the reallocation of resources across sectors. Our key result is that a high intensity of the government spending shock in non tradables can rationalize the increase in the share of non tradables, while the cross-country dispersion in the sectoral share responses is the result of international differences in the degree of labor mobility.

The remainder of the paper is organized as follows. In section 2, we investigate empirically the effects of a government spending shock on relative sector size and establish evidence suggesting that its variation across time and space is positively related to the degree of labor mobility across sectors. In section 3, we develop an open economy version of the neoclassical model with a difficulty in reallocating labor across sectors. In section 4, we abstract from physical capital accumulation in order to derive a number of analytical results and build up intuition on fiscal transmission with imperfect mobility of labor. In section 5, we report the results of our numerical simulations and assess the ability of the model to account for the evidence. In section 6 , we summarize our main results and present our conclusions. The online appendix contains all the robustness checks, proofs and derivations, as well as several extensions.

\footnotetext{
${ }^{4}$ More precisely, all else being equal, for the share of non tradables in real GDP to increase, the fraction of the rise in government consumption spent on non tradables must be higher than the share of non tradables in real GDP.
} 


\section{Stylized Facts on Fiscal Transmission}

In this section, we revisit the time-series evidence on fiscal transmission by differentiating the effects between the traded and non traded sectors. We first estimate sectoral fiscal multipliers and the responses of sectoral shares to a government spending shock. Then we document evidence which aims to explain the rise in the share of non tradables along with its variation across time and space. We denote below the level of the variable in upper case, the logarithm in lower case, and the percentage deviation from its initial steady-state by a hat.

\subsection{VAR Model and Identification}

In order to shed some light on fiscal transmission and guide our quantitative analysis, we estimate the VAR model in panel format on annual data. We consider a structural model with $k=2$ lags in the following form:

$$
A Z_{i, t}=\sum_{k=1}^{2} B_{k} Z_{i, t-k}+\epsilon_{i, t},
$$

where subscripts $i$ and $t$ denote the country and the year, respectively, $Z_{i, t}$ is the vector of endogenous variables, $A$ is a matrix that describes the contemporaneous relation among the variables collected in vector $Z_{i, t}, B_{k}$ is a matrix of lag specific own- and cross-effects of variables on current observations, and the vector $\epsilon_{i, t}$ contains the structural disturbances which are uncorrelated with each other.

Because the VAR model cannot be estimated in its structural form, we pre-multiply (1) by $A^{-1}$ which gives the reduced form of the VAR model:

$$
Z_{i, t}=\sum_{k=1}^{2} A^{-1} B_{k} Z_{i, t-k}+e_{i, t}
$$

where $A^{-1} B_{k}$ and $e_{i t}=A^{-1} \epsilon_{i t}$ are estimated by using a panel OLS regression with country fixed effects and country specific linear trends. To identify the VAR model and recover the government spending shocks, we need assumptions on the matrix $A$ as the reduced form of the VAR model that we estimate contains fewer parameters than the structural VAR model shown in eq. (1). Like Blanchard and Perotti [2002], we base the identification scheme on the assumption that discretionary government spending is subject to certain decision and implementation lags that prevent government spending from responding to current output developments. Since there are some delays inherent to the legislative system, this is a natural assumption when using quarterly data. However, this argument may not necessarily be true when using annual data since some adjustment could be possible. To address the potential endogeneity issue, we ran a number of robustness checks which confirm that our identifying strategy is not altered by the use of annual data. ${ }^{5}$ An additional obstacle is to

\footnotetext{
${ }^{5}$ To support our identifying assumption, we performed several robustness exercises detailed in the online
} 
identify unexpected fiscal events. We conducted an investigation of the potential presence of anticipation effects by using a dataset constructed by Born, Juessen and Müller [2013] which contains one year-ahead OECD forecasts for government spending. ${ }^{6}$ It turns out that differences are rather moderate when we control for the anticipation effects and that our main results are not affected by the inclusion of forecasts for government spending growth. ${ }^{7}$

\subsection{Data Construction}

Before presenting the VAR model, we briefly discuss the dataset we use. Our sample consists of a panel of 16 OECD countries over the period 1970-2007 (except for Japan: 1974-2007) and contains annual observations. ${ }^{8}$ All quantities are logged, expressed in real terms and scaled by the working age population. Government final consumption expenditure $\left(G_{i t}\right)$ in volume is taken from OECD Economic outlook. We describe below how we construct time series at a sectoral level.

We use the EU KLEMS [2011] and OECD STAN [2011] database which provides domestic currency series of value added in current and constant prices, labor compensation and employment (number of hours worked) for eleven 1-digit ISIC-rev.3 industries. To split these eleven industries into traded and non traded sectors, we follow the classification suggested by De Gregorio et al. [1994] that we updated by following Jensen and Kletzer $[2006]^{9}$

Once industries have been classified as traded or non traded, series for sectoral value added in current (constant) prices are constructed by adding value added in current (constant) prices for all sub-industries $k$ in sector $j=T, N$, i.e., $P_{i t}^{j} Y_{i t}^{j}=\sum_{k} P_{k, i t}^{j} Y_{k, i t}^{j}\left(\bar{P}_{i}^{j} Y_{i t}^{j}=\right.$ $\sum_{k} \bar{P}_{k, i}^{j} Y_{k, i t}^{j}$ where the bar indicates that prices $P^{j}$ are those at the base year), from which we compute price indices (or sectoral value added deflators), $P_{i t}^{j}$. Normalizing base year price indices $\bar{P}^{j}$ to 1 , the relative price of non tradables, $P_{i t}$, is defined as the ratio of the non traded value added deflator to the traded value added deflator (i.e., $P_{i t}=P_{i t}^{N} / P_{i t}^{T}$ ). The same logic applies to constructing series for hours worked $\left(L^{j}=\sum_{k} L_{k, i t}^{j}\right)$ and labor compensation in the traded and the non traded sectors which allow us to construct sectoral wages, $W_{i t}^{j}$. The relative wage, $\Omega_{i t}$, is computed as the ratio of the non traded wage to the traded wage (i.e., $\Omega_{i t}=W_{i t}^{N} / W_{i t}^{T}$ ). The real consumption wage in sector $j, W_{C, i t}^{j}$, is

Appendix E. In particular, we investigate whether our main conclusions hold when adopting a narrative approach which has the advantage of identifying fiscal policy changes that are exogenous to current economic developments. We use narratively-identified government spending shocks from the dataset constructed by Guajardo, Leigh, and Pescatori [2014] whose dataset contains 173 fiscal policy changes for 17 OECD countries over the period 1978-2009. The main conclusions reached in this paper are robust to the identification approach.

${ }^{6}$ We use an alternative dataset constructed by Fioramanti et al. [2016] which contains one year-ahead forecasts for the budget balance-GDP ratio performed by the European Commission and do not find any evidence of anticipation effects.

${ }^{7}$ Details about our empirical strategy and data construction can be found in the online Appendix E.

${ }^{8}$ Details of data construction and the source of variables used in our estimate are given in Appendix A.

${ }^{9}$ In contrast to De Gregorio et al. [1994] who treat 'Financial intermediation' as non tradable, we classify this industry as tradable in line with the evidence documented by Jensen and Kletzer [2006] on U.S. data. 
defined as the sectoral nominal wage, $W_{i t}^{j}$, divided by the consumption price index, $P_{C, i t}$. As detailed below, we also construct labor and value added shares (at constant prices), denoted by $\nu_{i t}^{L, j}$ and $\nu_{i t}^{Y, j}$.

\subsection{Good-Biased Government Spending Shock: Preliminary Definitions}

Before moving forward, it is useful to clarify our objective and some definitions. ${ }^{10}$ We consider an open economy which produces a traded and a non traded good, denoted by the superscripts $T$ and $N$, respectively. The traded good is the numeraire and its price, $P^{T}$, is normalized to 1 . We start with a simple equality which states that the aggregate fiscal multiplier is equal to the sum of sectoral fiscal multipliers expressed in GDP units:

$$
\hat{Y}_{R}(t)=\nu^{Y, N} \hat{Y}^{N}(t)+\nu^{Y, T} \hat{Y}^{T}(t)
$$

where $\hat{Y}_{R}(t)$ is real GDP growth following a rise in government spending by one percentage point of GDP and $\nu^{Y, j}=\bar{P}^{j} Y^{j} / Y_{R}$ is the share of sector $j$ in real GDP. If we subtract the share of real GDP growth received by each sector from their sectoral fiscal multiplier, we obtain the change in relative sector size which measures the contribution of the reallocation of resources across sectors to valued added growth in GDP units: ${ }^{11}$

$$
d \nu^{Y, j}(t)=\nu^{Y, j} \hat{Y}^{j}(t)-\nu^{Y, j} \hat{Y}_{R}(t)
$$

The growth differential in GDP units on the RHS of eq. (4) can be viewed as the sectoral fiscal multiplier if real GDP remained fixed and thus reflects sectoral value added growth resulting from the reallocation of resources. Our first objective is to estimate empirically the change in relative sector size following a rise in government spending. ${ }^{12}$

Our second objective is to uncover the factors determining the changes in relative sector size. To bring out these determinants in a simple way, we use the equality between value added and its final use, i.e., $Y^{j}=E^{j}+G^{j}$ where $G^{j}$ stands for government purchases of good $j$ whilst $E^{j}$ is private demand consisting of consumption $\left(C^{j}\right)$, private fixed investment $\left(J^{j}\right)$, and net exports (when considering the traded goods market). Denoting by $\omega_{G^{j}}$ the share of good $j$ in government consumption, we have $G(t)=\omega_{G^{N}} G(t)+\omega_{G^{T}} G(t)$; differentiating while assuming that $\omega_{G^{j}}$ is constant over time, a rise in government spending is split into

\footnotetext{
${ }^{10}$ Appendix $\mathrm{C}$ provides more details about the results discussed below.

${ }^{11}$ While in the main text we define the fiscal multiplier as the output growth following a rise in government spending for simplicity purposes, it should be mentioned in the interest of clarity that referring to $\nu^{Y, j} \hat{Y}^{j}(t)$ as the sectoral fiscal multiplier is an abuse of language as the latter should be computed as the ratio of the present value of the cumulative change in output to the present value of the cumulative change in government consumption. Since we base most of our analysis on impact effects such a simplification does not pose a problem.

${ }^{12}$ Whilst the same logic applies to the labor share, $\mathrm{d} \nu^{L, j}(t)$ measures the growth differential between sectoral and total hours worked in employment units, i.e., $d \nu^{L, j}(t)=\alpha^{L, j}\left(\hat{L}^{j}(t)-\hat{L}(t)\right)$ where $\alpha^{L, j}$ is the labor compensation share of sector $j$.
} 
non tradables and tradables in accordance with their respective shares: ${ }^{13}$

$$
d G(t)=\omega_{G^{N}} d G(t)+\omega_{G^{T}} d G(t) .
$$

Differentiating $Y^{j}=E^{j}+G^{j}$ while keeping private demand fixed and making use of (5), we find that the fiscal multiplier of sector $j$ increases with the intensity of this sector in the government spending shock, i.e., $\nu^{Y, j} \hat{Y}^{j}(t)=\omega_{G^{j}}(d G(t) / Y)$. Using the latter relationship, non traded output increases relative to traded output when the fraction of the rise in government consumption spent on non tradables is higher than that on tradables, i.e., $\omega_{G^{N}}>\omega_{G^{T}}$. Formally, we have:

$$
\nu^{Y, N} \hat{Y}^{N}(t)-\nu^{Y, T} \hat{Y}^{T}(t)=\left(\omega_{G^{N}}-\omega_{G^{T}}\right)(d G(t) / Y) .
$$

According to (6), the definition of a government shock biased toward non tradables is based on the comparison of sectoral fiscal multipliers. ${ }^{14}$

The problem with the above definition is that it does not take into account that the share of non tradables in real GDP is about $63 \%$ in OECD countries and thus the increase in non traded output relative to traded output may not be large enough to raise the share of non tradables in real GDP. Since we are interested in the reallocation effects of an expansionary budget policy leading to changes in relative sector size, we thus adopt an alternative definition which states that a government spending shock is biased toward non tradables if the non tradable content of the government spending shock is higher than the share of non tradables in real GDP so that the relative size of the non traded sector increases. Formally, this definition reads as follows: ${ }^{15}$

$$
d \nu^{Y, N}(t)=\left(\omega_{G^{N}}-\nu^{Y, N}\right)(d G(t) / Y) .
$$

Whilst the relative intensity of the non traded sector in the government spending shock, i.e., $\omega_{G^{N}}-\nu^{Y, N}$, determines whether its relative size increases or declines, the reallocation of resources influences the magnitude of this variation. The lower the mobility costs, the more resources are reallocated toward the non traded sector and the more its relative size should increase. Below, we present evidence pointing to the presence of imperfect mobility of labor and revealing that the degree of labor mobility matters in determining changes in relative sector size following a government spending shock.

\subsection{VAR Specification}

In order to investigate the size of sectoral fiscal multipliers, along with the contribution of the reallocation of resources to sectoral value added growth, we consider three alternative

\footnotetext{
${ }^{13}$ Based on our evidence documented later, we do not make the distinction between the share of good $j$ in government spending and the intensity of the government spending shock in this good $j$, since the two cannot be differentiated.

${ }^{14}$ This definition corresponds to that implicitly adopted by Monacelli and Perotti [2008] and Benetrix and Lane [2010].

${ }^{15}$ To derive the second definition, we use the fact that $\hat{Y}(t)=d G(t) / Y$ (by keeping private demand fixed) along with (4) and $\nu^{Y, j} \hat{Y}^{j}(t)=\omega_{G^{j}}(d G(t) / Y)$.
} 
VAR specifications in which the choice of variables is motivated by the variables discussed in the quantitative analysis. To alleviate notations, price indices at the base year are normalized to 1 , i.e., $\bar{P}_{i}^{j}=1$, so that (logged) value added at constant prices is reduced to $y_{i t}^{j}$ and $y_{i t}$ stands for (logged) real GDP when this causes no confusion.

- To investigate the magnitude of the sectoral fiscal multiplier, we consider a VAR model that includes value added at constant prices in sector $j, y_{i t}^{j}$, hours worked in sector $j, l_{i t}^{j}$, and the real consumption wage in sector $j, w_{C, i t}^{j}$. Our vector of endogenous variables, is given by: $z_{i t}^{j}=\left[g_{i t}, y_{i t}^{j}, l_{i t}^{j}, w_{C, i t}^{j}\right]$ with $j=T, N$.

- To estimate the change in the relative size of sector $j$, we consider a VAR model where we divide sectoral value added at constant prices (sectoral labor) by real GDP (total labor) in order to filter the change in sectoral output (sectoral labor) arising from real GDP (total labor) growth, which allows us to isolate the 'pure' reallocation effect and thus gauge the importance of the shift of resources across sectors, affecting their relative size. Our vector of endogenous variables, is given by: $z_{i t}^{S, j}=\left[g_{i t}, y_{i t}^{j}-y_{i t}, l_{i t}^{j}-l_{i t}, w_{C, i t}^{j}\right]$.

- Finally, to gain further insight into fiscal transmission, we estimate empirically the effects of a government spending shock on the relative price $(p)$ and relative wage $(\omega)$, and thus consider a VAR model where we replace sectoral quantities with the ratio of sectoral quantities for both the product and the labor market. Our vector of endogenous variables, is given by: $z_{i t}^{P}=\left[g_{i t}, y_{i t}^{T}-y_{i t}^{N}, p_{i t}\right]$ and $z_{i t}^{W}=\left[g_{i t}, l_{i t}^{T}-l_{i t}^{N}, \omega_{i t}\right]$.

Whilst in the main text we concentrate on the sectoral effects, in a longer version of the paper, we also document evidence on the aggregate effects of a government spending shock by estimating a VAR model which includes government final consumption expenditure, real GDP, total hours worked, private investment, and the real consumption wage, i.e., $z_{i t}=\left[g_{i t}, y_{i t}, l_{i t}, j e_{i t}, w_{C, i t}\right] .{ }^{16}$ We take this model as the baseline to calibrate the government spending shock in the quantitative analysis. ${ }^{17}$

\subsection{Effects of Government Spending Shocks: VAR Evidence}

We generated impulse response functions which summarize the responses of variables to an increase in government spending by 1 percentage point (henceforth ppt) of GDP. As displayed in the solid blue line in the left panel of Fig. 1, the response of government

\footnotetext{
${ }^{16}$ Aggregate effects of a government spending shock are displayed and discussed in Appendix D.1.

${ }^{17}$ As pointed out by a referee, because we consider alternative VAR models, the fact that identified government spending shocks display substantial differences across VAR specifications might be a concern. To address this issue, we ran a number of robustness checks by augmenting each VAR model with the same identified spending shock, ordered first. Because we take $z_{i t}=\left[g_{i t}, y_{i t}, l_{i t}, j e_{i t}, w_{C, i t}\right]$ as our benchmark model in the quantitative analysis to calibrate the government spending shock, we augment each VAR model with the spending shock identified for this benchmark specification on annual or quarterly data. Results reveal that the discrepancy in the estimated effects is quite moderate, see Appendix E.3.
} 
consumption is hump-shaped, peaking after one year and then gradually declining; it shows a high level of persistence over time as it is about 8 years before the shock dies out. ${ }^{18}$

In Fig. 2, we report results for our three VAR models. ${ }^{19}$ The blue and thick black lines show impulse response functions following an exogenous government spending shock by one ppt of GDP. The horizontal axis measures time after the shock in years and the vertical axis measures percentage deviations from trend. ${ }^{20}$ In each case, the solid line represents the point estimate, while the shaded area indicates the $90 \%$ confidence bounds obtained by bootstrap sampling. The first column displays fiscal multipliers for output. We find that a rise in government consumption has a strong expansionary effect on non traded output which increases significantly on impact by $0.70 \mathrm{ppt}$ of GDP. During the first four years after the shock, the non traded output multiplier of government spending averages out at about $0.47 \mathrm{ppt}$ of GDP. In contrast, the traded sector displays a negative fiscal multiplier over this period as the government spending shock gives rise to a contraction in traded output which remains below trend. Henceforth, our evidence shown in Fig. 2 reveals that the government spending shock is biased toward non tradable goods as it benefits the non traded sector at the expense of the traded sector. Furthermore, as shown in the second column of Fig. 2, higher non traded output is associated with a sharp increase in hours worked on impact, while the traded sector experiences a gradual decline in labor for the first five years.

The third column of Fig. 2 enables us to gauge the contribution of the reallocation of inputs, labor especially, to the expansion of the relative size of the non traded sector. The second row shows that the labor share of tradables declines by $0.27 \mathrm{ppt}$ of total labor (see the blue line) while the reverse is true for non tradables (see the thick black line). Since non traded hours worked increase by $0.55 \mathrm{ppt}$ of total employment, $50 \%$ of non traded employment growth is the result of labor reallocation. As shown in the first row of the third column, a fiscal shock lowers the output share of tradables (see the blue line) significantly and substantially increases that of non tradables (see the thick black line). Because changes in output shares indicate how much sectoral output would increase if GDP remained constant, they provide us with valuable information on the shift of inputs across sectors and the resulting changes in their relative size. Quantitatively, since non traded output rises by $0.7 \mathrm{ppt}$ of GDP while the output share of non tradables rises by 0.35 ppt of GDP, the shift of resources toward the non traded sector alone contributes $50 \%$ of non traded output growth. Our second set of findings shown in Fig. 2 thus reveals that

\footnotetext{
${ }^{18}$ The red line in the left panel of Fig. 1 shows the endogenous response of $G$ over the period 1995-2015 as we estimate the responses of $G^{T}$ and $G^{N}$ over this period.

${ }^{19}$ For reasons of space, we do not show the responses of real consumption wages. Point estimates are shown in Panel A of Table 5 at a one year-, two-year and four-year horizon. The Table is relegated to the online Appendix D.2.

${ }^{20}$ Sectoral output and sectoral output share are measured in percentage points of total output relative to trend. Sectoral labor shares are both measured as percentage deviations of total hours worked from trend. The remaining variables are measured as percentage deviations from trend.
} 
a government spending shock generates a reallocation of labor that significantly affects the relative size of sectors. ${ }^{21}$

As will be shown analytically in subsection 4.2, all else being equal (i.e., keeping private demand fixed), for the relative price of non tradables to appreciate, the government spending shock must be biased enough toward non traded goods, i.e., $\omega_{G^{N}}>\nu^{Y, N}$. The last column of Fig. 2 supports the conjecture that an aggregate government spending shock triggers a demand shock in favor of non tradables. More specifically, the relative price of non tradables (see the thick black line) appreciates significantly in the short-run, signaling excess demand in the non traded goods market, while the ratio of traded output relative to non traded output decreases substantially (see the blue line).

Obviously, for the increase in the GDP share of non tradables to materialize, resources must be reallocated away from the traded sector to the non traded sector. If workers experience mobility costs, the rise in the relative size of the non traded sector should be less. As can be seen in the second row of the last column of Fig. 2, the sharp decline in hours worked in the traded relative to the non traded sector (see the blue line) is associated with a significant increase in non traded wages relative to traded wages (see the thick black line). The positive response of the relative wage to a government spending shock suggests the presence of intersectoral labor mobility costs.

$<$ Please insert Figures 1-2 about here $>$

\subsection{Intensity of Government Spending Shock in Non Tradables}

We first investigate empirically whether the government shock is biased enough toward non traded goods to increase the relative size of the non traded sector. In order to quantify the intensity of the government spending shock in non tradables we split government final consumption expenditure between government consumption on non tradables, $g^{N}$, and tradables, $g^{T}$, by using the COFOG database from the OECD which provides a breakdown of government expenditure by function. ${ }^{22}$ The sample covers 13 OECD countries over the period 1995-2015. We chose this period as time series for government consumption by function are not available before 1995 for most of the countries in our sample, while the period 1995-2007 would be too short to obtain consistent estimates. ${ }^{23}$ Then, we estimate a VAR model in panel format on annual data that includes unanticipated govern-

\footnotetext{
${ }^{21}$ As suggested by a referee, labor mobility and thus the magnitude of changes in relative sector size following a government spending shock could vary across the state of economy. In Appendix F.1, we explore empirically this issue and find that when the economy is in expansion, the rise in the share of non tradables lies in the upper range of the confidence bound for the baseline scenario, while the increase in the output share of non tradables in recession lies in the lower range. The reason is twofold. Our evidence indicates that the non traded sector is more intensive in the government spending shock in expansions. We also find empirically that labor mobility is slightly higher when the economy is in expansion.

${ }^{22}$ See Appendix B for details about the breakdown of $g$ into $g^{N}$ and $g^{T}$.

${ }^{23}$ Data to construct time series for sectoral government consumption expenditure are available for all the countries in our sample except Canada. In efforts to have a balanced panel and time series of a reasonable length, Australia (1998-2015) and Japan (2005-2015) are removed from the sample, which leaves us with 13 OECD countries over the period 1995-2015.
} 
ment spending shocks, $\epsilon_{i t}^{G}$, ordered first, government consumption spending and sectoral government consumption on non tradables and tradables. To identify exogenous and unanticipated fiscal shocks, $\epsilon_{i, t}^{G}$, we estimate the VAR model that includes aggregate variables, i.e., $z_{i, t}=\left[g_{i, t}, y_{i, t}, l_{i, t}, j e_{i, t}, w_{C, i, t}\right]$, and adopt a Cholesky decomposition. The middle and right panels of Fig. 1 display the response of government consumption of non tradables and tradables to an exogenous and unanticipated increase in government spending by $1 \%$ of GDP, respectively. On impact, government consumption of non tradables increases by $0.88 \%$. Its contribution to the government spending shock averages $90 \%$ and is quite stable over time as it varies from $88 \%$ up to $91 \% .^{24}$ Moreover, we find that the responses of sectoral government consumption to an exogenous fiscal shock are both hump-shaped and seem to mimic the adjustment of government spending shown in Fig. 1(a).

These findings thus corroborate our conjecture according to which government shocks are strongly biased toward non traded goods and thus provide incentives to reallocate labor toward this sector. Whilst the relative intensity of the non traded sector in the government spending shock causes an increase in the share of non tradables by triggering a reallocation of labor toward the non traded sector, its rise should be mitigated by labor mobility costs.

\subsection{Implications of the Degree of Labor Mobility across Sectors}

To assess the importance of labor mobility costs for fiscal transmission, we investigate below whether the responses of sectoral shares vary across time and space, and whether these variations are positively related to differences in labor mobility.

A first way to gauge the role of labor mobility costs in determining the adjustment of the relative sector size to a government spending shock is to investigate whether the responses of sectoral shares vary over time and explore their relationship with the extent of labor reallocation across sectors triggered by a rise in government spending. To perform this experiment, like Miyamoto, Nguyen and Sergeyev [2018], we compute the responses of selected variables by using a two-step estimation procedure. We first identify government spending shocks by adopting a Cholesky decomposition in which government spending is ordered before the other variables. ${ }^{25}$ In the second step, we estimate the effects in a rolling 25-year window by using Jordà's [2005] single-equation method. ${ }^{26}$ The local projection

\footnotetext{
${ }^{24}$ See Table 2 in Appendix B.2 which displays the mean responses of the two components of government consumption.

${ }^{25}$ More specifically, we estimate the baseline VAR model that includes aggregate variables, i.e., $z_{i, t}=$ $\left[g_{i, t}, y_{i, t}, l_{i, t}, j e_{i, t}, w_{C, i, t}\right]$.

${ }^{26}$ By decoupling the shock identification and the estimate of the responses, the first advantage of Jordà's [2005] projection method is that traded and non traded variables respond to the same shock. However, our robustness check shows that the shock is identical across all VAR models. The second advantage over the standard VAR approach is that it considerably reduces the number of coefficients and thus is particularly suited when estimating the sectoral effects over overlapping subperiods of fixed length. The third advantage is that it does not impose the dynamic restrictions implicitly embedded in VARs and can accommodate non-linearities in the response function. By imposing fewer restrictions, impulse responses obtained by using the local projection method are rather erratic. Since we contrast empirical with theoretical responses in the quantitative analysis and smooth impulse responses are therefore more appropriate for this exercise, we stick to the VAR methodology, however, for most the empirical analysis undertaken in this paper. That
} 
method amounts to running a series of regressions of each variable of interest on a structural identified shock for each horizon $h=0,1,2, \ldots$ :

$$
x_{t+h}^{j}=\alpha_{h, i}^{j}+\beta_{h, i}^{j} \cdot t+\psi_{h}^{j}(L) z_{t-1}+\gamma_{h}^{j} \cdot \epsilon_{i, t}^{G}+\nu_{i, t}^{j},
$$

where $\alpha_{i}^{j}$ and $\beta_{i}^{j}$ are the country fixed effects and country-specific linear trends respectively, $x^{j}$ is the logarithm of the variable of interest of sector $j, z$ is a vector of control variables (i.e., past values of government spending and of the variable of interest), $\psi_{h}^{j}(L)$ is a polynomial (of order two) in the lag operator and $\epsilon_{i, t}^{G}$ is the identified government spending shock. ${ }^{27}$ Since we concentrate on impact effects, horizon $h$ is set to zero in eq. (8). Given that we are primarily interested in the reallocation effects, we estimate the impact of a government spending shock on the labor and value added share of tradables and non tradables, i.e., $x^{j}=\nu^{Y, j}, \nu^{L, j}$ (with $j=T, N$ ). As can be seen in Fig. 3 which reports impact responses of sectoral shares to the government spending shock (i.e., $\gamma_{0}^{j}$ ) in the blue lines, the magnitude of changes in relative sector size decreases over time, i.e., $\gamma_{0}^{N}$ becomes less positive and $\gamma_{0}^{T}$ less negative. In line with our conjecture, one obvious candidate to explain such a decline in $\left|\gamma^{j}\right|$ is an increase in labor mobility costs. If workers incur higher costs of switching sectors, then a rise in government spending should result in a smaller reallocation of labor between the traded and the non traded sector. ${ }^{28}$ As clearly stands out, the decline in the magnitude of changes in relative sector size is associated with less labor reallocation following a government spending shock, in line with our hypothesis. More specifically, our estimates reveal that, in about fifteen years, the responses of sectoral shares have been reduced over time by about $40 \%$ whilst the rate of workers shifting from one sector to another has decreased by the same amount as well. Strikingly, time-varying responses of labor and value added shares are highly correlated with those of labor reallocation, with the correlation coefficient ranging from 0.82 to 0.86 . This finding thus suggests that increasing labor mobility costs have contributed to declining effects of fiscal policy on relative sector size over time.

\section{$<$ Please insert Figures 3-4 about here $>$}

Whilst the above evidence shows that the reallocation effects of expansionary budget policy vary across time, we now investigate whether these effects vary across space. To conduct this study, we explore the cross-country relationship between changes in the relative size of sectors and the magnitude of workers' costs of switching sectors. To explore this cross-country relationship, we draw on Horvath [2000] and estimate the elasticity of labor

said, both methods lead to very similar, if not identical, results on impact and even at a longer time horizon.

${ }^{27}$ We allow for two lags on the variable of interest and government spending collected in vector $z$.

${ }^{28}$ Following Wacziarg and Wallack [2004], we compute the labor reallocation index in year $t$ for country $i$ denoted by $L R_{i, t}$ by calculating the rate of workers that have shifted from one sector to another over $\tau$ years:

$$
L R_{i, t}(\tau)=\frac{\sum_{j=T}^{N}\left|L_{i, t}^{j}-L_{i, t-\tau}^{j}\right|-\left|\sum_{j=T}^{N} L_{i, t}^{j}-\sum_{j=T}^{N} L_{i, t-\tau}^{j}\right|}{0.5 \sum_{j=T}^{N}\left(L_{i, t-\tau}^{j}+L_{i, t}^{j}\right)} .
$$

where $\tau=5$ and $L_{i, t}^{j}$ denotes employment in sector $j=T, N$. 
supply across sectors for each country. ${ }^{29}$ This parameter, which plays a pivotal role in our model presented in the next section, measures the extent to which workers are willing to reallocate their hours worked toward the non traded sector following a $1 \%$ increase in the relative wage. When the elasticity of labor supply across sectors is greater, workers' mobility costs are thus lower, which in turn implies a higher degree of labor mobility.

Once we have estimated the magnitude of workers mobility costs for each country, we then estimate the same model as in eq. (2) but for a single country at a time. ${ }^{30}$ In Fig. 4 , we plot the impact responses of sectoral labor and sectoral output shares on the vertical axis against our measure of the degree of labor mobility, denoted $\epsilon$, on the horizontal axis. This exercise may be viewed as tentative as the sectoral effect of a government spending shock varies considerably across countries and there is substantial uncertainty surrounding point estimates given the relatively small number of observations available per country.

The cross-country analysis displayed in Fig. 4 highlights two major findings. First, as shown in the top panels, whether we use labor or output, almost all countries in our sample experience a fall in the relative size of the traded sector as impact responses from the VAR model are below the X-axis. The bottom panels reveal that the reverse is true for the non traded sector which benefits from the reallocation of inputs. This evidence supports our earlier conjecture according to which a government spending shock is strongly biased toward non tradables. Second, as can be seen in the top panels of Fig. 4, countries where workers have lower mobility costs experience a larger decline in the share of tradables while the bottom panels show that the relative size of non tradables increases more in these economies. In sum, our findings reveal that the magnitude of the change in relative sector size following a government spending shock increases with the degree of labor mobility across sectors.

In the following, we develop an open economy version of the neoclassical model with imperfect mobility of labor and capital installation costs in order to account for our evidence on fiscal transmission. While these two features, along with high intensity of the government spending shock in non tradables are necessary to replicate the change in relative sector size for a representative OECD economy, we have to let the degree of labor mobility across sectors vary across countries to account for the cross-country dispersion in the sectoral output responses.

\footnotetext{
${ }^{29}$ See Appendix B which details our empirical strategy.

${ }^{30}$ When estimating the responses of sectoral labor and sectoral output shares to a government spending shock for each country, we omit $w_{C, i t}^{j}$ in order to economize some degrees of freedom; the vector of endogenous variables is thus $z_{i t}^{S, j}=\left[g_{i t}, \nu_{i t}^{Y, j}, \nu_{i t}^{L, j}\right]$. We also estimated the VAR model by including $\omega_{C, i t}^{j}$ and find that the results are similar. We allow for two lags (i.e., $k=2$ in eq. (1)), as we did for the panel data estimate. It is worth mentioning that Jordà's local projection method gives similar results, except for the crosscountry relationship. As shown in Appendix D.4, whilst impact responses obtained with VAR and local projection methods are highly correlated, and cross-country relationships between $d \nu^{Y, j}(0)$ and $\epsilon$ display the same pattern, the slopes of the trend line obtained with the local projection method display substantial differences between tradables and non tradables which would undermine the quantitative analysis because the slopes by construction should be identical.
} 


\section{Small Open Economy Model with Imperfect Mobility of Labor}

We consider a small open economy populated by a constant number of identical households and firms that have perfect foresight and live forever. ${ }^{31}$ The country is small in terms of both world goods and capital markets, and faces a given world interest rate, $r^{\star} .{ }^{32}$ One sector produces a traded good denoted by the superscript $T$ which can be exported at no cost, invested and consumed domestically. A second sector produces a non traded good denoted by the superscript $N$ which can be consumed domestically or invested. The traded good is chosen as the numeraire. Time is continuous and indexed by $t$.

\subsection{Households}

At each instant the representative household consumes traded and non traded goods denoted by $C^{T}$ and $C^{N}$, respectively, which are aggregated by means of a CES function:

$$
C(t)=\left[\varphi^{\frac{1}{\phi}}\left(C^{T}(t)\right)^{\frac{\phi-1}{\phi}}+(1-\varphi)^{\frac{1}{\phi}}\left(C^{N}(t)\right)^{\frac{\phi-1}{\phi}}\right]^{\frac{\phi}{\phi-1}},
$$

where $0<\varphi<1$ is the weight of the traded good in the overall consumption bundle and $\phi$ corresponds to the elasticity of substitution between traded goods and non traded goods.

The representative household supplies labor $L^{T}$ and $L^{N}$ in the traded and non traded sectors, respectively. To rationalize the rise in the non traded wage relative to the traded wage, we assume limited labor mobility across sectors. A shortcut to produce a difficulty in reallocating hours worked is to assume that workers experience a utility loss when shifting hours worked from one sector to another. We follow Horvath [2000] and consider that hours worked in the traded and the non traded sectors are aggregated by means of a CES function:

$$
L(t)=\left[\vartheta^{-1 / \epsilon}\left(L^{T}(t)\right)^{\frac{\epsilon+1}{\epsilon}}+(1-\vartheta)^{-1 / \epsilon}\left(L^{N}(t)\right)^{\frac{\epsilon+1}{\epsilon}}\right]^{\frac{\epsilon}{\epsilon+1}},
$$

and $0<\vartheta<1$ parametrizes the weight attached to the supply of hours worked in the traded sector and $\epsilon$ is the degree of substitutability in hours worked across sectors. ${ }^{33}$

The representative agent is endowed with one unit of time, she/he supplies a fraction $L(t)$ as labor, and consumes the remainder $l(t) \equiv 1-L(t)$ as leisure. At any instant of time,

\footnotetext{
${ }^{31}$ More details about the setup can be found in Appendix G.

${ }^{32}$ The price of the traded good is determined on the world market and exogenously given for the small open economy. In a Technical Appendix, we relax the assumption of exogenous terms of trade by considering a semi-small open economy model. As detailed in Appendix K.5, all the results obtained in the main text are robust to the assumption of exogenous terms of trade.

${ }^{33}$ As pointed out by a referee, eq. (10) implies that workers' costs of switching sectors are symmetric whether they move away from the traded to the non traded sector or the other way around. In Appendix F.2, we document evidence which lends credence to our hypothesis. More specifically, we estimate the effects on relative sector size according to whether government spending is going up or down. If workers' mobility costs were symmetric, then the magnitude of the increase in the labor share of non tradables when the shock is expansionary should be equivalent to that of its decline when the shock is recessionary. While our evidence indicates that labor mobility is less when government spending is going down, the difference is quite moderate.
} 
households derive utility from their consumption and experience disutility from working. Assuming that the felicity function is additively separable in consumption and labor, the representative household maximizes the following objective function: ${ }^{34}$

$$
U=\int_{0}^{\infty}\left\{\ln C(t)-\frac{L(t)^{1+\frac{1}{\sigma_{L}}}}{1+\frac{1}{\sigma_{L}}}\right\} e^{-\beta t} \mathrm{~d} t,
$$

where $\beta$ is the discount rate and $\sigma_{L}>0$ is the Frisch elasticity of labor supply.

Factor income is derived by supplying labor $L(t)$ at a wage rate $W(t)$, and capital $K(t)$ at a rental rate $R(t)$. In addition, households accumulate internationally traded bonds, $B(t)$, that yield net interest rate earnings of $r^{\star} B(t)$. Denoting lump-sum taxes by $T(t)$, households' flow budget constraint states that real disposable income (on the RHS) can be saved by accumulating traded bonds, consumed, $P_{C}(t) C(t)$, or invested, $P_{J}(t) J(t)$ :

$$
\dot{B}(t)+P_{C}(t) C(t)+P_{J}(t) J(t)=r^{\star} B(t)+R(t) K(t)+W(t) L(t)-T(t),
$$

where $P_{C}(P(t))$ and $P_{J}(P(t))$ are consumption and the investment price index, respectively, which are a function of the relative price of non traded goods, $P(t)$. The aggregate wage index, $W(t)=W\left(W^{T}(t), W^{N}(t)\right)$, associated with the labor index (10) is:

$$
W(t)=\left[\vartheta\left(W^{T}(t)\right)^{\epsilon+1}+(1-\vartheta)\left(W^{N}(t)\right)^{\epsilon+1}\right]^{\frac{1}{\epsilon+1}},
$$

where $W^{T}(t)$ and $W^{N}(t)$ are wages paid in the traded and the non traded sectors. The investment good is produced (costlessly) using traded good and non traded good inputs according to a constant returns to scale function which is assumed to take a Cobb-Douglas form: ${ }^{35}$

$$
J(t)=\left(\frac{J^{N}(t)}{\alpha_{J}}\right)^{\alpha_{J}}\left(\frac{J^{T}(t)}{1-\alpha_{J}}\right)^{1-\alpha_{J}}
$$

where $\alpha_{J}$ and $1-\alpha_{J}$ are the shares of investment expenditure on non tradables and tradables, respectively. Installation of new investment goods involves increasing and convex costs, assumed quadratic, of net investment. Thus, total investment $J(t)$ differs from effectively installed new capital, $I(t)$ :

$$
J(t)=I(t)+\frac{\kappa}{2}\left(\frac{I(t)}{K(t)}-\delta_{K}\right)^{2} K(t)
$$

where the parameter $\kappa>0$ governs the magnitude of adjustment costs to capital accumulation, and $0 \leq \delta_{K}<1$ is a fixed depreciation rate. Net investment gives rise to capital accumulation according to the dynamic equation:

$$
\dot{K}(t)=I(t)-\delta_{K} K(t)
$$

Households choose consumption, worked hours and investment in physical capital by maximizing lifetime utility (11) subject to (12) and (16) together with (15). Denoting by

\footnotetext{
${ }^{34}$ In a Technical Appendix, we find numerically that relaxing the assumption of separability in preferences between consumption and labor merely affects the results.

${ }^{35}$ In accordance with the empirical findings documented by Bems [2008] for OECD countries, we choose an elasticity of substitution between $J^{N}$ and $J^{T}$ of 1 .
} 
$\lambda$ and $Q^{\prime}$ the co-state variables associated with (12) and (16), the first-order conditions characterizing the representative household's optimal plans are: ${ }^{36}$

$$
\begin{gathered}
C(t)=\left(P_{C}(t) \lambda(t)\right)^{-1}, \\
L(t)=(W(t) \lambda(t))^{\sigma_{L}}, \\
\frac{I(t)}{K(t)}=\frac{1}{\kappa}\left(\frac{Q(t)}{P_{J}(t)}-1\right)+\delta_{K}, \\
\dot{\lambda}(t)=\lambda(t)\left(\beta-r^{\star}\right), \\
\dot{Q}(t)=\left(r^{\star}+\delta_{K}\right) Q(t)-\left\{R(t)+P_{J}(t) \frac{\kappa}{2}\left(\frac{I(t)}{K(t)}-\delta_{K}\right)\left(\frac{I(t)}{K(t)}+\delta_{K}\right)\right\},
\end{gathered}
$$

and the transversality conditions $\lim _{t \rightarrow \infty} \lambda B(t) e^{-\beta t}=0, \lim _{t \rightarrow \infty} Q(t) K(t) e^{-\beta t}=0$. In an open economy model with a representative agent who has perfect foresight, a constant rate of time preference and perfect access to world capital markets, we impose $\beta=r^{\star}$ in order to generate an interior solution. Setting $\beta=r^{\star}$ into (17d) yields $\lambda=\bar{\lambda}$. Eq. (17c) states that investment is an increasing function of Tobin's $q$, which is defined as the shadow value to the firm of installed capital, $Q(t)$, divided by its replacement cost, $P_{J}(t)$. For the sake of clarity, we drop the time argument below provided this causes no confusion.

Applying Shephard's lemma (or the envelope theorem) to consumption expenditure yields the following demand for the traded and non traded good, respectively:

$$
C^{T}=\varphi\left(1 / P_{C}\right)^{-\phi} C, \quad C^{N}=(1-\varphi)\left(P / P_{C}\right)^{-\phi} C .
$$

Denoting the share of non traded goods in consumption expenditure by $\alpha_{C}$, expenditure in non tradables and tradables is given by $P C^{N}=\alpha_{C} P_{C} C$ and $C^{T}=\left(1-\alpha_{C}\right) P_{C} C$.

Applying the same logic for labor, given the aggregate wage index (13), we can derive the allocation of aggregate labor supply to the traded and non traded sectors:

$$
L^{T}=\vartheta\left(W^{T} / W\right)^{\epsilon} L, \quad L^{N}=(1-\vartheta)\left(W^{N} / W\right)^{\epsilon} L,
$$

where $\epsilon$ is the elasticity of labor supply across sectors; it measures the extent to which agents are willing to increase their relative hours worked in sector $j, L^{j} / L$, following a $1 \%$ rise in the relative wage in sector $j, W^{j} / W$. As $\epsilon$ takes higher values, more labor shifts from one sector to another and thus the degree of labor mobility across sectors increases. When we let $\epsilon$ tend toward infinity, the special case of perfect labor mobility is obtained. Because workers are willing to devote their whole time to the sector that pays the highest wages, the sectors pay the same wage. Denoting by $\alpha_{L}$ the share of non tradable labor revenue in labor income, labor income from supplying hours worked in the non traded and the traded sectors are $W^{N} L^{N}=\alpha_{L} W L$ and $W^{T} L^{T}=\left(1-\alpha_{L}\right) W L$.

\footnotetext{
${ }^{36}$ To derive (17c), we used the fact that $Q(t)=Q^{\prime}(t) / \lambda$ which is the shadow value of capital in terms of foreign assets.
} 


\section{$3.2 \quad$ Firms}

Each sector consists of a large number of identical firms which use labor, $L^{j}$, and physical capital, $K^{j}$, according to a constant returns to scale technology:

$$
Y^{j}=Z^{j}\left(L^{j}\right)^{\theta^{j}}\left(K^{j}\right)^{1-\theta^{j}}
$$

where $Z^{j}$ represents the TFP index which is introduced for calibration purposes only and $\theta^{j}$ corresponds to the share of labor income in the value added of sector $j$. Firms lease capital from households and hire workers. They face two cost components: a capital rental cost equal to $R$, and wage rates in the traded and non traded sectors equal to $W^{T}$ and $W^{N}$, respectively. Both sectors are assumed to be perfectly competitive and thus choose capital and labor by taking prices as given. Since capital can move freely between the two sectors, the value of marginal products in the traded and non traded sectors equalizes while costly labor mobility implies a wage differential across sectors:

$$
\begin{gathered}
Z^{T}\left(1-\theta^{T}\right)\left(k^{T}\right)^{-\theta^{T}}=P Z^{N}\left(1-\theta^{N}\right)\left(k^{N}\right)^{-\theta^{N}} \equiv R \\
Z^{T} \theta^{T}\left(k^{T}\right)^{1-\theta^{T}} \equiv W^{T} \\
P Z^{N} \theta^{N}\left(k^{N}\right)^{1-\theta^{N}} \equiv W^{N}
\end{gathered}
$$

where $k^{j} \equiv K^{j} / L^{j}$ denotes the capital-labor ratio for sector $j=T, N$.

Aggregating over the two sectors gives us the resource constraint for capital:

$$
K^{T}+K^{N}=K
$$

\subsection{Government}

The final agent in the economy is the government. Total government spending, $G$, goes on goods, $G^{N}$, produced by non traded firms and goods, $G^{T}$, produced by traded firms. Both components of government spending are determined exogenously. The government finances public spending by raising lump-sum taxes, $T$. As a result, Ricardian equivalence obtains and the time path of taxes is irrelevant for the real allocation. We may thus assume without loss of generality that government budget is balanced at each instant: ${ }^{37}$

$$
G=G^{T}+P G^{N}=T
$$

\subsection{Model Closure and Equilibrium}

To fully describe equilibrium, we first impose the market clearing condition for non tradables:

$$
Y^{N}=C^{N}+J^{N}+G^{N} .
$$

\footnotetext{
${ }^{37}$ In a Technical Appendix, we allow for distortionary labor taxation and consider a rise in government spending which is debt-financed. Quantitative results in Appendix K.5 show that the sectoral impact of fiscal policy is similar to that obtained when assuming a balanced-budget government spending shock.
} 
Equality between non traded output and its demand counterpart is achieved through adjustments to the relative price of non tradables, $P$, which guarantee that eq. (24) holds at each point of time.

Regarding the allocation of government consumption to good $j=T, N$, we consider a rise in $G$ which is split between non tradables and tradables in accordance with their respective shares in government expenditure (see eq. (5)). In order to account for the non-monotonic pattern of the dynamic adjustment of $G(t)$ in line with our evidence (see Fig. 1(a)), we assume that the deviation of government spending relative to its initial value as a percentage of initial GDP is:

$$
(G(t)-\tilde{G}) / \tilde{Y}=e^{-\xi t}-(1-g) e^{-\chi t},
$$

where we denote the steady-state value with a tilde; $g>0$ parametrizes the magnitude of the exogenous fiscal shock, $\xi>0$ and $\chi>0$ parametrize the degree of persistence of the fiscal shock; as $\xi$ and $\chi$ take higher values, government spending returns to its initial level more rapidly. More specifically, eq. (25) allows us to generate an inverted $U$ pattern for the endogenous response of $G(t)$ : if $\chi>\xi$, we have $\dot{G}(t)>0$ following the exogenous fiscal shock and then $G(t)$ declines after reaching a peak at some time $t$.

After inserting appropriate first-order conditions into the non traded good market clearing condition (24) and the no arbitrage condition (17e), it can be shown that the adjustment of the open economy towards the steady-state is described by a dynamic system which comprises two equations that form a separate subsystem in $K$ and $Q$, i.e., $\dot{K} \equiv \Upsilon(K, Q, G)$ and $\dot{Q} \equiv \Sigma(K, Q, G)$. Linearizing these equations in the neighborhood of the steady-state and using (5) leads to a system of first-order linear differential equations which can be solved by applying standard methods and making use of $(25):^{38}$

$$
K(t)-\tilde{K}=X_{1}(t)+X_{2}(t), \quad Q(t)-\tilde{Q}=\omega_{2}^{1} X_{1}(t)+\omega_{2}^{2} X_{2}(t),
$$

where we denote the negative eigenvalue by $\nu_{1}$, the positive eigenvalue by $\nu_{2}$, and $\omega_{2}^{i}$ is the element of the eigenvector associated with the eigenvalue $\nu_{i}$ (with $i=1,2$ ) and $X_{1}(t)$ and $X_{2}(t)$ are solutions which characterize the trajectory of $K(t)$ and $Q(t):{ }^{39}$

$$
\begin{gathered}
X_{1}(t)=e^{\nu_{1} t}\left[\left(K_{0}-\tilde{K}\right)+\Gamma_{2}\left(1-\Theta_{2}\right)-\Gamma_{1}\left(1-\Theta_{1}\right)\right]+\Gamma_{1}\left(e^{-\xi t}-\Theta_{1} e^{-\chi t}\right), \\
X_{2}(t)=-\Gamma_{2}\left(e^{-\xi t}-\Theta_{2} e^{-\chi t}\right),
\end{gathered}
$$

where $K_{0}$ is initial stock of physical capital. When the shock is permanent, $X_{2}(t)=0$ while

\footnotetext{
${ }^{38}$ See e.g., Buiter [1984] who presents the continuous time adaptation of the method of Blanchard and Kahn. The steps of the derivations of equations in the main text can be found in Appendix G.3.

${ }^{39}$ The coefficients of the Jacobian matrix are partial derivatives evaluated at the steady-state, e.g., $\Upsilon_{X}=$ $\frac{\partial \Upsilon}{\partial X}$ with $X=K, Q$, and the direct effects of an exogenous change in government spending on $K$ and $Q$ are described by $\Upsilon_{G}=\frac{\partial \Upsilon}{\partial G}$ and $\Sigma_{G}=\frac{\partial \Sigma}{\partial G}$, also evaluated at the steady-state. The terms on the RHS of eq. (27) are functions of parameters and read as $\Gamma_{i}=-\frac{\Phi_{i} \tilde{Y}}{\nu_{1}-\nu_{2}} \frac{1}{\left(\nu_{i}+\xi\right)}, \Phi_{1}=\left(\Upsilon_{K}-\nu_{2}\right) \Upsilon_{G}+\Upsilon_{Q} \Sigma_{G}$, $\Phi_{2}=\left(\Upsilon_{K}-\nu_{1}\right) \Upsilon_{G}+\Upsilon_{Q} \Sigma_{G}$, and $\Theta_{i}=(1-g) \frac{\nu_{i}+\xi}{\nu_{i}+\chi}($ with $i=1,2)$.
} 
$X_{1}(t)$ reduces to $e^{\nu_{1} t}\left(K_{0}-\tilde{K}\right)$. Because our objective is to account for VAR evidence, we restrict our attention to a temporary fiscal shock.

Using the fact that $R K+W L=Y^{T}+P Y^{N}$ and inserting the market clearing condition for non tradables (24) into (12) gives the current account equation:

$$
\dot{B}=r^{\star} B+Y^{T}-C^{T}-G^{T}-J^{T} .
$$

Substituting appropriate short-run solutions, eq. (28) can be written as a function of state and control variables, i.e., $\dot{B} \equiv r^{\star} B+\Xi(K, Q, G)$. Linearizing around the steady state, substituting the solutions for $K(t)$ and $Q(t)$ given by (26), solving and invoking the transversality condition leads to the intertemporal solvency condition: ${ }^{40}$

$$
\tilde{B}-B_{0}=-\frac{\omega_{B}^{1}}{\nu_{1}-r^{\star}}+\frac{\omega_{B}^{2}}{\xi+r^{\star}},
$$

where $B_{0}$ is the initial stock of traded bonds. The assumption $\beta=r^{\star}$ implies that temporary policies have permanent effects. In this regard, eq. (29) determines the steady-state change in the net foreign asset position following a temporary fiscal expansion.

\section{Imperfect Mobility of Labor and Fiscal Transmission}

In this section, we solve the model analytically by abstracting from physical capital. ${ }^{41}$ This enables us to derive a number of analytical results which show that a model assuming imperfect mobility of labor across sectors can account for the evidence on fiscal transmission documented in section 2, as long as the government spending shock is biased toward non tradables. To avoid unnecessary complications, we solve the model by assuming that the endogenous response of $G(t)$ to an exogenous fiscal shock is governed by the following dynamic equation:

$$
d G(t) / \tilde{Y}=g e^{-\xi t}
$$

which amounts to setting $\xi=\chi$ into eq. (25). We consider a rise in $G$ which is split between non tradables and tradables in accordance with their respective shares in government spending, $\omega_{G^{j}}$, as described by (5). Building on our evidence which reveals that a rise in government consumption is biased toward non tradables, we consider that $\omega_{G^{N}}$ is high enough to produce an appreciation in the relative price of non tradables, in line with our empirical findings.

Both sectors use labor as the sole input in a constant returns to scale technology, i.e., $Y^{j}=L^{j}$ with $j=T, N$. Because there is a difficulty in reallocating labor, sectoral

\footnotetext{
${ }^{40}$ The terms in the RHS of eq. (29) are functions of parameters. The first term reads as $\omega_{B}^{1}=$ $\left[\Xi_{K}+\Xi_{Q} \omega_{2}^{1}\right]\left[\left(K_{0}-\tilde{K}\right)+\Gamma_{2}\left(1-\Theta_{2}\right)-\Gamma_{1}\left(1-\Theta_{1}\right)\right]$, with $\Xi_{K}=\frac{\partial \Xi}{\partial K}, \Xi_{Q}=\frac{\partial \Xi}{\partial Q}, \Xi_{G}=\frac{\partial \Xi}{\partial G}$ evaluated at the steady-state. The second term reads as $\omega_{B}^{2}=\Xi_{G} \tilde{Y}\left(1-\Theta^{\prime}\right)+\left[\Xi_{K}+\Xi_{Q} \omega_{2}^{1}\right] \Gamma_{1}\left(1-\Theta_{1}^{\prime}\right)-$ $\left[\Xi_{K}+\Xi_{Q} \omega_{2}^{2}\right] \Gamma_{2}\left(1-\Theta_{2}^{\prime}\right)$ where $\Theta^{\prime}=(1-g) \frac{r^{\star}+\xi}{r^{\star}+\chi}$, and $\Theta_{i}^{\prime}=\Theta_{i} \frac{r^{\star}+\xi}{r^{\star}+\chi}$ (with $\left.i=1,2\right)$.

${ }^{41}$ The steps of derivation of all equations in the main text are detailed in Appendix $\mathrm{H}$.
} 
wages do not equalize, i.e., $1=W^{T}$ and $P=W^{N}$. The key equations characterizing optimal household behavior are given by first-order conditions described by (17a)-(17b) and (18)-(19). The market clearing conditions for non traded and traded goods read as $Y^{N}=C^{N}+G^{N}$ and $\dot{B}=r^{\star} B+Y^{T}-C^{T}-G^{T}$, respectively.

\subsection{Solving the Model Analytically}

Substituting first (17a) into (18), (17b) into (19), using $W^{N}=P$, totally differentiating the market clearing condition for the non traded good and denoting the percentage deviation relative to initial steady-state by a hat leads to the change in the relative price of non tradables:

$$
\hat{P}(t)=\frac{-\left[\alpha_{L} \sigma_{L}+\alpha_{C} \omega_{C}\right]}{\Psi} \hat{\bar{\lambda}}+\frac{\omega_{G^{N}}}{\Psi} \frac{d G(t)}{\tilde{Y}},
$$

where we set $\Psi=\alpha_{L}\left[\epsilon\left(1-\alpha_{L}\right)+\sigma_{L} \alpha_{L}\right]+\omega_{C} \alpha_{C}\left[\left(1-\alpha_{C}\right) \phi+\alpha_{C}\right]>0$. In eq. (31), we denote by $\omega_{C}=P_{C} C / Y$ consumption expenditure as a share of GDP, $\alpha_{C}$ and $\alpha_{L}$ the non tradable content of consumption expenditure and labor compensation, respectively; in a model without capital, $\alpha_{L}$ also measures the share of non tradables in GDP, i.e., $\alpha_{L}=P Y^{N} / Y$.

Inserting first the demand for tradables (18) and labor supply to the traded sector (19), linearizing in the neighborhood of the steady-state, substituting the law of motion of government spending (30), solving and invoking the transversality condition leads to the solution for the net foreign asset position as a share of GDP:

$$
(B(t)-\tilde{B}) / \tilde{Y}=\left[\Upsilon_{G} /\left(\xi+r^{\star}\right)\right] g e^{-\xi t},
$$

consistent with the intertemporal solvency condition

$$
\left(\tilde{B}-B_{0}\right) / \tilde{Y}=-\left[\Upsilon_{G} /\left(\xi+r^{\star}\right)\right] g
$$

where $\Upsilon_{G}=\Upsilon_{G}^{N} \omega_{G^{N}}+\omega_{G^{T}}$ with $\Upsilon_{G}^{N}=\left[\left(1-\alpha_{L}\right) \alpha_{L}\left(\epsilon-\sigma_{L}\right)+\left(1-\alpha_{C}\right) \omega_{C} \alpha_{C}(\phi-1)\right] / \Psi$. If the elasticity of labor supply across sectors, $\epsilon$, is large enough with respect to aggregate labor supply, $\sigma_{L}$, then we have $\Upsilon_{G}^{N}>0$, so that the current account unambiguously deteriorates following a temporary fiscal expansion, in line with our VAR evidence. ${ }^{42}$

To determine the change in the equilibrium value of the marginal utility of wealth, we have to differentiate the market clearing condition for the traded good evaluated at the steady-state (i.e., $\dot{B}(t)=0$ ), using the fact that in the long-run, government spending is restored to its initial level (i.e., $d G=0$ ); next, inserting (33) into the resulting expression leads to the change in the equilibrium value of the marginal utility of wealth:

$$
\hat{\bar{\lambda}}=\frac{\Psi \Upsilon_{G}}{\Gamma} \frac{r^{\star}}{\xi+r^{\star}} g>0,
$$

\footnotetext{
${ }^{42}$ Differentiating (32) with respect to time leads to the current account response as a percentage of GDP which is unambiguously negative as long as $\Upsilon_{G}^{N}>0$. Intuitively, non traded output must increase to meet higher demand for non tradables. At the same time, households wish to avoid a large reduction in consumption and/or a large increase in labor supply. Because traded goods can be imported, resources are reallocated toward the non traded sector, generating a current account deficit.
} 
where $\Gamma=\Psi\left\{\left[\left(1-\alpha_{L}\right) \sigma_{L}+\omega_{C}\left(1-\alpha_{C}\right) \sigma_{C}\right]+\left[\alpha_{L} \sigma_{L}+\omega_{C} \alpha_{C} \sigma_{C}\right] \Upsilon_{G}^{N}\right\}>0$.

\subsection{Implications of Imperfect Mobility of Labor}

What are the implications of imperfect mobility for fiscal transmission? As in a model that imposes perfect mobility of labor, a rise in $G$ produces an increase in the shadow value of wealth as taxes must be raised to balance the budget which reduces households' disposable income. The negative wealth effect described by (34) encourages agents to work more and cut real expenditure. Because the decline in real expenditure is spread over the two goods, the rise in $G^{N}$ more than offsets the fall in $C^{N}$ if $\omega_{G^{N}}$ is high enough. As long as there is a difficulty in reallocating labor, excess demand arises in the non traded goods market, which in turn causes the relative price of non tradables to appreciate. To show this formally, we determine the initial response of $P$ by evaluating (31) at time $t=0$ and inserting (34):

$$
\hat{P}(0)=\left\{\omega_{G^{N}}-\left[\alpha_{L} \sigma_{L}+\alpha_{C} \omega_{C}\right] \frac{\Psi\left[\Upsilon_{G}^{N} \omega_{G^{N}}+\omega_{G^{T}}\right]}{\Gamma} \frac{r^{\star}}{\xi+r^{\star}}\right\} \frac{g}{\Psi}>0 .
$$

Eq. (35) shows that both the composition of government spending and the degree of labor mobility across sectors matter in determining the response of $P$. First, when the rise in $G$ is fully biased toward non tradables (i.e., $\omega_{G^{N}}=1$ ), the relative price of non tradables appreciates unambiguously. ${ }^{43}$ In contrast, if the government spending shock were fully biased toward tradables (i.e., $\omega_{G^{T}}=1$ ), the relative price would depreciate, in contradiction with our evidence. Because $\hat{P}(0)$ is increasing monotonically with $\omega_{G^{N}}$, there is a critical value $\bar{\omega}_{G^{N}}$ so that $\hat{P}(0)>0$ for $\omega_{G^{N}}>\bar{\omega}_{G^{N}}$. Second, as the degree of labor mobility across sectors increases, a government spending shock leads to a lower appreciation in $P$. The reason is that the shadow value of wealth, $\bar{\lambda}$, increases further, which results in a larger increase in non traded output and a greater decline in $C^{N} \cdot{ }^{44}$ In a model imposing perfect mobility of labor across sectors (i.e., $\epsilon \rightarrow \infty), P$ remains unaffected by a fiscal shock. Intuitively, the appropriate amount of labor moves instantaneously toward the non traded sector to eliminate any excess demand in the non traded goods market.

Conversely, as long as $\epsilon<\infty$ and $\omega_{G^{N}}>\bar{\omega}_{G^{N}}$, an excess demand shows up in the non traded goods market so that $P$ appreciates on impact. Non traded firms are encouraged to produce and thus to hire more workers. To persuade workers who experience mobility costs to increase their hours worked in the non traded sector, non traded firms must pay higher wages, i.e., $\hat{W}^{N}(0)=\hat{P}(0)>0$. The subsequent shift of labor toward the non traded sector raises non traded output unambiguously. It can be shown analytically that the response of traded output is ambiguous; more precisely, $Y^{T}$ may fall if the degree of labor mobility, $\epsilon$,

\footnotetext{
${ }^{43}$ To see this formally, the sign of the term in braces is unambiguously positive since $0<$ $\left[\alpha_{L} \sigma_{L}+\omega_{C} \alpha_{C}\right] \frac{\Upsilon_{G}^{N} \Psi}{\Gamma}<1$ and $0<\frac{r^{\star}}{\xi+r^{\star}}<1$.

${ }^{44}$ As the degree of labor mobility across sectors increases, more labor shifts toward the non traded sector which results in a greater decline in traded labor and thus triggers a larger current account deficit. In the long-run, for the intertemporal solvency condition to hold, the open economy must run a trade surplus and consumption must thus be reduced more though a stronger negative wealth effect.
} 
is higher than $\sigma_{L}$.

We now turn to the initial response of the sectoral output share. As documented in section 2, we find that a government spending shock increases the share of non tradables in real GDP and all the more so in countries where the degree of labor mobility across sectors is higher. In the data, the response of the sectoral output share is calculated as the growth differential in GDP units between sectoral value added at constant prices and real GDP denoted by $Y_{R}$. Totally differentiating non traded output and real GDP, the latter being equal to overall labor compensation $W L$ with $L=(\bar{\lambda} W)^{\sigma_{L}}$, and evaluating at time $t=0$ leads to the impact response of the share of non tradables in output in real terms:

$$
\alpha_{L}\left(\hat{Y}^{N}(0)-\hat{Y}_{R}(0)\right)=\alpha_{L}\left(1-\alpha_{L}\right) \epsilon \hat{P}(0)>0
$$

where $\hat{P}(0)$ is given by (35). According to (36), the appreciation in $P$ and the subsequent increase in $W^{N}$ leads to a shift of labor toward the non traded sector which increases its share in real GDP. A rise in the parameter $\epsilon$ exerts two opposite effects on the magnitude of the positive response of the share of non tradables in output. On the one hand, as the parameter $\epsilon$ on the RHS of (36) takes higher values, more labor shifts toward the non traded sector, thus amplifying the positive response of the share of non tradables in output. On the other hand, as mentioned above, the negative wealth effect turns out to be greater as labor becomes more mobile across sectors; as a result, increased labor mobility mitigates the excess demand in the non traded goods market and thus results in smaller values of $\hat{P}(0)>0$. It can be shown analytically that the former effect predominates so that $\alpha_{L}\left(\hat{Y}^{N}(0)-\hat{Y}_{R}(0)\right)$ is increasing with $\epsilon$, since the elasticity of the relative price response with respect to the degree of labor mobility is smaller than one, i.e., $-\frac{\partial \hat{P}(0)}{\partial \epsilon} \frac{\epsilon}{\hat{P}(0)}<1$. Letting $\epsilon$ tend toward infinity in eq. (36) and applying l'Hôpital's rule leads to: ${ }^{45}$

$$
\lim _{\epsilon \rightarrow \infty} \alpha_{L}\left(\hat{Y}^{N}(0)-\hat{Y}_{R}(0)\right)=\left[\omega_{G^{N}}-\left(\frac{\alpha_{L} \sigma_{L}+\alpha_{C} \omega_{C}}{\sigma_{L}+\omega_{C}} \frac{r^{\star}}{\xi+r^{\star}}\right)\right] g>0 .
$$

The analytical expression of the response of the share of non tradables in real GDP described by (37) in the special case of perfect mobility of labor enables us to shed some light on the relationship between the non tradable content of the government spending shock, $\omega_{G^{N}}$, and $\alpha_{L}\left(\hat{Y}^{N}(0)-\hat{Y}_{R}(0)\right)$. Keeping the responses of the private sector's demand components fixed, it is straightforward to show that the share of non tradables in real GDP increases as long as $\omega_{G^{N}}>\alpha_{L}$. In a general equilibrium model, demand components react to the government spending shock and thus slightly modify this condition. Adding and subtracting $\alpha_{L}$ in the RHS of (37) implies that the response $\alpha_{L}\left(\hat{Y}^{N}(0)-\hat{Y}_{R}(0)\right)$ is larger than $\left(\omega_{G^{N}}-\alpha_{L}\right) g$ since $\alpha_{L}>\left(\frac{\alpha_{L} \sigma_{L}+\alpha_{C} \omega_{C}}{\sigma_{L}+\omega_{C}} \frac{r^{\star}}{\xi+r^{\star}}\right)$. Intuitively, while after-tax income is lower, households want to keep their consumption high, which in turn produces excess demand in

\footnotetext{
${ }^{45}$ First inserting (35) into eq. (36), letting $\epsilon$ tend toward infinity and applying l'Hôpital's rule that implies that $\lim _{\epsilon \rightarrow \infty} \frac{\Psi \Upsilon_{G}}{\Gamma}=\frac{1}{\sigma_{L}+\omega_{C}}$ together with $\lim _{\epsilon \rightarrow \infty} \frac{\alpha_{L}\left(1-\alpha_{L}\right)}{\Psi}=1$ gives eq. (37).
} 
the traded and non traded goods market. However, labor supply does not increase enough to meet additional demand on both markets. Since traded goods can be imported while non traded goods must be produced by domestic firms, it is optimal for the open economy to run a current account deficit which further biases the government spending shock toward the non traded sector. Because $0<\left[\alpha_{L} \sigma_{L}+\alpha_{C} \omega_{C}\right] \frac{\Psi\left[\Upsilon_{G}^{N} \omega_{G N}+\omega_{G}\right]}{\Gamma}<\frac{\alpha_{L} \sigma_{L}+\alpha_{C} \omega_{C}}{\sigma_{L}+\omega_{C}}$ (see the second term on the RHS of eq. (35)), this result also holds when assuming imperfect mobility of labor across sectors. Henceforth, the critical value $\bar{\omega}_{G^{N}}$ above which the relative price appreciates on impact, i.e., $\hat{P}(0)>0$, and thus the share of non tradables in real GDP increases, is smaller than $\alpha_{L}$ but would (almost) reduce to $\alpha_{L}$ if the current account were unresponsive to the fiscal shock. In sum, the change in the relative size of the non traded sector is positively related to the relative intensity of this sector in the government spending shock, $\omega_{G^{N}}-\alpha_{L}$, the degree of labor mobility across sectors, $\epsilon$, and financial openness as the current account deficit further biases the demand shock in favor of non tradables.

\section{Quantitative Analysis}

In this section, we analyze the effects of a temporary and unanticipated rise in government consumption quantitatively. For this purpose we solve the model described in section 3 numerically. ${ }^{46}$ We begin by discussing the parameter values before turning to the shortterm consequences of higher government consumption.

\subsection{Calibration}

To calibrate our model, we estimated a set of parameters so that the initial steady state is consistent with the key empirical properties of a representative OECD economy. Our sample covers the sixteen OECD economies in our dataset. Our reference period for the calibration corresponds to the period 1990-2007. ${ }^{47}$ Table 4 summarizes our estimates of the non tradable content of GDP, employment, consumption, gross fixed capital formation, government spending, labor compensation, and gives the share of government spending on traded and non traded goods in their respective sectoral output, the shares of labor income in output in both sectors, for all countries in our sample. Moreover, columns 12-14 of Table 4 display investment expenditure and government spending as a percentage of GDP together with the labor income share, respectively, for the whole economy. To capture the key properties of a typical OECD economy, chosen as the baseline scenario, we take unweighted average values, as shown in the last line of Table 4. Some of the parameter values can be taken directly from the data, but others like $\varphi, \vartheta, \delta_{K}$ together with initial conditions $\left(B_{0}, K_{0}\right)$ need to be calibrated endogenously to fit a set of aggregate and sectoral

\footnotetext{
${ }^{46}$ Technically, the assumption $\beta=r^{\star}$ requires the joint determination of the transition and the steady state.

${ }^{47}$ The choice of this period was dictated by data availability for all the countries in the sample.
} 
ratios. ${ }^{48}$ We choose the model period to be one year and therefore set the world interest rate, $r^{\star}$, which is equal to the subjective time discount rate, $\beta$, to $4 \%$.

In light of our discussion above, $\epsilon$ plays a key role in fiscal transmission. The degree of labor mobility captured by $\epsilon$ is set to 0.75 , in line with the average of our estimates shown in the last line of Table $4 .{ }^{49}$ Our estimates display a marked dispersion across countries and we therefore conduct a sensitivity analysis with respect to this parameter. Excluding the estimates of $\epsilon$ for Denmark and Norway which are not statistically significant at $10 \%$, estimates of $\epsilon$ range from a low of 0.22 for the Netherlands to a high of 1.39 for the U.S. and 1.64 for Spain. Hence, we allow for $\epsilon$ to vary between 0.22 and 1.64 in the sensitivity analysis.

Building on our panel data estimates, the elasticity of substitution $\phi$ between traded and non traded goods is set to 0.77 in the baseline calibration since this value corresponds to the average of estimates shown in the last line of column 15 of Table $4 .^{50}$ The weight of consumption in non tradables $1-\varphi$ is set to 0.51 to target a non-tradable content in total consumption expenditure, $\alpha_{C}$, of $53 \%$, in line with the average of our estimates shown in the last line of column 2. In our baseline parametrization, we set intertemporal elasticity of substitution for labor supply $\sigma_{L}$ to 0.4 , in line with evidence reported by Fiorito and Zanella [2012]. The weight of labor supply to the non traded sector, $1-\vartheta$, is set to 0.68 to target a non-tradable content of labor compensation of $66 \%$, in line with the average of our estimates shown in the last line of column 6 of Table 4 .

We now describe the calibration of production-side parameters. We assume that physical capital depreciates at a rate $\delta_{K}$ of $6 \%$ to target an investment-to-GDP ratio of $21 \%$ (see column 12 of Table 4). Labor income shares in the traded $\left(\theta^{T}\right)$ and non traded sectors $\left(\theta^{N}\right)$ are set to 0.58 and 0.68 , respectively, which correspond roughly to the averages for countries with $k^{T}>k^{N}$ (see columns 9 and 10 of Table 4). Such values give an aggregate labor income share of $64 \%$, in line with the average value shown in the last line of column 14 of Table 4 . In line with our evidence shown in the last column of Table 4, we assume that traded firms are 28 percent more productive than non traded firms; hence we set $Z^{T}$ and $Z^{N}$ to 1.28 and 1 respectively. We set the share of investment expenditure on non-tradable goods, $\alpha_{J}$, to $64 \%$, in accordance with the evidence shown in column 3 of Table 4 . We choose the value of parameter $\kappa$ so that the elasticity of $I / K$ with respect to Tobin's q, i.e., $Q / P_{J}$, is equal to the value implied by estimates in Eberly, Rebelo, and Vincent [2008]. The resulting value of $\kappa$ is equal to 17 .

As shown in column 4 of Table 4, the non tradable content of government spending,

\footnotetext{
${ }^{48}$ See Appendix I.

${ }^{49}$ Since estimates of $\epsilon$ for Denmark and Norway are not statistically significant at a standard threshold, the values are left blank and we set $\phi$ to 0.75 which corresponds to the average value. To estimate $\epsilon$, we run the regression of the sectoral employment growth arising from labor reallocation across sectors on the percentage change in the relative share of sectoral value added accrued to labor, see Appendix B.

${ }^{50}$ The average value is calculated by excluding estimates for Italy which are negative.
} 
$\omega_{G^{N}}$, averages $90 \%$. We set government consumption on non traded goods, $G^{N}$, and traded goods, $G^{T}$, so as to yield a non tradable share of government spending, $\omega_{G^{N}}$, of $90 \%$, and government spending as a share of GDP to $20 \%$.

We choose initial conditions for $B_{0}$ and $K_{0}$ so that trade is initially balanced. Since net exports are nil and $P_{J} I / Y=21 \%$ and $G / Y=20 \%$, the accounting identity according to which GDP is equal to the sum of the final uses of goods and services, leads to a consumption-to-GDP ratio of $P_{C} C / Y=59 \%$. It is worthwhile mentioning that the non tradable content of GDP is determined endogenously by the non tradable content of consumption, $\alpha_{C}$, investment, $\alpha_{J}$, and government expenditure, $\omega_{G^{N}}$, along with the consumption-to-GDP ratio, $\omega_{C}$, and the investment-to-GDP ratio, $\omega_{J}$. More precisely, dividing the non traded good market clearing condition (24) by $Y$ leads to the non tradable content of GDP:

$$
P Y^{N} / Y=\omega_{C} \alpha_{C}+\omega_{J} \alpha_{J}+\omega_{G^{N}} \omega_{G}=63 \%
$$

where $\omega_{C}=59 \%, \alpha_{C}=53 \%, \omega_{J}=21 \%, \alpha_{J}=64 \%, \omega_{G^{N}}=90 \%$, and $\omega_{G}=20 \%$. According to (38), the ratios we target are consistent with a non tradable content of GDP of $63 \%$ found in the data (see the last line of column 1 of Table 4 ).

In order to capture the endogenous response of government spending to exogenous fiscal shock, we assume that the dynamic adjustment of government consumption is governed by eq. (25). In the quantitative analysis, we set $g=0.01$ so that government consumption increases by 1 ppt of initial GDP. To calibrate $\xi$ and $\chi$ that parametrize the shape of the dynamic adjustment of government consumption along with its persistence, we proceed as follows. ${ }^{51}$ Because $G(t)$ peaks after one year, we have $d G(1) / Y=\left[e^{-\xi}-(1-g) e^{-\chi}\right]=$ $g^{\prime}>g$ with $g^{\prime}=0.011265$ and $\dot{G}(1) / Y=-\left[\xi e^{-\xi}-\chi(1-g) e^{-\chi}\right]=0$. Solving the system gives us $\xi=0.408$ and $\chi=0.415$. Left-multiplying eq. (25) by $\omega_{G^{j}}$ (with $j=N, T$ ) gives the dynamic adjustment of sectoral government consumption to an exogenous fiscal shock:

$$
\omega_{G^{j}}(G(t)-\tilde{G}) / Y=\omega_{G^{j}}\left[e^{-\xi t}-(1-g) e^{-\chi t}\right],
$$

where $\omega_{G^{j}}$ is the fraction of government consumption in good $j$. To determine (39), we assume that the parameters that govern the persistence and shape of the response of sectoral government consumption are identical across sectors, while the sectoral intensity of the government spending shock is constant over time and thus corresponds to the share of government final consumption expenditure on good $j$.

As the baseline scenario, we take the model with imperfect mobility of labor across sectors and capital adjustments costs. In our baseline calibration we set $\epsilon=0.75$ and $\kappa=17$, but we also conduct a sensitivity analysis with respect to these two parameters by

\footnotetext{
${ }^{51}$ Our calibration of the government consumption shock is based on estimates of the first VAR model $z_{i t}=\left[g_{i t}, y_{i t}, l_{i t}, j e_{i t}, w_{C, i t}\right]$. In Appendix E.3, we show that alternative VAR specifications give identical results.
} 
setting alternatively: $\epsilon$ to 0.22 and 1.64 and $\kappa$ to 0 . In order to contrast our results with those obtained when imposing perfect mobility of labor across sectors, we let $\epsilon$ tend toward infinity.

\subsection{Results}

In this subsection, we analyze in detail the role of imperfect mobility of labor in shaping the dynamics of the open economy in response to a government spending shock. Our primary objective is to explain how workers' costs of switching sectors change the model's predictions in a way that makes them consistent with our empirical findings on fiscal policy transmission.

Table 1 shows the simulated impact effects of an exogenous and unanticipated increase in government consumption by 1 ppt of GDP while column 1 shows impact responses from our VAR model for comparison purposes. Column 2 shows results for the baseline model which we contrast with those obtained when we impose perfect mobility of labor (i.e., we set $\epsilon \rightarrow \infty)$ and abstract from capital installation costs (i.e., we set $\kappa=0$ ), as displayed in column 6. Other columns give the results for the alternative scenarios discussed below. While in Table 1, we restrict our attention to impact responses, in Fig. 5 and 6 we show the dynamic adjustment to an unanticipated increase in government consumption by $1 \%$ of GDP. Figures display the model predictions together with the respective VAR evidence. In each panel, the solid blue line displays the point estimate of the VAR model, with the shaded area indicating the $90 \%$ confidence bounds whilst the thick solid black line with circles shows theoretical responses from the baseline model.

As shown in the left panel of Fig. 5, the endogenous response of government spending to an exogenous fiscal shock that we generate theoretically by specifying the law of motion (25) reproduces the dynamic adjustment from the VAR model remarkably well, as the black line and the blue line cannot be differentiated. The right panel of Fig. 5 contrasts empirical responses of sectoral government consumption to an exogenous fiscal shock with theoretical responses derived from eq. (39) by setting $\omega_{G^{N}}$ and $\omega_{G^{T}}$ to 0.9 and 0.1 , respectively. The upper and lower lines show the responses of $G^{N}$ and $G^{T}$, respectively. Overall, the theoretical responses perform well in reproducing the evidence and thus the assumptions underlying the dynamic equation (39) which governs the adjustment of $G^{j}$ are consistent with data.

$<$ Please insert Table 1 and Figures 5-6 about here $>$

\subsubsection{Effects on Relative Sector Size}

We need to start with the whole picture as the aggregate and sectoral effects of a government spending shock biased toward non tradables are strongly intertwined. Impact effects of a government spending shock on GDP, its demand components and labor market variables 
are shown in panels $\mathrm{A}$ and $\mathrm{B}$ of Table $1 .^{52}$ By producing a negative wealth effect, a balanced-budget government spending shock leads agents to supply more labor, which in turn increases real GDP. In contrast to a setup assuming $\epsilon \rightarrow \infty$ (columns 6-7), the baseline model (column 2) does a better job in replicating the evidence. First, because workers' costs of switching sectors put upward pressure on $W^{N}$ and thus on the aggregate wage, the positive response of $L$ and the size of the aggregate fiscal multiplier are amplified with imperfect mobility of labor. Moreover, the rise in $W$ is large enough to increase the real consumption wage. Second, whilst a model imposing perfect mobility of labor overstates the current account deficit or predicts a current account surplus depending on whether capital adjustment costs are included or not (see columns 7 and 6), the baseline model (see column 2) is also able to produce a decline in investment and the current account on impact which accords well with our VAR estimates. Intuitively, following a temporary government spending shock, households lower their savings in order to avoid a large decrease in their consumption and/or mitigate the rise in their labor supply. Lower savings result in a decline in investment or the current account or both. With imperfect mobility, capital shifts toward the non traded sector which lowers $k^{H}$ and increases the return on domestic capital. As a result, the fall in investment is mitigated whilst a current account deficit appears (see column 5 where $\kappa=0)$ ). Capital adjustment costs further moderate the decline in investment and amplify the current account deficit (see column 2 where $\kappa=17$ ).

We turn to the sectoral and reallocation effects. Panels C and D of Table 1 show impact responses of labor and product market variables, respectively, while in Fig. 6, we report the model predictions together with the VAR evidence of sectoral variables. In Fig. 6, we also contrast the responses from the benchmark setup with those from a model imposing $\epsilon \rightarrow \infty$ and $\kappa=0$, as displayed in the dashed dotted black line.

Focusing first on impact responses, column 6 of Table 1 shows that a model assuming perfect mobility of labor fails to account for the evidence along a number of dimensions. More specifically, comparing the VAR evidence reported in column 1 with simulated impact effects, we find that a model abstracting from workers' mobility costs understates the expansionary effect of a government spending shock on non traded output, cannot generate an appreciation in the $P$ or a rise in $W^{N} / W^{T}$, and substantially understates the changes in sectoral output shares.

In contrast, as displayed in column 2, the performance of the neoclassical model improves, as long as we allow for imperfect mobility of labor. To begin with, the baseline model which considers costs of switching sectors can account for the rise in the relative wage. Intuitively, because government spending is biased toward non tradables, non traded

\footnotetext{
${ }^{52}$ For reasons of space, the empirical and theoretical responses of GDP, its demand components and labor market variables are contrasted in Appendix J.1. It is worthwhile mentioning that the simulated responses lie within the confidence interval along the transitional adjustment for all aggregate variables, with the exception of the real consumption wage.
} 
firms are encouraged to produce and thus to hire more to meet additional demand. As workers experience intersectoral mobility costs, non traded firms must pay higher wages to attract workers which raises the relative wage, $\Omega$, by $1.44 \%$ (see Panel C).

Because labor shifts toward the non traded sector, the baseline model predicts a rise in hours worked in non tradables by $0.44 \%$, which accords well with the evidence shown in column 1. Labor reallocation pushes up non traded output by $0.50 \%$, the response being almost double that obtained with perfect labor mobility (see column 6). The reason is as follows. Because the aggregate wage increases when we allow for imperfect mobility of labor, workers supply more labor, which further raises output in the non traded sector since it is relatively more labor intensive. While the baseline model is able to account pretty well for impact responses of hours worked and output of non tradables, it tends to somewhat overstate the contraction in hours worked and the output of tradables which are fairly muted according to VAR evidence.

As long as there is a difficulty in reallocating labor across sectors, excess demand shows up in the non traded goods market. As a result, the price of non traded goods relative to traded goods appreciates by $0.88 \%$, as shown in the fourth line of panel D. The appreciation in the $P$ triggers a reallocation of resources toward the non traded sector, raising its output share by $0.38 \%$ of GDP, while that of tradables falls by exactly the same amount. As we move from column 3 to column 4 of Table 1, the utility loss resulting from the shift from one sector to another is reduced. As shown analytically in section 4, a rise in the degree of labor mobility exerts two opposite effects on sectoral output shares: while workers are more willing to shift across sectors, the relative price of non tradables appreciates less, which mitigates the incentive for labor reallocation. We find numerically that raising the elasticity of labor supply across sectors, $\epsilon$, from 0.22 to 1.64 amplifies the rise in the output share of non tradables from $0.26 \%$ to $0.49 \%$ of GDP, in accordance with our evidence documented in section 2.7. Thus, the former effect more than offsets the latter. ${ }^{53}$

Turning to the adjustment of sectoral variables following a government spending shock as shown by the solid black line with circles in Fig. 6, the dynamics of the relative price and relative wage are captured fairly well by the baseline model. As government spending falls and is restored to its initial level, excess demand in the non traded goods market is reduced, which depreciates the relative price of non tradables along the transitional path, as shown in Fig. 6(a). Decreasing prices of non tradables relative to tradables encourage non traded firms to reduce hours worked and thus to lower output, in line with the evidence in Fig. 6(h) and $6(\mathrm{~g})$. Because non traded wages fall relative to traded wages during the transitional adjustment, as shown in Fig. 6(b), labor is reallocated toward the traded sector, which

\footnotetext{
${ }^{53}$ However, the latter influence may predominate if the values of $\epsilon$ are higher, because the relative price merely appreciates in this case. In the polar case where $\epsilon$ tends toward infinity, the output share of non tradables increases by only $0.24 \%$, a value that is much smaller than the estimated response of $0.35 \%$ of GDP.
} 
recovers gradually, while both hours worked and output remain below their initial levels for almost ten years. As shown in Fig. 6(e) and 6(d), the model tends to somewhat understate the contraction of labor and the output of tradables in the medium run. ${ }^{54}$

Conversely, as displayed by dashed dotted black line, the performance of the model declines considerably when imposing $\epsilon \rightarrow \infty$ and setting $\kappa=0$; in this special case, the model predicts a flat temporal path for $\Omega$ and $P$, which is in conflict with the evidence; whilst it understates the responses of sectoral output shares on impact, the model overstates their changes along the transitional path. The reason is that the capital stock falls sharply in the short-run and then recovers rapidly after two years, resulting in sharp changes in the relative size of sectors due to the Rybczynski effect.

\subsubsection{Sensitivity Analysis}

To gauge the relative role of limited labor mobility and capital adjustment costs, we also report results from two restricted versions of the model where one of the two features is, respectively, shutdown. Column 7 of Table 1 shows the predictions of a model allowing for perfect mobility of labor along with capital installation costs while column 5 reports impact responses from a model assuming imperfect mobility while setting $\kappa=0 .{ }^{55}$ Both models fail to account for the responses of sectoral output shares to a government spending shock. While introducing capital installation costs restores transitional dynamics for the relative price of non tradables, the restricted model where labor is perfectly mobile across sectors considerably overstates the responses of sectoral output shares. Intuitively, workers no longer experience a mobility cost and are thus willing to shift their whole time to the sector that pays the highest wage. As a result, sectoral labor and thus sectoral output become unrealistically sensitive to a change in relative price, thus leading to a change in the sectoral output share which is about twice what is estimated empirically, as can be seen in column 7. In contrast, as reported in column 5, a model assuming imperfect mobility of labor while abstracting from capital installation costs tends to substantially understate the responses of sectoral output shares. As investment is crowded out by a larger amount than if capital were subject to adjustment costs, the excess demand in the non traded goods market is lower so that the relative price appreciates less, resulting in smaller shifts of labor and capital toward the non traded sector.

\footnotetext{
${ }^{54}$ The explanation is intuitive: the baseline model underpredicts the decumulation of physical capital along the transitional path while the traded sector is more capital intensive.

${ }^{55}$ To save space we develop intuition regarding the implications of imperfect mobility of labor and capital adjustment costs by restricting attention to impact responses. In Appendix J.3, we contrast the dynamic adjustment from the baseline model with the responses from the restricted model where one of the two features is shut down.
} 


\subsection{Cross-Country Differences: Taking the Model to Data}

We have shown above that the performance of the neoclassical model in replicating the evidence related to fiscal transmission improves as long as we allow for imperfect mobility of labor and capital adjustment costs. We now move a step further and assess the ability of the model to generate a similar cross-country relationship between the degree of labor mobility and changes in the relative size of sectors to that in the data.

To compute the impact responses of sectoral output shares to a government spending shock numerically, we calibrate our model to match the key characteristics of the 16 OECD economies in our sample, including the share of non traded hours worked to total hours worked, the non tradable content of consumption, investment and public expenditure, investment- and government spending-to-GDP ratios, and the degree of labor mobility across sectors. Table 4 summarizes the country-specific data for non tradable and GDP component shares. The elasticity of labor supply across sectors, $\epsilon$, which plays a pivotal role in fiscal transmission, is set in accordance with our estimates shown in the last column of Table 4. While we explore the sectoral effects of a rise in $G$ by 1 ppt of GDP for each country in our sample, to be consistent with the calibration to a representative OECD economy described in section 5.1, we assume that the increase in public purchases is split between non tradables and tradables in accordance with their respective shares in government spending, i.e., $\omega_{G^{N}}$ and $1-\omega_{G^{N}}$, respectively, where $\omega_{G^{N}}$ is set in accordance with its country-specific value shown in column 4 of Table 4 , except for Australia and Ireland. ${ }^{56}$

$<$ Please insert Figures 7-8 about here $>$

To explore the cross-country relationship quantitatively, we first plot in Fig. 7 the simulated responses of sectoral output shares on the vertical axis against the degree of labor mobility captured by the parameter $\epsilon$ on the horizontal axis. ${ }^{57}$ Restricting our attention to countries where the rise in government consumption is biased toward non tradables, impact changes in non traded output relative to real GDP range from $0.26 \%$ of GDP for the Netherlands to $0.49 \%$ of GDP for Spain. Fig. $7(\mathrm{a})$ and $7(\mathrm{~b})$ also show that these differences in the responses of sectoral output shares are positively correlated with the measure of the degree of labor mobility across sectors. This result thus reveals that the sectoral impact of fiscal policy increases with the degree of labor mobility, which accords with our evidence. Quantitatively, as we move along the trend line shown in Fig. $7(\mathrm{a})$, our model predicts that a country with a low degree of labor mobility, as captured by

\footnotetext{
${ }^{56}$ For Australia and Ireland, we find empirically that the output share of tradables increases on impact while the share of non tradables declines. To be consistent with empirical evidence, we consider a rise in public purchases which is fully biased toward tradables. It is worthwhile mentioning that at the initial steady-state, we set the non tradable content of government spending, $\omega_{G^{N}}$, to $88 \%$ and $90 \%$ for Australia and Ireland, respectively, in accordance with the shares reported in column 4 of Table 4.

${ }^{57}$ Because our panel data estimates are not statistically significant at $10 \%$ for Denmark and Norway, these two countries are removed from the cross-country analysis. If we include them, the conclusions are unaffected.
} 
a value of $\epsilon$ of 0.2 , will experience a decline in the output share of tradables of $0.2 \%$ of GDP, while a country with a higher degree of labor mobility, as captured by a value of $\epsilon$ of 1.2 , will face a fall by $0.4 \%$ of GDP, a decline which is twice as great. Hence, cross-country differences in the degree of labor mobility generate substantial dispersion in the sectoral impact of fiscal policy.

In Fig. 8, we contrast the cross-country relationship from the calibrated baseline model shown by the solid black line with circles with the cross-country relationship from the VAR model shown by the solid blue line. When we calibrate our model to cross-country data, we obtain a correlation between the responses of sectoral output shares and the measure of the degree of labor mobility of -0.207 for tradables $(t-s t a t=-2.238)$ and 0.207 for non tradables $(t-s t a t=2.238)$. While it tends to understate the changes in the relative size of sectors since the cross-country relationship is higher for tradables and lower for non tradables, the model is able to generate a cross-country relationship between the responses of sectoral output shares and the degree of labor mobility which is quite similar to that in the data.

\section{Conclusion}

This paper contributes to the literature related to the effects of a government spending shock both empirically and theoretically. From an empirical point of view, we provide new evidence on fiscal transmission by focusing on changes in relative sector size. Using a panel of 16 OECD countries over the period 1970-2007 and adopting a SVAR approach, our estimates reveal that the non traded sector is very intensive in government spending shocks which trigger a shift of resources toward this sector. More precisely, our evidence reveals that the non tradable content of the government spending shock averages $90 \%$, while the reallocation of inputs alone contributes to $50 \%$ of non traded output growth on impact. Whilst the shift of labor is responsible for half of the increase in non traded hours worked, our evidence points to the presence of labor mobility costs, as we detect empirically a significant increase in non traded wages relative to traded wages. The degree of labor mobility across sectors appears empirically to be a key determinant of the response of the share of non tradables to a government spending shock, which varies across time and space. Whilst the rise in the relative size of the non traded sector has been declining over time, this decrease is highly correlated with the declining response of the intersectoral reallocation of labor. Labor mobility also matters for the variations in sectoral shares across space. Whilst the responses of sectoral shares vary substantially across countries, we detect empirically a positive cross-country relationship between changes in relative sector size and the degree of labor mobility across sectors.

To rationalize our evidence, we develop a two-sector neoclassical model with two key 
features. First, we allow the government spending shock to be biased toward non tradables in line with our empirical findings while financial openness also matters in replicating the evidence. Since traded goods can be imported while non traded goods must be produced by domestic firms, the current account deficit further biases the demand boom toward non traded goods. Second, as in Horvath [2000], agents cannot costlessly reallocate hours worked from one sector to another. Because mobility is costly in utility terms, workers demand higher wages in order to compensate for their cost of switching sectors. Calibrating the model to a representative OECD economy and considering a rise in government consumption biased toward non tradables, we find quantitatively that the open economy version of the neoclassical model with tradables and non tradables can account for the panel VAR evidence, in particular the changes in relative sector size, as long as we allow for adjustment costs to physical capital accumulation along with imperfect mobility of labor across sectors. The former feature mitigates the decline in investment and thus guarantees that the excess demand and therefore incentives to shift resources toward the non traded sector are high enough. By reducing the elasticity of labor supply across sectors, the latter feature hampers the reallocation of labor and thus allows the model to match the changes in relative sector size quantitatively. In contrast, the restricted version of the model where one of the two features is shut down fails to account for the evidence.

When we calibrate our baseline model to each OECD economy in our sample, our numerical results reveal that international differences in the degree of labor mobility generate a wide dispersion in the responses of sectoral output shares to a government spending shock: changes in the relative size of sectors are twice as strong in the country with the highest degree of labor mobility than in the economy with the lowest labor mobility. Finally, we find quantitatively that the model reproduces pretty well the cross-country relationship between the degree of labor mobility and the responses of sectoral output shares that we estimate empirically.

\section{References}

Bems, Rudolfs (2008) Aggregate Investment Expenditures on Tradable and Nontradable Goods. Review of Economic Dynamics, 4, pp. 852-883.

Benetrix, Agustin and Philip R. Lane (2010) Fiscal Shocks and the Sectoral Composition of Output. Open Economies Review 21(3), pp. 335-350.

Blanchard, Olivier J., and Roberto Perotti (2002) An Empirical Characterization of the Dynamic Effects of Changes in Government Spending and Taxes on Output. Quarterly Journal of Economcis 177, pp. 1329-1368.

Born, Benjamin, Falko Juessen, and Gernot J. Müller (2013) Exchange Rate Regimes and Fiscal Multipliers. Journal of Economic Dynamics and Control, 37(2), pp. 446-465.

Bouakez, Hafedh, Emanuela Cardia, and Franciso J. Ruge-Murcia (2009) Durable Goods, InterSectoral Linkages and Monetary Policy. International Economic Review, 35, pp. 730-745.

Brinca, Pedro, Hans A. Holter, Per Krusell and Laurence Malafry (2016) Fiscal Multipliers in the 21st Century. Journal of Monetary Economics, 77(C), pp. 53-69.

Buiter, Willem H. (1984) Saddlepoint Problems in Continuous Time Rational Expectations Models: A General Method and some Macroeconomic Examples. Econometrica, 52, pp. 665-80. 
Cardi Olivier and Romain Restout (2015) Imperfect Mobility of Labor across Sectors: A Reappraisal of the Balassa-Samuelson Effect. Journal of International Economics, 97(2), pp. 249-265.

De Gregorio, Jose, Alberto Giovannini and Holger C. Wolf (1994) International Evidence on Tradables and Nontradables Inflation. European Economic Review 38, pp. 1225-1244.

Eberly, Janice Sergio Rebelo, and Nicolas Vincent, 2008. Investment and Value: A Neoclassical Benchmark. NBER Working Papers 13866.

European Union KLEMS, 2011. Growth and productivity accounts.

Fioramanti, Marco, Laura González Cabanillas, Bjorn Roelstraete and Salvador Adrian Ferrandis Vallterra (2016) European Commission's Forecasts Accuracy Revisited: Statistical Properties and Possible Causes of Forecast Errors. European Economy Discussion Papers, $\mathrm{n}^{\circ} 027$.

Fiorito, Ricardo and Giulio Zanella (2012) The Anatomy of the Aggregate Labor Supply Elasticity Review of Economic Dynamics, 15(2), pp. 171-187.

Guajardo, Jaime, Daniel Leigh, and Andrea Pescatori (2014) Expansionary Austerity? International Evidence. Journal of the European Economic Association, 12(4), pp. 949-968.

Horvath, Michael (2000) Sectoral Shocks and Aggregate Fluctuations. Journal of Monetary Economics, 45, pp. 69-106.

Ilzetzki, Ethan, Enrique G., Mendoza and Carlos A. Végh, (2013) How Big (Small?) are Fiscal Multipliers. Journal of Monetary Economics, 60(2), pp 239-254.

Jensen, Bradford J., and Lori G. Kletzer, (2006) Offshoring White-Collar Work, in Susan M. Collins and Lael Brainard, eds., Brookings Trade Forum 2005, Offshoring White-Collar Work. Brookings Institution: Washington, DC, pp. 75-134.

Jordà, Òscar (2005) Estimation and Inference of Impulse Responses by Local Projections. American Economic Review, 95(1), pp. 161-182.

Miyamoto, Wataru, Thuy Lan Nguyen and Dmitriy Sergeyev (2018) Government Spending Multipliers under the Zero Lower Bound: Evidence from Japan. American Economic Journal: Macroeconomics, 10(3), pp. 247-277.

Monacelli, Tommaso and Robert Perotti (2008) Openness and the Sectoral Effects of Fiscal Policy. Journal of the European Economic Association 6(2-3), pp. 395-403.

Perotti, Roberto (2008) In Search of the Transmission Mechanism of Fiscal Policy. NBER Chapters in: NBER Macroeconomics Annual 2007, Volume 22, pp. 169-226.

Phelan, Christopher, and Alberto Trejos (2000) The Aggregate Effects of Sectoral Reallocations. Journal of Monetary Economics, 45(2), pp. 249-268.

Organization for Economic Cooperation and Development (2011), Structural Analysis Database, OECD, Paris.

Ramey, Valerie A., and Matthew D. Shapiro (1998) Costly Capital Reallocation and the Effects of Government Spending. Carnegie-Rochester Conference Series on Public Policy, 48, pp. 145194.

Wacziarg, Romain and Jessica S. Wallack (2004) Trade Liberalization and Intersectoral Labor Movements. Journal of International Economics, 64, pp. 411-439. 


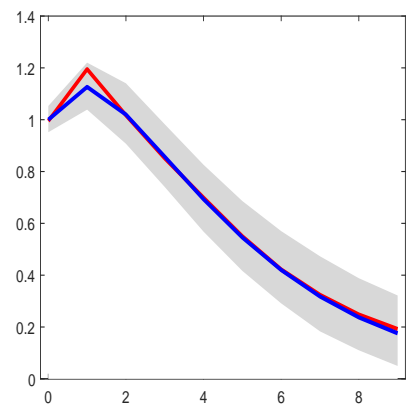

(a) Government Final Consumption

Expenditure, $G$

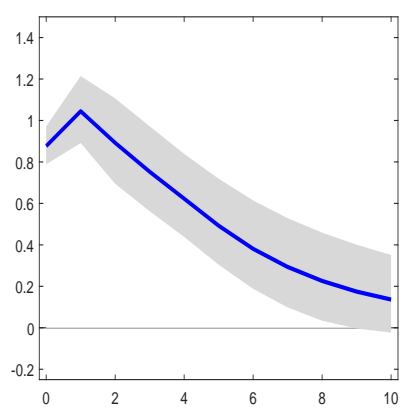

(b) Gov. Exp. on Non Tradables, $G^{N}$

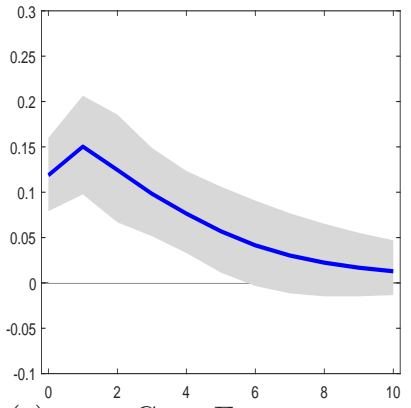

(c) Gov. Exp. on Tradables, $G^{T}$

Figure 1: Effects of Unanticipated Government Spending Shock on Government Final Consumption Expenditure and its Non Tradable and Tradable Components. Notes: Exogenous increase of government consumption by $1 \%$ of GDP. The government spending shock is identified by estimating a VAR model that includes real government final consumption expenditure, GDP (constant prices), total hours worked, private fixed investment, and the real consumption wage. The baseline response of government final consumption expenditure is displayed by the solid blue line in the left panel with shaded area indicating the 90 percent confidence bounds obtained by bootstrap sampling; sample: 16 OECD countries, 1970-2007, annual data. The responses of government final consumption expenditure on non tradables (i.e., $g^{N}$ ) and tradables (i.e., $g^{T}$ ) to the identified government spending shock (in the baseline VAR model) are displayed by solid blue lines in the right panel with shaded area indicating the 90 percent confidence bounds; sample: 13 OECD countries, 1995-2015, annual data. The red line in the left panel displays the dynamic response of government final consumption expenditure which has been computed by summing mean responses of government consumption expenditure on non tradables and tradables.

Output Multipliers

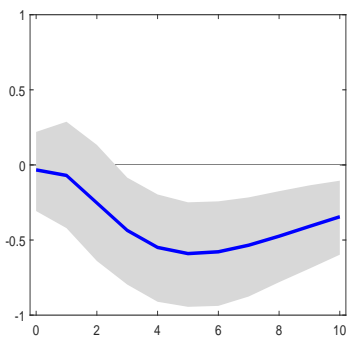

(a) Traded Output, $Y^{T}$

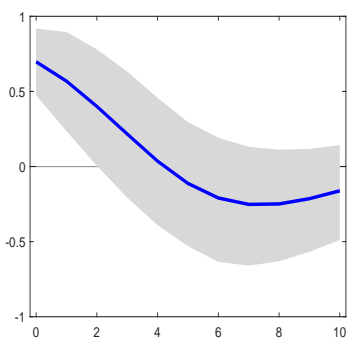

(e) Non Traded Output, $Y^{N}$
Labor Multipliers

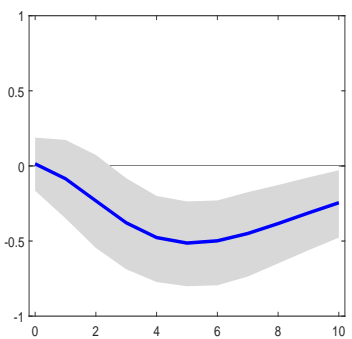

(b) Traded Labor, $L^{T}$

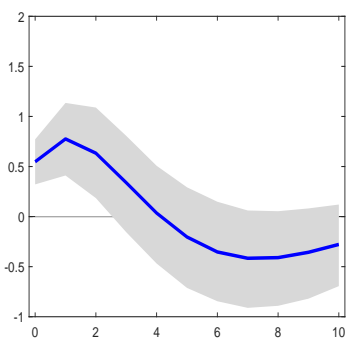

(f) Non Traded Labor, $L^{N}$
Sectoral Shares

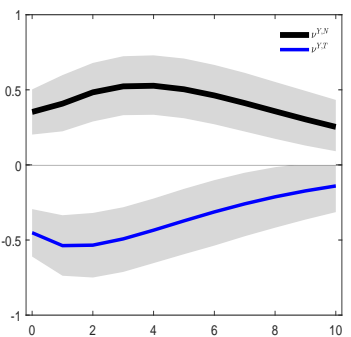

(c) Output Shares.

Black line: $\nu^{Y, N}$;

blue line: $\nu^{Y, T}$

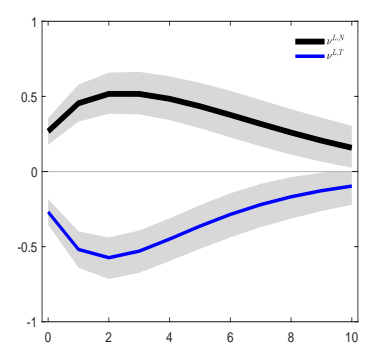

(g) Labor Shares.

Black line: $\nu^{L, N}$; blue line: $\nu^{L, T}$
Goods \& Labor Markets

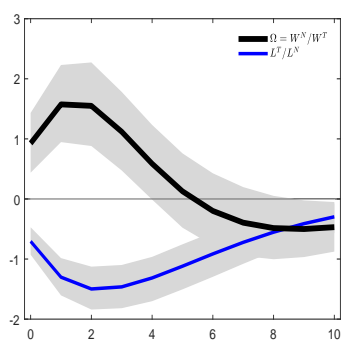

(d) Black line: $\Omega$; blue line: $L^{T} / L^{N}$

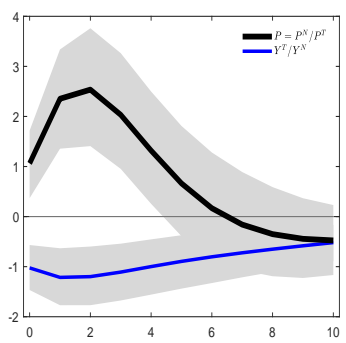

(h) Black line: $P$; blue line: $Y^{T} / Y^{N}$

Figure 2: Effects of Unanticipated Government Spending Shock on Sectoral Variables. Notes: Exogenous increase of government consumption by $1 \%$ of GDP. Horizontal axes indicate years. Vertical axes measure percentage deviation from trend in output units (sectoral output, sectoral output shares), percentage deviation from trend in labor units (sectoral labor, sectoral labor shares), deviations from trend (ratio of traded value added to non traded value added, ratio of hours worked of tradables to hours worked of non tradables), and percentage deviation from trend (relative price, relative wage). Solid blue and solid black lines display point estimates; thick black lines which are above the X-axis show responses of $\nu^{Y, N}$ in Fig. 2(c), $\nu^{L, N}$ in Fig. 2(g), $\Omega$, in Fig. 2(d), $P$ in Fig. 2(h); shaded areas: bootstrapped 90\% confidence intervals; sample: 16 OECD countries, 1970-2007, annual data. 


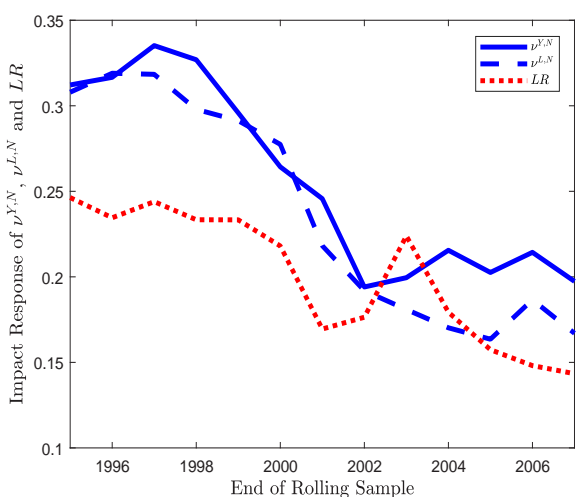

(a) Non Traded Goods Share, $\nu^{N}$

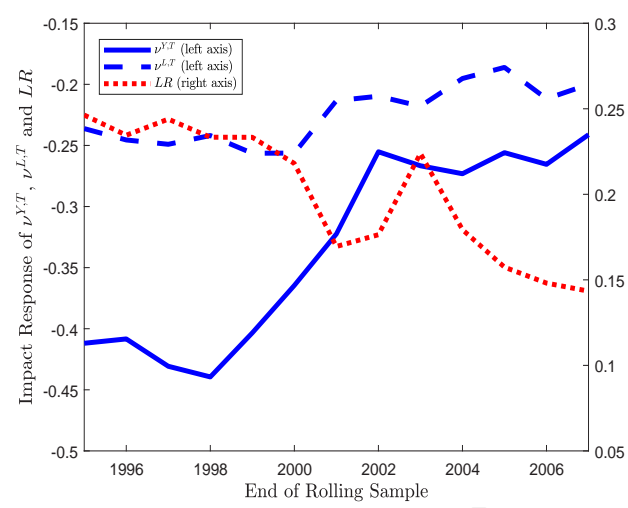

(b) Traded Goods Share, $\nu^{T}$

Figure 3: Plot of Impact Responses of Sectoral Shares to a Government Spending Shock in Rolling Sub-Samples against Impact Response of Intersectoral Labor Reallocation. Notes: Exogenous increase of government consumption by $1 \%$ of GDP. The government spending shock is identified by estimating a VAR model that includes real government final consumption expenditure, GDP (constant prices), total hours worked, private fixed investment, and the real consumption wage. We adopt the local projection method for estimating impulse responses of the sectoral shares (i.e., $\nu^{Y, j}, \nu^{L, j}$ ) and the labor reallocation index (i.e., $L R$ ) to identified government spending shock; as we restrict attention to impact effects, we run the regression of each variable of interest on the structural shock, setting $h=0$ into eq. (8). To explore empirically time-varying effects of government spending shocks, we estimate impact effects on rolling 25-year window. The time-varying impact response of the value added (labor) share of sector $j$ is shown in the solid (dashed) blue line while the time-varying impact response of intersectoral labor reallocation is displayed in the dotted red line; sample: 16 OECD countries, 1970-2007, annual data.

Labor Shares

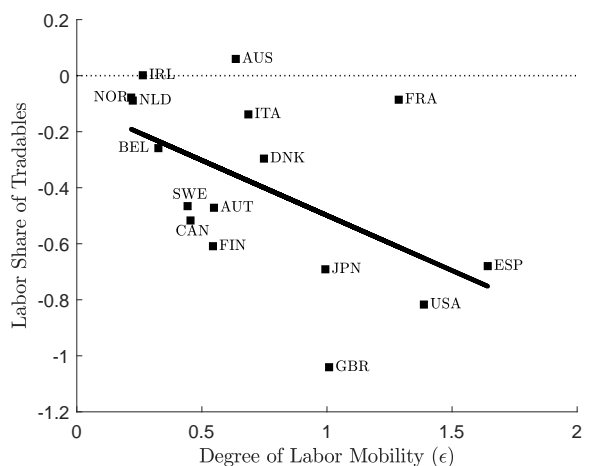

(a) Labor Share of Tradables

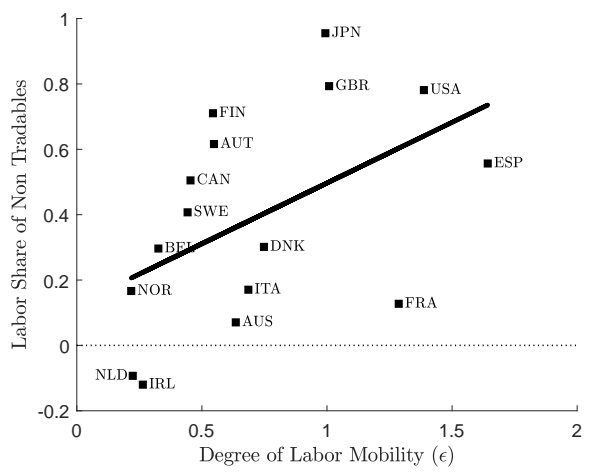

(c) Labor Share of Non Tradables
Output Shares

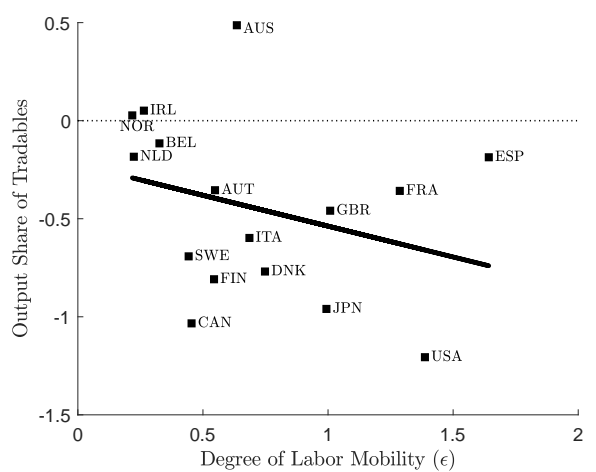

(b) Output Share of Tradables

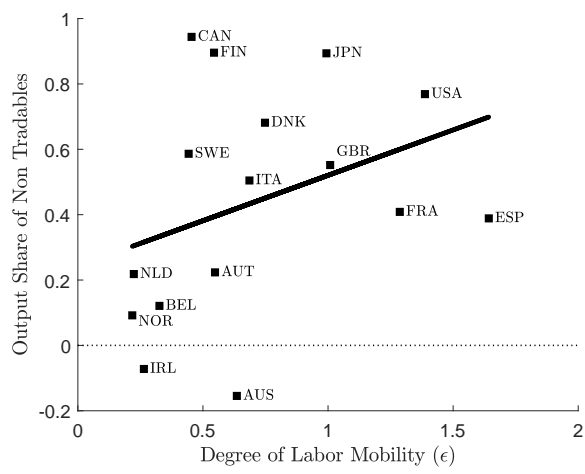

(d) Output Share of Non Tradables

Figure 4: Effect of Government Spending Shocks on Sectoral Shares against the Degree of Labor Mobility across Sectors. Notes: Figure 4 plots impact responses of sectoral labor and sectoral output shares. Impact responses shown in the vertical axis are obtained by running a VAR model for each country and are expressed in percentage point. Horizontal axis displays the elasticity of labor supply across sectors, $\epsilon$, which captures the degree of labor mobility across sectors; panel data estimates for $\epsilon$ are taken from column 16 of Table 4 . 


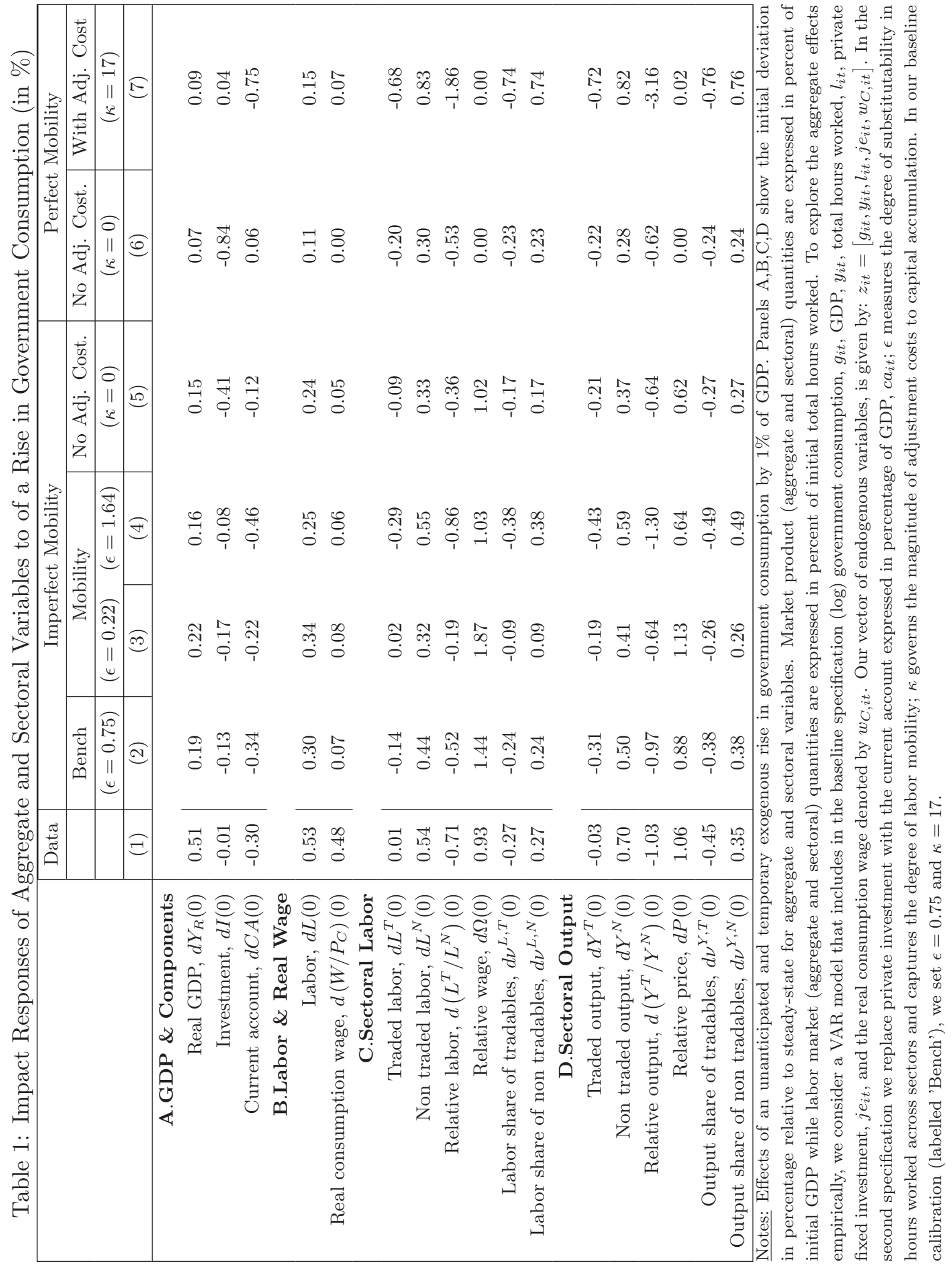




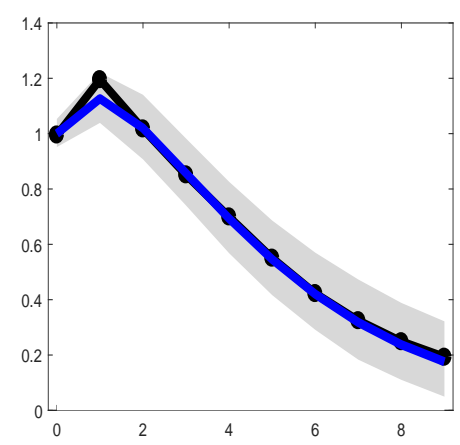

(a) Government Spending

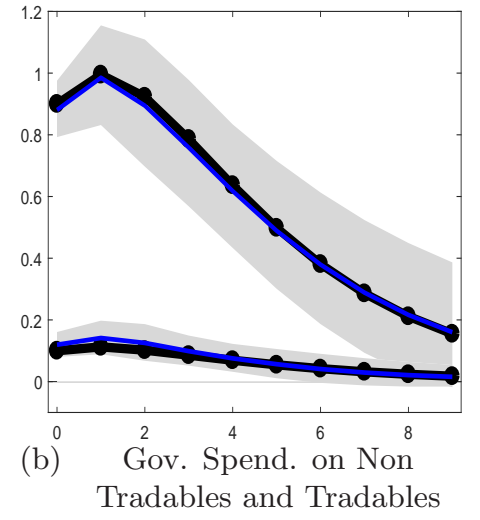

Figure 5: Effects of Unanticipated Government Spending Shock on Government Final Consumption Expenditure and Its Two Components: Empirical vs. Theoretical Impulse Response Functions. Notes: The baseline response of government final consumption expenditure is displayed by the solid blue line in the left panel with shaded area indicating the 90 percent confidence bounds obtained by bootstrap sampling; sample: 16 OECD countries, 1970-2007, annual data. The responses of government final consumption expenditure on non tradables (i.e., $g^{N}$ ) and tradables (i.e., $g^{T}$ ) to the identified government spending shock (in the baseline VAR model) are displayed by solid blue lines in the right panel; sample: 13 OECD countries, 1995-2015, annual data. Theoretical responses of government final consumption expenditure, $g$, along with of those of its two components, $g^{N}$ and $g^{T}$, are displayed by thick solid black lines with circles in the left and the right panel, respectively.

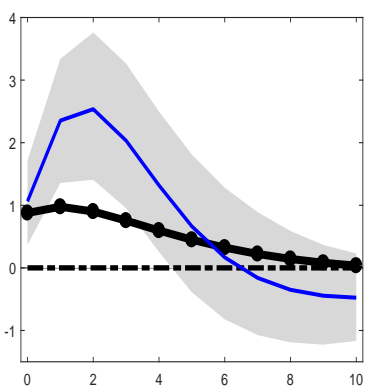

(a) Relative Price, $P$

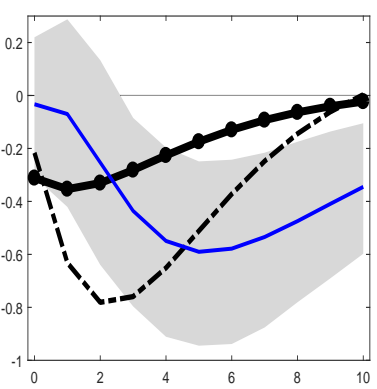

(d) Traded Output, $Y^{T}$

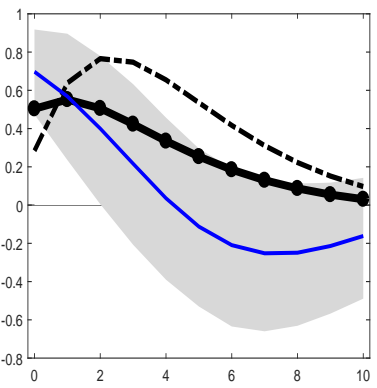

(g) Non Traded Output, $Y^{N}$

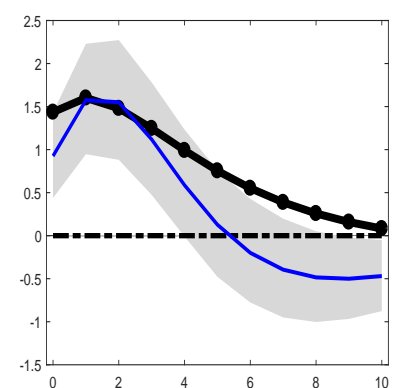

(b)

Relative Wage, $W^{N} / W^{T}$

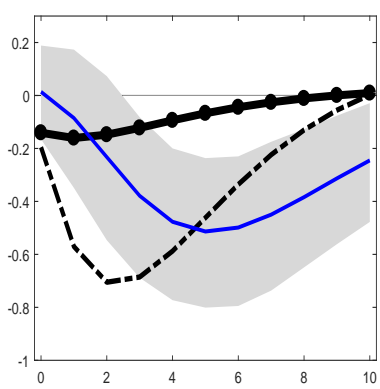

(e) Traded Labor, $L^{T}$

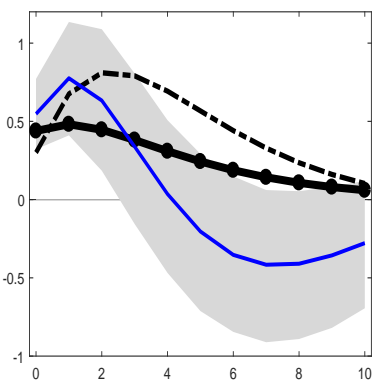

(h) Non Traded Labor, $L^{N}$

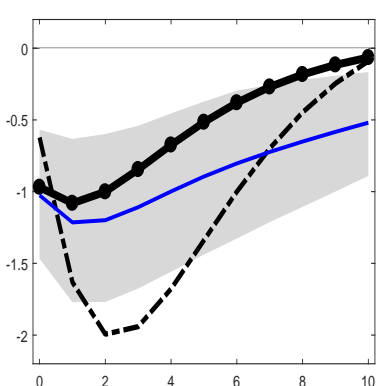

(c) Relative Output, $Y^{T} / Y^{N}$

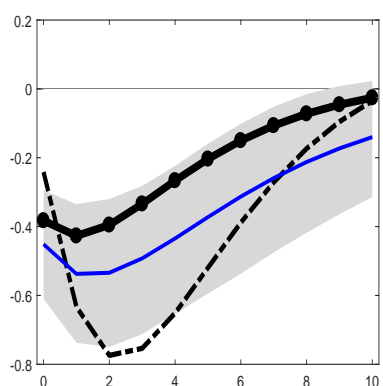

(f) Share of Tradables, $\nu^{Y, T}$

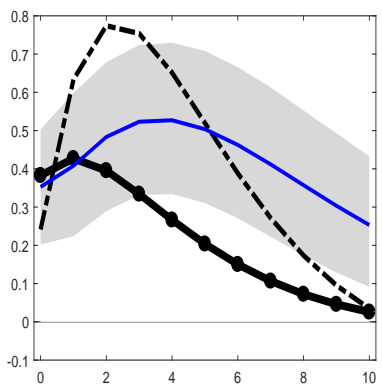

(i) Share of Non Trad. $\nu^{Y, N}$

Figure 6: Theoretical vs. Empirical Responses Following Unanticipated Government Spending Shock. Notes: Solid blue line displays point estimate of VAR with shaded areas indicating $90 \%$ confidence bounds; the thick solid black line with circles displays model predictions in the baseline scenario with imperfect mobility of labor across sectors $(\epsilon=0.75)$ and capital installation costs $(\kappa=17)$ while the dashed dotted black line shows predictions of the model imposing perfect mobility of labor $(\epsilon \rightarrow \infty)$ and abstracting from capital adjustment $\operatorname{costs}(\kappa=0)$. 


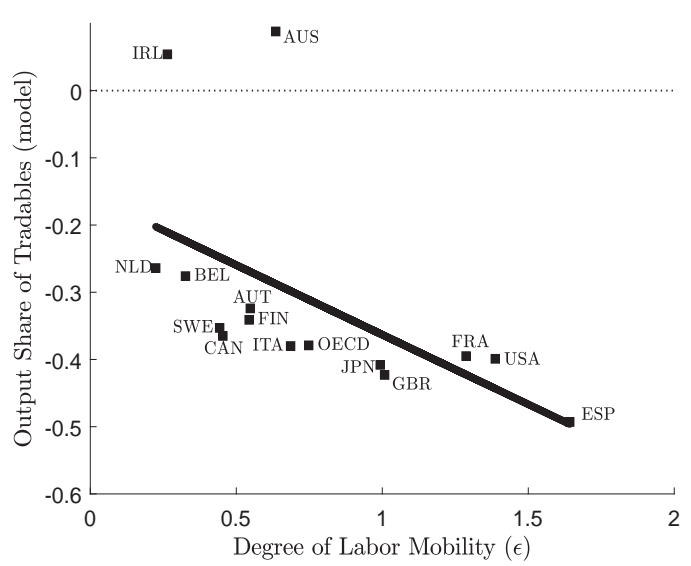

(a) Output Share of Tradables

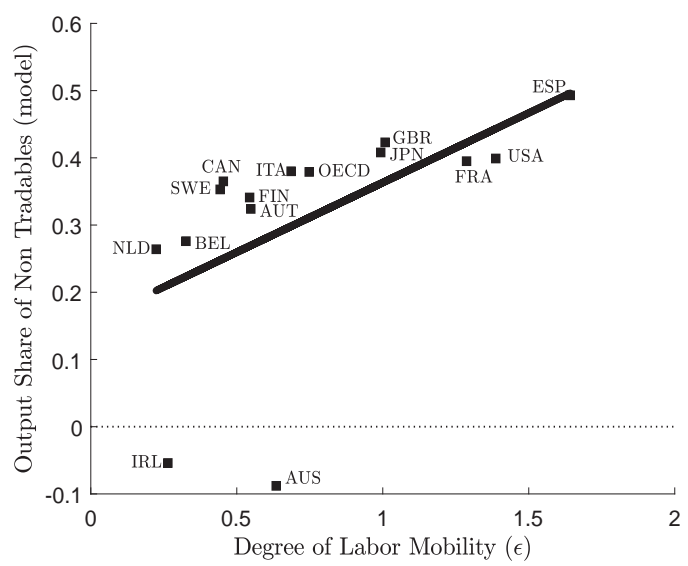

(b) Output Share of Non Tradables

Figure 7: Cross-Country Relationship between the Responses of Sectoral Output Shares to Government Spending shock and the Degree of Labor Mobility across Sectors. Notes: Horizontal axes display panel data estimates of the elasticity of labor supply across sectors, $\epsilon$, taken from the last column of Table 4, which captures the degree of labor mobility across sectors. Vertical axes report simulated impact responses from the baseline model with imperfect mobility of labor across sectors and adjustments costs to capital accumulation.

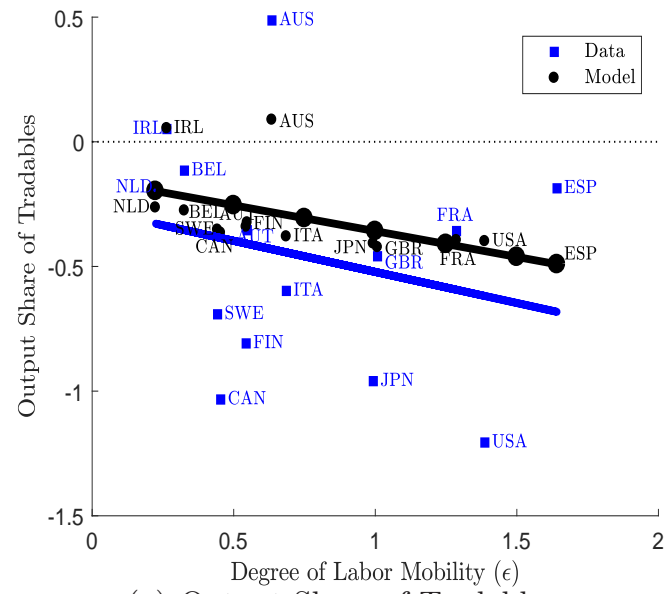

(a) Output Share of Tradables

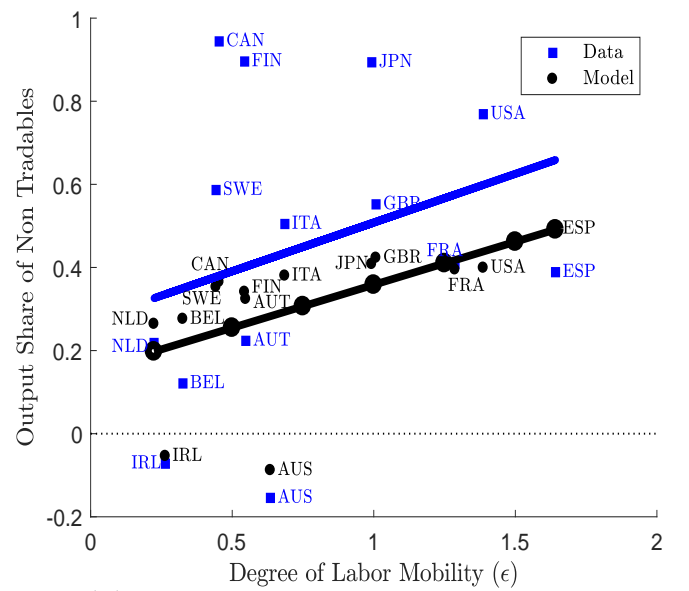

(b) Output Share of Non Tradables

Figure 8: Cross-Country Relationship from Simulated Responses vs. Cross-Country Relationship from VAR Estimates. Notes: Horizontal axes display panel data estimates of the elasticity of labor supply across sectors, $\epsilon$, taken from the last column of Table 4, which captures the degree of labor mobility across sectors. Vertical axes report simulated responses from the baseline model (black circles) and impact responses from the VAR model (blue squares). The solid blue line shows the cross-country relationship from VAR estimates whilst the solid black line with circles displays the cross-country relationship from numerical estimates. 


\title{
IMPERFECT MOBILITY OF LABOR ACROSS SECTORS AND FISCAL TRANSMISSION
}

\author{
Online Appendix
}

Olivier CARDI, Romain RESTOUT, and Peter CLAEYS

- Appendix A and B present the source and construction of the data used in the empirical and quantitative analysis, and empirical strategies to estimate the elasticity of substitution between traded and non traded goods and the elasticity of labor supply across sectors.

- Appendix C provides more details about the interpretation of our empirical results and determines the conditions under which a government spending shock is biased toward non traded goods.

- Appendix D provides more VAR results, conducts a robustness check with respect to the classification of industries as tradables or non tradables, and contrasts responses obtained in the main text by adopting a VAR approach with those estimated by using local projection method.

- Section E deals with the potential endogeneity problem by using narratively identified government spending shocks from the dataset constructed by Guajardo, Leigh, and Pescatori [2014], conducts an investigation of the potential presence of anticipation effects, addresses a potential concern related to the fact that various VAR models could identify different structural government spending shocks.

- Section F explores the potential presence of state-dependent effects by contrasting the effects of our identified government spending shock when the economy is in expansion with those when the economy is in recession. We also investigate a potential asymmetry in the effects of government spending spending shocks by contrasting their effects on variables when government consumption is going up with those when it is going down.

- Section G derives first-order conditions and sets out the approach taken to solve the model. Then we provide the main steps leading to formal solutions following a temporary rise in government consumption in a continuous time setup.

- Section $\mathrm{H}$ give more details on the model without physical capital accumulation, sets out the approach taken to solve the model, provides formal solutions for temporary fiscal shocks, investigates the effects of a rise in government consumption, analyzes the role of the degree of labor mobility across sectors, and provides the main steps leading to equations in the main text of section 4 .

- Section I gives more details about the calibration of the model to data.

- Section J gives more numerical results. In particular, we contrast empirical with theoretical results for aggregate variables, and we conduct a robustness check of our results by contrasting responses from our baseline model and VAR estimates with those from variants of the baseline model where one feature is shut down.

- In section K, we conduct a robustness check of our quantitative analysis. More specifically, we contrast empirical and theoretical results presented in the main text with those obtained by considering four variants of the baseline model; we explore the effects a deficit-financed government spending shock, we allow for endogenous markups, we consider a model where both labor and capital are imperfectly mobile across sectors, we relax the assumption of exogenous terms of trade by considering a semi-small open economy. 


\section{A Data Description for Empirical Analysis}

Coverage: Our sample consists of a panel of 16 countries: Australia (AUS), Austria (AUT), Belgium (BEL), Canada (CAN), Denmark (DNK), Finland (FIN), France (FRA), Ireland (IRL), Italy (ITA), Japan (JPN), the Netherlands (NLD), Norway (NOR), Spain (ESP), Sweden (SWE), the United Kingdom (GBR) and the United States (USA). The period is running from 1970 to 2007, except for Japan (1974-2007).

Sources: Our primary sources for sectoral data are the OECD and EU KLEMS databases. We use the EU KLEMS [2011] sectoral database (the March 2011 data release, available at http: //www. euklems.net) which provides annual data for eleven 1-digit ISIC-rev.3 industries for all countries of our sample with the exceptions of Canada and Norway. For Canada and Norway, sectoral data are taken from the Structural Analysis (STAN) database provided by the OECD [2011]. In addition, expenditure aggregates are obtained from the Economic Outlook Database provided by the OECD [2017].

The eleven 1-digit ISIC-rev.3 industries are classified as tradables or non tradables. To do so, we adopt the classification proposed by De Gregorio et al. [1994]. Following Jensen and Kletzer [2006], we have updated this classification by treating "Financial Intermediation" as a traded industry. We construct traded and non traded sectors as follows (EU KLEMS codes are given in parentheses):

- Traded Sector: "Agriculture, Hunting, Forestry and Fishing" (AtB), "Mining and Quarrying" (C), "Total Manufacturing" (D), "Transport, Storage and Communication" (I) and "Financial Intermediation" (J).

- Non Traded Sector: "Electricity, Gas and Water Supply" (E), "Construction" (F), "Wholesale and Retail Trade" (G), "Hotels and Restaurants" (H), "Real Estate, Renting and Business Services" (K) and "Community Social and Personal Services" (LtQ).

Once industries have been classified as traded or non traded, for any macroeconomic variable $X$, its sectoral counterpart $X^{j}$ for $j=T, N$ is constructed by adding the $X_{k}$ of all sub-industries $k$ classified in sector $j=T, N$ as follows $X^{j}=\sum_{k \in j} X_{k}$.

Relevant to our work, the EU KLEMS and OECD STAN databases provide data, for each industry and year, on value added at current and constant prices, permitting the construction of sectoral deflators of value added, as well as details on labor compensation and employment data, allowing the construction of sectoral wage rates. In the VAR models, with the exception of the current account, all quantity variables are in log levels and scaled by the working age population (15-64 years old), while price deflators and wage rates are in natural logs. Source: OECD ALFS Database for the working age population. Setting price indices at the base year to 1 , i.e., $\bar{P}^{j}=1$, for simplicity, we describe below the construction for the sectoral data employed in section 2 (mnemonics are given in parentheses):

- Sectoral output, $Y^{j}$ : sectoral value added at constant prices in sector $j=T, N$ (VA_QI). Sources: EU KLEMS and OECD STAN databases.

- Relative output, $Y^{T} / Y^{N}$ : ratio of traded value added at constant prices to non traded value added at constant prices.

- Sectoral output share: ratio of value added in sector $j$ to GDP both at constant prices, i.e., $\left.Y^{j} / Y_{R}\right)$ where $j=T, N$ and $Y_{R}$ is real GDP .

- Relative price of non tradables, $P$ : ratio of the non traded value added deflator to the traded value added deflator, i.e., $P=P^{N} / P^{T}$. The sectoral value added deflator $P^{j}$ for sector $j=T, N$ is calculated by dividing value added at current prices (VA) by value added at constant prices (VA_QI) in sector $j$. Sources: EU KLEMS and OECD STAN databases.

- Sectoral labor, $L^{j}$ : total hours worked by persons engaged in sector $j$ (H_EMP). Sources: EU KLEMS and OECD STAN databases.

- Relative labor, $L^{T} / L^{N}$ : ratio of hours worked in the traded sector to hours worked in the non traded sector.

- Sectoral labor share: ratio of hours worked in sector $j$ to total hours worked, i.e., $L^{j} /\left(L^{T}+\right.$ $L^{N}$ ) for $j=T, N$.

- Sectoral real consumption wage, $W^{j} / C P I$ : nominal wage in sector $j$ divided by the consumer price index (CPI). Source: OECD Prices and Purchasing Power Parities for the consumer price index. The sectoral nominal wage $W^{j}$ for sector $j=T, N$ is calculated by dividing labor compensation in sector $j$ (LAB) by total hours worked by persons engaged (H_EMP) in that sector. Sources: EU KLEMS and OECD STAN databases.

- Relative wage, $\Omega$ : ratio of the nominal wage in the non traded sector $W^{N}$ to the nominal wage in the traded sector $W^{T}$, i.e., $\Omega=W^{N} / W^{T}$. 
- Labor reallocation index, $L R$ : measures the ratio of the absolute change in sectoral employment resulting from labor reallocation to average employment over 5 years:

$$
L R_{t}(5)=\frac{\sum_{j=T}^{N}\left|L_{t}^{j}-L_{t-\tau}^{j}\right|-\left|\sum_{j=T}^{N} L_{t}^{j}-\sum_{j=T}^{N} L_{t-\tau}^{j}\right|}{0.5 \sum_{j=T}^{N}\left(L_{t-\tau}^{j}+L_{t}^{j}\right)},
$$

Data for labor (H_EMP), used to compute $L R$, are taken from EU KLEMS and OECD STAN databases.

In the following, we provide details on data construction for aggregate variables (mnemonics are in parentheses):

- Government spending, $G$ : real government final consumption expenditure (CGV). Source: OECD Economic Outlook Database.

- Gross domestic product, $Y_{R}$ : real gross domestic product (GDPV). Source: OECD Economic Outlook Database.

- Private investment, $J E$ : real private non-residential gross fixed capital formation (IBV). Source: OECD Economic Outlook Database.

- Current account, $C A$ : ratio of the current account to the gross domestic product at current prices (CBGDPR). Source: OECD Economic Outlook Database.

- Labor, L: total hours worked by persons engaged (H_EMP). Sources: EU KLEMS and OECD STAN databases.

- Real consumption wage, $W / C P I$ : nominal wage divided by the consumer price index (CPI). Source: OECD Prices and Purchasing Power Parities for the consumer price index. The nominal wage is calculated by dividing labor compensation (LAB) by total hours worked by persons engaged (H_EMP). Sources: EU KLEMS and OECD STAN databases.

Government spending, investment and GDP variables are deflated with their own deflators.

\section{B Data for Calibration}

\section{B.1 Non Tradable Content of GDP and its Components}

Table 4 shows the non tradable content of GDP, consumption, investment, government spending, labor and labor compensation. In addition, it gives information about the share of government spending on the traded and non traded goods in the corresponding sectoral value added and the sectoral labor income shares. The column 11 shows the ratio of labor productivity of tradables to labor productivity of non tradables as we use labor productivity to approximate technological change. Columns 12 to 14 display the investment-to-GDP ratio and government spending in \% of GDP and the labor income share, respectively, for the whole economy. Our sample covers the 16 OECD countries mentioned in Section A. Our reference period for the calibration corresponds to the period 1990-2007. The choice of this period has been dictated by data availability. Columns 15 and 16 report estimates for the elasticity of substitution in consumption between traded and non traded goods, $\phi$, and the elasticity of labor supply across sectors, $\epsilon$. In the following, statistics for the sample as a whole represent (unweighted) averages of the corresponding variables among the group.

To calculate the non tradable share of output, labor and labor compensation, we split the eleven industries into traded and non-traded sectors by adopting the classification proposed by De Gregorio et al. [1994] and updated by Jensen and Kletzer [2006]. Details about data construction for sectoral output and sectoral labor are provided in section A. We calculate the non-tradable share of labor compensation as the ratio of labor compensation in the non traded sector (i.e., $W^{N} L^{N}$ ) to overall labor compensation (i.e., $W L$ ). Sources: EU KLEMS [2011] and STAN databases. Data coverage: 1990-2007 for all countries. The non tradable content of GDP, labor and labor compensation, shown in columns 1, 5 and 6 of Table 4, average to $63 \%, 67 \%$ and $66 \%$ respectively.

To split consumption expenditure (at current prices) into consumption in traded and non traded goods, we made use of the Classification of Individual Consumption by Purpose (COICOP) published by the United Nations (Source: United Nations [2011]). Among the twelve items, the following ones are treated as consumption in traded goods: "Food and Non-Alcoholic Beverages", "Alcoholic Beverages Tobacco and Narcotics", "Clothing and Footwear", "Furnishings, Household Equipment" and "Transport". The remaining items are treated as consumption in non traded goods: "Housing, Water, Electricity, Gas and Fuels", "Health", "Communication", "Recreation and Culture", "Education", "Restaurants and Hotels". Because the item "Miscellaneous Goods and Services" is somewhat problematic, we decided to consider it as both tradable (50\%) and non tradable (50\%) in 
equal shares. Data coverage: 1990-2007 for AUS, AUT, CAN, DNK, FIN, FRA, GBR, ITA, JPN, NLD, NOR and USA, 1993-2007 for SWE and 1995-2007 for BEL, ESP and IRL. The non-tradable share of consumption shown in column 2 of Table 4 averages to $53 \%$.

To calculate the non tradable share of investment expenditure, we follow the methodology proposed by Burstein et al. [2004] who treat "Housing", "Other Constructions" and "Other Products" as non-tradable investment and "Products of Agriculture, Forestry, Fisheries and Aquaculture", "Metal Products and Machinery", "Transport Equipment" as tradable investment expenditure. Source: OECD Input-Output database [2012]. Data coverage: 1990-2007 for AUT, CAN, ESP, FIN, GBR, IRL, JPN, NLD, and NOR, 1990-2006 for DNK, FRA, ITA and USA, and 1993-2007 for SWE. Data are not available for AUS and BEL. The non tradable share of investment shown in column 3 of Table 4 averages to $64 \%$, in line with estimates provided by Burstein et al. [2004] and Bems [2008].

Sectoral government final consumption expenditure data (at current prices) were obtained from the OECD General Government Accounts database (Source: COFOG, OECD [2017]). "Economic Affairs" which includes "Fuel and Energy", "Agriculture, Forestry, Fishing, and Hunting", "Mining, Manufacturing, and Construction", "Transport and Communications" is classified as tradable. Items treated as non traded are: "General Public Services", "Defense", "Public Order and Safety", "Environment Protection", "Housing and Community Amenities", "Health", "Recreation, Culture and Religion", "Education", "Social Protection". Data coverage: 1995-2007 for AUT, BEL, DNK, ESP, FRA, GBR, IRL, ITA, NLD, NOR and SWE, 1998-2007 for AUS, 1990-2007 for FIN, 2005-2007 for JPN and 1970-2007 for the USA. Data are not available for CAN. The non tradable component of government spending shown in column 4 of Table 4 averages to 90\% over the period 1990-2007. Government spending on traded and non traded goods in $\%$ of the corresponding sectoral output, i.e., $G^{T} / Y^{T}$ and $G^{N} / Y^{N}$, respectively, is shown in columns 7 and 8 of Table 4 . They average $5 \%$ and $30 \%$, respectively.

The labor income share for sector $j$ denoted by $\theta^{j}$ is calculated as the ratio of labor compensation of sector $j$ to value added of sector $j$ at current prices. Sources: EU KLEMS [2011] and STAN databases. Data coverage: 1990-2007 for all countries. As shown in columns 9 and 10 of Table 4, $\theta^{T}$ and $\theta^{N}$ average 0.60 and 0.67 , respectively. When $k^{T}>k^{N}$, the shares of labor income average 0.58 and 0.67 for the traded and the non traded sector, respectively, while if $k^{N}>k^{T}, \theta^{T}$ and $\theta^{N}$ average 0.70 and 0.64 , respectively. In addition, column 14 of Table 4 gives the aggregate labor income share which averages 0.64 in our sample.

We use sectoral labor productivities to approximate technological change. Column 11 of Table 4 displays the ratio of labor productivity in tradables to labor productivity in non tradables $\left(Z^{T} / Z^{N}\right)$ averaged over the period 1990-2007. To measure labor productivity in sector $j=T, N$, we divide value added at constant prices in sector $j$ (VA_QI) by total hours worked by persons engaged (H_EMP) in that sector. Sources: EU KLEMS [2011] and STAN databases. Data coverage: 19902007 for all countries. As shown in column 11, the traded sector is 28 percent more productive on average than the non traded sector for the whole sample.

Columns 12 and 13 of Table 4 display gross capital formation and final consumption expenditure of general government as a share of GDP, respectively. Source: OECD National Accounts Database. Data coverage: 1990-2007 for all countries.

\section{B.2 Non Tradable Intensity of the Government Spending Shock}

We turn to the calibration of the breakdown of the government spending shock between non tradables and tradables. In first approximation, the share of the government spending shock received by the non traded sector could be measured by the non tradable content of government spending we calculated above by using the COFOG dataset from the OECD. Denoting by $\omega_{G^{j}}$ the content of government spending in good $j$, we have:

$$
G(t)=\omega_{G^{N}} G(t)+\omega_{G^{T}} G(t) .
$$

Assuming that $\omega_{G^{j}}$ is fixed over time and differentiating (41) leads to:

$$
d G(t) / Y=\omega_{G^{N}}(d G(t) / Y)+\omega_{G^{T}}(d G(t) / Y) .
$$

Thus according to (42), the non tradable intensity of the government spending shock corresponds to the fraction of government consumption spent on non tradables. In order to reproduce the humpshaped pattern of the endogenous response of government spending to an exogenous fiscal shock, we assume that the deviation of government spending relative to its initial value as a percentage of initial GDP is governed by the dynamic equation (25). Left-multiplying (25) by $\omega_{G^{j}}$ (with $j=N, T$ ) gives the dynamic adjustment of sectoral government consumption to an exogenous fiscal shock:

$$
\omega_{G^{j}}(G(t)-\tilde{G}) / Y=\omega_{G^{j}}\left[e^{-\xi t}-(1-g) e^{-\chi t}\right] .
$$


We set $g$ to 0.01 as we consider an exogenous increase in government spending by $1 \%$ of GDP and choose values of $\xi$ and $\chi$ in order to reproduce the hump-shaped pattern of the endogenous response of government spending to the exogenous fiscal shock. To the extent that $\omega_{G^{j}}$ is considered as fixed over time, we set $\omega_{G^{j}}$ to the share of government consumption on good $j$ in government final consumption expenditure, i.e., we set $\omega_{G^{N}}$ to $90 \%$ and $\omega_{G^{T}}$ to $10 \%$.

The derivation of the dynamic equation (43) that governs the adjustment of sectoral government consumption following an exogenous fiscal shock relies on a number of assumptions. We assume that the parameters that govern the persistence and shape of the response of sectoral government consumption are identical across sectors, while the sectoral intensity of the government spending shock is constant over time and thus corresponds to the share of government final consumption expenditure in good $j$. To investigate whether our assumptions are consistent with the data, we contrast empirical with theoretical impulse response functions of sectoral government consumption. To estimate the dynamic effects on sectoral government consumption of an exogenous fiscal shock, we have to identify the government spending shock. We thus estimate the first VAR model that includes government final consumption expenditure, real GDP, total hours worked, private investment, and the real consumption wage. Then, we estimate a VAR model in panel format on annual data that includes unanticipated government spending shocks, $\epsilon_{i t}^{G}$, ordered first, government spending, $g_{i t}$, government consumption on non tradables, $g_{i t}^{N}$, and government consumption on tradables, $g_{i t}^{T}$, i.e., $z_{i, t}^{G}=\left[\epsilon_{i t}^{G}, g_{i t}, g_{i t}^{N}, g_{i t}^{T}\right]$. All quantities are logged, expressed in real terms and scaled by the working age population.

Since time series for government consumption by function taken from the COFOG dataset are not available before 1995 for most of the countries in our sample, and because our objective is to estimate the non tradable content of the aggregate government spending shock, we consider a period running from 1995 to 2015 in order to have time series of a reasonable length. Data to construct time series for sectoral government consumption expenditure are available for all the countries in our sample except Canada. In efforts to have a balanced panel and time series of a reasonable length, Australia (1998-2015) and Japan (2005-2015) are removed from the sample, which leaves us with 13 OECD countries over the period 1995-2015.

Table 2 reports, for various horizons, the responses of government consumption expenditure on non tradables and tradables to the identified government spending shock. We normalize the impulse responses so that government spending rises by one percentage point of GDP on impact. As can be seen in the first two columns of Table 2, a government spending shock leads to an increase in government consumption expenditure on non tradables by $0.88 \%$ on impact while the rise in public purchases of tradables accounts for the remaining share, i.e., $12 \%$. The contribution of government consumption on non tradables to the government spending shock is displayed in the last column of Table 2. Its contribution is quite stable over time and varies between $88 \%$ and $91 \%$. The contribution of government expenditure on non tradables averages $90 \%$ as can be seen in the last line of the table.

Empirical and theoretical impulse response functions for government spending and its two components are contrasted and displayed in Figure 5. Before discussing the results, we first focus on the response of government final consumption expenditure to the exogenous fiscal shock shown in the left panel of Figure 5. The endogenous response of government spending to an exogenous fiscal shock displayed in the solid blue line corresponds to the baseline government spending shock shown in the blue line in Fig. 1(a) we obtain from estimates of the first VAR model. The dynamic response of government final consumption expenditure which has been computed by summing mean responses of government consumption consumption on non tradables and tradables is displayed by the solid red line in Figure 1(a). While the solid blue line displays point estimate from a sample of 16 OECD countries over 1970-2007, the solid red line displays point estimate from a sample of 13 OECD countries over 1995-2015. Whereas the samples are different, the discrepancy is quite moderate. Since theoretical responses of sectoral government consumption are based on the response of government spending shown in the solid blue line in the left panel while the sum of mean responses of government consumption expenditure on non tradables and tradables gives a slightly different response of government spending as shown in the solid red line, we have to rescale empirical responses for $G^{j}$ so that the sum of mean responses corresponds exactly to the point estimate displayed in the solid blue line. The rescaled empirical responses of sectoral government consumption are displayed by solid blue lines in the right panel of Figure 5 with shaded areas indicating the 90 percent confidence bounds obtained by bootstrap sampling. We contrast empirical with theoretical responses displayed by the solid black lines with circles. It turns out that differences are rather moderate, if not absent. We may notice that whereas the theoretical response of government consumption of non tradables (tradables) slightly overstates (understates) the estimated response in the short-run, it lies within the confidence bounds for both goods. To conclude, the assumptions underlying the dynamic equation (43) which governs theoretical responses of $G^{j}$ are reasonable and consistent with data. 
Table 2: Responses of $G^{N}$ and $G^{T}$ to Identified Government Spending Shock: Point Estimates

\begin{tabular}{l|ccc}
\hline Horizon & \multicolumn{2}{|c}{ Responses } & $\begin{array}{c}\text { Non tradable intensity } \\
\text { of gov. spending shock }\end{array}$ \\
\hline 0 & $G^{N}$ & $G^{T}$ & $88 \%$ \\
1 & 0.876 & 0.119 & $87 \%$ \\
2 & 0.045 & 0.150 & $88 \%$ \\
3 & 0.753 & 0.125 & $88 \%$ \\
4 & 0.623 & 0.098 & $89 \%$ \\
5 & 0.493 & 0.057 & $90 \%$ \\
6 & 0.381 & 0.041 & $90 \%$ \\
7 & 0.294 & 0.030 & $91 \%$ \\
8 & 0.226 & 0.022 & $91 \%$ \\
9 & 0.175 & 0.017 & $91 \%$ \\
10 & 0.136 & 0.013 & $91 \%$ \\
Mean & - & - & $90 \%$ \\
\hline
\end{tabular}

Notes: Horizon measured in year units. We generate impulse response functions by using a simple VAR, i.e., $z_{i, t}^{G}=\left[\epsilon_{i, t}^{G}, g_{i, t}, g_{i, t}^{N}, g_{i, t}^{T}\right]$, with 2 lags. To identify the government spending shock $\epsilon_{i, t}^{G}$ we estimate the VAR model that includes aggregate variables, i.e., $z_{i, t}=\left[g_{i, t}, y_{i, t}, l_{i, t}, j e_{i, t}, w_{C, i, t}\right]$, and adopt a Choleski decomposition. The last column of the table displays, for all horizons, the contribution of the response of non tradable component to the government spending shock. Data coverage: 1995-2015 for AUT, BEL, DNK, ESP, FIN, FRA, GBR, IRL, ITA, NLD, NOR, SWE and the USA. All variables are real and scaled by the working age population.

\section{B.3 Estimates of $\epsilon$ and $\phi$ : Empirical strategy}

Column 1 of Table 3 shows our estimates of the elasticity of labor supply across sectors, $\epsilon$, while columns 2-3 show our estimates of the elasticity of substitution in consumption between traded and non traded goods, $\phi$. We detail our empirical strategy to estimate these two parameters.

Along the lines of Horvath [2000], we derive a testable equation by combining optimal rules for labor supply and labor demand and estimate $\epsilon$ by running the regression of the worker inflow in sector $j=T, N$ of country $i$ at time $t$ arising from labor reallocation across sectors computed as $\hat{l}_{i, t}^{j}-\hat{l}_{i, t}$ on the relative labor's share percentage changes in sector $j, \hat{\beta}_{i, t}^{j}:{ }^{58}$

$$
\hat{l}_{i, t}^{j}-\hat{l}_{i, t}=f_{i}+f_{t}+\gamma_{i} \hat{\beta}_{i, t}^{j}+\nu_{i, t}^{j},
$$

where we denote logarithm in lower case and the deviation from initial steady-state by a hat; $\nu_{i, t}^{j}$ is an i.i.d. error term; country fixed effects are captured by country dummies, $f_{i}$, and common macroeconomic shocks by year dummies, $f_{t}$. The LHS term of (44) is calculated as the difference between changes (in percentage) in hours worked in sector $j, \hat{l}_{i, t}^{j}$, and in total hours worked, $\hat{l}_{i, t}$. The RHS term $\beta^{j}$ corresponds to the fraction of labor's share of output accumulating to labor in sector $j$. Denoting by $P_{t}^{j} Q_{t}^{j}$ output at current prices in sector $j=T, N$ at time $t, \beta_{t}^{j}$ is computed as $\frac{\xi^{j} P_{t}^{j} Q_{t}^{j}}{\sum_{j=N}^{T} \xi^{j} P_{t}^{j} Q_{t}^{j}}$ where $\xi^{j}$ is labor's share in output in sector $j=T, N$ defined as the ratio of the compensation of employees to output in the $j$ th sector, averaged over the period 1971-2007. ${ }^{59}$ Because hours worked are aggregated by means of a CES function, total hours percentage change $\hat{l}_{i, t}$ is calculated as a weighted average of sectoral employment percentage changes, i.e., $\hat{l}_{t}=\sum_{j=N}^{T} \beta_{t-1}^{j} \hat{l}_{t}^{j}$. The parameter we are interested in, the degree of substitutability of hours worked across sectors, is given by $\epsilon_{i}=\gamma_{i} /\left(1-\gamma_{i}\right)$. In the regressions that follow, the parameter $\gamma_{i}$ is alternatively assumed to be identical across countries when estimating for the whole sample $\left(\gamma_{i}=\gamma_{i^{\prime}} \equiv \gamma\right.$ for $\left.i \neq i^{\prime}\right)$ or to be different across countries when estimating $\epsilon$ for each economy $\left(\gamma_{i} \neq \gamma_{i^{\prime}}\right.$ for $\left.i \neq i^{\prime}\right)$. Data are taken from the EU KLEMS [2011] and STAN databases, and the sample includes the 16 OECD countries mentioned above over the period 1971-2007 (except for Japan: 1975-2007). Table 3 reports empirical estimates that are consistent with $\epsilon>0$. All values are statistically significant at $10 \%$, except for Denmark and Norway. ${ }^{60}$

\footnotetext{
${ }^{58}$ Details of derivation of the equation we explore empirically can be found in a Technical Appendix.

${ }^{59}$ As Horvath [2000], we use time series for output instead of value added so that our estimates can be compared with those documented by the author.

${ }^{60}$ In a Technical Appendix, we address one potential econometric issue. While $\beta_{i, t}^{j}$ (i.e., the RHS term in eq. (44)) is constructed independently from the dependent variable (i.e., the LHS term in eq. (44)), if the
} 
To estimate the elasticity of substitution in consumption, $\phi$, between traded and non traded goods, we first derive a testable equation by inserting the optimal rule for intra-temporal allocation of consumption (18) into the goods market equilibrium which gives $\frac{C^{T}}{C^{N}}=\frac{Y^{T}-N X-G^{T}-I^{T}}{Y^{N}-G^{N}-I^{N}}=\left(\frac{\varphi}{1-\varphi}\right) P^{\phi}$ where $N X \equiv \dot{B}-r^{\star} B$ is net exports, $I^{j}$ and $G^{j}$ are investment in physical capital and government spending in sector $j$, respectively. Isolating $\left(Y^{T}-N X\right) / Y^{N}$ and taking logarithm yields $\ln \left(\frac{Y^{T}-N X}{Y^{N}}\right)=\alpha+\phi \ln P$. Adding an error term $\mu$, we estimate $\phi$ by running the regression of the (logged) output of tradables adjusted with net exports at constant prices in terms of output of non tradables on the (logged) relative price of non tradables:

$$
\ln \left(\frac{Y^{T}-N X}{Y^{N}}\right)_{i, t}=f_{i}+f_{t}+\alpha_{i} t+\phi_{i} \ln P_{i, t}+\mu_{i, t},
$$

where $f_{i}$ and $f_{t}$ are the country fixed effects and time dummies, respectively. Because the term $\alpha \equiv \ln \frac{\left(1-v_{G^{N}}-v_{I^{N}}\right)}{\left(1-v_{G^{T}}-v_{I^{T}}\right)}+\ln \left(\frac{\varphi}{1-\varphi}\right)$ is composed of ratios, denoted by $v_{G^{j}}$ and $v_{I^{j}}$, of $G^{T}\left(G^{N}\right)$ and $I^{T}$ $\left(I^{N}\right)$ to $Y^{T}-N X\left(Y^{N}\right)$ and hence may display a trend over time, we add country-specific linear trends, as captured by $\alpha_{i} t .^{61}$

Instead of using time series for sectoral value added, we can alternatively make use of series for sectoral labor compensation by inserting the first-order condition equating the marginal revenue of labor and the sectoral wage, i.e., $\frac{\theta^{j} P^{j} Y^{j}}{T^{j}}=W^{j}$, into the goods market clearing condition. Eliminating $Y^{j}$, denoting by $\gamma^{T}=\left(W^{T} L^{T^{J}}-\theta^{T} P^{T} N X\right)$ and $\gamma^{N}=W^{N} L^{N}$, and taking logarithm yields $\ln \left(\frac{\gamma^{T}}{\gamma^{N}}\right)=\eta+\phi \ln P$ where $\eta$ is a term composed of both preference (i.e., $\varphi$ ) and production (i.e., $\left.\theta^{j}\right)$ parameters, and (logged) ratios of $G^{T}\left(G^{N}\right)$ and $I^{T}\left(I^{N}\right)$ to $W^{T} L^{T}-\theta^{T} P^{T} N X\left(W^{N} L^{N}\right)$. We estimate $\phi$ by exploring alternatively the following empirical relationship:

$$
\ln \left(\gamma^{T} / \gamma^{N}\right)_{i, t}=g_{i}+g_{t}+\sigma_{i} t+\phi_{i} \ln P_{i, t}+\zeta_{i, t},
$$

where $g_{i}$ and $g_{t}$ are the country fixed effects and time dummies, respectively, and we add countryspecific trends, as captured by $\sigma_{i} t$, because $\eta$ is composed of ratios that may display a trend over time.

Time series for sectoral value added at constant prices, labor compensation, and the relative price of non tradables are taken from the EU KLEMS [2011] and STAN databases (see Section A). Net exports correspond to the external balance of goods and services at current prices taken from OECD Economic Outlook Database. To construct time series for net exports at constant prices, $N X$, data are deflated by the value added deflator of traded goods $P_{t}^{T}$.

Since LHS terms of (45) and (46) and the relative price of non tradables display trends, we ran unit root and then cointegration tests. Having verified that these two assumptions are empirically supported, we estimate the cointegrating relationships by using fully modified OLS (FMOLS) procedure for cointegrated panel proposed by Pedroni [2000], [2001]. FMOLS estimates of (45) and (46) are reported in the second and the third column of Table 3 respectively. As a reference model, we consider eq. (45) which gives an estimate for the whole sample of $\phi=0.66$. This value is roughly halfway between estimates documented by cross-section studies, notably Stockman and Tesar [1995] who find a value for $\phi$ of 0.44 and Mendoza [1995] who reports an estimate of 0.74 .

\section{Condition for the Government Spending Shock to be Bi- ased toward Non Tradables}

In this section, we provide more details about the interpretation of our empirical results and the condition(s) for a government spending shock to be biased toward non tradables.

\section{C.1 Standard Definition of Government Spending Shocks Biased toward Non Tradables}

In subsection 2.3, we interpret the rise in non traded output relative to traded output that we document empirically as the result of government spending shocks biased toward non tradables. In

\footnotetext{
labor's share is (almost) constant over time and thus is close from the average $\xi^{j}$, an endogeneity problem may potentially show up. Our empirical results reveal that for the majority of the countries in our sample, the dependent variable does not Granger-cause the explanatory variable.

${ }^{61}$ Because an endogeneity problem of relative prices may potentially affect our econometric results, we ran Granger causality tests. Our empirical results reveal that for the majority of the countries in our sample, the dependent variable does not Granger-cause the explanatory variable. Our results show that one can consider the regressor in eq. (45) as exogenous with respect to the dependent variable.
} 
Table 3: Estimates of the Elasticity of Labor Supply across Sectors $(\epsilon)$ and the Elasticity of Substitution in Consumption between Tradables and Non Tradables $(\phi)$

\begin{tabular}{|c|c|c|c|}
\hline \multirow[t]{3}{*}{ Country } & Labor Mobility $(\epsilon)$ & \multicolumn{2}{|c|}{ Elasticity of Substitution $(\phi)$} \\
\hline & eq. (44) & eq. (45) & eq. (46) \\
\hline & $\hat{\epsilon}_{i}$ & $\hat{\phi}_{i}^{F M O L S}$ & $\hat{\phi}_{i}^{F M O L S}$ \\
\hline AUS & $\begin{array}{c}0.635^{a} \\
(3.55)\end{array}$ & $\begin{array}{c}0.268^{a} \\
(2.99)\end{array}$ & $\begin{array}{c}0.409^{b} \\
(2.52)\end{array}$ \\
\hline AUT & $\begin{array}{c}0.548^{a} \\
(2.66)\end{array}$ & $\begin{array}{c}0.986^{a} \\
(3.09)\end{array}$ & $1_{(4.99)}$ \\
\hline BEL & ${ }_{(2.51)}^{0.326^{b}}$ & $\begin{array}{c}0.070 \\
(0.41)\end{array}$ & $\begin{array}{c}0.795^{a} \\
(4.99)\end{array}$ \\
\hline CAN & $\begin{array}{c}0.454^{a} \\
(3.41)\end{array}$ & $\begin{array}{c}0.391^{a} \\
(3.74)\end{array}$ & $\begin{array}{c}0.582^{a} \\
(5.53)\end{array}$ \\
\hline DNK & $\begin{array}{c}0.150 \\
(1.46)\end{array}$ & $\begin{array}{c}2.071^{a} \\
(2.95)\end{array}$ & $\begin{array}{c}1.323^{a} \\
(2.93)\end{array}$ \\
\hline ESP & $\begin{array}{c}1.642^{a} \\
(3.02)\end{array}$ & $\begin{array}{c}0.783^{a} \\
(4.96)\end{array}$ & $\begin{array}{c}0.413^{b} \\
(2.04)\end{array}$ \\
\hline FIN & $\begin{array}{c}0.544^{a} \\
(3.62)\end{array}$ & $\begin{array}{c}1.072^{a} \\
(8.57)\end{array}$ & $\begin{array}{c}1.421^{a} \\
(8.12)\end{array}$ \\
\hline FRA & $\begin{array}{c}1.287^{b} \\
(2.44)\end{array}$ & $\begin{array}{c}0.937^{a} \\
(6.22)\end{array}$ & $\begin{array}{c}1.038^{a} \\
(5.25)\end{array}$ \\
\hline GBR & $\begin{array}{c}1.008^{a} \\
(3.79)\end{array}$ & $\begin{array}{c}0.477^{a} \\
(9.64)\end{array}$ & ${ }_{(14.07)}^{1.164^{a}}$ \\
\hline IRL & $\begin{array}{c}0.264^{a} \\
(3.18)\end{array}$ & $\begin{array}{c}0.374^{c} \\
(1.71)\end{array}$ & $\begin{array}{c}0.158 \\
(0.35)\end{array}$ \\
\hline ITA & $\begin{array}{c}0.686^{a} \\
(2.84)\end{array}$ & $\begin{array}{c}-0.308 \\
(-1.60)\end{array}$ & $\begin{array}{c}-0.187 \\
(-0.98)\end{array}$ \\
\hline JPN & $\begin{array}{c}0.993^{a} \\
(2.87)\end{array}$ & $\begin{array}{c}0.654^{a} \\
(2.98)\end{array}$ & $\begin{array}{c}0.676^{a} \\
(4.33)\end{array}$ \\
\hline NLD & $\begin{array}{c}0.224^{b} \\
(1.97)\end{array}$ & $\begin{array}{c}0.709^{b} \\
(2.33)\end{array}$ & $\begin{array}{l}0.428 \\
(1.18)\end{array}$ \\
\hline NOR & $\begin{array}{l}0.097 \\
(1.49)\end{array}$ & $\begin{array}{c}0.979^{a} \\
(9.72)\end{array}$ & $\begin{array}{c}2.056^{a} \\
(13.66)\end{array}$ \\
\hline SWE & $\begin{array}{c}0.443^{a} \\
(3.61)\end{array}$ & $\begin{array}{c}0.356^{a} \\
(4.02)\end{array}$ & $\begin{array}{c}0.900^{a} \\
(7.23)\end{array}$ \\
\hline USA & $\begin{array}{c}1.387^{a} \\
(2.59)\end{array}$ & $\begin{array}{c}0.668^{a} \\
(2.81)\end{array}$ & $\begin{array}{c}0.799^{b} \\
(2.02)\end{array}$ \\
\hline Whole Sample & $\begin{array}{c}0.479^{a} \\
(12.16)\end{array}$ & $\begin{array}{c}0.656^{a} \\
(16.13)\end{array}$ & $\begin{array}{c}0.837^{a} \\
(14.16)\end{array}$ \\
\hline Countries & 16 & 16 & 16 \\
\hline Observations & 1178 & 605 & 605 \\
\hline Data coverage & 1971-2007 & $1970-2007$ & $1970-2007$ \\
\hline Country fixed effects & yes & yes & yes \\
\hline Time dummies & yes & yes & yes \\
\hline Time trend & no & yes & yes \\
\hline
\end{tabular}

Notes: ${ }^{a},{ }^{b}$ and ${ }^{c}$ denote significance at $1 \%, 5 \%$ and $10 \%$ levels; t-statistics are reported in parentheses. 


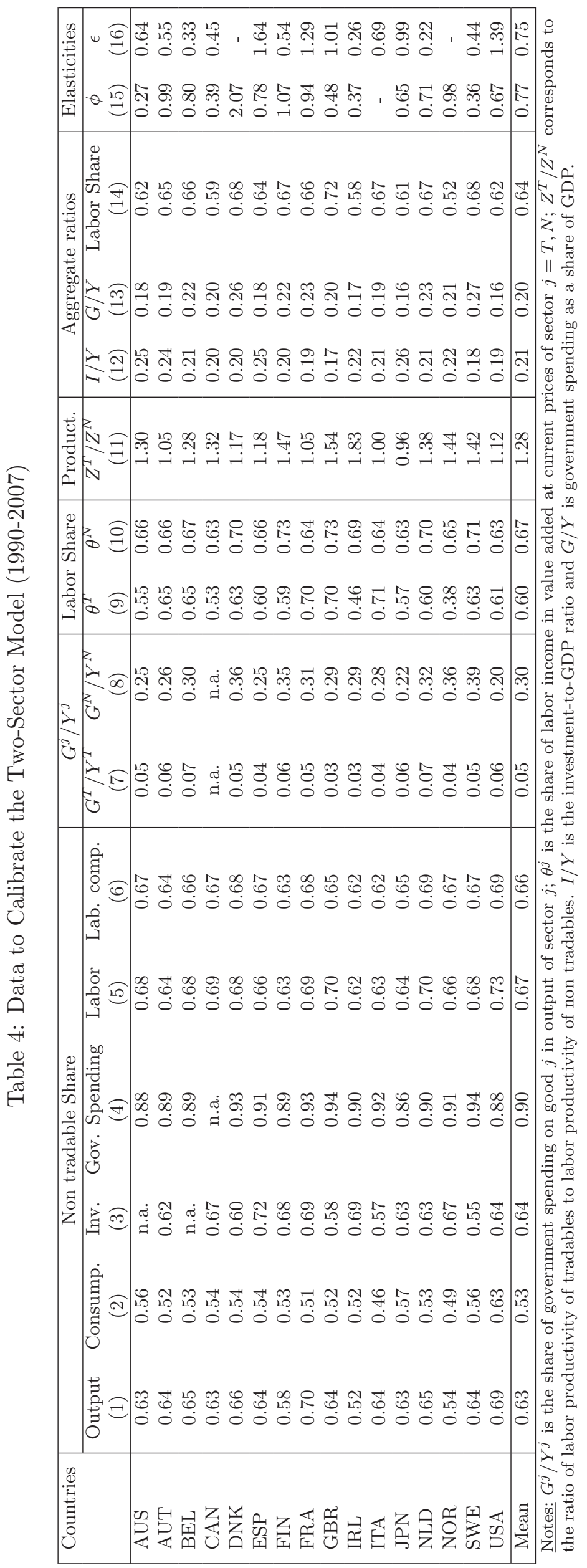


this subsection, we provide more details about our interpretation and the assumptions underlying this conjecture. The traded good is the numeraire and its price, $P^{T}$, is normalized to 1.

To begin with, we write down the market clearing conditions:

$$
\begin{gathered}
Y^{N}(t)=C^{N}(t)+J^{N}(t)+G^{N}(t), \\
Y^{T}(t)=C^{T}(t)+J^{T}(t)+G^{T}(t)+N X(t),
\end{gathered}
$$

where $Y^{j}$ is value added at constant prices in sector $j=N, T, C^{j}$ and $G^{j}$ stand for private and public consumption of good $j=N, T$, respectively, $J^{j}$ corresponds to private investment in sector $j=N, T$, and $N X$ is net exports. Summing value added at constant prices across sectors gives real GDP which we denote by $Y_{R}$ :

$$
Y_{R}(t)=Y^{T}(t)+P Y^{N}(t)
$$

where $P$ is the price of non traded goods in terms of traded goods that is kept fixed in order to evaluate non traded value added at constant prices. Note that at the initial steady-state, real GDP and nominal GDP coincide, i.e., $Y_{R}=Y$.

Government spending, $G$, is the sum of public purchases on non traded goods, $G^{N}$, and traded goods, $G^{T}$ :

$$
G(t)=P G^{N}(t)+G^{T}(t) .
$$

We denote by $\omega_{G^{N}}=\frac{P G^{N}}{G}$ and $\omega_{G^{T}}=\frac{G^{T}}{G}=1-\omega_{G^{N}}$ the non tradable and tradable content of government spending. Assuming that the share $\omega_{G^{j}}$ is constant over time, eq. (49) can be rewritten as follows:

$$
G(t)=\omega_{G^{N}} G(t)+\omega_{G^{T}} G(t),
$$

with $\omega_{G^{N}}+\omega_{G^{T}}=1$.

Below, we note by a hat the deviation of variable $X(t)$ relative to its initial level, $X$, in percentage:

$$
\hat{X}(t)=\frac{X(t)-X}{X} .
$$

Totally differentiating (50) and dividing by initial GDP, a rise in government spending is split into non tradadables and tradables in accordance with their respective shares:

$$
\frac{d G(t)}{Y}=\omega_{G^{N}} \frac{d G(t)}{Y}+\omega_{G^{T}} \frac{d G(t)}{Y} .
$$

A government spending shock is said to be biased toward non tradables if

$$
\omega_{G^{N}}>\omega_{G^{T}} .
$$

As will be useful later, we totally differentiate (49) and divide the resulting expression by initial GDP:

$$
\frac{d G(t)}{Y}=\omega_{G} \omega_{G^{N}} \hat{G}^{N}(t)+\omega_{G} \omega_{G^{T}} \hat{G}^{T}(t) .
$$

where $\omega_{G}=\frac{G}{Y}$ stands for government consumption-to-GDP ratio. Combining eq. (52) and (54), we thus have:

$$
\omega_{G} \omega_{G^{j}} \hat{G}^{j}(t)=\omega_{G^{j}} \frac{d G(t)}{Y}, \quad j=N, T .
$$

Before investigating the impact of higher government spending on sectoral value added, it is convenient to denote by $\nu_{Y}^{N}=\frac{P Y^{N}}{Y}$ the share of non tradables in GDP and $\nu^{Y, T}=\frac{Y^{T}}{Y}$ the share of tradables in GDP. Keeping private consumption, $C^{j}$, private investment, $J^{j}$, and net exports, $N X$, constant, totally differentiating market clearing conditions for non tradables and tradables described by (47a) and (47b), respectively, leads to:

$$
\begin{aligned}
\nu^{Y, N} \hat{Y}^{N}(t) & =\omega_{G} \omega_{G^{N}} G^{N}(t), \\
\nu^{Y, T} \hat{Y}^{T}(t) & =\omega_{G} \omega_{G^{T}} G^{T}(t),
\end{aligned}
$$

where $\nu^{Y, T}=1-\nu^{Y, N}$. The LHS of eqs. (56), $\nu^{Y, j} \hat{Y}^{j}(t)$, corresponds to the deviation of value added in sector $j$ relative to its initial steady-state value in percentage of initial GDP. Subtracting (56b) from (56a) allows us to relate the change in output of non tradables relative to tradables, both expressed in percentage points of GDP, to changes in sectoral government consumption:

$$
\begin{aligned}
\nu^{Y, N} \hat{Y}^{N}(t)-\nu^{Y, T} \hat{Y}^{T}(t) & =\omega_{G} \omega_{G^{N}} G^{N}(t)-\omega_{G^{\prime}} \omega_{G^{T}} G^{T}(t), \\
& =\left(\omega_{G^{N}}-\omega_{G^{T}}\right) \frac{d G(t)}{Y},
\end{aligned}
$$

where use has been made of (55) to obtain the second line of eq. (57). In accordance with the definition (53), eq. (57) implies that non traded output increases relative to traded output when government spending is biased toward non tradables, i.e.,

$$
\nu^{Y, N} \hat{Y}^{N}(t)-\nu^{Y, T} \hat{Y}^{T}(t)>0, \quad \text { if } \omega_{G^{N}}>\omega_{G^{T}} .
$$




\section{C.2 Stricter Definition of Government Spending Shocks Biased toward Non Tradables}

In subsection 2.3 we document a second empirical fact which reveals that the share of non tradables in GDP (in real terms) increases while the share of tradables in GDP (in real terms) falls following a rise in government consumption. In this subsection, we relate the responses of sectoral output shares to changes in sectoral government spending.

To begin with, summing value added at constant prices across sectors, i.e., (47a) and (47b), and using the definition (48) leads to the standard accounting identity according to which GDP is equal to final expenditure:

$$
Y_{R}(t)=P_{C} C(t)+P_{J} J(t)+G(t)+N X(t),
$$

where $P_{C}$ and $P_{J}$ are the consumption $(C)$ and investment $(J)$ price index, respectively.

Keeping consumption and investment expenditure along with net exports fixed, totally differentiating (59) leads to:

$$
\hat{Y}_{R}(t)=\omega_{G} \hat{G}(t)=\frac{d G(t)}{Y} .
$$

Totally differentiating (48) leads to:

$$
\hat{Y}_{R}(t)=\nu_{Y}^{N} \hat{Y}^{N}(t)+\nu^{Y, T} \hat{Y}^{T}(t),
$$

where $\nu^{Y, j}=\frac{P^{j} Y^{j}}{Y}$, remembering that $P^{T}=1$. Subtracting $\hat{Y}_{R}(t)$ from both sides of eq. (61) and using the fact that $\nu^{Y, T}=1-\nu_{Y}^{N}$ leads to:

$$
\nu^{Y, N}\left(\hat{Y}^{N}(t)-\hat{Y}_{R}(t)\right)+\nu^{Y, T}\left(\hat{Y}^{T}(t)-\hat{Y}_{R}(t)\right)=0
$$

The term $\nu^{Y, j}\left(\hat{Y}^{j}(t)-\hat{Y}_{R}(t)\right)$ corresponds to the deviation of sectoral output share in GDP relative to its initial value:

$$
\nu^{Y, j}\left(\hat{Y}^{j}(t)-\hat{Y}_{R}(t)\right)=\nu^{Y, j} \hat{\nu}^{Y, j}(t)
$$

To relate the response of the share of non tradables in GDP to changes in sectoral government consumption, we make use of eq. (56a) and eq. (60) which relate the change in output to changes in government spending:

$$
\begin{aligned}
\nu^{Y, N}\left(\hat{Y}^{N}-\hat{Y}_{R}\right) & =\omega_{G} \omega_{G^{N}} G^{N}(t)-\nu^{Y, N} \omega_{G} \hat{G}(t), \\
& =\omega_{G^{N}} \frac{d G(t)}{Y}-\nu^{Y, N} \frac{d G(t)}{Y}, \\
& =\left(\omega_{G^{N}}-\nu^{Y, N}\right) \frac{d G(t)}{Y}
\end{aligned}
$$

where we use eq. (55) to obtain the second line of eq. (64). According to (64), the share of non tradables in GDP increases following a fiscal shock as long as the fraction of government expenditure spent on non traded goods, $\omega_{G^{N}}$, is higher than that the share of non tradables in GDP, $\nu^{Y, N}$. Thus, a government spending shock is biased toward non tradables if:

$$
\omega_{G^{N}}>\nu^{Y, N} \text {. }
$$

Building on (53) and (65), there exists two definitions of government spending biased toward non traded goods. The first definition establishes that government spending is biased toward non traded goods if a larger fraction of public spending is spent on non traded traded goods than on traded goods. Such a definition implies that non traded output increases relative to traded output, as documented in Figure 2(h), as long as $\omega_{G^{N}}>\omega_{G^{T}}$. However, this definition does not take into account that non traded output accounts for a larger fraction of GDP. Thus, for the share of non tradables in GDP to increase, inequality (53) is a necessary but not sufficient condition. For the share of non tradables in GDP to increase, as documented in Figure 2(c), the fraction of government spending spent on non traded goods must exceed the share of non tradables in GDP, in line with the stricter inequality (65).

It is worth noting that for the increase in the GDP share of non tradables to materialize, resources must be reallocated away from the traded sector to the non traded sector. In other words, the fact that government spending is biased toward non tradables in accordance with the stricter definition (65) is sufficient as long as labor and/or capital can shift toward the non traded sector.

So far, we have investigated the response of the share of non tradables in real GDP to a rise in government spending by keeping the private sector's demand components fixed. We now investigate how much the responses of the private sector's demand components influence our results. To avoid unnecessary complications, we assume that the elasticity of substitution between tradables and non 
tradables is equal to one for both consumption and investment. Thus, consumption (investment) in non tradables is a fixed fraction $\alpha_{C}\left(\alpha_{J}\right)$ of consumption (investment) expenditure described by $P_{C} C\left(P_{J} J\right)$. First, log-linearizing (59) leads to the deviation from initial steady-state in percentage for real GDP, $Y_{R}$ :

$$
\hat{Y}_{R}(t)=\omega_{C} \hat{C}(t)+\omega_{J} \hat{J}(t)+\frac{d G(t)}{Y}+\frac{d N X(t)}{Y},
$$

where $Y$ is initial real GDP. Totally differentiating (47a) leads to the fiscal multiplier for non traded output in GDP units:

$$
\nu^{Y, N} \hat{Y}_{N}(t)=\alpha_{C} \omega_{C} \hat{C}(t)+\alpha_{J} \omega_{J} \hat{J}(t)+\omega_{G^{N}} \frac{d G(t)}{Y}
$$

Pre-multiplying (66) by $\nu^{Y, N}$, the initial response of the share of non tradables in real GDP to a government spending shock is:

$$
\begin{aligned}
\nu^{Y, N}\left(\hat{Y}^{N}(0)-\hat{Y}_{R}(0)\right) & =-\left(\nu^{Y, N}-\alpha_{C}\right) \omega_{C} \hat{C}-\left(\nu^{Y, N}-\alpha_{J}\right) \omega_{J} \hat{J} \\
& +\left(\omega_{G^{N}}-\nu^{Y, N}\right)(d G(0) / Y)-\nu^{Y, N}(d N X(0) / Y) .
\end{aligned}
$$

Since $\nu^{Y, N}$ takes values which are close to both $\alpha_{J}$ and $\alpha_{C}$, the response of the share of non tradables in real GDP is mostly affected by $\left(\omega_{G^{N}}-\nu^{Y, N}\right)$ along with the deficit in the balance of trade on impact. In sum, when taking into account the reaction of the private sector's demand components, the current account deficit triggered by the rise in government spending tends to reinforce the fact that the government spending shock is biased toward non tradables.

\section{More VAR Results and Robustness Check}

In this section, we provide more VAR results, conduct a robustness check with respect to the classification of industries, and contrast VAR results with those obtained by adopting local projection method.

\section{D.1 Estimated Effects on GDP and Demand Components of Government Spending Shock}

Importance of aggregate effects for understanding the sectoral effects. To provide an elaborate and clear understanding of the inter-sectoral reallocation effects triggered by a government spending shock, we need to have the whole picture as aggregate and sectoral effects are strongly intertwined. In this regard, as pointed out in section 2 in the main text, the response of the sectoral output share can be defined as the excess of the sectoral fiscal multiplier over the aggregate fiscal multiplier (both adjusted with the share of the sector in real GDP). The same logic applies to the sectoral labor share which can be defined as the excess of the government spending multiplier for sectoral labor over the government spending multiplier for total labor (both adjusted with the corresponding sectoral content of overall labor compensation). Additionally, the changes in aggregate demand components such as the responses of investment and current account play a key role in driving the inter-sectoral reallocation effects. A muted response of investment guarantees a substantial appreciation in the relative price of non tradables that provides incentives to shift capital toward the non traded sector. By considering an open economy which has perfect access to world capital markets, it is optimal for the country to run a significant current account deficit. Because traded goods can be imported while non traded goods must be produced by the home country, the ability of the country to borrow abroad tends to make the non traded sector more intensive in the aggregate government spending shock. Third, while our main contribution is to investigate the magnitude of changes in relative sector size following a government spending shock, the assumptions set in the paper can be considered reasonable only if the model can account for both the aggregate and sectoral effects. In this regard, because the use of an open economy version of the neoclassical model to address the effects of a government spending shocks quantitatively are somewhat less common, we find it convenient to show how the model behaves regarding aggregate economic variables. Fourth, we aim at providing a better understanding of fiscal transmission in an open economy by shedding some light on the implications of the imperfect mobility of labor across sectors, which requires a back and forth between aggregate and sectoral effects. More specifically, by amplifying the rise in the aggregate wage and thus the positive response of labor supply to a fiscal shock, the open economy version of the neoclassical model with imperfect mobility of labor can produce an increase in hours worked in line with evidence in contrast to a model imposing perfect mobility of labor across sectors. The increase in total hours worked has an expansionary effect on both sectors (with imperfect mobility of labor, the Rybczynski theorem does not hold). Because the non traded sector is more intensive in labor, the rise in non traded output is amplified and in line 
with the evidence. Fifth, our calibration of the government consumption shock is based on estimates of the first VAR model that includes aggregates variables, i.e., $z_{i t}=\left[g_{i t}, y_{i t}, l_{i t}, j e_{i t}, w_{C, i t}\right]$. While the endogenous response of government spending is almost identical across VAR models, we find it more appropriate to base our calibration strategy on estimates of a VAR model, which is fairly standard in the literature instead of a specification that includes sectoral variables.

VAR specification. Because their movements are strongly intertwined, we explore empirically the effects of government spending shocks on both aggregate and sectoral variables. The former variables consist of government consumption $\left(G_{i t}\right)$, GDP $\left(Y_{i t}\right)$, private fixed investment $\left(J E_{i t}\right)$, current account $\left(C A_{i t}\right)$, labor $\left(L_{i t}\right)$, and real consumption wage $\left(W_{C, i t}\right)$. All data are obtained from the OECD Economic outlook and OECD STAN database together with EU KLEMS database. ${ }^{62}$ To explore the magnitude of the aggregate fiscal multiplier empirically, we consider a VAR model that includes in the baseline specification (log) government consumption, $g_{i t}$, GDP, $y_{i t}$, total hours worked, $l_{i t}$, private fixed investment, $j e_{i t}$, and the real consumption wage denoted by $w_{C, i t}$. Our vector of endogenous variables, is given by: $z_{i t}=\left[g_{i t}, y_{i t}, l_{i t}, j e_{i t}, w_{C, i t}\right]$. In the second specification we replace private investment with the current account expressed in percentage of GDP, $c a_{i t}$.

Empirical Results. Figure 9 shows aggregate effects of a government spending shock. The impact on GDP is fairly moderate as the fiscal multiplier is about 0.5 and averages 0.29 during the first four years after the shock. ${ }^{63}$ As shown in the last row, the dynamic adjustment of real GDP seems to mimic the dynamic adjustment of hours worked which increase on impact by $0.53 \%$ and declines after one year. In addition, we detect a moderate increase in the real consumption wage followed by a rapid decline. Its cumulative response over a two-year horizon is $0.6 \%$ approximately, and subsequently becomes negative.

Turning to the response of investment and the current account as shown in the second column of Fig. 9, the top panel indicates that investment is fairly unresponsive on impact which suggests the presence of installation costs, while the middle panel reveals that the current account moves into deficit in the short-run. The government spending shock leads to a protracted decline in investment which remains below trend while the current account recovers after two years and moves into surplus after about 5 years.

\section{D.2 Point Estimates for Responses to Government Spending Shock and Split-Sample Analysis}

Table 5 shows point estimates at a one year-, two-year and four-year horizon. While panel A displays results for the whole sample, panel B shows estimates for sectoral effects when we split our sample into groups of 'high mobility' and 'low mobility' economies. The 'low mobility' economies are those for which the switching cost is above average for the sample and comprise Australia, Austria, Belgium, Canada, Denmark, Finland, Ireland, Italy, Netherlands, Norway, Sweden, while 'high mobility' economies consist of France, Japan, Spain, United-Kingdom, United States. In order to provide some support for our measure of workers' mobility cost, we compute an intersectoral labor reallocation index in year $t$ for each country $i$, denoted by $L R_{i, t}$, by calculating the absolute change in sectoral employment resulting from labor reallocation over $\tau=5$ years in sector $j$ as a fraction of the average employment over five years: ${ }^{64}$ The first term in the numerator of (40) captures the change in employment over five years in sector $j$ while the second term "filters" the change in labor arising from total employment growth. The term in the denominator of (40) is a measure of total employment in the economy (i.e., the average employment computed over $t$ and $t-5$ ). Dividing one by the other gives the rate of workers that have shifted from one sector to another over five years. We choose $\tau=5$ to eschew year-to-year changes because of the low frequency changes in labor at that horizon and consider only differences over 5 years. As the values of the labor reallocation index, $L R$, increase, the fraction of workers who are working in a different sector in year $t$ than in year $t-\tau$ is thus larger. ${ }^{65}$

In the following, we compare the cumulative responses of the labor reallocation index, hours worked in tradables relative to non tradables, and the relative wage for the 'low mobility' group with those for the 'high mobility' group. The last two columns of Panel B of Table 5 show the point estimates for both sub-samples for selected horizons. Contrasting point estimates reported in columns 5 and 6 of Table 5, we find that the magnitude of the shift of labor in the 'low mobility'

\footnotetext{
${ }^{62}$ Details of data construction and the source of variables used in our estimate are given in Appendix A.

${ }^{63}$ Like Ilzetzki, Mendoza, and Vegh [2013], we calculate the (aggregate or sectoral) multiplier at a $k$-year horizon by computing the ratio of the present value of the cumulative change in output to the present value of the cumulative change in government consumption, setting the world interest rate set to $4 \%$ to be consistent with the model calibration.

${ }^{64}$ See e.g., Wacziarg and Wallack [2004] who compute the same labor reallocation index (40).

${ }^{65}$ When we estimate the response of the intersectoral labor reallocation index to a government spending shock, we replace hours worked in the traded sector in terms of hours worked in the non traded sector, $l_{i t}^{T}-l_{i t}^{N}$ with $L R(5)_{i t}$ and thus consider the 'labor reallocation' specification that is given by: $z_{i t}^{W}=\left[g_{i t}, L R_{i t}(5), \omega_{i t}\right]$.
} 


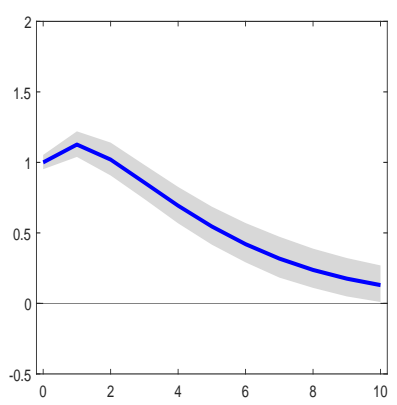

(a) Government spending,

G

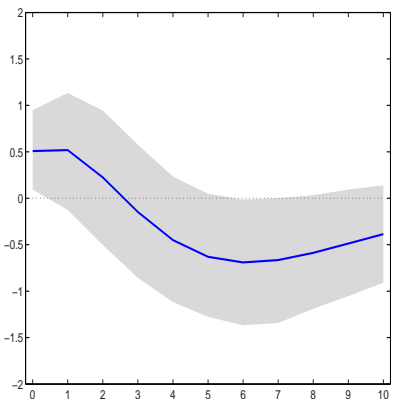

(c) Real GDP, $Y$

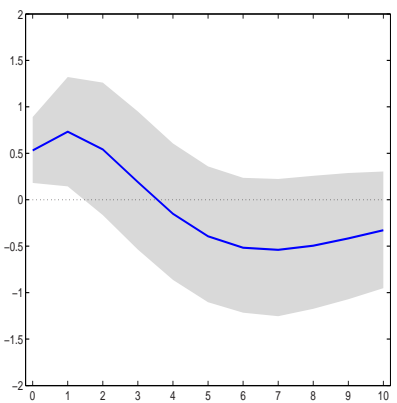

(e) Labor, $L$

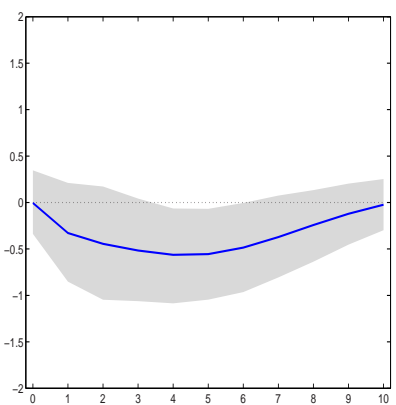

(b) Investment, $J E$

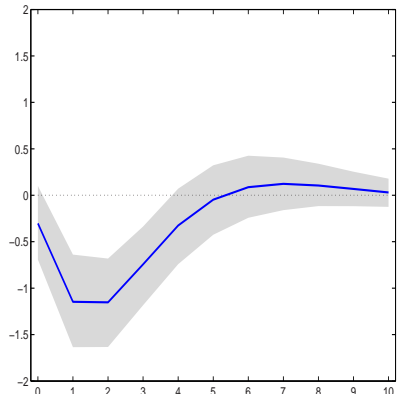

(d) Current Account, $C A$

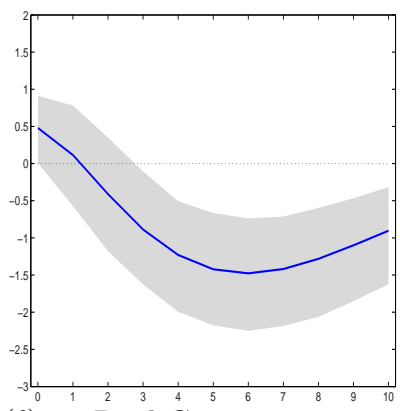

(f) Real Consumption Wage, $W / P_{C}$

Figure 9: Effects of Unanticipated Government Spending Shock on Aggregate Variables. Notes: Exogenous increase of government consumption by $1 \%$ of GDP. Aggregate variables include GDP (constant prices), total hours worked, private fixed investment, the current account and the real consumption wage. Horizontal axes indicate years. Vertical axes measure percentage deviation from trend in output units (government spending, GDP, investment, current account), percentage deviation from trend in labor units (total hours worked), percentage deviation from trend (real consumption wage). Solid blue lines: point estimates; shaded areas: bootstrapped $90 \%$ confidence intervals; sample: 16 OECD countries, 1970-2007, annual data. 
group, as captured by the LR index (40), is about four times less in first year. This finding thus lends credence to our measure of mobility costs. Importantly, in accordance with our conjecture, we find that the magnitude of the responses of the relative wage and relative hours worked in tradables are different across the sub-samples. As can be seen in the last two columns of Table 5, non traded wages increase substantially relative to traded wages for the 'low mobility' economies while the relative wage response for 'high mobility' countries is not statistically different from zero. Columns 5 and 6 of Table 5 also show that the 'low mobility' economies experience a fall in relative hours worked of tradables which is less pronounced as labor supply is less elastic to the relative wage. Because the shift of labor toward the non traded sector is less, 'low mobility' economies also experience a smaller decline in output of tradables relative to non tradables as shown by point estimates reported in the last two columns of Table 5 .

\section{D.3 Sectoral Classification}

This section explores the robustness of our findings to the classification of the eleven 1-digit ISICrev.3 industries as tradables or non tradables. When we conduct the robustness analysis, we modify the baseline classification in a number of ways to ensure that some industries with specific characteristics are not driving the results. In particular, the classification of items "Wholesale and Retail Trade", "Hotels and Restaurants", "Transport, Storage and Communication", "Financial Intermediation" and "Real Estate, Renting and Business Services" may display some ambiguity. In order to address this issue, we re-estimate the various VAR specifications for different classifications in which one of the five above industries initially marked as tradable (non tradable resp.) is classified as non tradable (tradable resp.), all other industries staying in their original sector. In doing so, the classification of only one industry is altered, allowing us to see if the results are sensitive to the inclusion of a particular industry in the traded or the non traded sector. The baseline and the five alternative classifications considered in this exercise are shown in Table 6.

Figures 10 and 11 report the responses of variables of interest to an exogenous increase in government spending by one percent of GDP. The solid blue line shows results for the baseline classification while the responses for alternative classifications are shown in the five colored lines. The last line of Table 6 provides the matching between the color line and the classification between tradables and non tradables. In each panel, the shaded area corresponds to the $90 \%$ confidence bounds. ${ }^{66}$ Figure 10 contrasts the responses of sectoral output $\left(Y^{j}\right)$, sectoral labor $\left(L^{j}\right)$, sectoral output shares $\left(Y^{j} / Y\right)$, sectoral labor shares $\left(L^{j} / L\right)$, real consumption sectoral wages $\left(W^{j} / P_{C}\right)$ for the baseline classification with those obtained for alternative classifications of industries as tradables or non tradables. Alternative responses are fairly close to those for the baseline classification as they lie within the confidence interval (for the baseline classification) for almost all the selected horizons (8 years). Figure 11 reports the effects of an exogenous increase in government consumption by $1 \%$ of GDP on the ratio of sectoral output $\left(Y^{T} / Y^{N}\right)$, sectoral labor $\left(L^{T} / L^{N}\right)$, the intersectoral labor reallocation index $(L R)$, the relative price $(P)$ and the relative wage $(\Omega)$. For $L R, P$ and $\Omega$, the responses are remarkably similar across the baseline and alternative classifications. While the pattern of the dynamic adjustment of $Y^{T} / Y^{N}$ is similar across all classifications, the decline in output of tradables relative to non tradables is more pronounced when the industry "Wholesale and Retail Tarde" is treated as tradables (classification \#1). We can also notice some differences in responses of $L^{T} / L^{N}$ across the baseline and the five alternative classifications. For specifications $\# 1$ and \#5, the response of $L^{T} / L^{N}$ does not lie within the confidence interval of the baseline. Yet, across all classifications, $L^{T} / L^{N}$ declines significantly on impact, and stay below trend for a number of periods. By and large, our main findings hold and remain unsensitive to the classification of one specific industry as tradable or non tradable; in sum, the specific treatment of "Wholesale and Retail Trade", "Hotels and Restaurants", "Transport, Storage and Communication", "Financial Intermediation" and "Real Estate, Renting and Business Services" does not drive the results.

\footnotetext{
${ }^{66}$ We do not report the responses for aggregate variables included since these variables, by construction, are unsensitive to the definition of traded and non traded sectors.
} 


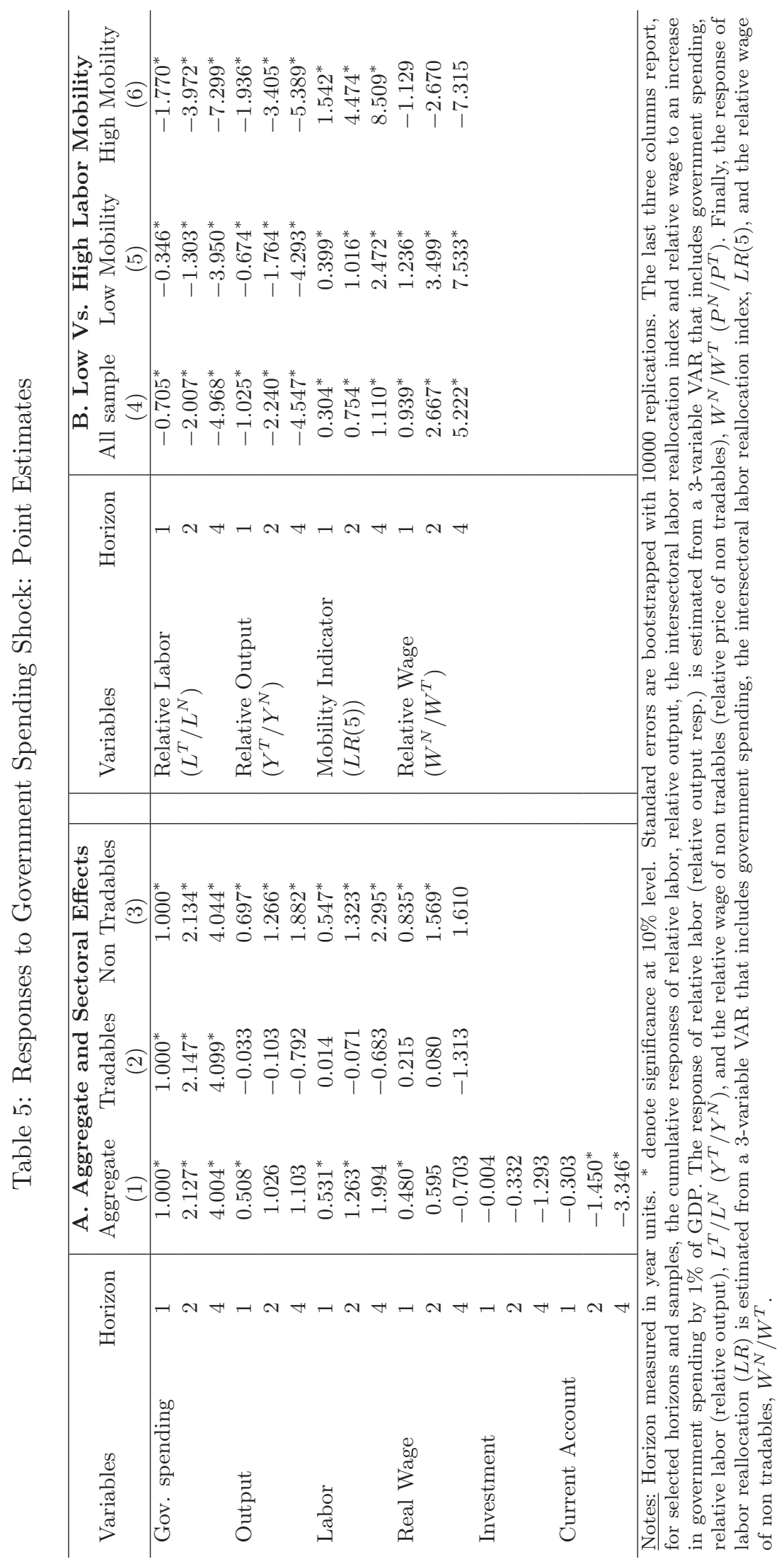




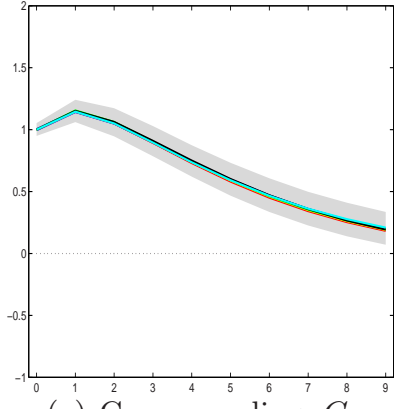

(a) Gov. spending, $G$

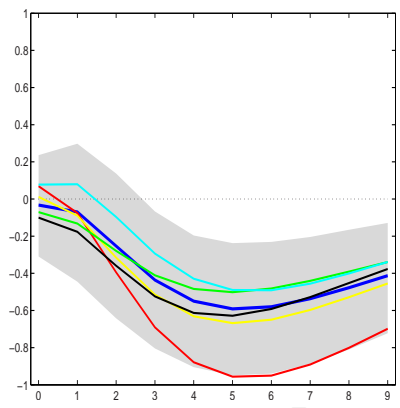

(e) Output, $Y^{T}$

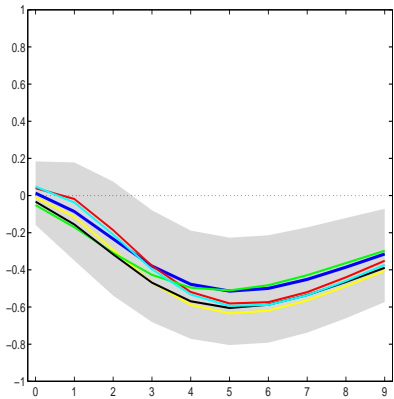

(i) Labor, $L^{T}$

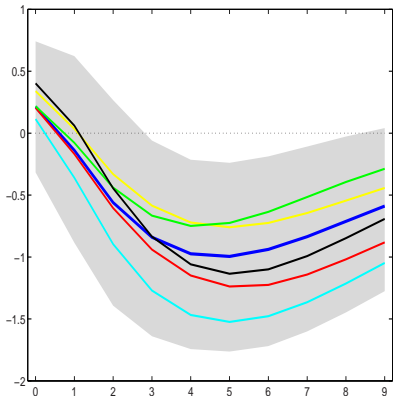

(m) Real Wage, $W^{T} / P_{C}$

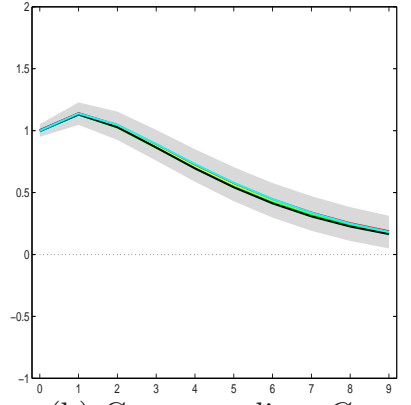

(b) Gov. spending, $G$

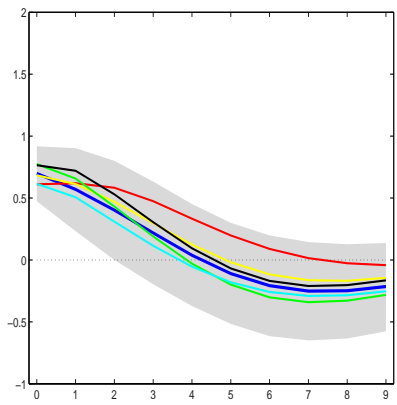

(f) Output, $Y^{N}$

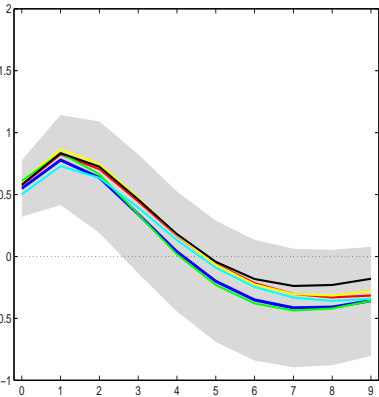

(j) Labor, $L^{N}$

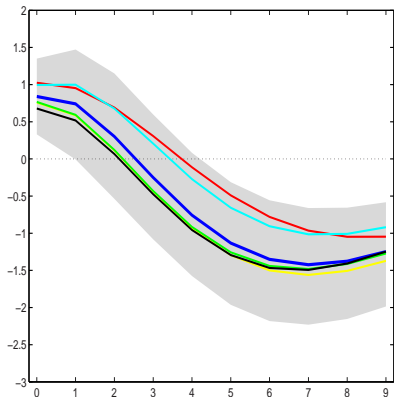

(n) Real Wage, ${ }^{6}{ }^{N^{7}} / P_{C}^{8}$

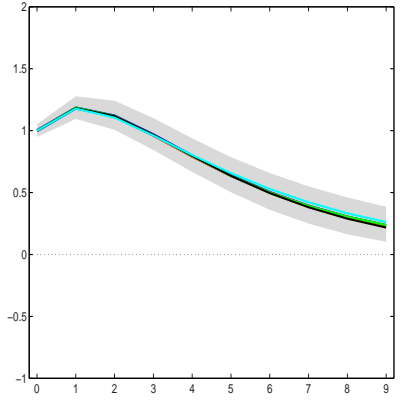

(c) ${ }^{2}{ }^{3}{ }^{4}{ }^{5}{ }^{6}{ }^{6}{ }^{7}{ }^{8}$

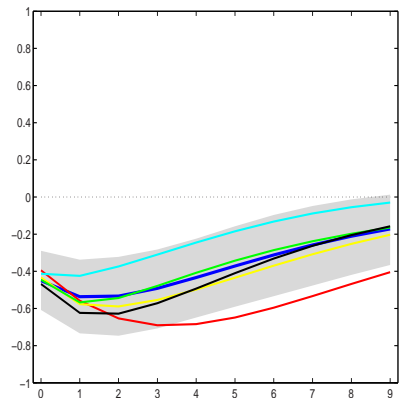

(g)

Output Share of Tradables, $Y^{T} / Y$

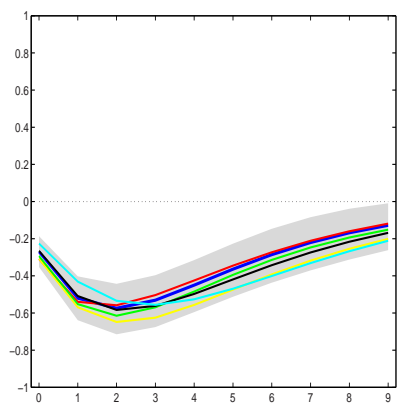

(k) Traded Labor Share, $L^{T} / L$

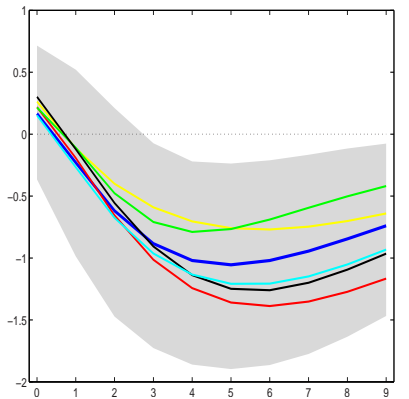

(o) Real Wage, $W^{T} / P_{C}$

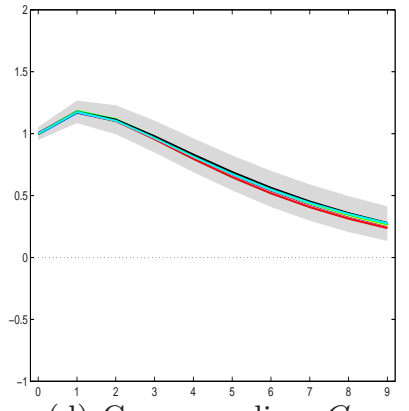

(d) Gov. spending, $G$

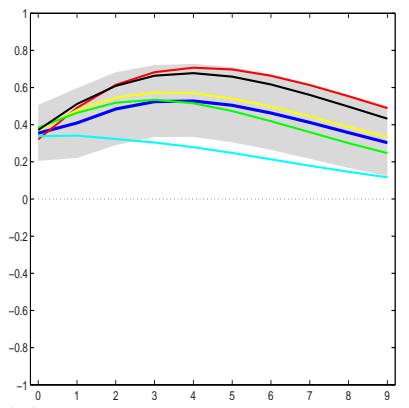

(h) Output Share of Non Tradables, $Y^{N} / Y$

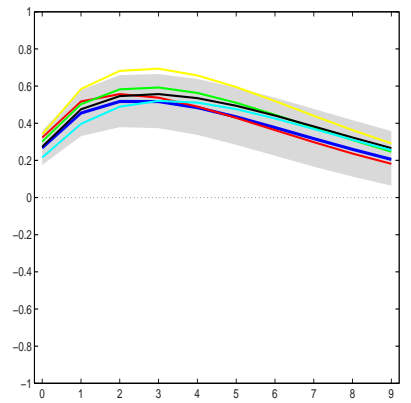

(1) Non Traded Labor Share, $L^{N} / L$

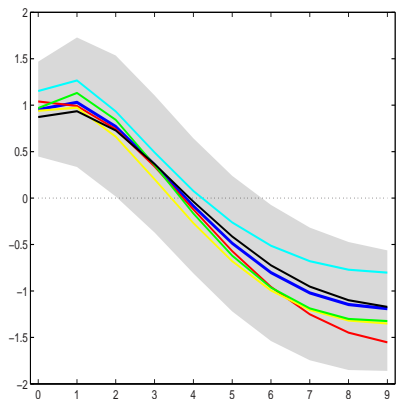

(p) Real Wage, $W^{N} / P_{C}$

Figure 10: Sensitivity of the Effects of Unanticipated Government Spending Shock on Sectoral Variables to the Classification of Industries as Tradable or Non Tradable. Notes: The blue line shows results for the baseline classification. The red line and the yellow line show results when 'Whole and retail traded' and 'Hotels and restaurants' are treated as tradables, respectively. The green line and the black line show results when 'Transport, storage and communication' and 'Financial intermediation' are classified as tradables, respectively. The cyan line reports results when 'Real Estate, renting and business services' is treated as tradables. 


\begin{tabular}{|c|c|c|c|c|c|c|c|}
\hline & \multirow[t]{2}{*}{ KLEMS code } & \multicolumn{6}{|c|}{ Classification } \\
\hline & & Baseline & $\# 1$ & $\# 2$ & $\# 3$ & $\# 4$ & $\# 5$ \\
\hline Agriculture, Hunting, Forestry and Fishing & AtB & $\mathrm{T}$ & $\mathrm{T}$ & $\mathrm{T}$ & $\mathrm{T}$ & $\mathrm{T}$ & $\mathrm{T}$ \\
\hline Mining and Quarrying & $\mathrm{C}$ & $\mathrm{T}$ & $\mathrm{T}$ & $\mathrm{T}$ & $\mathrm{T}$ & $\mathrm{T}$ & $\mathrm{T}$ \\
\hline Total Manufacturing & $\mathrm{D}$ & $\mathrm{T}$ & $\mathrm{T}$ & $\mathrm{T}$ & $\mathrm{T}$ & $\mathrm{T}$ & $\mathrm{T}$ \\
\hline Electricity, Gas and Water Supply & $\mathrm{E}$ & $\mathrm{N}$ & $\mathrm{N}$ & $\mathrm{N}$ & $\mathrm{N}$ & $\mathrm{N}$ & $\mathrm{N}$ \\
\hline Construction & $\mathrm{F}$ & $\mathrm{N}$ & $\mathrm{N}$ & $\mathrm{N}$ & $\mathrm{N}$ & $\mathrm{N}$ & $\mathrm{N}$ \\
\hline Wholesale and Retail Trade & G & $\mathrm{N}$ & $\mathbf{T}$ & $\mathrm{N}$ & $\mathrm{N}$ & $\mathrm{N}$ & $\mathrm{N}$ \\
\hline Hotels and Restaurants & $\mathrm{H}$ & $\mathrm{N}$ & $\mathrm{N}$ & $\mathbf{T}$ & $\mathrm{N}$ & $\mathrm{N}$ & $\mathrm{N}$ \\
\hline Transport, Storage and Communication & $\mathrm{I}$ & $\mathrm{T}$ & $\mathrm{T}$ & $\mathrm{T}$ & $\mathbf{N}$ & $\mathrm{T}$ & $\mathrm{T}$ \\
\hline Financial Intermediation & $\mathrm{J}$ & $\mathrm{T}$ & $\mathrm{T}$ & $\mathrm{T}$ & $\mathrm{T}$ & $\mathbf{N}$ & $\mathrm{T}$ \\
\hline Real Estate, Renting and Business Services & K & $\mathrm{N}$ & $\mathrm{N}$ & $\mathrm{N}$ & $\mathrm{N}$ & $\mathrm{N}$ & $\mathbf{T}$ \\
\hline Community Social and Personal Services & LtQ & $\mathrm{N}$ & $\mathrm{N}$ & $\mathrm{N}$ & $\mathrm{N}$ & $\mathrm{N}$ & $\mathrm{N}$ \\
\hline Color line in Fig. 10 and 11 & & blue & red & yellow & green & black & cyan \\
\hline
\end{tabular}

Notes: $\mathrm{T}$ stands for the Traded sector and $\mathrm{N}$ for the Non traded sector.

\section{D.4 Cross-Country Analysis: Local Projection vs. VAR Method}

In the main text, we estimate impact responses of sectoral shares in real GDP or employment to a government spending shock for each country in our sample by adopting a VAR methodology. More specifically, we estimate the responses of sectoral labor and sectoral output shares to a government spending shock by running the same VAR as for the whole sample, i.e., $z_{i t}^{S, j}=\left[g_{i t}, \nu_{i t}^{Y, j}, \nu_{i t}^{L, j}\right]$, but for one single country as a time. While we omit the sectoral real consumption wage, we also estimated the VAR model by including $\omega_{C, i t}^{j}$ and find that the results are similar. We allow for two lags (i.e., $k=2$ in eq. (1)), as we did for the panel data estimate.

One potential issue with the VAR methodology is related to the fact that we estimate two VAR models, one including non traded variables and the other traded variables, and each VAR model is used to simultaneously identify the government spending shock and generate impulse response functions. In doing that, one might be potentially concerned by the fact that structural government spending shocks are different and thus responses of the shares of non tradables and tradables cannot be compared with. Instead of adopting a VAR approach, we can choose a two-step method. In the first step, we identify the shock by estimating the baseline VAR model that includes aggregate variables, i.e., $z_{i, t}=\left[g_{i, t}, y_{i, t}, l_{i, t}, j e_{i, t}, w_{C, i, t}\right]$. In the second step, we estimate the effects by using the Jordà's [2005] single-equation method. The local projection method amounts to running a series of regression of each variable of interest on a structural identified shock for each horizon $h=0,1,2, \ldots$ :

$$
x_{i, t+h}^{j}=\alpha_{i, h}^{j}+\beta_{i, h}^{j} \cdot t+\psi_{i, h}^{j}(L) z_{t-1}+\gamma_{i, h}^{j} \cdot \epsilon_{i, t}^{G}+\nu_{i, t}^{j}
$$

where $\alpha_{i}^{j}$ and $\beta_{i}^{j}$ are the constant and linear trends respectively, $x^{j}$ is the logarithm of the variable of interest of sector $j, z$ is a vector of control variables (i.e., past values of government spending and of the variable of interest), $\psi_{i, h}^{j}(L)$ is a polynomial (of order two) in the lag operator and $\epsilon_{i, t}^{G}$ is the identified government spending shock. While we allow for two lags on the variable of interest and government spending collected in vector $z$, we consider the effects of a current exogenous government spending shock. Since we concentrate on impact effects, horizon $h$ is set to zero in eq. (69).

We estimate impact responses, i.e., coefficient $\gamma_{i, 0}^{j}$ in eq. (69), for each country in our sample. Columns 1-4 of Table 7 show impact responses when adopting the VAR approach, as in the main text, while columns 5-8 display results when adopting the local projection method. First, for the four variables of interest, the correlation coefficient is high, as it varies between 0.91 and 0.93 for labor shares and from 0.95 to 0.97 for output shares. In Fig. 12, we plot impact responses obtained by using a SVAR approach against those estimated by adopting a local projection method. As it stands out, both methods lead to very similar results.

Whereas Jordà's local projection method gives similar results, one can notice some differences in Fig. 13 which plots impact responses of sectoral output shares against the degree of labor mobility across sectors. More specifically, cross-country relationships between $d \nu^{Y, j}(0)$ and $\epsilon$ obtained using a VAR methodology (solid blue line) display the same pattern, as the slope is 0.235 for non tradables and -0.249 for tradables. Since by construction, a rise in the share of non tradables must be exactly offset by a decline of the same amount in the share of tradables, such symmetry between the traded and the non traded sector is consistent with our quantitative analysis. While the pattern of solid black lines with circles which display the cross country relationship from local projection estimates is similar to that of solid blue lines, the slope is 0.30 for non tradables and -0.43 for tradables. When we simulate the model, we obtain the same slope in absolute terms and adopting the local projection 


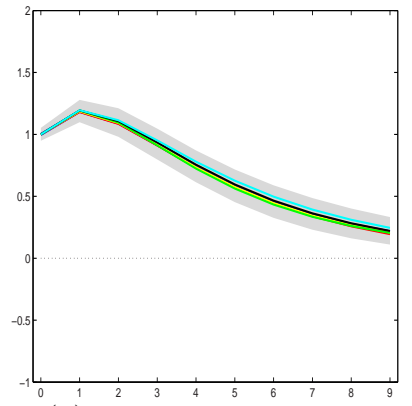

(a) Gov. spending, $G$

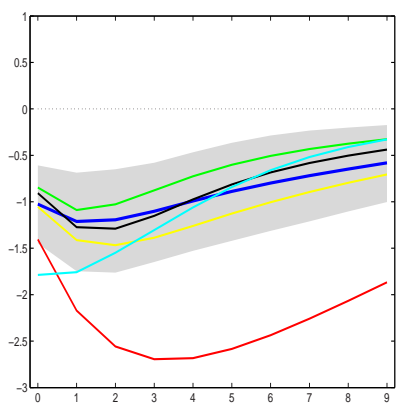

(d) Relative Value Added $Y^{T} / Y^{N}$

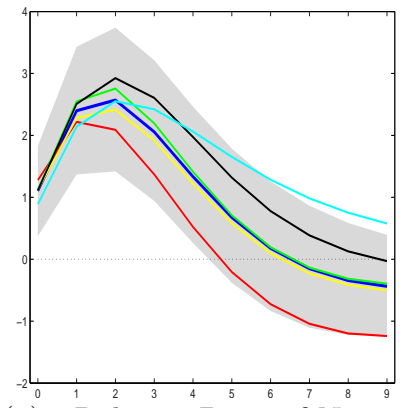

(g) Relative Price of Non Tradables, $P=P^{N} / P^{T}$

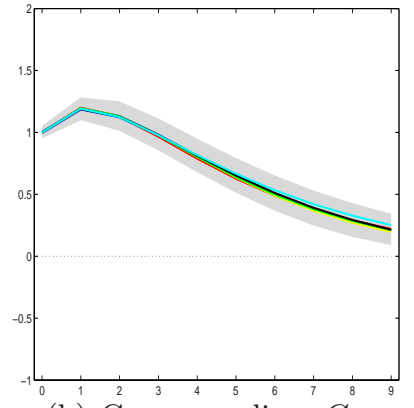

(b) Gov. spending, $G$

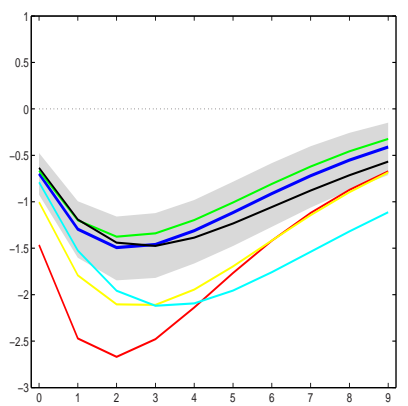

(e) Relative Hours Worked, $L^{T} / L^{N}$

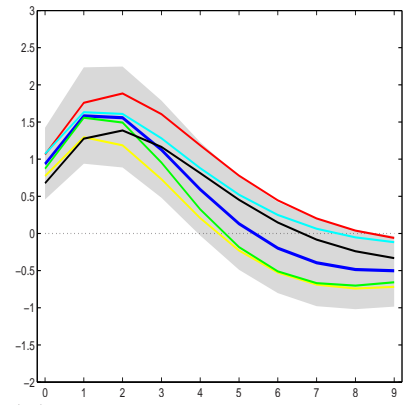

$(\mathrm{h})$

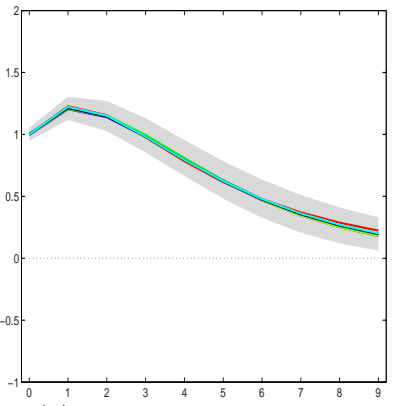

(c) Gov. spending, $G$

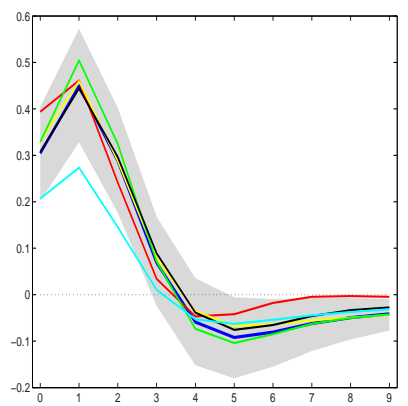

(f) Labor Reallocation

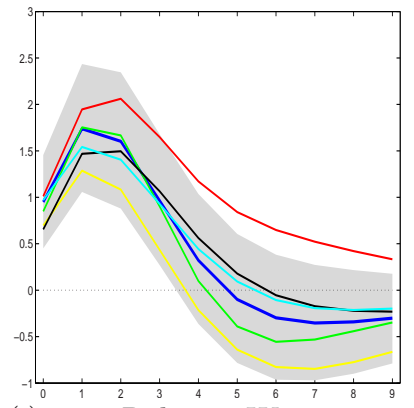

(i) $\Omega=W^{N} / W^{T}$ $\Omega=W^{N} / W^{T}$

Figure 11: Sensitivity of the Effects of Unanticipated Government Spending Shock on Relative Price and Relative Wage to the Classification of Industries as Tradable or Non Tradable. Notes: The blue line shows results for the baseline specification. The red line and the yellow line show results when 'Whole and retail traded' and 'Hotels and restaurants' are treated as tradables, respectively. The green line and the black line show results when 'Transport, storage and communication' and 'Financial intermediation' are classified as tradables, respectively. The cyan line reports results when 'Real Estate, renting and business services' is treated as tradables. 
Table 7: Impact Responses of Sectoral Shares: VAR vs. Local Projection Method

\begin{tabular}{l|cccc|cccc}
\hline Country & \multicolumn{5}{|c|}{ VAR } & \multicolumn{4}{c}{ Local Projection } \\
& $\nu^{Y, T}$ & $\nu^{Y, N}$ & $\nu^{L, T}$ & $\nu^{L, N}$ & $\nu^{Y, T}$ & $\nu^{Y, N}$ & $\nu^{L, T}$ & $\nu^{L, N}$ \\
& $(1)$ & $(2)$ & $(3)$ & $(4)$ & $(5)$ & $(6)$ & $(7)$ & $(8)$ \\
\hline AUS & 0.487 & -0.155 & 0.058 & 0.072 & 0.669 & -0.568 & 0.035 & 0.239 \\
AUT & -0.355 & 0.223 & -0.488 & 0.601 & -0.223 & 0.185 & -0.422 & 0.485 \\
BEL & -0.116 & 0.121 & -0.246 & 0.306 & -0.095 & 0.043 & -0.502 & 0.415 \\
CAN & -1.034 & 0.944 & -0.497 & 0.516 & -1.066 & 0.976 & -0.496 & 0.442 \\
DNK & -0.769 & 0.681 & -0.311 & 0.294 & -0.725 & 0.676 & -0.224 & 0.310 \\
ESP & -0.187 & 0.389 & -0.726 & 0.532 & -0.265 & 0.320 & -0.826 & 1.015 \\
FIN & -0.809 & 0.896 & -0.648 & 0.678 & -0.688 & 0.725 & -0.530 & 0.568 \\
FRA & -0.358 & 0.409 & -0.092 & 0.123 & -0.412 & 0.338 & -0.084 & 0.076 \\
GBR & -0.459 & 0.552 & -0.928 & 0.853 & -0.756 & 0.766 & -0.839 & 0.727 \\
IRL & 0.051 & -0.072 & 0.002 & -0.114 & -0.021 & -0.077 & 0.085 & -0.242 \\
ITA & -0.598 & 0.505 & -0.141 & 0.168 & -0.624 & 0.517 & -0.182 & 0.248 \\
JPN & -0.960 & 0.894 & -0.730 & 0.923 & -1.060 & 0.730 & -0.968 & 1.076 \\
NLD & -0.184 & 0.218 & -0.090 & -0.093 & -0.212 & 0.202 & -0.074 & -0.075 \\
NOR & 0.027 & 0.092 & -0.082 & 0.161 & 0.233 & -0.193 & -0.065 & 0.136 \\
SWE & -0.692 & 0.586 & -0.457 & 0.412 & -0.502 & 0.566 & -0.288 & 0.264 \\
USA & -1.206 & 0.769 & -0.723 & 0.830 & -1.494 & 0.975 & -0.770 & 0.966 \\
\hline
\end{tabular}

Traded Sector

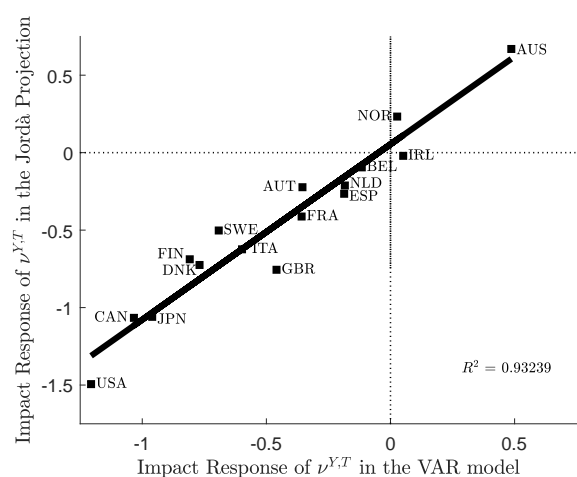

(a) Impact Response, $d \nu^{Y, T}(0)$

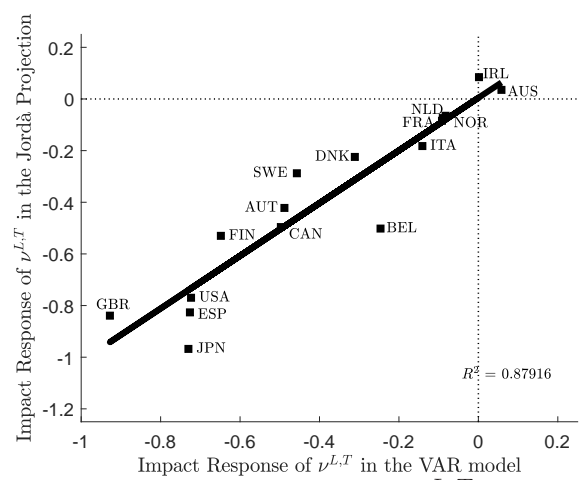

(c) Impact Response, $d \nu^{L, T}(0)$
Non Traded Sector

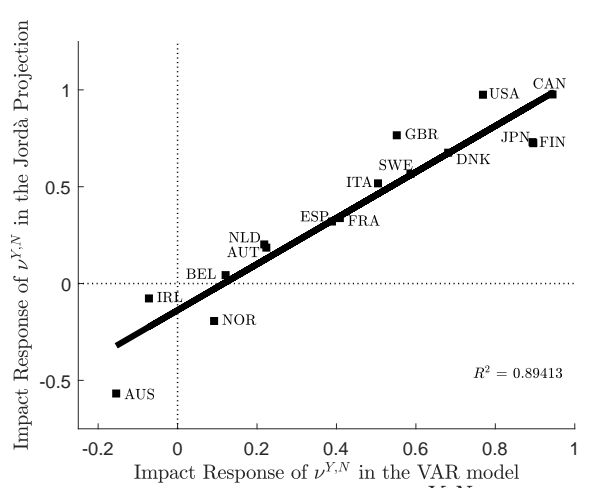

(b) Impact Response, $d \nu^{Y, N}(0)$

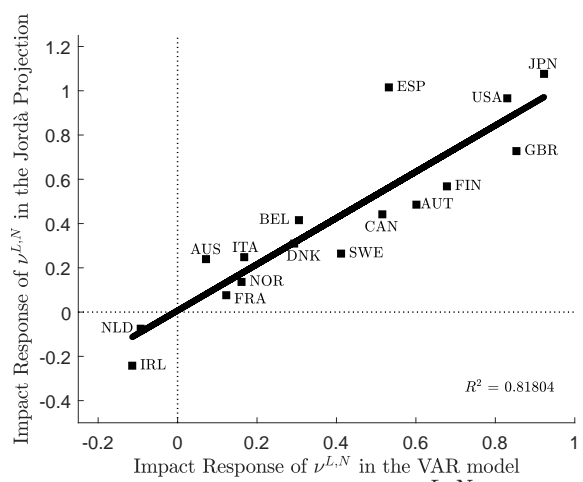

(d) Impact Response, $d \nu^{L, N}(0)$

Figure 12: Impact Responses of Sectoral Output and Labor Shares: VAR vs. Local Projection Method. Notes: Figure 12 plots impact (i.e., at time $t=0$ ) responses obtained when adopting a VAR approach (horizontal axis) against those estimated by adopting a two-step approach in which the second step consists in estimating eq. (69) (vertical axis). Sample: 16 OECD countries, 1970-2007, annual data.

analysis would therefore undermine the quantitative analysis because the slopes by construction should be identical. 


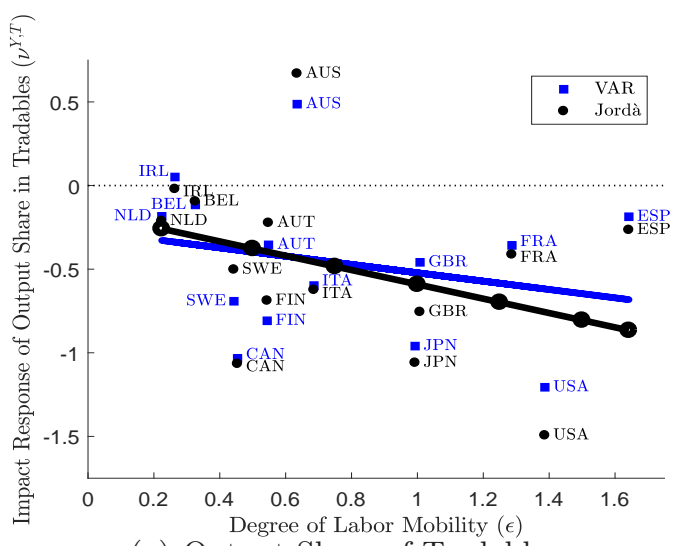

(a) Output Share of Tradables

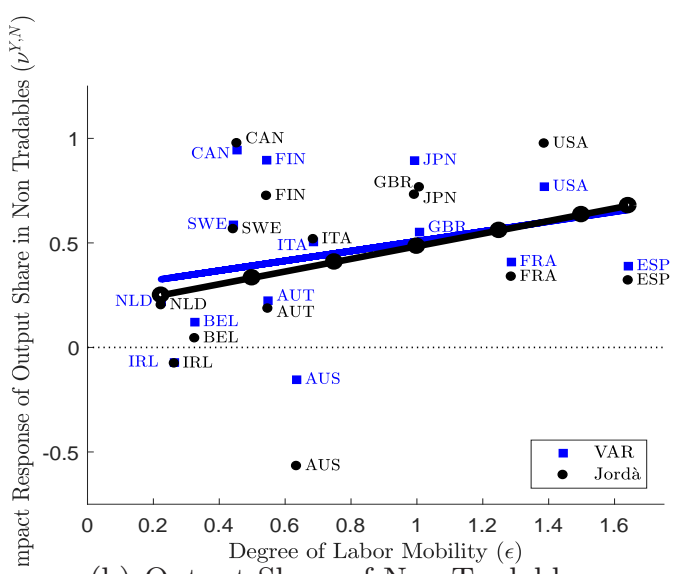

(b) Output Share of Non Tradables

Figure 13: Cross-Country Relationship from VAR estimates against Cross-Country Relationship from Local Projection Estimates. Notes: Horizontal axes display panel data estimates of the elasticity of labor supply across sectors, $\epsilon$, taken from the last column of Table 4, which captures the degree of labor mobility across sectors. Vertical axes report impact responses from the VAR model (blue squares) and those from the local projection method (black circles). The solid blue line shows the cross-country relationship from VAR estimates whilst the solid black line with circles displays the cross-country relationship from local projection estimates.

\section{E VAR Evidence: Robustness Check}

The main obstacle in empirical fiscal policy analysis is to identify exogenous and unexpected fiscal events. Following Blanchard and Perotti [2002], identification of fiscal shocks is based on the assumption that government spending does not react contemporaneously to other variables included in the VAR model. Since there are some delays inherent to the legislative system, this is a natural assumption when using quarterly data. However, this argument may not necessarily be true when using annual data since some adjustment could be possible. Another concern is related to the presence of anticipation effects. As argued by Ramey [2011], Blanchard and Perotti's [2002] approach to identifying government spending shocks in VAR models may lead to incorrect timing of the identified fiscal shocks. If the fiscal shock is anticipated in advance, agents may have modified their decisions before the rise in government spending actually materializes. Consequently, when the fiscal shock is anticipated, and thus VAR approach captures the shocks too late, it misses the initial changes in variables that occur as soon as the news is learned. We conduct below a number of robustness checks to investigate whether our empirical strategy is subject to endogeneity or anticipation issues. Finally, we address a potential concern related to the fact that various VAR models could identify different structural government spending shocks.

\section{E.1 Endogeneity Issue}

In the main text, we identify fiscal shocks by adopting the SVAR methodology pioneered by Blanchard and Perotti [2002]. Like the authors, we base the identification scheme on the assumption that discretionary government spending is subject to certain decision and/or implementation lags that prevent government spending from responding to current output developments. The advantage of the Blanchard and Perotti's approach over the first approach by Ramey and Shapiro [1998] is that it can be implemented for a large set of countries. However, the potential drawback is that we use annual data instead and thus the Blanchard and Perotti identifying assumption is somewhat less natural in our case. In order to address this potential endogeneity issue, we alternatively used narratively-identified government spending shocks from the dataset constructed by Guajardo, Leigh, and Pescatori [2014] who do not consider war times but rather identify unexpected changes in government spending directly from historical policy documents. Reassuringly, we find that both methodologies lead to the same results, in particular the share of non tradables increases substantially.

Before discussing the results from the narrative approach, it is worth mentioning that we conducted alternative robustness checks. Following Beetsma and Giuliodori [2011], for the largest available subset of the countries in our current sample, we estimate the same VAR model on a quarterly basis, assuming that government purchases take at least one quarter to react to an output shock. We find that the dynamic responses of government spending along with the remaining aggregate variables included in the VAR model are similar to those when estimating the same VAR model on annual data. To deal further with the potential endogeneity problem, like Beetsma and 


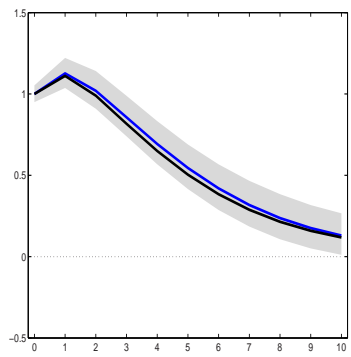

(a) VAR Model with $J E$

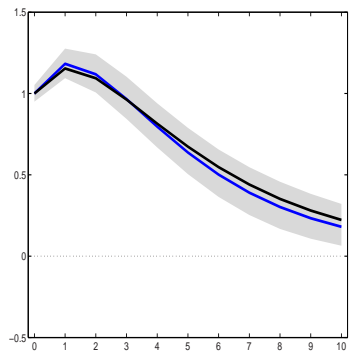

(e) VAR model with $\nu_{Y}^{T}$

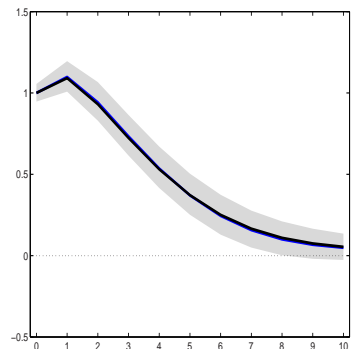

(b) VAR model with $C A$

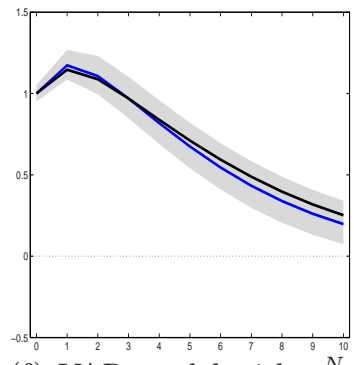

(f) VAR model with $\nu_{Y}^{N}$

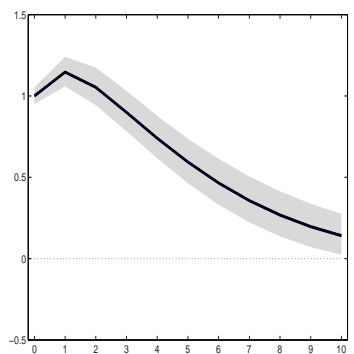

(c) VAR model with $Y^{T}$

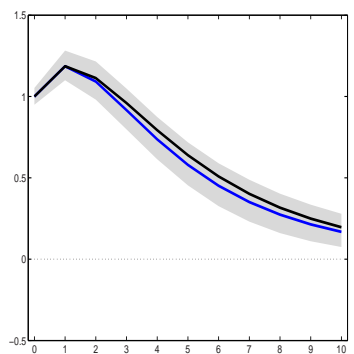

(g) VAR model with $P$

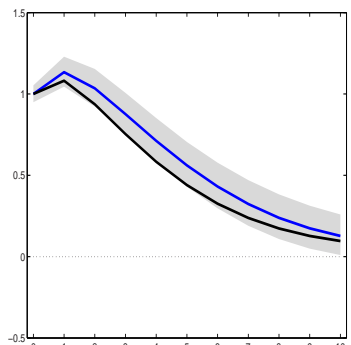

(d) VAR model with $Y^{N}$

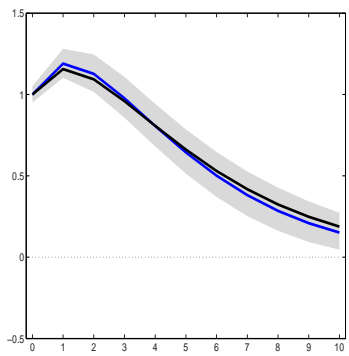

(h) VAR model with $\Omega$

Figure 14: Impulse Response Functions for Government Spending across VAR specifications when $G$ is Ordered Last in the VAR Model. Notes: Exogenous increase in government consumption by $1 \%$ of GDP. Results for baseline specification, i.e., $G$ is ordered first in the VAR model, are displayed by solid blue lines with the shaded area indicating 90 percent confidence bounds obtained by bootstrap sampling; the black line reports results for a VAR model in which $G$ is ordered last; sample: 16 OECD countries, 1970-2007, annual data.

Giuliodori [2011] and Brückner and Pappa [2012], we also order government purchases last in the VAR model and thus alow for $G$ to respond to all variables included in the VAR model. If the endogenous response of $G$ to an exogenous fiscal shock is similar to that when the VAR is estimated by ordering $G$ first, then we can be confident that the endogeneity problem is mitigated as $G$ is not or at least little responsive to output shocks. As displayed in Figure 14, the endogenous response of $G$ lies within the confidence bounds of the primary VAR model where $G$ is ordered first across all VAR specifications. This finding could be explained by the fact that automatic stabilizers which operate through unemployment benefits or transfers should not pose a problem, since we consider government spending net of transfers. Finally, Born and Müller [2012] test whether annual government spending is predetermined conditional on being predetermined at the quarterly frequency for four countries, i.e., United States, United Kingdom, Canada, and Australia. Their main result is that the restriction that government spending does not respond to other variables in the VAR within a year cannot be rejected.

An alternative estimation strategy is suggested by Ramey and Shapiro [1998]. Their narrative approach amounts to considering major political events which led to large military buildups associated with significant increases in government spending. The advantage of the narrative approach over alternatives is that political events are arguably exogenous (with respect to economic conditions) and thus identified government spending shocks are not subject to the potential endogeneity problem. To further explore the potential endogeneity problem empirically, we use a dataset constructed by Guajardo, Leigh, and Pescatori [2014]. Our objective is to investigate whether our main conclusions hold when adopting an alternative identification method. Using a narrative approach. Guajardo, Leigh, and Pescatori [2014] identify changes in fiscal policy directly from historical documents. More precisely, the dataset contains 173 fiscal policy changes for 17 OECD countries over the period 1978-2009. In order to make our results when adopting the 'event' approach comparable with our evidence obtained by adopting the Blanchard and Perotti's [2002] identifying assumption, we restrict the set of countries to 15 and the period to 1978-2007. We then estimate the same VAR models described in section 2 in the main text. ${ }^{67}$ We augment each VAR model with identified fiscal events (ordered first in the VAR specification) corresponding to changes in government spending, i.e. 'spending-based' events.

While our results obtained by adopting Blanchard and Perotti's [2002] identifying assumption are broadly in line with those obtained with the narrative approach, we may nevertheless note some differences. Before discussing these differences, it is worth mentioning that Guajardo, Leigh, and Pescatori [2014] identify cases of fiscal consolidation motivated by a desire to reduce the budget deficit. To be consistent with the objective of our paper, we concentrate on episodes of fiscal

\footnotetext{
${ }^{67}$ We exclude DEU and PRT which are not included in our empirical study while NOR is removed from our sample.
} 


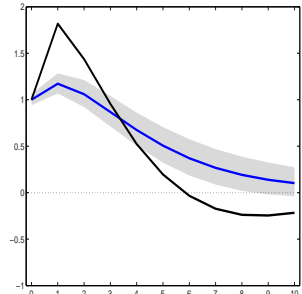

(a) Gov. spending

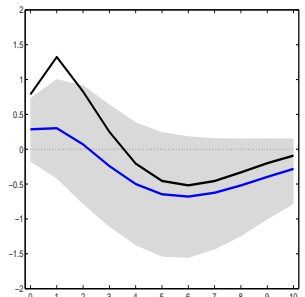

(e) $Y$

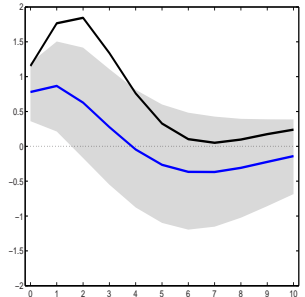

(i) $L$

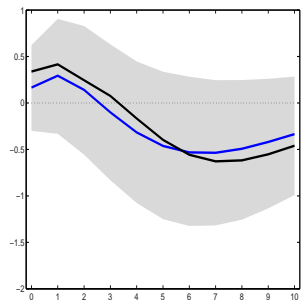

(m) $W / P_{C}$

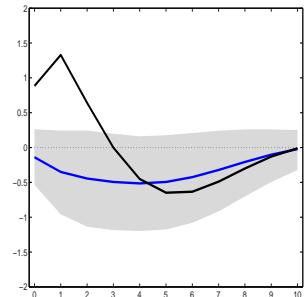

(q) Investment

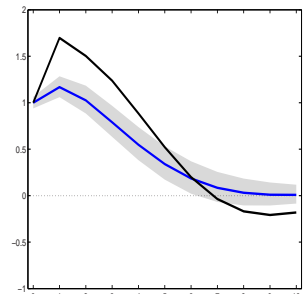

(b) Gov. spending

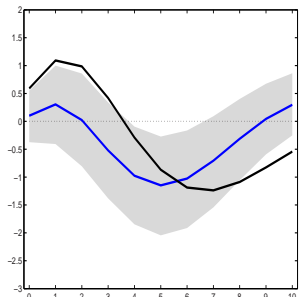

(f) $Y$

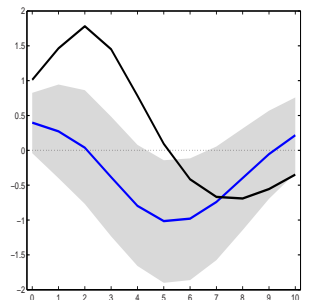

(j) $L$

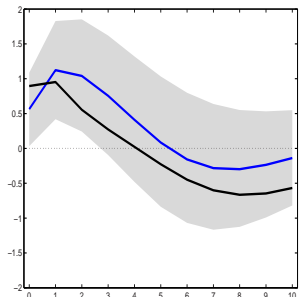

(n) $W / P_{C}$

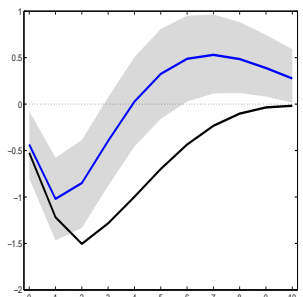

(r) Current Account

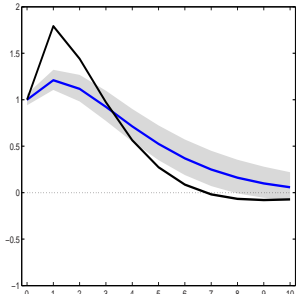

(c) Gov. spending

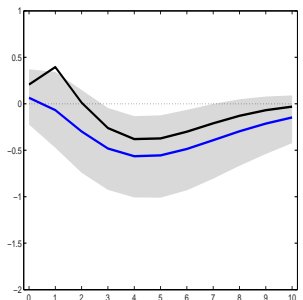

(g) $Y^{T}$

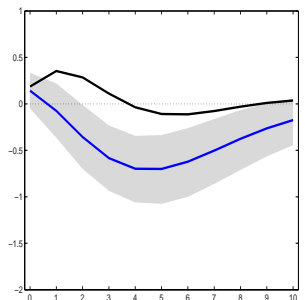

(k) $L^{T}$

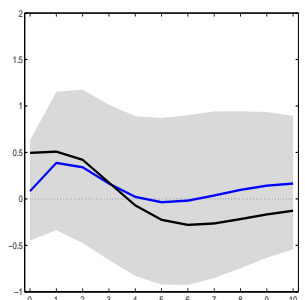

(o) $W^{T} / P_{C}$

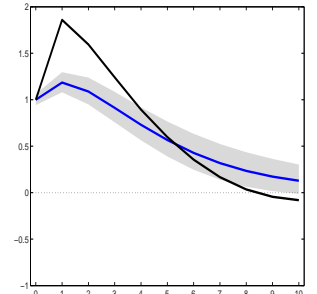

(d) Gov. spending

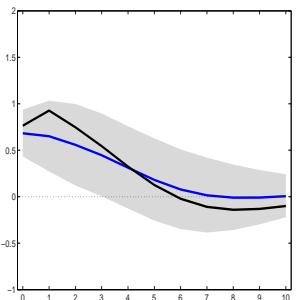

(h) $Y^{N}$

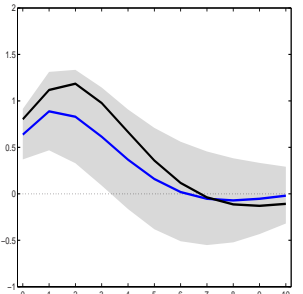

(l) $L^{N}$

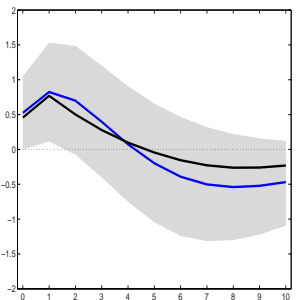

(p) $W^{N} / P_{C}$

Figure 15: Contrasting Aggregate and Sectoral Effects of an Unanticipated Government Spending Shock between Alternative Identification Schemes of Government Spending Shock. Notes: Exogenous increase in government consumption by $1 \%$ of GDP. In the baseline case, government spending shocks are identified by assuming that government spending is predetermined relative to the other variables in the VAR model. Results for the baseline case are displayed by solid blue lines with the shaded area indicating 90 percent confidence bounds obtained by bootstrap sampling; the solid black line reports results for narratively-identified government spending shocks from the dataset constructed by Guajardo, Leigh, and Pescatori [2014]; sample: 15 OECD countries, 1978-2007, annual data. 


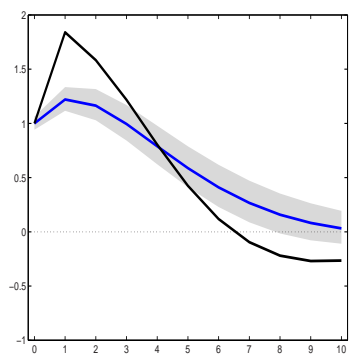

(a) Gov. spending

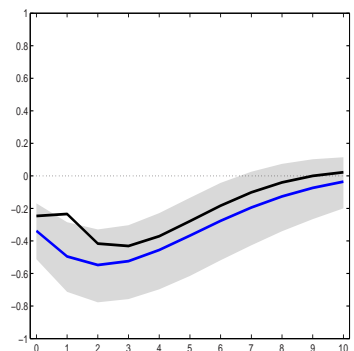

(e) $Y^{T} / Y$

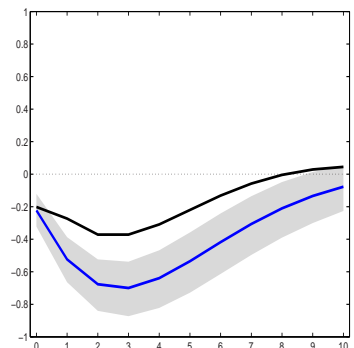

(i) $L^{T} / L$

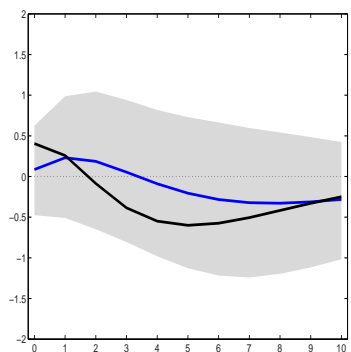

(m) $W^{T} / P_{C}$

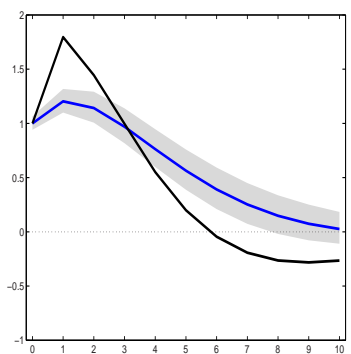

(b) Gov. spending

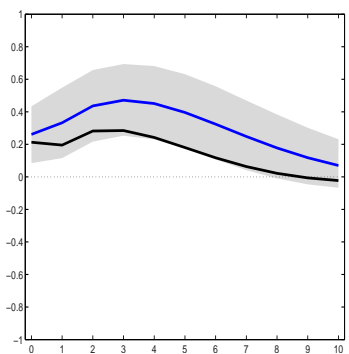

(f) $Y^{N} / Y$

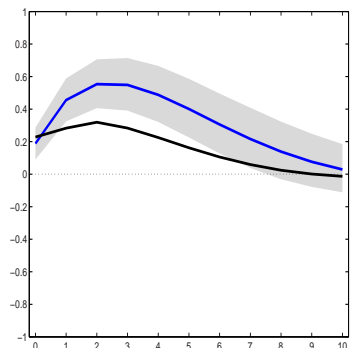

(j) $L^{N} / L$

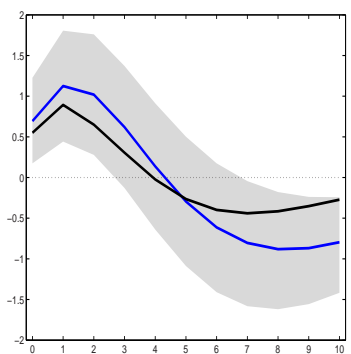

(n) $W^{N} / P_{C}$

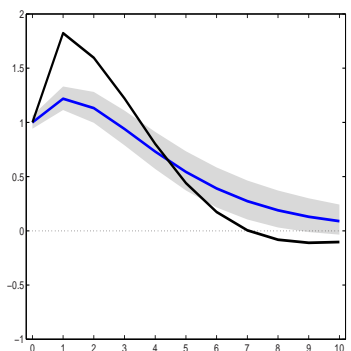

(c) Gov. spending

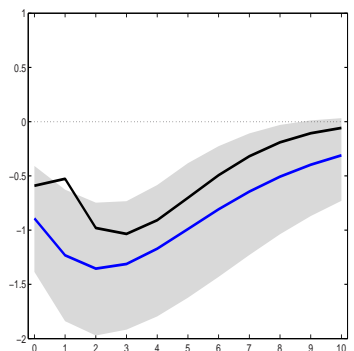

(g) $Y^{T} / Y^{N}$

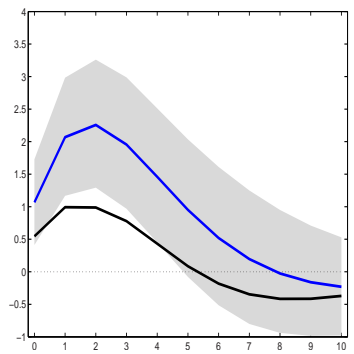

(k) $P$

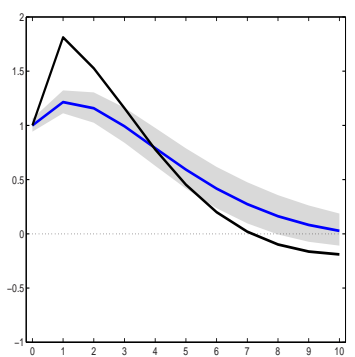

(d) Gov. spending

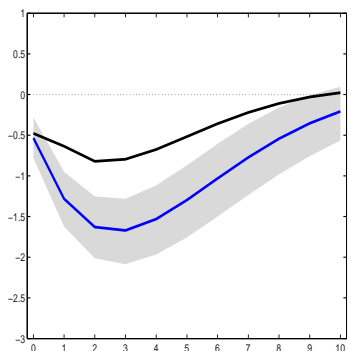

(h) $L^{T} / L^{N}$

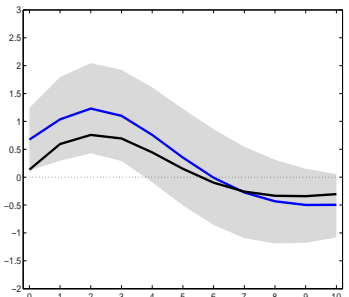

(l) $\Omega$

Figure 16: Contrasting Sectoral Composition Effects of an Unanticipated Government Spending Shock between Alternative Identification Schemes of Government Spending Shock. Notes: Exogenous increase in government consumption by $1 \%$ of GDP. In the baseline case, government spending shocks are identified by assuming that government spending is predetermined relative to the other variables in the VAR model. Results for the baseline case are displayed by solid blue lines with the shaded area indicating 90 percent confidence bounds obtained by bootstrap sampling; the solid black line reports results for narratively-identified government spending shocks from the dataset constructed by Guajardo, Leigh, and Pescatori [2014]; sample: 15 OECD countries, 1978-2007, annual data. 
consolidation implemented through changes in government spending rather than changes in tax rates. The authors find that fiscal consolidation through spending cuts gives rise to a contraction in GDP and investment. In order to be able to compare the effects of a government spending shock identified by applying Blanchard and Perotti's [2002] identification scheme with those following fiscal shocks identified by Guajardo, Leigh, and Pescatori [2014], we normalize the impulse response functions so that government consumption rises by 1 percentage point of GDP. In Figures 15 and 16 , we report aggregate and sectoral effects along with the sectoral composition effects. Results for the 'event' study are displayed in the solid black line while the solid blue line shows results for the baseline case in which government spending shocks are identified by applying Blanchard and Perotti's [2002] method.

Differences in responses of aggregate variables. As displayed in the first row of Figure 15, while the shape of endogenous responses of government spending is similar, the fiscal shock displays less persistence over time in the 'event' approach and is greater in the short-run; more precisely, we observe that increases in government spending over the first two years are more pronounced, while $G$ is restored back toward its initial level more rapidly. In addition, in most of the cases, we observe a spending reversal which echoes Corsetti et al. [2012]; the magnitude of the cut in government spending during the reversal period (after 5 years approximately) is moderate though. Inspection of the dynamic effects of a government spending shock shows that the responses of aggregate variables are qualitatively similar whether the fiscal shock is identified by applying Blanchard and Perotti's [2002] method or by using an 'event' approach, except for investment. More precisely, while a rise in government spending increases both real GDP and hours worked and leads to a decline in the current account, we detect a significant increase in investment on impact in the 'event' approach, while investment declines gradually in the baseline case. We may also note some differences quantitatively, as real GDP and hours worked increase more in the 'event' approach than in the baseline case while the current account deficit is more pronounced. This result is not surprising since the government spending shock is more pronounced in the short-run.

Differences in responses of sectoral variables. The last two columns of Figure 15 show the responses of sectoral labor and output, while Figure 16 displays the dynamic adjustment of sectoral shares along with the responses of the relative price and relative wage of non tradables. As can be seen in the last two columns of Figure 15, hours worked in the traded sector increase in the 'event' study while traded output rises in the short-run. Because the rise in government spending is more pronounced in the 'event' study, we also find empirically that labor and output in the non traded sector increase by a larger amount. While we detect a positive impact on traded output in the short run, the first column of Figure 16 shows that the share of tradables, whether measured in total employment or real GDP, declines after a fiscal shock. As can be seen in the first two columns of Figure 16, the responses of sectoral output shares are somewhat less pronounced in the 'event' study but lie within the confidence bounds of the baseline case. As displayed in the last two columns of Figure 16, hours worked and output in the traded sector falls relative to the non traded sector. Yet, the decline is much less pronounced than that in the baseline case. Moreover, both the relative price and the relative wage of non tradables appreciate by a smaller amount.

In sum, whether we consider a narrative approach or Blanchard and Perotti's [2002] identification scheme, all our results hold qualitatively, except for investment which is found to be crowded-in in the former approach. As mentioned above, we may notice some quantitative differences though. In particular, we find empirically that the rise in government spending has an expansionary effect on non traded output relative to traded output which is somewhat less pronounced in the 'event' study. In addition, the government spending shock gives rise to a positive response of traded output on impact and a contraction in the medium-run only.

How can the discrepancy between the two approaches be rationalized? Because the appreciation in the relative price of non tradables along with the decline in traded output relative to non traded output are less pronounced when using narratively-identified government spending shocks, it seems reasonable to conjecture that changes in government spending identified by Guajardo, Leigh, and Pescatori [2014] are somewhat less biased toward non tradables than those identified by applying Blanchard and Perotti's [2002] method. This conjecture could provide an explanation to the mitigated responses of sectoral output and sectoral labor shares to narratively-identified government spending shocks. Furthermore, a relatively less intensive non traded sector in the government spending shock could rationalize the increase in investment expenditure in the short-run in the event approach. The reason is that the relative price of non tradables appreciates less which results in a much smaller increase in the investment price index. The rise in the shadow value of capital, $Q$, could thus offset the smaller increase in the investment price index, $P_{J}$. A second potential cause of the discrepancy between the results obtained in the narrative approach and those obtained by applying Blanchard and Perotti's [2002] identification scheme could be based on the change in public investment. It may be possible that narratively-identified fiscal shocks are associated with changes in public investment. 


\section{E.2 Anticipation Issue}

We address a major concern regarding the evidence on fiscal transmission we document in the main text due to anticipation effects. We conduct below an investigation of the potential presence of anticipation effects, using alternative measures of forecasts for government spending. The former measure was provided by Born, Juessen and Müller [2013] and stems from the OECD, while the latter measure is taken from a dataset constructed by Fioramanti et al. [2016] where forecasts are performed by the European Commission. We use two alternative datasets as the former contains observations from 1986 to 2007 for all countries, while the latter provides a longer time horizon for a restricted set of countries. As is common in the literature, we alternatively include forward-looking variables like stock prices into the VAR model in order to control for potential fiscal foresight. We first summarize our main results. First, we run Granger-causality tests and do not find that fiscal forecasts have any predictive power for our identified government spending shocks. Second, our main results are not altered by the inclusion of forecasts for government spending. We detect some differences quantitatively however, when we include the OECD forecast for spending growth in the VAR model. More precisely, when we control for anticipation effects, the responses of sectoral output shares are more pronounced, while the appreciation in the relative price and the relative wage of non tradables are somewhat more muted.

Drawing on previous studies, we conduct three robustness exercises to explore the potential implications of anticipations effects:

- Like Beetsma and Giuliodori [2011], we run Granger-causality tests in order to investigate whether fiscal forecasts have any predictive power for the identified government consumption shocks.

- A second way to deal with the complications of possibly anticipated government spending shocks is to augment the VAR specification with the forecasts for government spending, see Beetsma and Giuliodori [2011], Born, Juessen and Müller [2013].

- A third route followed by Beetsma and Giuliodori [2011], Brückner and Pappa [2012] is to augment the baseline VAR specification with forward-looking variables such as short-term interest rates, the log of the GDP deflator, stock prices, or oil prices in order to control for fiscal-foresight effects.

In the following, we conduct an investigation of the potential presence of anticipation effects by performing the three robustness exercises mentioned above. To perform the first robustness exercise, we use a dataset constructed by Born, Juessen and Müller [2013] that contains time series for forecasts for government spending from the OECD. ${ }^{68}$ Since the OECD prepares forecasts in June and December for each year, the dataset contains semi-annual observations for the period running from 1986 to 2011. To investigate the extent to which evidence on fiscal transmission can be affected by anticipation effects, we use the December forecasts. Data are available over the period 1986-2007 for CAN, FRA, GBR, ITA, JPN and USA, 1997-2007 for AUS, BEL, DNK, ESP, FIN, IRL, NLD, NOR, SWE and 1997-2004 for AUT. We denote $f c_{t}^{t+1}$ the period-t forecast of the growth rate of government spending for the next year $t+1$.

Granger-causality tests. Before exploring the VAR model augmented with forecasts for government spending empirically, we first test whether the anticipation problem is relevant in our annual VAR. We run a Granger-causality test (see Table 8). In particular, we test whether fiscal forecasts $f c_{i t}^{t+1}$ have any predictive power for the government spending shocks estimated from our benchmark model $z_{i t}=\left[g_{i t}, y_{i t}, l_{i t}, j e_{i t}, w_{C, i t}\right]$. The results for individual countries show that, with the exception of GBR, ITA and JPN, there is no causality running from $f c_{i t}^{t+1}$ to the VAR-based government spending shocks, $\epsilon_{i, t}^{G}$, at the $5 \%$ level of significance suggesting that VAR shocks are not forecastable. For the whole sample, we find that forecasts for government spending $f c_{i t}^{t+1}$ do not Granger-cause the VAR shocks using the Cholesky decomposition to the benchmark specification $z_{i t}=\left[g_{i t}, y_{i t}, l_{i t}, j e_{i t}, w_{C, i t}\right]$.

First robustness exercise to control for potential anticipation effects. Following Born et al. [2013], we augment the four VAR specifications with the forecasts for real government spending growth (ordered after $g_{t}$ ). In order to make our evidence comparable with that without government spending forecasts, we estimate the four sets of VAR specifications over the same period, i.e., from 1986 to 2007.

Figures 17 and 18 show IRF when augmenting each baseline VAR specification with forecasts for government spending. The solid blue line reports the results for the baseline case without forecasts for government spending growth, while the solid black line displays the results for the VAR model augmented with forecasts. In both cases, the VAR model is estimated over the period running from 1986 to 2007. Overall, it turns out that differences are rather moderate and anticipation effects thus play a limited quantitative role in the dynamic adjustment to a government spending shock.

${ }^{68}$ We thank Born, Juessen and Müller [2013] for providing this dataset to us. 
Table 8: Granger Causality Tests (p-values)

\begin{tabular}{|c|c|c|c|}
\hline Country & p-value & Country & p-value \\
\hline AUS & 0.545 & GBR & 0.042 \\
\hline $\mathrm{AUT}$ & 0.090 & IRL & 0.752 \\
\hline BEL & 0.884 & ITA & 0.017 \\
\hline $\mathrm{CAN}$ & 0.218 & JPN & 0.000 \\
\hline DNK & 0.617 & NLD & 0.723 \\
\hline ESP & 0.532 & NOR & 0.905 \\
\hline FIN & 0.817 & SWE & 0.761 \\
\hline FRA & 0.073 & USA & 0.884 \\
\hline Whole Sample & 0.258 & & \\
\hline
\end{tabular}

Yet, some differences can be noticed. Once anticipation effects are controlled for, the rise in hours worked displays more persistence and is more in line with what we obtained numerically. In this regard, this conclusion squares well with evidence documented by Born et al. [2013], except that the authors detect a smaller increase in real GDP when anticipation effects are not controlled for, while this finding applies to hours worked in our case as differences in the dynamic effects for real GDP are almost insignificant quantitatively. Likewise, impact responses of sectoral outputs are also very similar to impact effects computed numerically once the VAR model is augmented with forecasts for government spending. Some slight differences can be noticed, however. The decline in empirically-estimated traded output is found to be more pronounced while the increase in non traded output is slightly smaller. We may also note that the reallocation effects are slightly greater as changes in sectoral shares in real GDP are somewhat more pronounced while the relative wage of non tradables increases less than in the baseline case. However, the responses of the sectoral shares in labor, $L^{j} / L$, are merely affected once the anticipation effects are controlled for.

Second and third robustness exercise to control for potential anticipation effects. As emphasized above, to ensure that our results are not subject to the fiscal foresight problem, we carry out a number of robustness exercises by augmenting the baseline VAR model with forward-looking variables along the lines of Beetsma and Giuliodori [2011], and Bruckner and Pappa [2012]. Since one major contribution in this paper is to shed some light on the reallocation effects of a government spending shock, we restrict attention to the dynamic responses of the sectoral shares. Columns 1 and 2 of Figure 19 show results when augmenting the baseline VAR model with the forecast for the budget balance-GDP ratio which we denote by $b b r_{t}^{t+1}$. The year-ahead forecasts are taken from the Commission's Fall forecasts, which are published in November. In terms of VAR specifications shown above, we replace $f c_{t}^{t+1}$ with $b b r_{t}^{t+1}$. It is worth mentioning that Beetsma and Giuliodori [2011] find empirically that the balance-ratio forecast has strong predictive power for $g_{t}$. Time series for the general government balance to GDP ratio forecast (one year ahead) are available for BEL (1971-2007), DNK (1977-2007), ESP (1987-2007), FRA (1970-2007), GBR (1974-2007), IRL (19742007), ITA (1970-2007), NLD (1970-2007). The impulse response functions shown in the solid black line, reported in columns 1-2 of Figure 19, are similar, if not identical, to those under the baseline shown in the solid blue line and thus do not deserve more comments. As an additional, and final, test we augment the baseline model with the log of nominal stock prices denoted by $p s_{t}$. In terms of VAR specifications, we replace $f c_{t}^{t+1}$ with $s p_{t}$ as this variable captures information about the future effects of fiscal shocks. Time series for stock prices are taken from OECD Main Economic Indicators. Data are available over 1970-2007 for AUS, AUT, CAN, FIN, FRA, GBR, IRL, ITA, JPN, NLD, SWE and USA, 1983-2007 for DNK, 1985-2007 for ESP and 1986-2007 for BEL and NOR. Again, the discrepancy in the estimated responses is quite moderate.

To conclude, we do not find that OECD forecasts of government spending predict our identified government spending shocks. Next, in estimating the fiscal shock and reducing potential fiscalforesight problems, we augment each VAR model with OECD or European Commission forecasts in order to control for anticipated changes in government spending. It turns out that fiscal foresight has little impact on our findings.

\section{E.3 Identified Government Spending Shocks across Alternative VAR Spec- ifications}

We address a potential concern related to the fact that the government spending shock may display noticeable differences across alternative VAR specifications. Such differences could potentially make the comparison of the effects of a government shock across sectors difficult. Because in the quanti- 


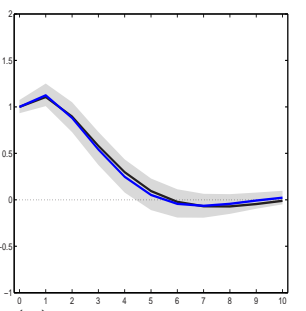

(a) Gov. spending

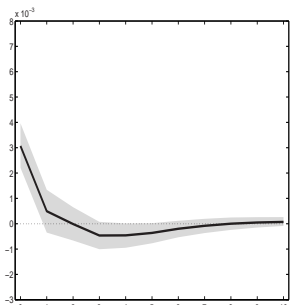

(e) Forecasts

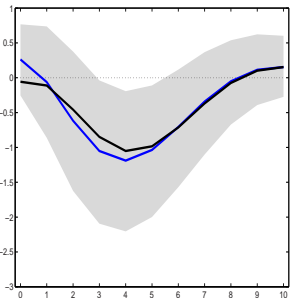

(i) $Y$

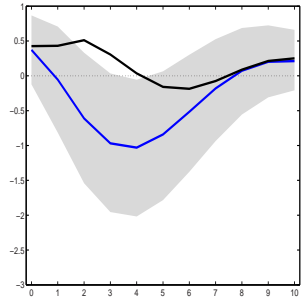

(m) $L$

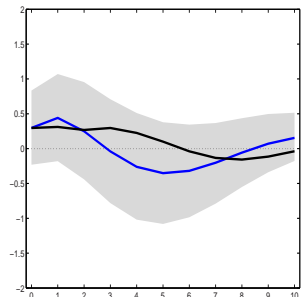

(q) $W / P_{C}$

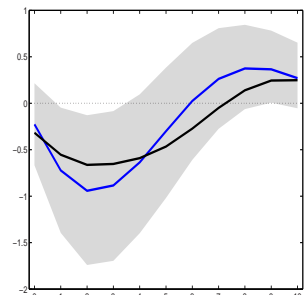

(u) Investment, $J E$

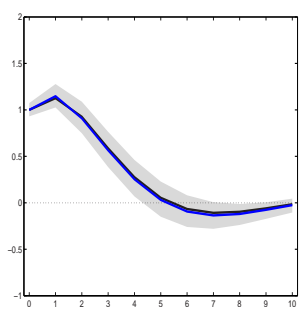

(b) Gov. spending

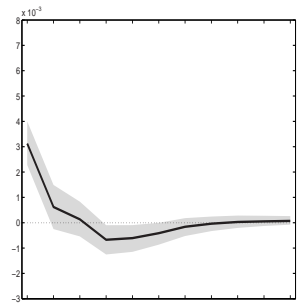

(f) Forecasts

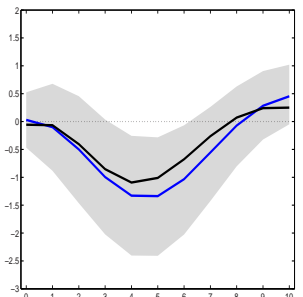

(j) $Y$

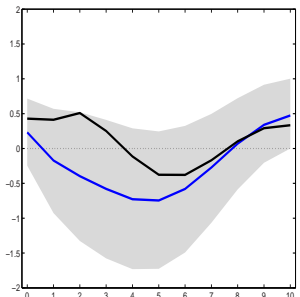

(n) $L$

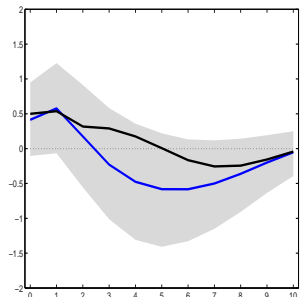

(r) $W / P_{C}$

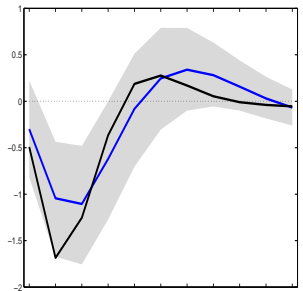

(v) Current Account

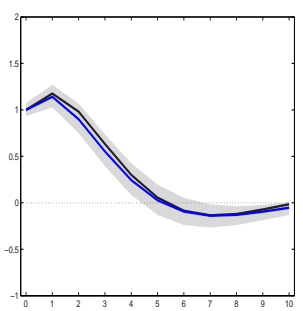

(c) Gov. spending

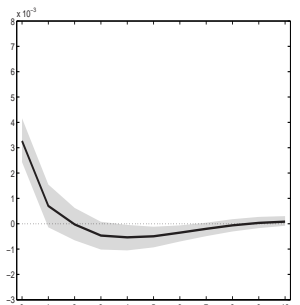

(g) Forecasts

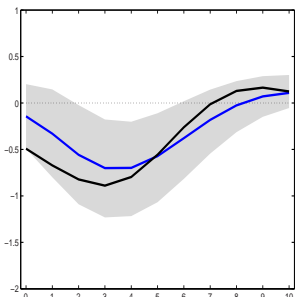

(k) $Y^{T}$

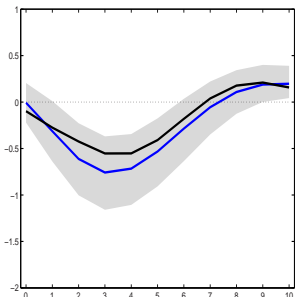

(o) $L^{T}$

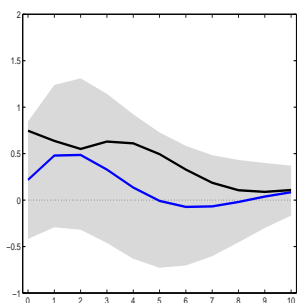

(s) $W^{T} / P_{C}$

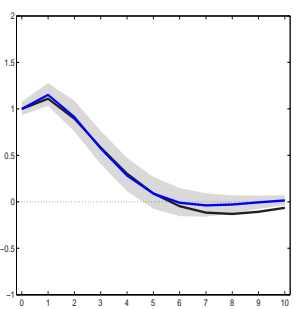

(d) Gov. spending

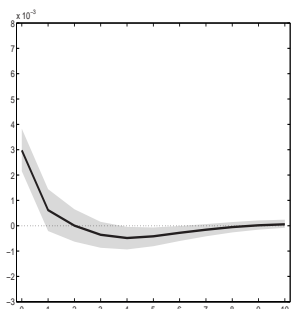

(h) Forecasts

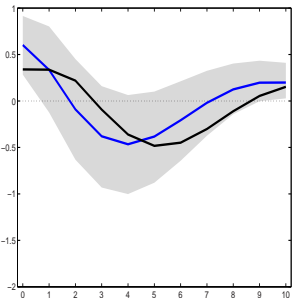

(1) $Y^{N}$

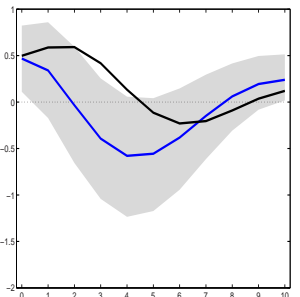

(p) $L^{N}$

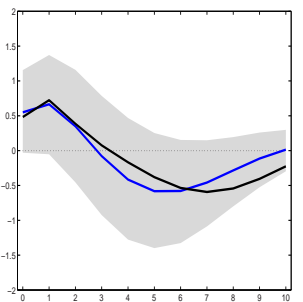

(t) $W^{N} / P_{C}$

Figure 17: Aggregate and Sectoral Effects of an Unanticipated Government Spending Shock: Anticipation Effects. Notes: Exogenous increase in government consumption by $1 \%$ of GDP. Baseline sample: 16 OECD countries, 1986-2007. Solid blue line: Results for baseline case without controlling for anticipation effects; the shaded area indicates the 90 percent confidence bounds obtained by bootstrap sampling; the solid black line reports the results from estimates of VAR models with forecast of government spending growth (ordered after $g_{t}$ ). 


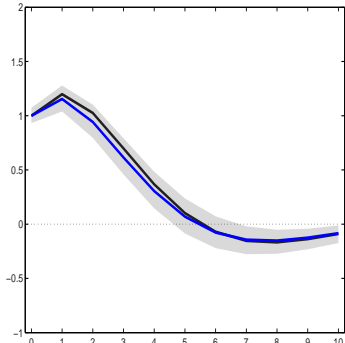

(a) Gov. spending

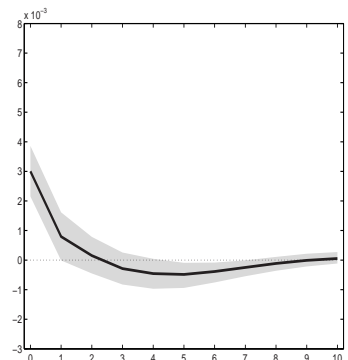

(e) Forecasts

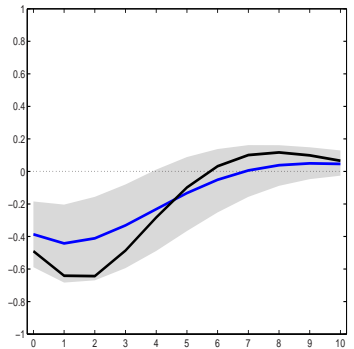

(i) $Y^{T} / Y$

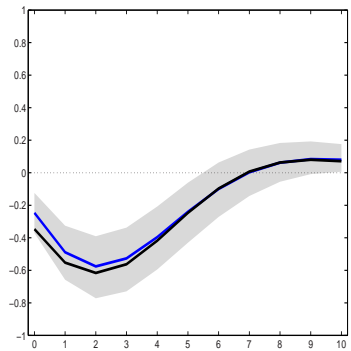

(m) $L^{T} / L$

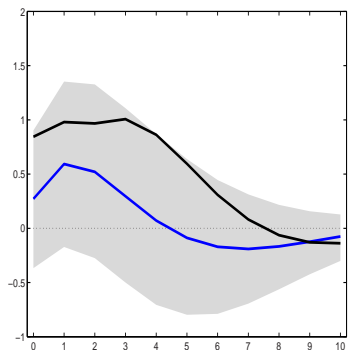

(q) $W^{T} / P_{C}$

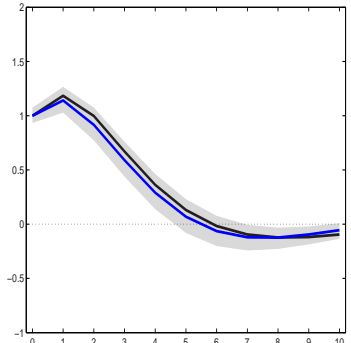

(b) Gov. spending

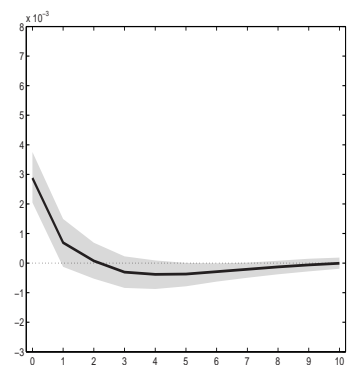

(f) Forecasts

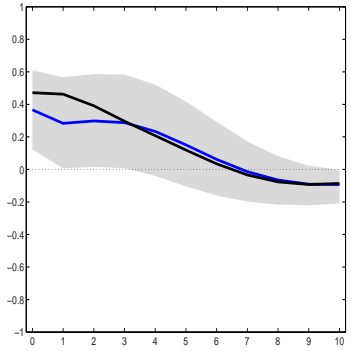

(j) $Y^{N} / Y$

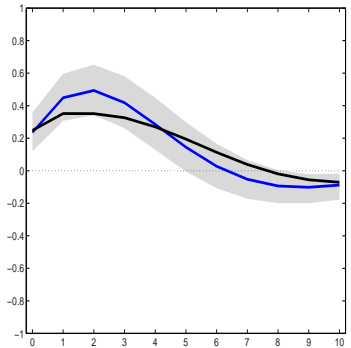

(n) $L^{N} / L$

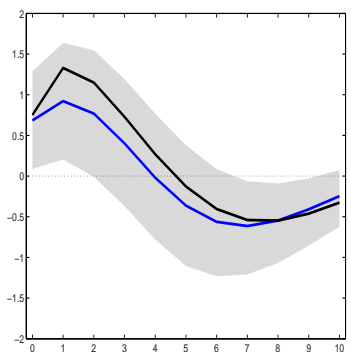

(r) $W^{N} / P_{C}$

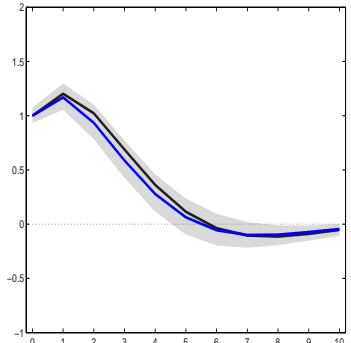

(c) Gov. spending

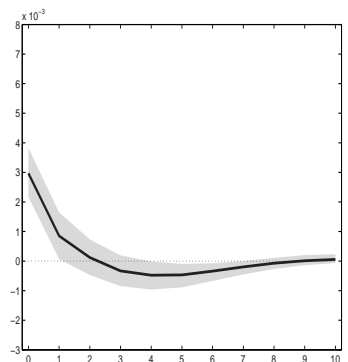

(g) Forecasts

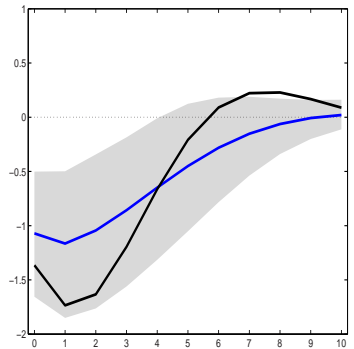

(k) $Y^{T^{5}} / Y^{N}$

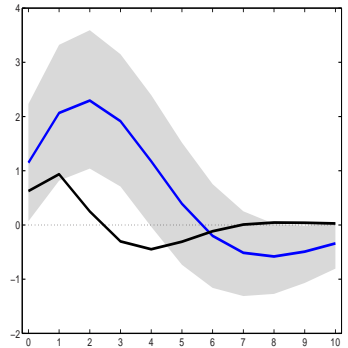

(o) $P^{6}$

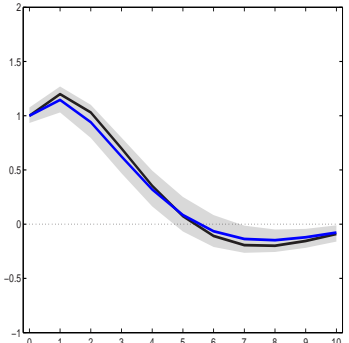

(d) Gov. spending

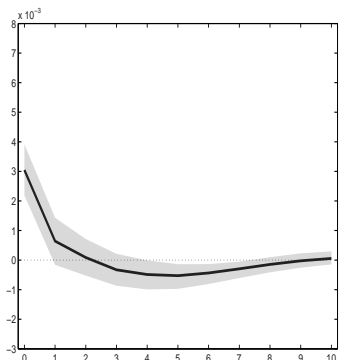

(h) Forecasts

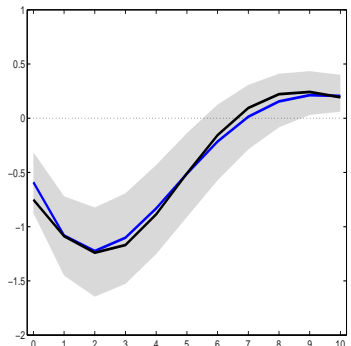

(l) $L^{T} / L^{N}$

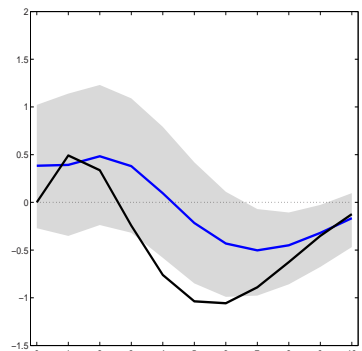

$(\mathrm{p})^{5} \Omega^{6}$

Figure 18: Sectoral Composition Effects of an Unanticipated Government Spending Shock: Anticipation Effects. Notes: Exogenous increase in government consumption by $1 \%$ of GDP. Baseline sample: 16 OECD countries, 1986-2007. Solid blue line: Results for baseline case without controlling for anticipation effects; the shaded area indicates the 90 percent confidence bounds obtained by bootstrap sampling; the solid black line reports the results from estimates of VAR models with forecast of government spending growth (ordered after $g_{t}$ ). 
budget balance-GDP ratio

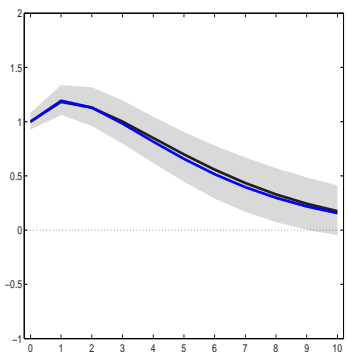

(a) Gov. spending

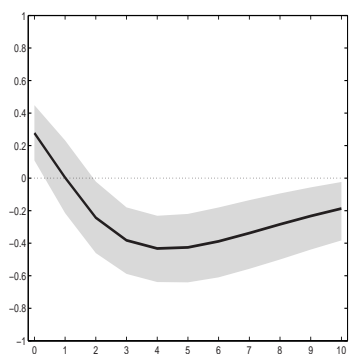

(e) Public Balance-GDP ratio forecast

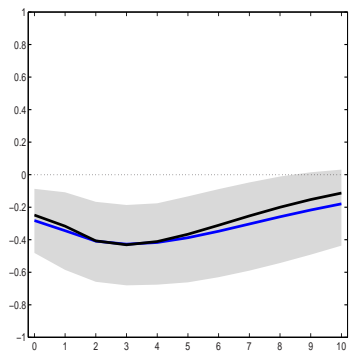

(i) $Y^{T} / Y$

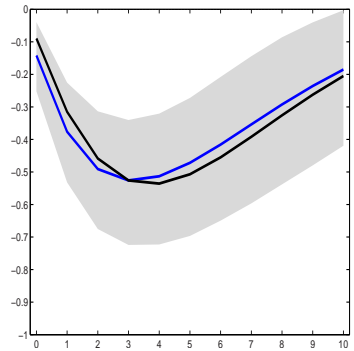

(m) $L^{T} / L$

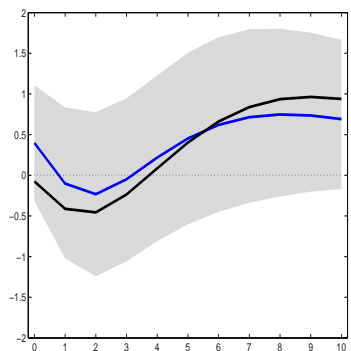

(q) $W^{T} / P_{C}$

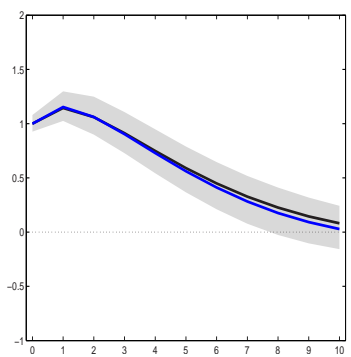

(b) Gov. spending

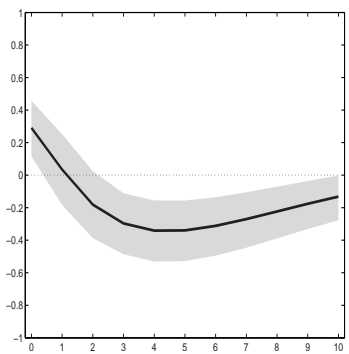

(f) Public Balance-GDP ratio forecast

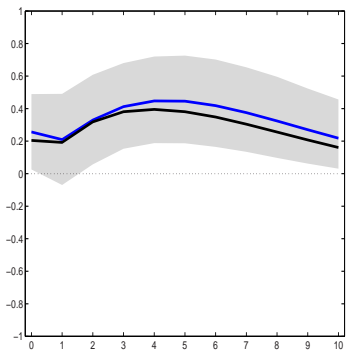

(j) $Y^{N} / Y$

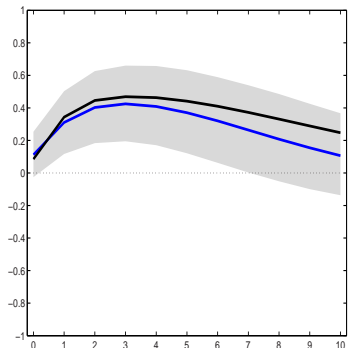

(n) $L^{N} / L$

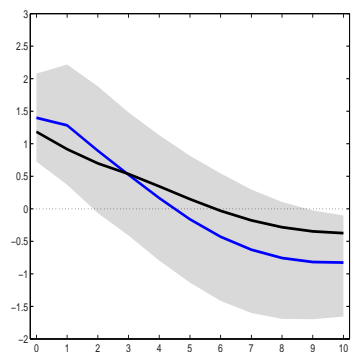

(r) $W^{N} / P_{C}$

stock prices

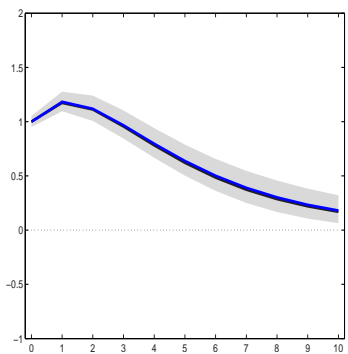

(c) Gov. spending

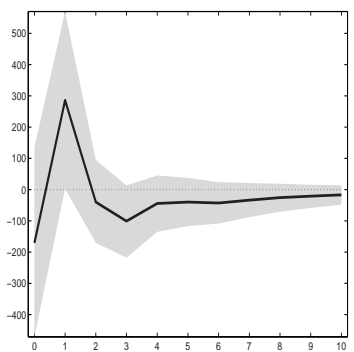

(g) Stock Price Index

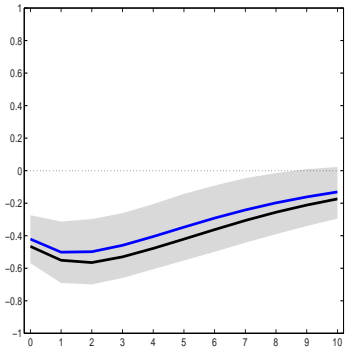

(k) $Y^{T} / Y$

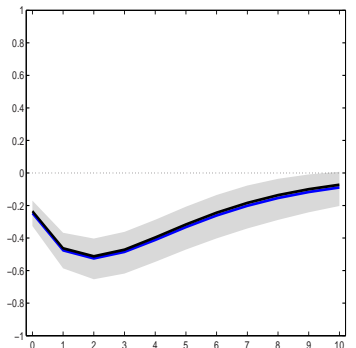

(o) $L^{T} / L$

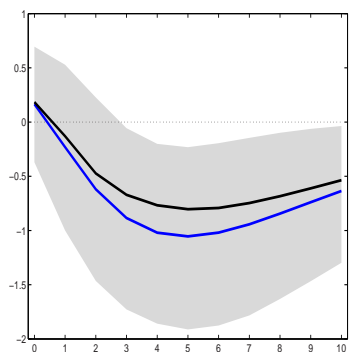

(s) $W^{T} / P_{C}$

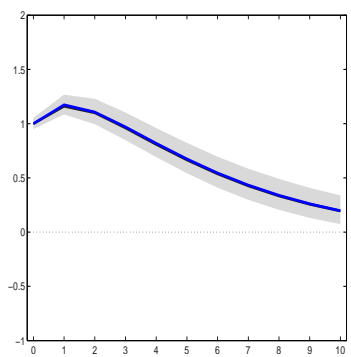

(d) Gov. spending

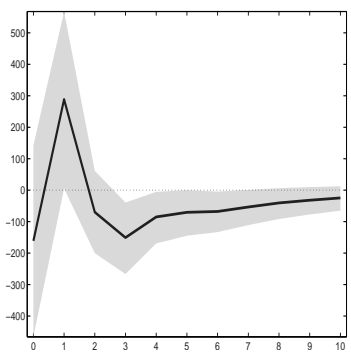

(h) Stock Price Index

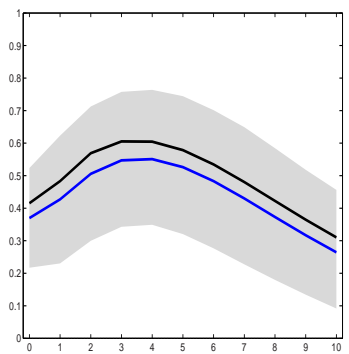

(l) $Y^{N} / Y$

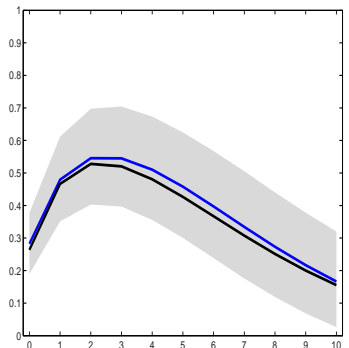

(p) $L^{N} / L$

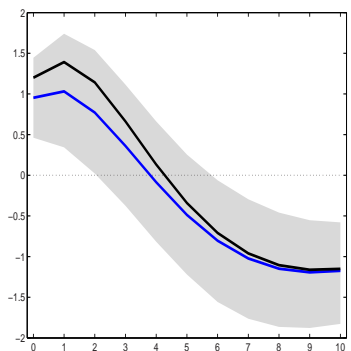

(t) $W^{N} / P_{C}$

Figure 19: Sectoral Composition Effects of an Unanticipated Government Spending Shock: Alternative Forecasts Measures and Anticipation Effects. Notes: Exogenous increase in government consumption by $1 \%$ of GDP. Baseline sample: 8 OECD countries (first two columns) and 16 OECD countries (last two columns), 1970-2007. Solid blue line: Results for the baseline case without controlling for anticipation effects; the solid black line reports the results from estimates of VAR models with balance-ratio forecast (first two columns) or stock prices (last two columns). 
tative analysis we base our calibration on one unique government spending shock, such differences could potentially undermine the comparison of theoretical with empirical responses. Before summarizing the main conclusions of robustness exercises, it is worth mentioning that, in line with the current practice, to facilitate the interpretation of our results, we normalize the impulse responses so that government consumption rises by one percentage point of GDP on impact. Such a normalization thus makes the responses of economic variables directly comparable quantitatively across VAR models. Since we base the greatest part of our analysis and discussion on impact effects, potential problems caused by differences in the government spending shock could be mitigated. However, even if the magnitude and the shape of the government spending shock is similar across VAR specifications, different VAR models could pickup different structural government spending shocks. In order to investigate the extent of the discrepancy in the estimated responses caused by potentially different government spending shocks across VAR specifications, we proceed in four stages. Reassuringly, the discrepancy in estimated responses turns out to be quite moderate in all robustness exercises.

First robustness exercise: testing for differences in endogenous responses of government spending across VAR models. A straightforward check of the extent of differences of the government spending shock across VAR specifications is performed by contrasting impulse response functions for $G$. Figure 20 compares the dynamic response of government consumption to an exogenous fiscal shock for the first VAR model with the endogenous response of $G$ for alternative VAR models. The solid blue line displays the point estimates for the first VAR model while the solid black line in each panel displays the point estimates for an alternative VAR model. All of the empirical impulse response functions for $G$, and to a lesser extent the response of $G$ we generate from estimates of the VAR model that includes the current account, lie within the $90 \%$ confidence bounds of the first IRF for $G$ for all horizons. Moreover, the test we perform indicates that the assumption that the point estimate for the response of $G$ in the first VAR model is significantly different from that for alternative VAR models is strongly rejected.

Second robustness exercise: Assessing the discrepancy caused by potentially different identified government spending shocks on annual data. We now conduct an elaborate investigation of the potential discrepancy in the estimated effects caused by considering alternative VAR models. To perform such an analysis, we proceed as follows. Once we identified the government spending shock in the first VAR model that includes private investment, $z_{i t}=\left[g_{i t}, y_{i t}, l_{i t}, j e_{i t}, w_{C, i t}\right]$, we augment each VAR model with the identified government spending shocks, ordered first, and use shocks to government spending (identified with the Cholesky decomposition) as the fiscal shock, see e.g., Ramey [2011] who adopts a similar procedure to identify military spending shocks. Then, we contrast the responses for the baseline model with those for augmented VAR models. Figures 21 and 22 compare the results in the main text displayed in the solid blue line with those for the same VAR model augmented with the identified government spending shock in the first VAR model estimated on annual data. As shown in the first row of Figures 21 and 22, across all VAR specifications, the endogenous response of government spending is quite similar, if not identical, whether the fiscal shock is identified in the first VAR model (solid black line) or is identified in the corresponding VAR model (solid blue line). The dynamic effects displayed in Figure 21 do not deserve comments as impulse response functions are very similar. Turning to the sectoral composition effects displayed in Figure 22, while we may notice some slight differences for the responses of sectoral shares, the real consumption wage in non tradables, and the relative wage of non tradables, the discrepancy is not statistically significant, except for the relative wage in the short-run. Overall, reassuringly, this robustness exercise shows that our different VAR models identify similar structural government spending shocks and it turns out that differences are quantitatively rather moderate, if not absent.

Third robustness exercise: Identifying the government spending shock in the first VAR model on quarterly data and assessing the potential discrepancy in estimated responses. The identification scheme proposed by Blanchard and Perotti [2002] is based on the assumption that government spending does not respond contemporaneously to current output developments due to delays between current output observation and the implementation of fiscal measures. The potential problem is that Blanchard and Perotti's argument is not necessarily true when using annual data, as some adjustment could be possible within the year. Below we assess the legitimacy of our identifying restriction in one more way. We use quarterly data and assume that government spending does not respond within the quarter to the other variables included in the VAR model. This assumption is in the spirit of Blanchard and Perotti [2002]. We take the identified government spending shock in the first VAR model as the baseline spending shock and annualize the estimated shock. Then we augment each VAR model with the baseline spending shock identified on a quarterly basis. Such a procedure should ensure that the fiscal shock is exogenous and variables respond to the same identified government spending shock. The disadvantage is that the largest available subset of the countries in our current sample for which we have sufficient quarterly fiscal data is 8 instead of 16 . In order to make our baseline results comparable with those when we augment each VAR model with the spending shock identified in the first VAR model, i.e. 
$z_{i t}=\left[g_{i t}, y_{i t}, l_{i t}, j e_{i t}, w_{C, i t}\right]$, we re-estimate each VAR model on annual data for the set of countries restricted to eight. In the latter case, we do not augment VAR models with the identified government spending shock in the first VAR model. The solid blue line in Figures 23 and 24 displays the baseline results for a government spending shock identified on annual data, while the solid black line displays the results when each VAR model is augmented with the government spending shock identified in the first VAR model on quarterly data. As shown in the first row of Figures 23 and 24, the response of government spending to the exogenous fiscal shock identified on quarterly data displayed in the solid black line is somewhat more pronounced in the short term and the IRF of $G$ remains above that in the baseline. In sum, the government spending shock displays more persistence and is somewhat more pronounced when identified on quarterly data. Because the government spending shock is larger in this configuration, as can be seen in Figure 23, hours worked and output fall more in the traded sector while they increase more in the non traded sector. It is thus not surprising that the responses of sectoral shares are more pronounced, as can be seen in Figure 24. Regarding the responses for the relative price and the relative wage, differences are quantitatively rather moderate.

Fourth robustness exercise: Assessing numerically the discrepancy caused by potentially different identified government spending shocks. In the last robustness exercise we perform, we take a different approach. We normalize the exogenous fiscal shock to a rise in $G$ by 1 percentage point of GDP in the quantitative analysis but let the endogenous response of government consumption vary across VAR specifications. Thus, when we compute the theoretical impulse response functions of one variable, we calibrate the government spending shock so as to reproduce the endogenous response of $G$ we generate from estimates of the VAR model in which the variable is included. The objective of this exercise is to compute quantitatively the discrepancy in the estimated response of each variable caused by an identified government spending shock that potentially varies across VAR models while in the baseline quantitative analysis, we consider one unique spending shock identified in the first VAR model $z_{i t}=\left[g_{i t}, y_{i t}, l_{i t}, j e_{i t}, w_{C, i t}\right]$. In the first row of Figures 25 and 26, the solid blue line displays the adjustment of government spending we generate from estimates of the first VAR model $z_{i t}=\left[g_{i t}, y_{i t}, l_{i t}, j e_{i t}, w_{C, i t}\right]$ while the solid red line displays the endogenous response of $G$ we generate from estimates of the VAR model in which the variable shown in the second row is included.

As discussed above, the differences between the government spending shock identified in the first VAR model and the government spending shock identified in alternative VAR models are quite moderate, and in most of the cases insignificant, except for the specification that includes the current account shown the first column of Figure 25. The solid blue line in the second row of Figures 25 and 26 shows empirical impulse response functions, while the solid black line displays theoretical responses when the government spending shock is calibrated on the basis of the first VAR model. The dotted black line displays the theoretical responses when the government spending shock is identified in the VAR model in which the economic variable (shown in the second row) is included. Overall, the differences between the solid and the dotted black line are quantitatively small or hardly noticeable for all variables. Thus, our quantitative analysis should not be altered by the small differences in the government spending shock across VAR specifications. 


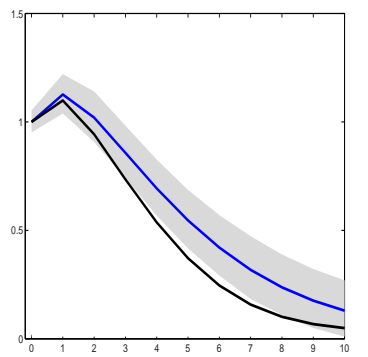

(a) VAR $z$ with $C A$

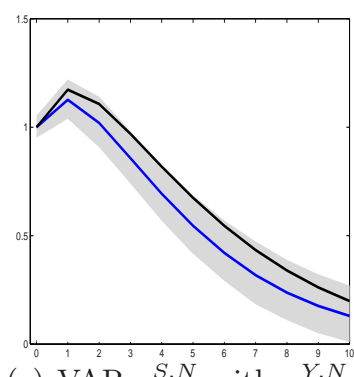

(e) $\operatorname{VAR}^{2} z^{4^{4}, N^{5}}$ with $\nu^{Y, N}$

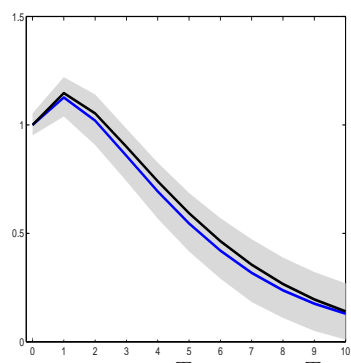

(b) VAR $z^{T^{5}}{ }^{6}$ with $Y^{\frac{9}{9}}$

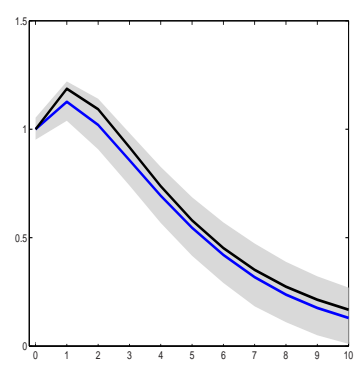

(f) VAR $z^{P}$ with $P$

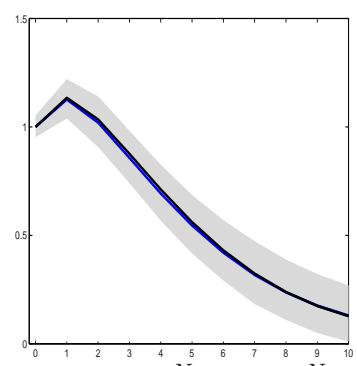

(c) $\operatorname{VAR} z^{N}$ with $Y^{N}$

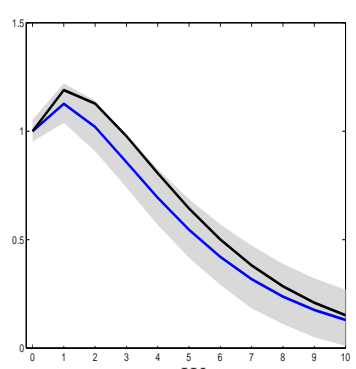

(g) VAR $z^{W}$ with $\Omega$

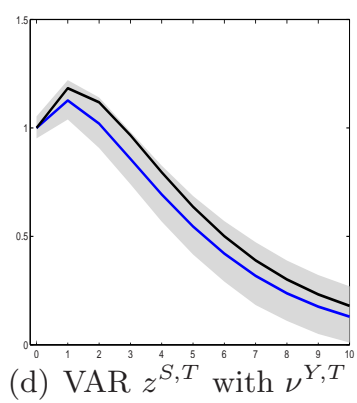

(d) $\operatorname{VAR} z^{S, T}{ }^{\frac{5}{6}}$ with $\nu^{Y, T}$

Figure 20: Effects of an Unanticipated Fiscal Shock on Government Spending. Notes: Exogenous increase in government consumption by $1 \%$ of GDP. Blue line: baseline VAR model $z_{i t}=\left[g_{i t}, y_{i t}, l_{i t}, j e_{i t}, w_{C, i t}\right]$; shaded areas: 90 percent confidence intervals; black line: alternative VAR specifications. 


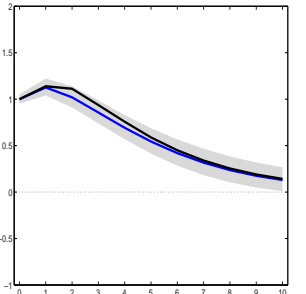

(a) Gov. spending

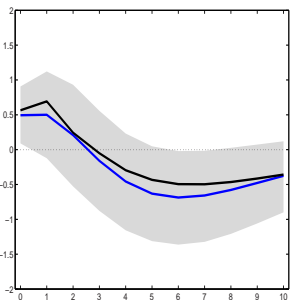

(e) $Y$

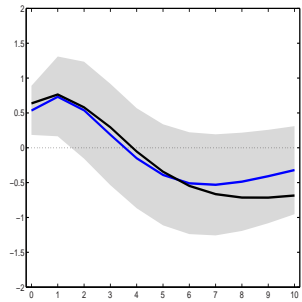

(i) $L$

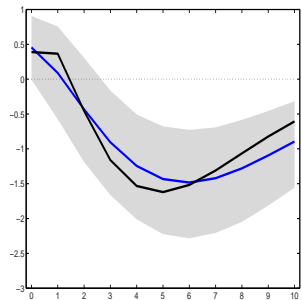

(m) $W / P_{C}$

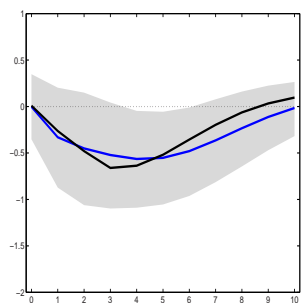

(q) Investment

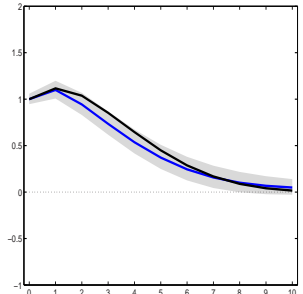

(b) Gov. spending

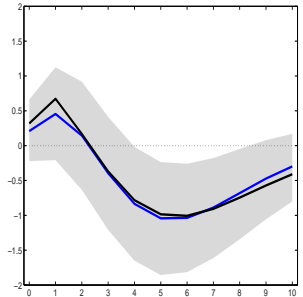

(f) $Y$

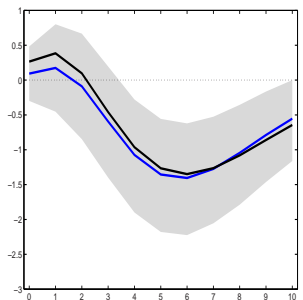

(j) $L$

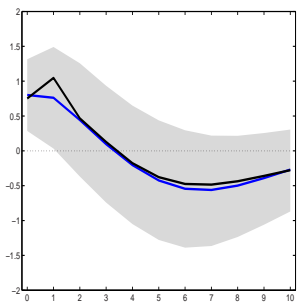

(n) $W / P_{C}$

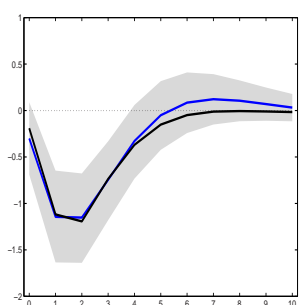

(r) Current Account

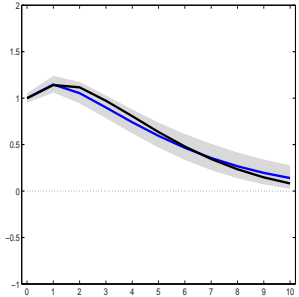

(c) Gov. spending

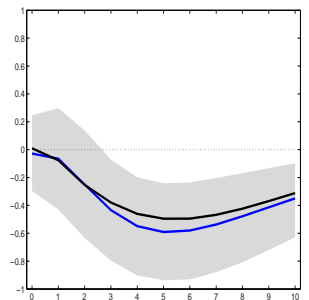

(g) $Y^{T}$

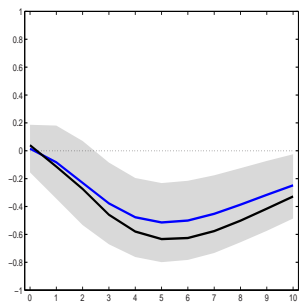

(k) $L^{T}$

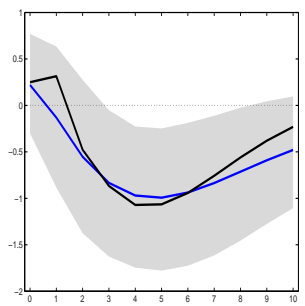

(o) $W^{T} / P_{C}$

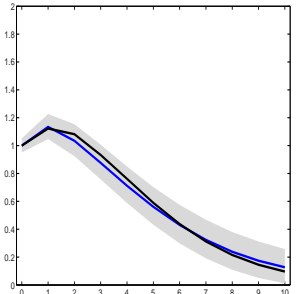

(d) Gov. spending

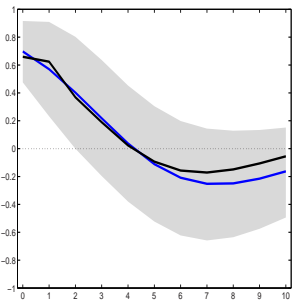

(h) $Y^{N}$

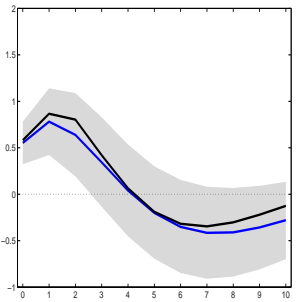

(1) $L^{N}$

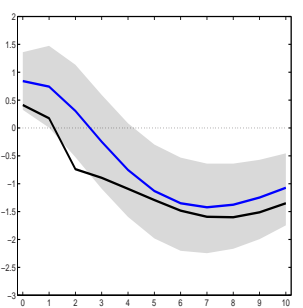

(p) $W^{N} / P_{C}$

Figure 21: Aggregate and Sectoral Effects of an Unanticipated Government Spending Shock: Assessing Differences Caused by Identifying Different Government Spending Shocks on Annual Data. Notes: Exogenous increase in government consumption by 1\% of GDP. Results for the baseline specification are displayed by solid lines with the shaded area indicating the 90 percent confidence bounds obtained by bootstrap sampling; the solid black line reports the results for the same VAR model which is augmented with the identified government spending shock in the first VAR model estimated on annual data; sample: 16 OECD countries, 1970-2007, annual data. 


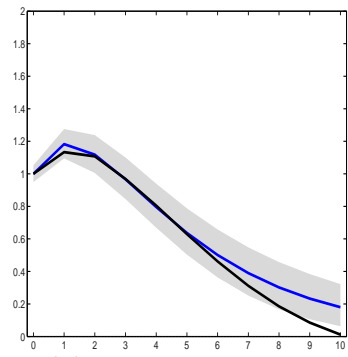

(a) Gov. spending

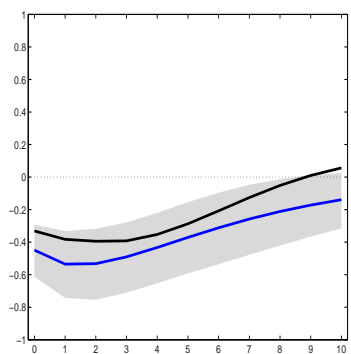

(e) $Y^{T} / Y$

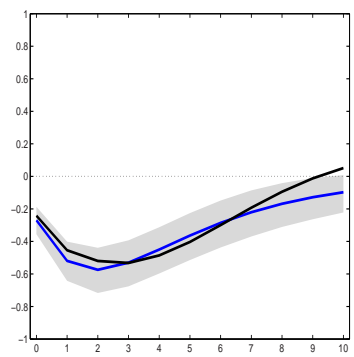

(i) $L^{T} / L$

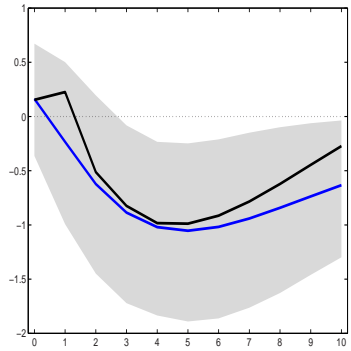

(m) $W^{T} / P_{C}$

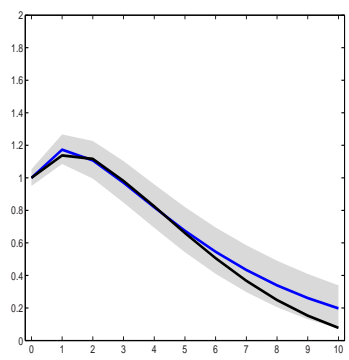

(b) Gov. spending

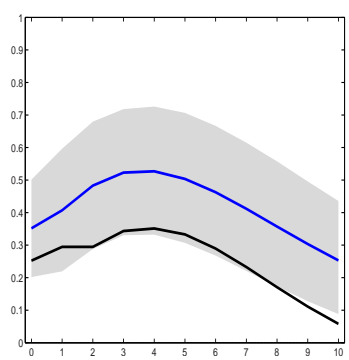

(f) $Y^{N} / Y$

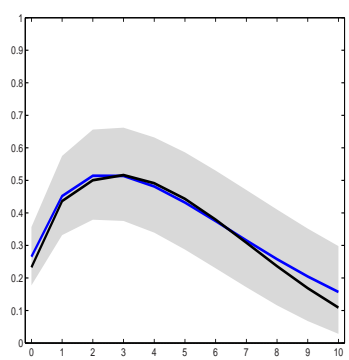

(j) $L^{N} / L$

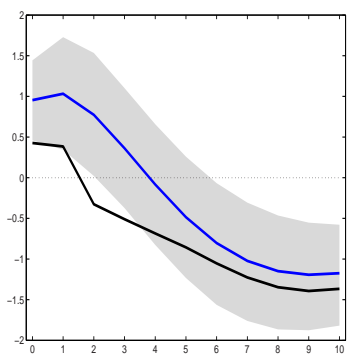

(n) $W^{N} / P_{C}$

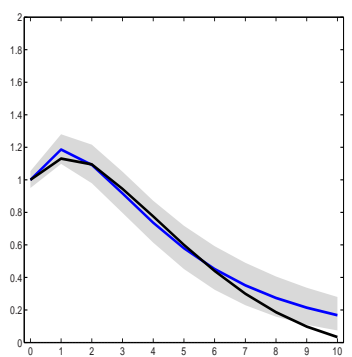

(c) Gov. spending

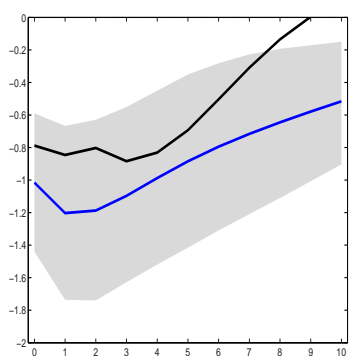

(g) $Y^{T} / Y^{N}$

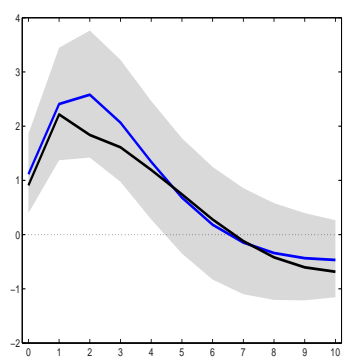

(k) $P$

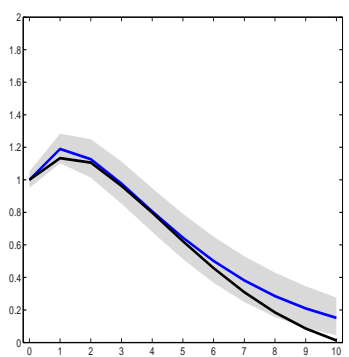

(d) Gov. spending

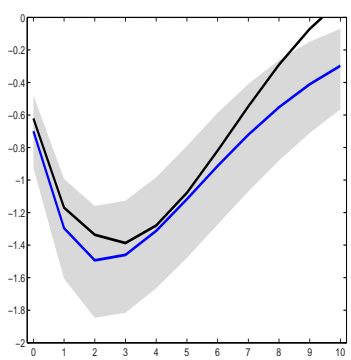

(h) $L^{T} / L^{N}$

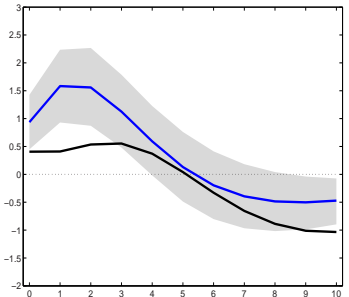

(1) $\Omega$

Figure 22: Sectoral Composition Effects of an Unanticipated Government Spending Shock: Assessing Differences Caused by Identifying Different Government Spending Shocks on Annual Data. Notes: Exogenous increase in government consumption by $1 \%$ of GDP. Results for the baseline specification are displayed by solid lines with the shaded area indicating the 90 percent confidence bounds obtained by bootstrap sampling; the solid black line reports the results for the same VAR model which is augmented with the identified government spending shock in the first VAR model estimated on annual data; sample: 16 OECD countries, 1970-2007, annual data. 


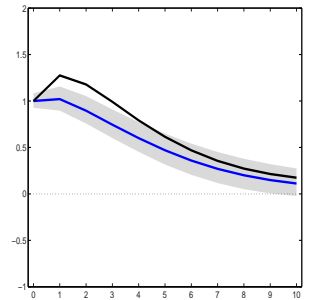

(a) Gov. spending

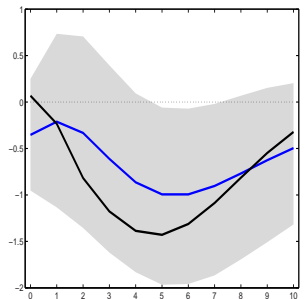

(e) $Y$

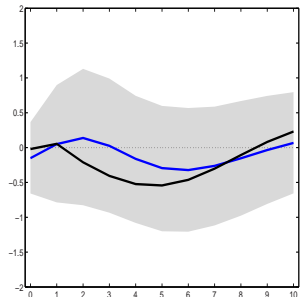

(i) $L$

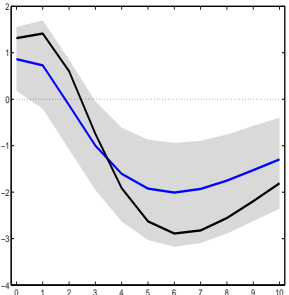

(m) $W / P_{C}$

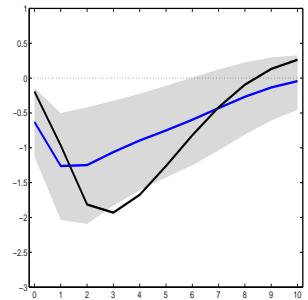

(q) Investment

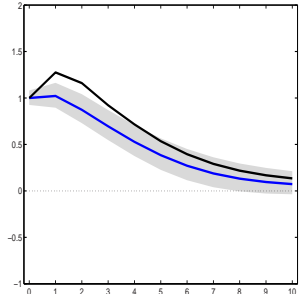

(b) Gov. spending

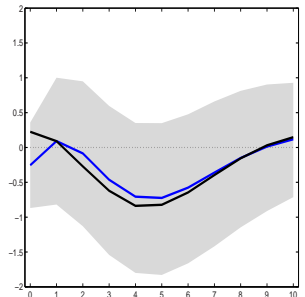

(f) $Y$

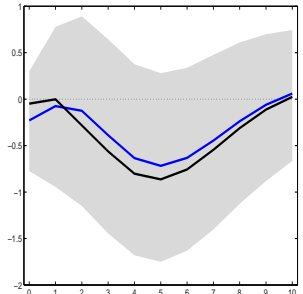

(j) $L$

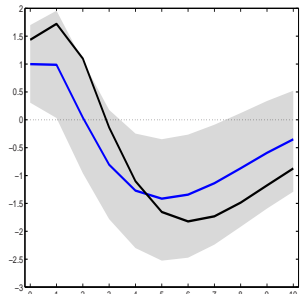

(n) $W / P_{C}$

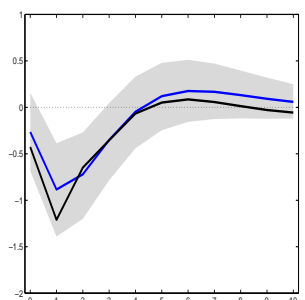

(r) Current Account

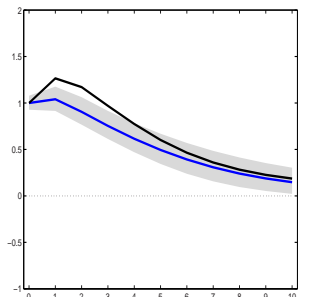

(c) Gov. spending

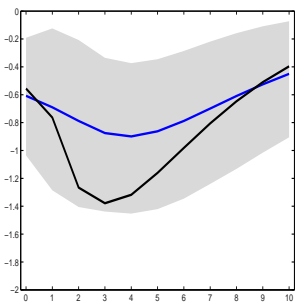

(g) $Y^{T}$

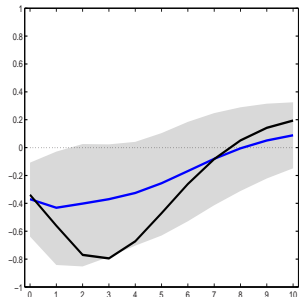

(k) $L^{T}$

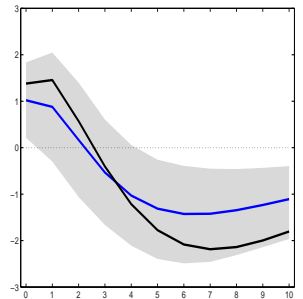

(o) $W^{T} / P_{C}$

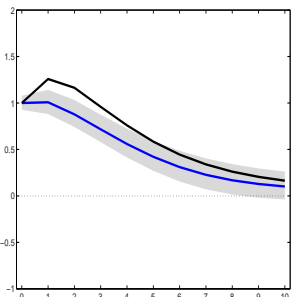

(d) Gov. spending

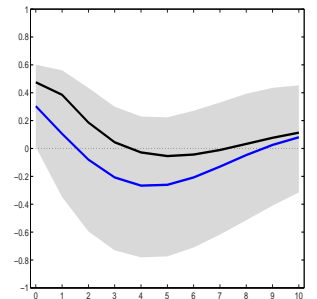

(h) $Y^{N}$

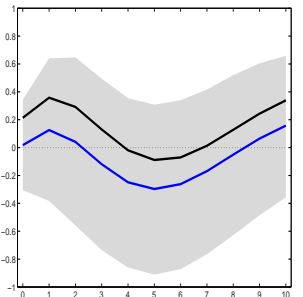

(1) $L^{N}$

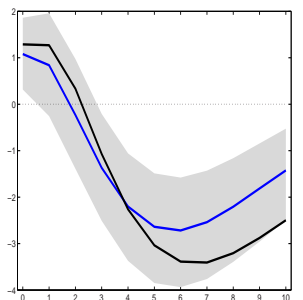

(p) $W^{N} / P_{C}$

Figure 23: Aggregate and Sectoral Effects of an Unanticipated Government Spending Shock: Assessing Differences Caused by Identifying Different Government Spending Shocks. Notes: Exogenous increase in government consumption by $1 \%$ of GDP. Results for the baseline specification are displayed by solid lines with the shaded area indicating the 90 percent confidence bounds obtained by bootstrap sampling; the solid black line reports the results for the same VAR model which is augmented with the identified government spending shock in the first VAR model estimated on quarterly data; sample: 8 OECD countries, 1970-2007, annual data. 


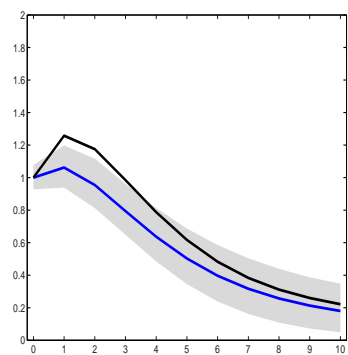

(a) Gov. spending

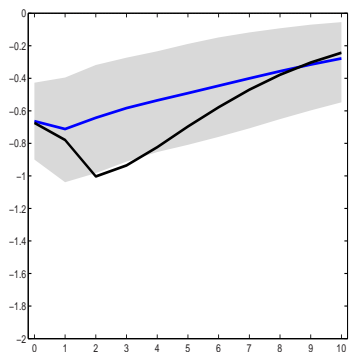

(e) $Y^{T} / Y$

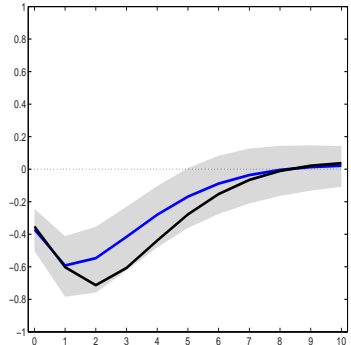

(i) $L^{T} / L^{6}$

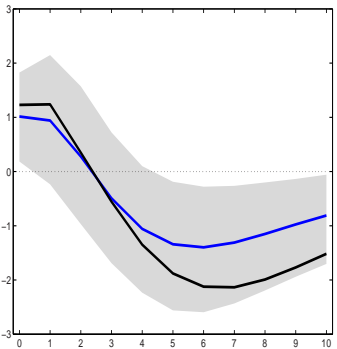

(m) $W^{T} / P_{C}$

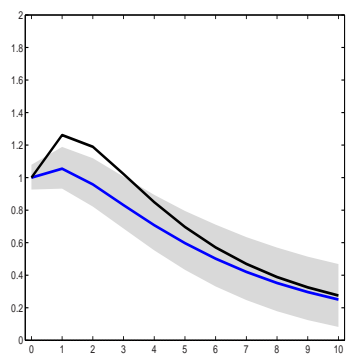

(b) Gov. spending

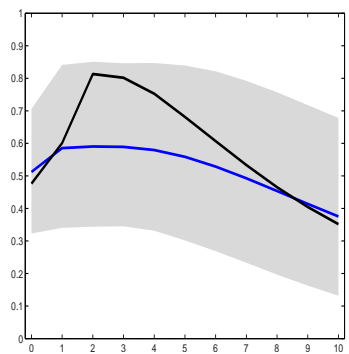

(f) $Y^{N} / Y$

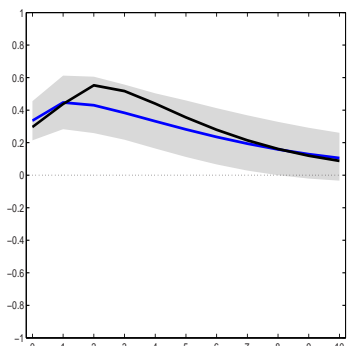

(j) $L^{N} / L$

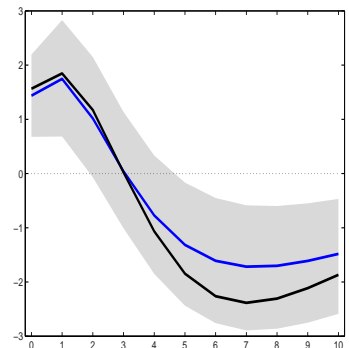

(n) $W^{N} / P_{C}^{7}$

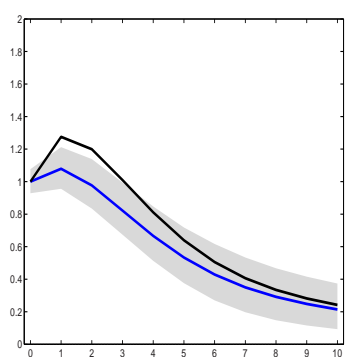

(c) Gov. spending

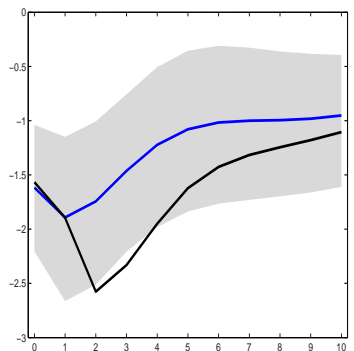

(g) $Y^{T} / Y^{N}$

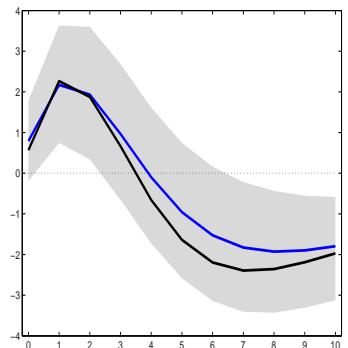

(k) $P$

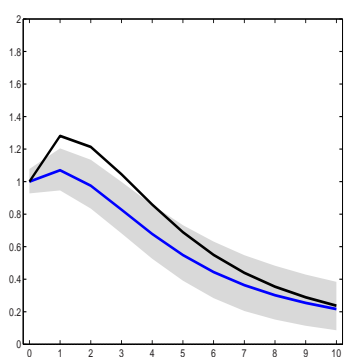

(d) Gov. spending

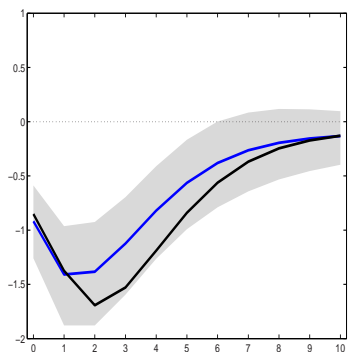

(h) $L^{T} / L^{N}$

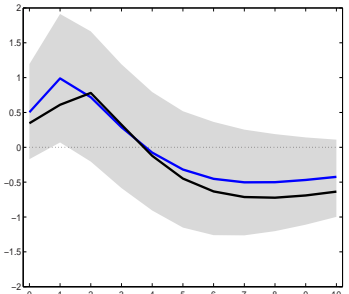

(l) $\Omega$

Figure 24: Sectoral Composition Effects of an Unanticipated Government Spending Shock: Assessing Differences Caused by Identifying Different Government Spending Shocks. Notes: Exogenous increase in government consumption by $1 \%$ of GDP. Results for the baseline specification are displayed by solid lines with the shaded area indicating the 90 percent confidence bounds obtained by bootstrap sampling; the solid black line reports the results for the same VAR model which is augmented with the identified government spending shock in the first VAR model estimated on quarterly data; sample: 8 OECD countries, 1970-2007, annual data. 


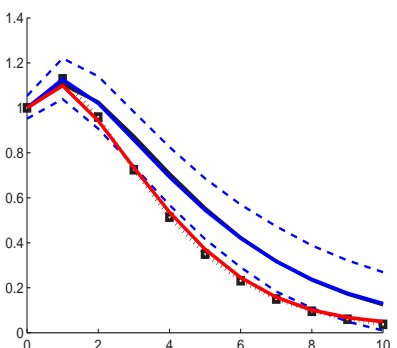

(a) Gov. spending

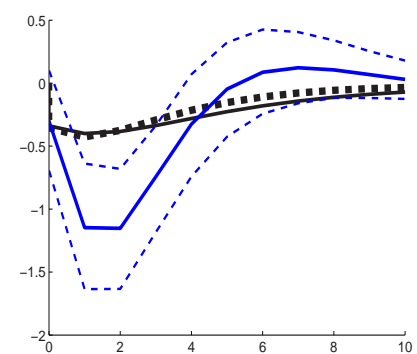

$(\mathrm{e})^{2}$ Current Áccount

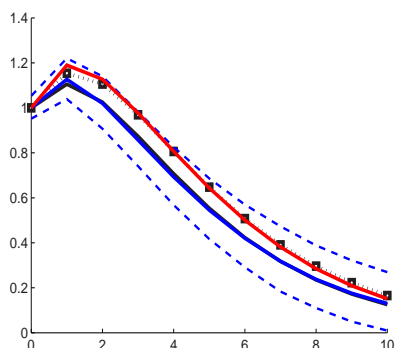

(b) Gov. spending

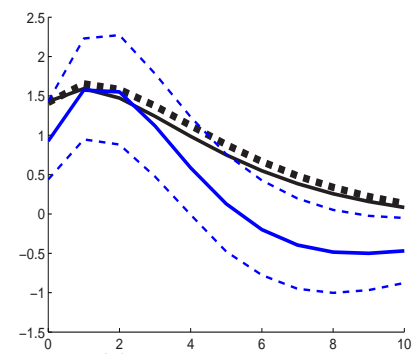

(f) Relative Wage

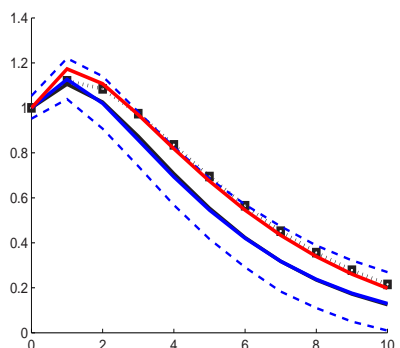

(c) Gov. spending

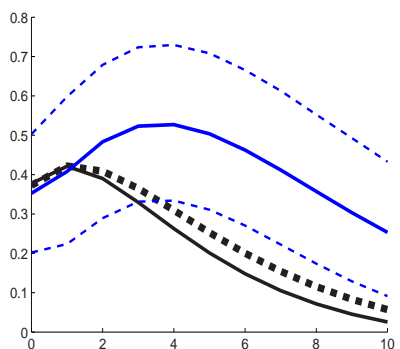

(g) Share of Non Tradables

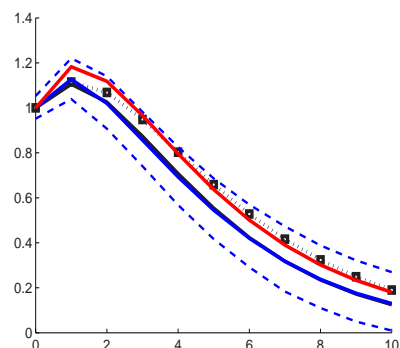

(d) Gov. spending

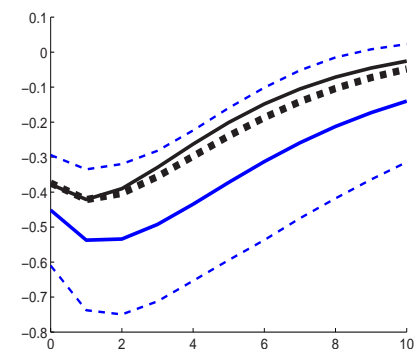

(h) ${ }^{2}$ Share of Tradables

Figure 25: Contrasting Theoretical Impulse Response Functions for Potentially Varying Government Spending Shock. Notes: Impulse response functions to an exogenous increase in real government spending by one percent of GDP. The solid blue line displays the point estimate of VAR with the dotted blue lines indicating $90 \%$ confidence bounds; the solid black line displays model predictions in the baseline scenario, i.e., when we calibrate the model on the basis of the first VAR model, $z_{i t}=\left[g_{i t}, y_{i t}, l_{i t}, j e_{i t}, w_{C, i t}\right]$; the dotted black line displays model predictions when we calibrate the model for a government spending shock specific to the VAR specification. In the first row, the red line and the dotted black line with squares display the empirical and theoretical response of government spending specific to the VAR specification, respectively. 


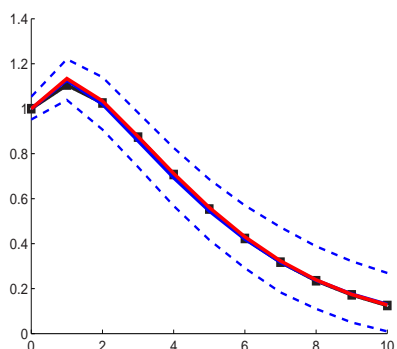

(a) Gov. spending

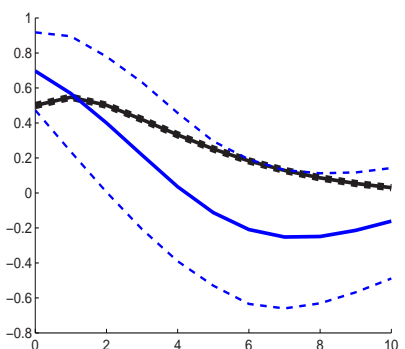

(d) ${ }^{2}$ Non Traded Output

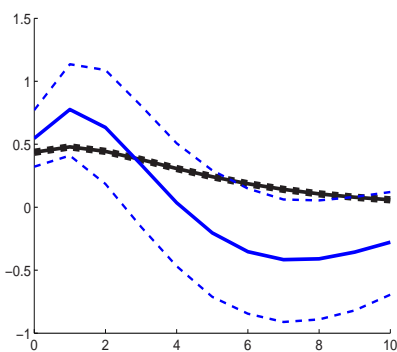

(g) Non Traded Labor

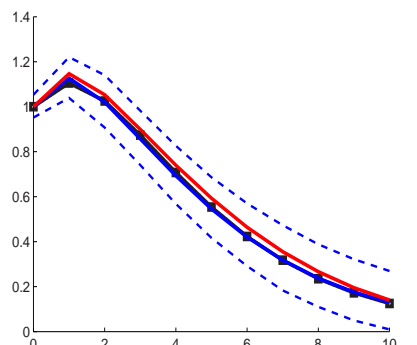

(b) Gov. spending

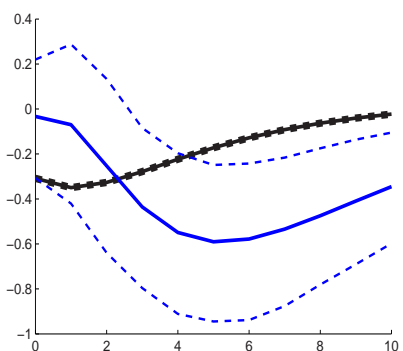

(e) Traded Output

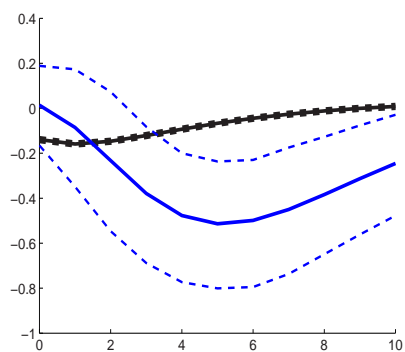

(h) Traded Labor

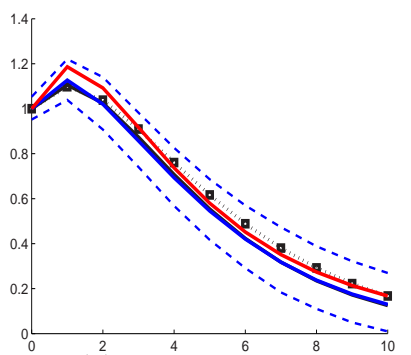

(c) Gov. spending

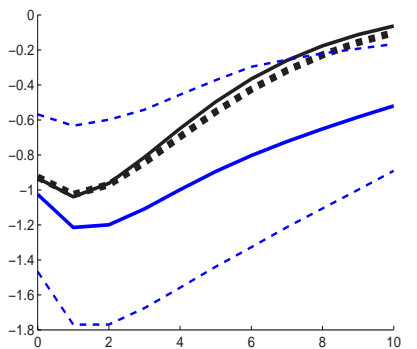

(f) ${ }^{2}$ Relative Output

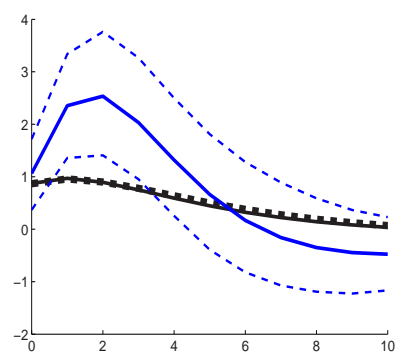

(i) Relative Price

Figure 26: Contrasting Theoretical Impulse Response Functions for Potentially Varying Government Spending Shock. Notes: Impulse response functions to an exogenous increase in real government spending by one percent of GDP. The solid blue line displays the point estimate of VAR with the dotted blue lines indicating $90 \%$ confidence bounds; the solid black line displays model predictions in the baseline scenario, i.e., when we calibrate the model on the basis of the first VAR model, $z_{i t}=\left[g_{i t}, y_{i t}, l_{i t}, j e_{i t}, w_{C, i t}\right]$; the dotted black line displays model predictions when we calibrate the model for a government spending shock specific to the VAR specification. In the first row, the red line and the dotted black line with squares display the empirical and theoretical response of government spending specific to the VAR specification, respectively. 


\section{F State-Dependent and Potential Asymmetry Effects of Gov- ernment Spending Shocks}

Recently, the literature investigating the effects of a rise in government consumption contrasted the effects of fiscal policy on output across a number of countries' characteristics. Using a panel of 44 industrialized and developing countries, Ilzetzki, Mendoza, and Vegh [2013] find that fiscal multipliers increase with the level of development, decrease with the level of public debt, and are lower in countries which are more open to international trade, or operating under flexible exchange rate regimes. These findings have also been further explored by Corsetti Meier and Müller [2012] who show in a panel of 17 OECD countries for the period 1975-2008 that fiscal multipliers are larger under fixed than under flexible exchange rates, lower when debt is high and larger during financial crises. A third noteworthy work is the paper by Brinca, Holter, Krusell, Malafry [2016] who show both empirically and theoretically that there is a strong positive relationship across countries between the magnitude of fiscal multipliers and wealth inequality captured by the Gini index.

Another key characteristic which appears to play a pivotal role in determining the size of the output multiplier is the state of the business cycle. For the United States, evidence documented by Auerbach and Gorodnichenko [2012] reveals that the size of fiscal multipliers is higher in recessions than in expansions, i.e., ranging between 1 and 1.5 in recessions and between 0 and 0.5 in expansions. These findings can be rationalized on the basis of the Keynesian approach which predicts that a rise in government spending is less likely to crowd out private consumption and/or investment. Extending their work to a panel of $300 \mathrm{ECD}$ countries, Auerbach and Gorodnichenko [2013] estimate the impact output multiplier to be essentially zero during expansions and about 0 to 0.5 in recessions. Moreover, Christiano, Eichenbaum, Rebelo [2011] show that monetary policy can affect government spending multipliers as the fiscal multiplier is above 3 when the zero lower bound on the nominal interest binds. Intuitively, when the nominal interest rate does not respond to an increase in government spending, there is no crowding out of investment or consumption, which thus leads to much higher fiscal multipliers.

Whereas empirical and theoretical findings documented by Auerbach and Gorodnichenko [2012], [2013] and Christiano, Eichenbaum, Rebelo [2011], among others, provide some support for the the state dependence of fiscal multipliers, the debate about whether the size of the output multiplier varies over the business cycle is unsettled both empirically and theoretically, see e.g., Canzoneri, Collard, Dellas and Diba [2016]. In particular, Ramey and Zubairy [2017] have questioned the Auerbach and Gorodnichenko [2012] findings. Using quarterly data from 1889 through 2015 for the U.S, covering multiple large wars and deep recessions, the authors report the absence of any state dependence of government spending multipliers. ${ }^{69}$

In the same vein, Riera-Crichton, Vegh, and Vuletin [2015] tackles a new dimension of fiscal policy. Collecting data for a panel of 29 OECD countries over the period from 1986 to 2008, the authors explore empirically the size of the fiscal multiplier whether government spending is going up or down. They show that not treating separately increases and decreases in government spending can lead to biased state-dependent multiplier estimates. In particular, the long-run expansionary multiplier (the multiplier associated with an increase in government spending) is 2.3 in times of economic slack while the multiplier is only 1.3 in recession when no distinction is made between increases and decreases in government spending. We also explore the implications of such a dimension for the sectoral effects of a government spending shock by using our sample of 16 OECD countries over 1970-2007. However, due to data limitation, we do not differentiate between expansions and recessions. As emphasized below, differentiating between contractionary and expansionary government spending shocks allows us to investigate whether labor mobility costs are symmetrical or asymmetrical. If mobility costs are greater when shifting hours worked away from the non traded to the traded sector than the other way around, the share of tradables in employment should increase less when the shock is contractionary. Our evidence tends to corroborate this hypothesis.

\section{F.1 Sectoral Effects of Government Spending Shocks in Good and Bad Times}

In the main text, we do not differentiate the effect of a rise in government spending on the relative size of the non traded sector across the state of economy. In this subsection, we investigate empirically whether the size of the increase in the share of non tradables, whether measured in total employment or GDP terms, varies over the business cycle.

Identifying Recession and Expansion Periods. In order to contrast the sectoral effects

\footnotetext{
${ }^{69}$ It is worthwhile mentioning that Auerbach and Gorodnichenko [2012] find that a government spending multiplier on impact of 0.5 whether the economy is in recession or in expansion. Since in our paper we base most of our analysis on impact effects, this empirical finding (on U.S. data only though) suggests that not differentiating between good and bad times should not affect the results.
} 
of a government spending shock in expansions with those in recessions, we have to identify the state of the economy across the business cycle. Following standard practice (see Riera-Crichton, Vegh, and Vuletin [2015] for instance), we define a recession period as a situation where the output gap declines, i.e., the economy is moving from its peak to trough, and an expansion period as a situation where the output gap increases, i.e., the economy is moving from its trough to peak. Such a definition implies that unemployment increases in recessions and declines in expansions. This measure of the state of the economy can be criticized on the grounds that recession periods are not necessarily periods of high unemployment, see Ramey and Zubairy [2017]. Denoting real GDP in country $i$ at time $t$ by $Y_{i t}$, taking logarithm and applying a Hodrick-Prescott filter with a smoothing parameter of $\lambda=100$ (as we use annual data), we obtain a measure of the output gap which allows us to identify expansions and recessions:

$$
\begin{array}{ll}
\text { Expansions: } & d \ln \left(\frac{Y_{i t}}{\bar{Y}_{i t}}\right)>0, \\
\text { Recessions: } & d \ln \left(\frac{Y_{i t}}{\bar{Y}_{i t}}\right)<0,
\end{array}
$$

where $\bar{Y}_{i t}$ is the potential GDP at time $t$ in country $i$. Once we have identified expansions and recessions for each OECD country in our sample, we define a dummy variable $D U_{k}$ which takes i) a value of one (i.e., $D U^{E}=1$ ) in expansions and 0 otherwise, ii) a value of one (i.e., $\left.D U^{R}=1\right)$ in recessions and 0 otherwise.

Empirical Strategy. To assess the role of the state of economy for the transmission of fiscal shocks, we perform a two-stage estimation strategy. In the first step, we identify government spending shocks in a structural VAR by adopting the Blanchard and Perotti's [2002] identification procedure procedure based on the assumption of delays between current output observation and the implication of fiscal measures. In the second step, we use the estimated government spending shocks to explore the state-dependency of the effects of an increase in government spending. Drawing on previous studies, we conduct two robustness exercises in this step to explore the potential implications of state-dependency effects:

- We augment the VAR specification with the set of dummy variables $D U^{k}$ (with $k=R, E$ ) scaled by the size of the fiscal shock. This estimation strategy is advocated by the narrative approach proposed by Ramey [2011] in which the military date dummy variable is embedded in the standard VAR, but ordered before the other variables.

- A second route followed by Auerbach and Gorodnichenko [2013], Riera-Crichton, Vegh, and Vuletin [2015] and Ramey and Zubairy [2017] is to use the Jordà's [2005] single-equation local projection method. This approach has the advantage to easily accommodate state-dependence in the response function of variables of interest to an exogenous government spending shock.

In accordance with the empirical strategy in the main text, the first step amounts to identifying government spending shocks by adopting the Blanchard and Perotti's [2002] identification procedure based on the assumption of implementation delays. We thus adopt a Cholesky decomposition in which government spending is ordered before the other variables so that the fiscal shock is exogenous. We estimate a VAR model which includes government final consumption expenditure, real GDP, total hours worked, private investment, and the real consumption wage, i.e., $z_{i t}=\left[g_{i t}, y_{i t}, l_{i t}, j e_{i t}, w_{C, i t}\right]$, with two lags which corresponds to the baseline model in the main text. All quantities are logged, expressed in real terms and scaled by the working age population.

Once we have identified structural government spending shocks, i.e., denoted by $\epsilon_{G, i t}$, we perform a second step by estimating each VAR model augmented with the identified government spending shocks, ordered first. More specifically, we consider the three following augmented VAR models to explore the state-dependency of the effects of fiscal shocks:

$$
\begin{aligned}
z_{i t} & =\left[\epsilon_{G, i t}, g_{i t}, \operatorname{variables}_{i t}\right] \\
z_{i t}^{R} & =\left[\epsilon_{G, i t}^{R}, g_{i t}, \text { variables }_{i t}\right] \\
z_{i t}^{E} & =\left[\epsilon_{G, i t}^{E}, g_{i t}, \text { variables }_{i t}\right]
\end{aligned}
$$

where the shock is simply given by $\epsilon_{G, i t}$ in the baseline model 71a), $\epsilon_{G, i t}^{R}=D U_{i t}^{R} \epsilon_{G, i t}$ in recessions (eq. (71b)), $\epsilon_{G, i t}^{E}=D U_{i t}^{E} \epsilon_{G, i t}$ in expansions (eq. (71c)) where $D U_{i t}^{k}$ (with $k=R, E$ ) is a dummy variable that indicates the state of the economy $i$ at time $t$ when the shock hits. By exploring empirically these three VAR specifications, we thus consider the same government spending shock but allow all of the coefficients of the model to vary according to the state of the economy. To have a reference point, we estimate all VAR specifications detailed in the main text and then we contrast them with those obtained when the economy is in recession or in expansion.

Local Projection. Following Auerbach and Gorodnichenko [2013] and Ramey and Zubairy [2017], we alternatively use Jordà's [2005] projection method to estimate impulse responses in the 
second step. The first advantage of this method over the standard VAR approach is that it reduces considerably the number of coefficients. The second advantage is that it does not impose the dynamic restrictions implicitly embedded in VARs and can accommodate non-linearities in the response function. The Jordà method amounts to running a series of regression for each horizon $h=0,1,2, \ldots$ for each variable of interest. The linear model reads as follows:

$$
x_{t+h}=\alpha_{h, i}+\beta_{h, i} . t+\psi_{h}(L) z_{t-1}+\gamma_{h} . \epsilon_{G, i t}+\nu_{i, t},
$$

where $\alpha_{i}$ and $\beta_{i}$ are the country fixed effects and country-specific linear trends respectively, $x$ is the logarithm of the variable of interest, $z$ is a vector of control variables (i.e., past values of government spending and of the variable of interest), $\psi_{h}(L)$ is a polynomial (of order two) in the lag operator and $\epsilon_{G, i, t}$ is the identified government spending shock. While we allow for two lags on the variable of interest and government spending collected in vector $z$, we consider the effects of a current exogenous government spending shock. We thus construct the impulses responses directly from the $\gamma_{h}$ estimated coefficient which gives the response of $x$ at time $t+h$ to the shock $\epsilon_{G, t}$ at time $t$. We compute confidence intervals that correct for serial correlation by using Newey-West standard errors (Newey and West [1987]). The local projection method can be easily adapted to estimating the state-dependent model:

$$
\begin{aligned}
x_{t+h}^{k}= & D U^{k} \cdot\left[\psi_{h}^{k}(L) z_{t-1}+\gamma_{h}^{k} \cdot \epsilon_{G, i t}\right] \\
& +D U^{-k} \cdot\left[\psi_{h}^{-k}(L) z_{t-1}+\gamma_{h}^{-k} \cdot \epsilon_{G, i t}\right]+\alpha_{i, h}+\beta_{i, h} \cdot t+\nu_{i, t},
\end{aligned}
$$

where $k=R, E,-k=E, R$ and $D U^{k}$ (with $k=R, E$ ) is a dummy variable that indicates the state of the economy when the shock hits. Like for the VAR approach, our aim is to estimate the coefficients of the model (other than deterministic terms) which are allowed to vary according to the state of the economy. The impulse responses for the two regimes can be computed directly from estimated coefficients $\gamma_{h}^{k}$ and $\gamma_{h}^{-k}$.

Descriptive Statistics. Before turning to estimates, it is useful to look at the descriptive statistics related to expansions and recessions summarized in Table 9. The first two columns gives the percentage of time expansion and recession regimes. Some features deserve some comments. First, with the exception of Spain, the number of years of expansions are substantially higher than those associated with recessions. As shown in the last line of Table 9, the average share of the number of observations associated with an increasing output gap is $55 \%$ and thus is slightly higher than that of observations associated with a declining output gap. This finding is well in line with that reported in Riera-Crichton, Vegh, and Vuletin [2015] who document that industrial countries spend, on average, $50 \%$ of the time in a recessionary regime. While we will come back to this point later, it is worth mentioning that both recessions and expansions can be associated with a positive or a negative government spending shock as can be seen in the last four columns of Table 9 .

Aggregate and Sectoral Effects. We first present the main results of our analysis using the augmented VAR method. We generate impulse response functions which are normalized so that government consumption increases by 1 percentage point of GDP. Figure 27 shows aggregate and sectoral effects effects when augmenting each baseline VAR with the estimated structural fiscal shock. The solid blue line reports results for the model (71a) which assumes that the effects of $\epsilon_{G, i t}$ are invariant to the state of the economy. The solid red line displays results when we restrict the government spending shocks to occur when the economy is in recession and contrast them with those obtained when the economy is in expansion (shown in the green line). In Figure 27 (and in subsequent Figures 28 and 29 as well), the shaded bands are 90 percent confidence intervals for the baseline scenario. Reassuringly, all conclusions drawn in the main text hold since estimates from the state-dependent model lie within the confidence interval of those obtained from the baseline model in which effects of fiscal shocks are invariant to the state of the economy. A detailed description of our results is performed below.

First, as can be seen in the first row of Figure 27, the government spending shock is somewhat less persistent in recessions. Second, focusing on the first two columns which report aggregate effects of a government spending shocks, our evidence indicate that in accordance with empirical findings documented by Auerbach and Gorodnichenko [2013] who use a panel of 30 OECD countries, output effects of an unanticipated government spending shock are of a greater magnitude when the economy is in recession. More specifically, as can be seen in the first column of Figure 27, the fiscal multiplier for output on impact is 0.5 in the baseline model and ranges from 0.1 in expansions and 1 in recessions. ${ }^{70}$ As can be seen in the third row, such an outcome is the result of a larger increase in hours worked following a government spending shock. However, one can notice that the positive impact of the government spending shock on the real consumption wage is less in recessions; more precisely, the rise in $W / P_{C}$ is approximately as much as two times smaller than that in expansions.

\footnotetext{
${ }^{70}$ However, we find no significant difference between fiscal multipliers in the expansion regime and the recession regime.
} 
Hours worked increase more on impact in recession though. Such an outcome could be the result of an increased fraction of poor non credit constrained agents who are at risk of hitting the constraint; according to the explanation put forward by Brinca et al. [2016], these agents react to the negative wealth effect by increasing their labor supply substantially in order to avoid hitting the constraint. Third, inspection of results in the fifth row reveals that the responses of investment and the current account do not vary much across the state of the economy on impact. As a result, it is very likely that private consumption increases by a larger amount in recessions. As suggested by Auerbach and Gorodnichenko [2012], private expenditure are less likely to be crowded out since the economy operates below its potential.

Fourth, turning to the sectoral multipliers for output and labor shown in the last two columns of Figure 27, the conclusion that emerges is that a government spending shock increases sectoral hours worked and output more in recessions. In particular, the adjustment in hours worked and output in the traded sector is quite distinct whether the government spending shock occurs when the economy is in recession or in expansion. The explanation lies in the fact that households supply more labor when the economy is in recession, as mentioned above. Strikingly, our evidence shows that a rise in public expenditure raises $L^{T}$ and $Y^{T}$ in recessions while both hours worked and output fall in the traded sector during expansions. The reason is twofold. First, we find that government spending shocks are somewhat less biased toward non tradables during recessions; however, the difference is very moderate and not statistically significant. Second, less workers decide to shift hours worked from one sector to another in recession than in expansion which is the main explanation of the increase in traded output. We make inference of this result from the evidence related to changes in sectoral labor shares which allow us to gauge the extent of labor mobility.

Non Tradable Content of Government Spending Shocks. To generate impulse response functions of sectoral government consumption to our identified government spending shock, we estimate a VAR model in panel format on annual data that includes unanticipated government spending shocks ordered first, government spending, $g_{i t}$, government consumption on non tradables, $g_{i t}^{N}$, and government consumption on tradables, $g_{i t}^{T}$. As before, the shock is $\epsilon_{i t}^{G}$ for the baseline model or alternatively either $\epsilon_{G, i t}^{R}$ in bad times or $\epsilon_{G, i t}^{E}$ in good times when estimating the state-dependent model. ${ }^{71}$ As can be seen in the second column of Figure 28, the tradable content of the government spending shock is slightly larger in recession than that in expansion on impact. Because the non traded sector is somewhat less intensive in the government spending shock when the economy is in recession, incentives to reallocate resources toward the non traded sector are less.

Sectoral Composition Effects. The first two columns of Figure 29 show the dynamic adjustment of sectoral shares in employment and real GDP as well following a government spending shock. As displayed in the red and green line, respectively, the fall in the traded goods share of employment and real GDP in recession lies in the upper range of the confidence bound for the baseline scenario while the decline in the share of tradables in expansion lies in the lower range. Conversely, the share of non tradables increases more in expansions than in recessions. As stressed above, the non traded sector is somewhat more intensive in the government spending shock which results in greater incentives to move resources toward the non traded sector. In accordance with this interpretation, the relative price of non tradables, $P$, appreciates more in expansions than in recessions because the larger non tradable content of the government spending shock in the former situation produces a greater excess demand in the non traded goods market. Whereas the non traded sector is more intensive in the government spending shock in expansions, the difference in the non tradable content of the shock between expansions and recessions is not large enough to rationalize the rise in the share of non tradables in expansion relative to that in recession. As can be seen in the second column of Figure 29, the share of non tradables in real GDP increases by 0.4 ppt of GDP in expansion and $0.1 \mathrm{ppt}$ when the economy is in recession. Beside the non tradable content of the government spending shock, such a discrepancy can be attributed to higher mobility of labor across sectors. Our estimates reveal that more labor shifts from one sector to another in expansions (displayed in the green line) than in recessions (displayed in the red line). As workers are willing to shift more hours toward the non traded sector, they require a higher increase in non traded wages, as can be seen in the last column of Figure 29. The reason is that the utility loss from switching is increasing with the additional amount of hours worked. However, for a reason which remains unexplained by our model, less workers decide to shift hours worked from one sector to another in recession than in expansion. To rationalize our evidence, we believe that the model should be extended to search frictions in the labor market with endogenous sectoral labor force

\footnotetext{
${ }^{71}$ When estimating the VAR $z_{i t}^{G}=\left[\operatorname{shock}_{i t}, g_{i t}, g_{i t}^{N}, g_{i t}^{T}\right]$, all quantities are logged, expressed in real terms and scaled by the working age population. As mentioned above, data to construct time series for sectoral government consumption expenditure are available for all countries in our sample except Canada. In an effort to have a balanced panel and time series of a reasonable length, Australia (1998-2015) and Japan (2005-2015) are removed from the sample which leaves us with 13 OECD countries over the period 19952015. To be consistent, we estimate the first VAR model that includes aggregate variables for these 13 OECD countries only.
} 
participation decision. More precisely, in recession, demand is low for both traded and non traded goods and thus firms post less job vacancies which reduces the marginal benefit of searching for a job. As job search is lower, less people shift from one sector to another.

Local Projection. While our first results obtained by augmenting the VAR models with the identified government spending shocks estimated in expansions or recessions show no significant state-dependence effects, we present now the results using the Jordà's [2005] local projection approach. This robustness check also gives us the opportunity to test whether all of our results hold when we depart from the VAR method for estimating the effects of a rise in government consumption in the linear baseline model. Figure 30 shows the responses obtained with the local projections methods to the three identified shocks: $\epsilon_{G, t}$ for the linear model (the solid blue line and the shaded area which indicates the 90 percent confidence bands), $\epsilon_{G, i t}^{E}$ when the economy is in expansion (the green line) and $\epsilon_{G, i t}^{R}$ during slack states (the red line). ${ }^{72}$ Overall, it turns out that differences are rather moderate and state-dependence effects thus play a limited quantitative role in the dynamic adjustment to a government spending shock.

\section{F.2 Differentiating between Negative and Positive Government Spending Shocks}

We now investigate whether effects of government spending shocks depend on the sign of the shock. Few papers have attempted to relax the assumption of symmetric government spending shocks. To the best of our knowledge, only two examples exist. Riera-Crichton, Vegh, and Vuletin [2015] conduct an empirical analysis which reveal that estimation of state-dependent multipliers may underestimate output effects of government spending shocks by not taking into account increases and decreases in government spending. The authors use a panel of 29 OECD countries and estimate state-dependent multipliers on semiannual data by taking into account whether the shock is contractionary or expansionary. Using a novel econometric procedure applied to the US economy over the period 1966-2014, Barnichon and Matthes [2018], show that the fiscal multiplier does vary according to the direction of the fiscal action.

While this analysis is beyond the scope of our paper, we find it interesting to evaluate whether government spending going up or down matters for the size of the sectoral composition effects. It is worth mentioning that we are not able to simultaneously allow for shocks' asymmetry and state dependence due to the small size of the sample in either cases; we can differentiate though the sectoral effects according to whether government spending shocks are positive and negative. Importantly, such a study can alternatively be viewed as an indirect test of our assumption of symmetry of intersectoral labor mobility costs. The explanation is as follows. In our paper, we show that the change in relative sector size depends on two factors, namely the non tradable intensity of government spending shocks and the degree of labor mobility across sectors. While a rise in government spending raises the relative size of the non traded sector because the non traded sector is intensive in the government spending shock, the same logic applies to contractionary government spending shocks. Hence, the share of non tradables should decline when government spending is going down, and more so in countries where labor mobility across sectors is higher. In the main text, we consider that workers' costs of switching sectors are symmetric whether they move away from the traded to the non traded sector or the other way around. Since a decline in government spending produces a reallocation of labor toward the traded sector, evidence should indicate that the extent of labor reallocation after a contractionary shock is identical to that following an expansionary shock. We document evidence below which supports our assumption and thus indicates that workers' costs of switching sectors can be considered as symmetric between sectors. We may notice some differences, quite moderate though. We find that labor shifts from the traded to the non traded sector are higher than those from the non traded to the traded sector. However, at the same time, evidence reveals that the non traded sector is more intensive in the government spending shock when public expenditure are going up than if they are going down.

Empirical Strategy. To determine whether effects of fiscal shocks are asymmetric depending on whether government spending is increasing or decreasing, we perform a two-stage procedure similar to the one detailed in the previous section. In the first step and as detailed above, we identify government spending shocks by adopting the Blanchard and Perotti's [2002] assumption and thus adopt a Cholesky decomposition in which government spending is ordered before the other variables so that the fiscal shock is exogenous. We estimate a VAR model which includes government final consumption expenditure, real GDP, total hours worked, private investment, and the real consumption wage, i.e., $z_{i t}=\left[g_{i t}, y_{i t}, l_{i t}, j e_{i t}, w_{C, i t}\right]$. Once we have identified the VAR model, we

\footnotetext{
${ }^{72}$ When estimating eq. (72) or (73), we lose observations from the end of the sample as the horizon $h$ increases. As discussed in Ramey and Zubairy [2017], the Jordà method tends to produce erratic estimates of $\gamma_{h}$ at longer horizons. Since in our paper, our analysis focuses mainly on impact effects, we limit the time horizon to $t=6$ years in Figure 30.
} 


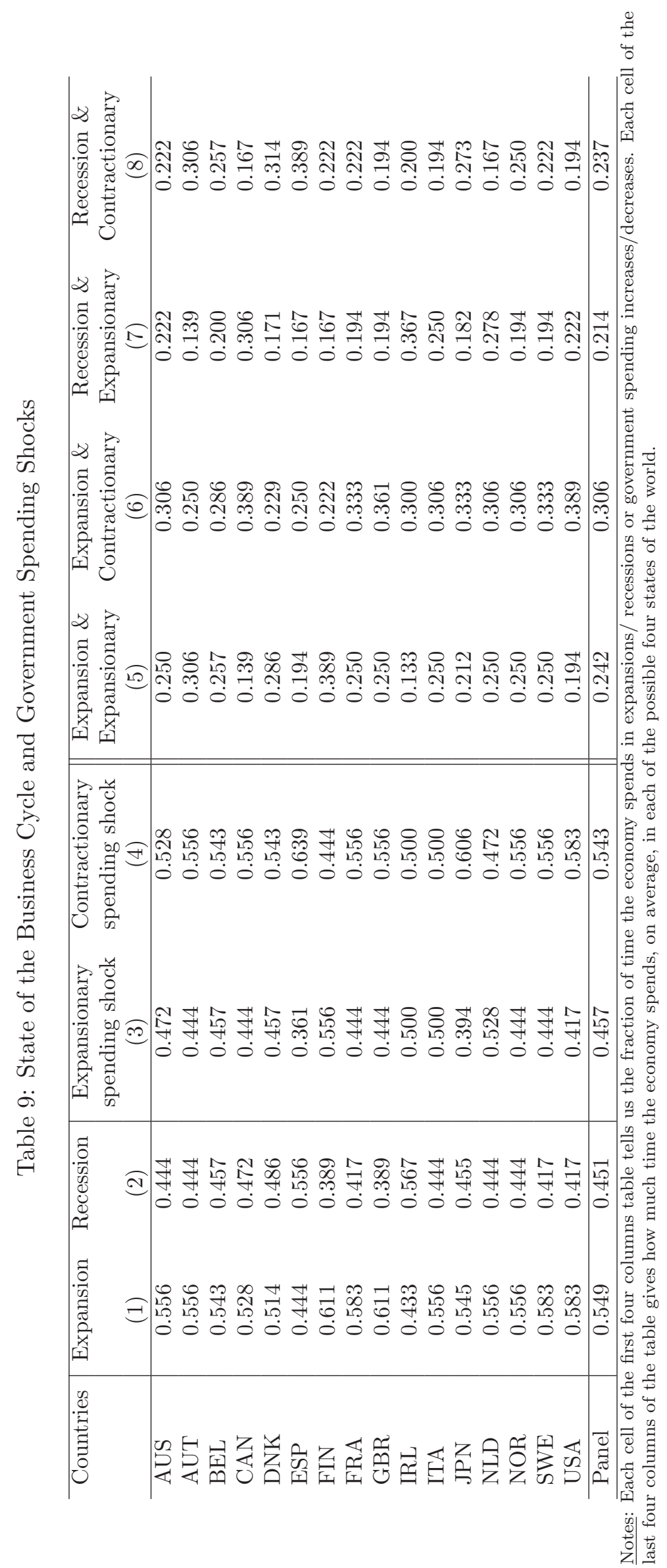




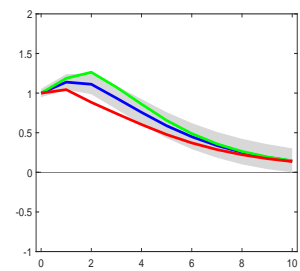

(a) Gov. spending

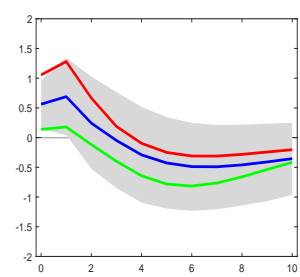

(e) $Y$

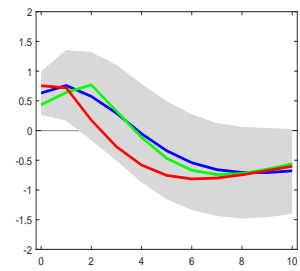

(i) $L$

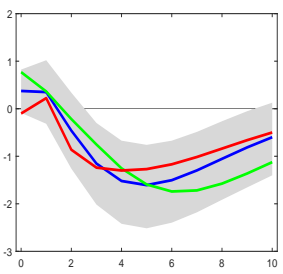

(m) $W / P_{C}$

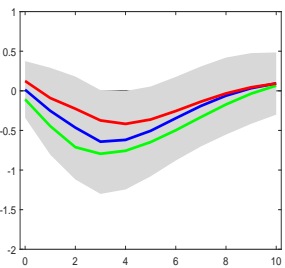

(q) Investment

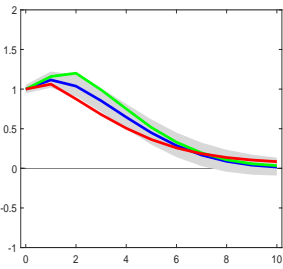

(b) Gov. spending

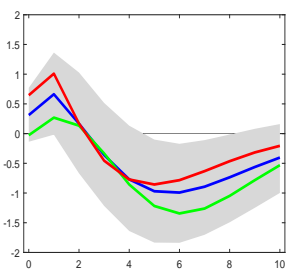

(f) $Y$

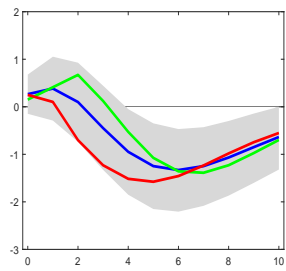

(j) $L$

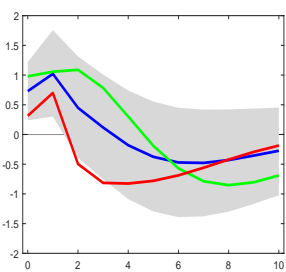

(n) $W / P_{C}$

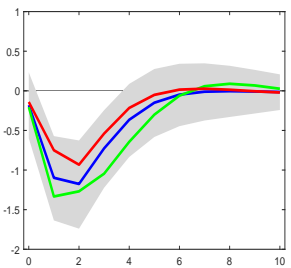

(r) Current Account

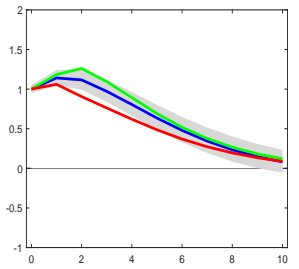

(c) Gov. spending

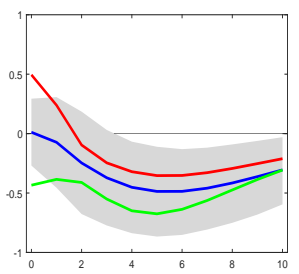

(g) $Y^{T}$

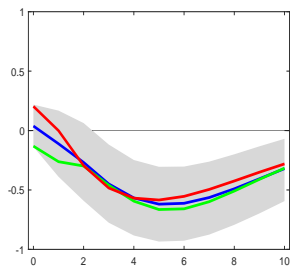

(k) $L^{T}$

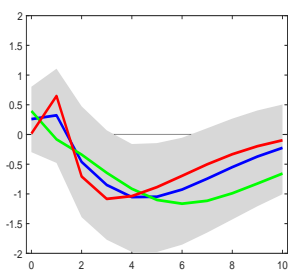

(o) $W^{T} / P_{C}$

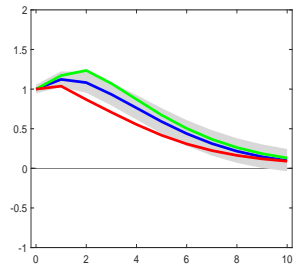

(d) Gov. spending

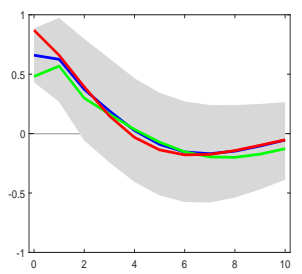

(h) $Y^{N}$

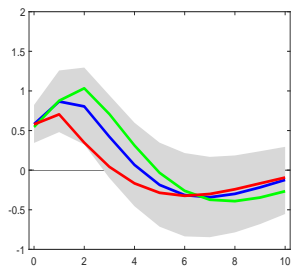

(1) $L^{N}$

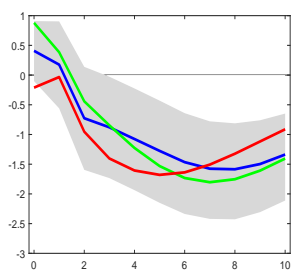

(p) $W^{N} / P_{C}$

Figure 27: Aggregate and Sectoral Effects of an Unanticipated Government Spending Shock: Assessing Differences between Recessions and Expansions. Notes: Exogenous increase in government final consumption expenditure by $1 \%$ of GDP. The solid blue line reports the results for VAR models which are augmented with the identified government spending shock, $\epsilon_{G, i t}$ in the first VAR model $z_{i t}=\left[g_{i t}, y_{i t}, l_{i t}, j e_{i t}, w_{C, i t}\right]$. The shaded area indicates the 90 percent confidence bounds obtained by bootstrap sampling. The solid red (green) line shows aggregate and sectoral effects of the same identified government spending shock except that changes in public expenditure are implemented when the economy is in recession (expansion). Sample: 16 OECD countries, 1970-2007, annual data. 


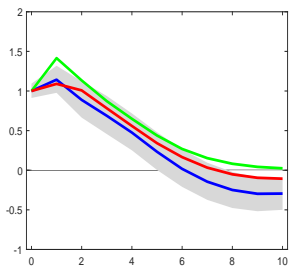

(a) Gov. spending

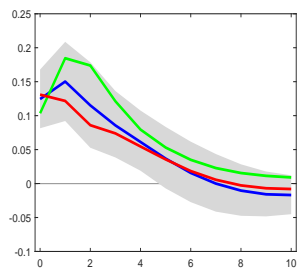

(b) $G^{T}$

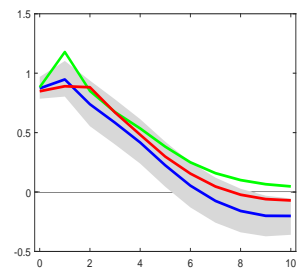

(c) $G^{N}$

Figure 28: Effects of an Unanticipated Government Spending Shock on Government Final Consumption Expenditure on Non Tradables and Tradables: Assessing Differences between Recessions and Expansions. Notes: Exogenous increase in government consumption by 1\% of GDP. The government spending shock is identified by estimating a VAR model that includes real government final consumption expenditure, GDP (constant prices), total hours worked, private fixed investment, and the real consumption wage. The responses of government final consumption expenditure on non tradables (i.e., $G^{N}$ ) and tradables (i.e., $G^{T}$ ) to the identified government spending shock are displayed by solid blue lines with the shaded area indicating the 90 percent confidence bounds obtained by bootstrap sampling. Sample: 13 OECD countries, 1995-2015, annual data. The solid red (green) line shows the effects of the same identified government spending shock except that changes in public expenditure are implemented when the economy is in recession (expansion).

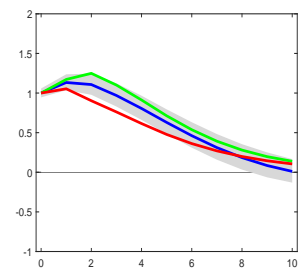

(a) Gov. spending

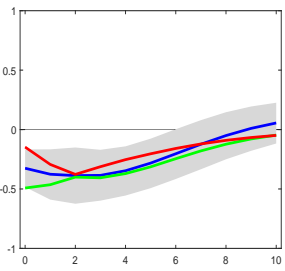

(e) $Y^{T} / Y$

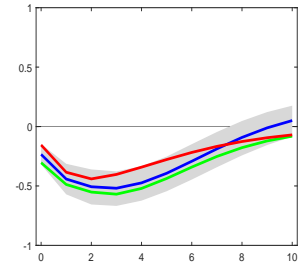

(i) $L^{T} / L$

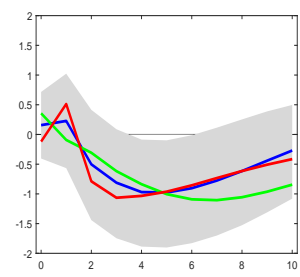

(m) $W^{T} / P_{C}$

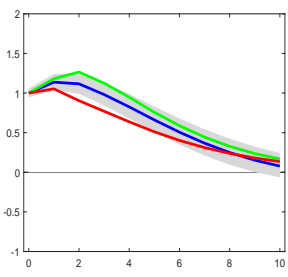

(b) Gov. spending

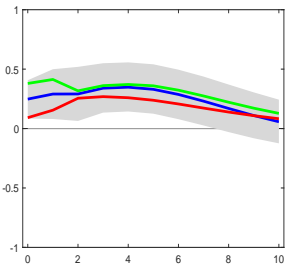

(f) $Y^{N} / Y$

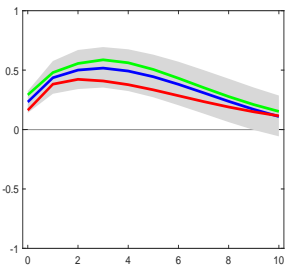

(j) $L^{N} / L$

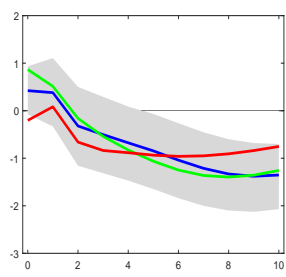

(n) $W^{N} / P_{C}$

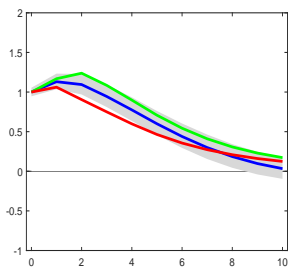

(c) Gov. spending

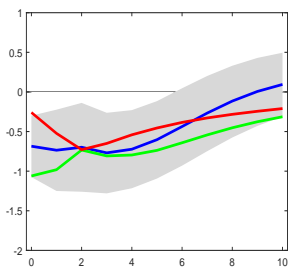

(g) $Y^{T} / Y^{N}$

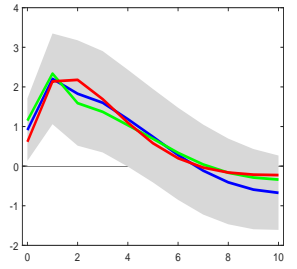

(k) $P$

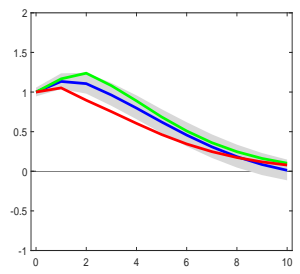

(d) Gov. spending

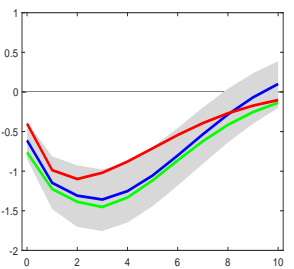

(h) $L^{T} / L^{N}$

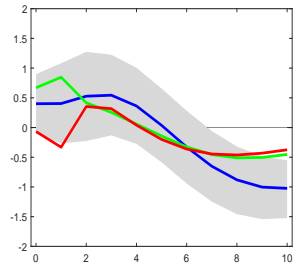

(1) $\Omega$

Figure 29: Sectoral Composition Effects of an Unanticipated Government Spending Shock: Assessing Differences between Recessions and Expansions. Notes: Exogenous increase in government final consumption expenditure by $1 \%$ of GDP. The solid blue line reports the results for VAR models which are augmented with the identified government spending shock, $\epsilon_{G, i t}$ in the first VAR model $z_{i t}=\left[g_{i t}, y_{i t}, l_{i t}, j e_{i t}, w_{C, i t}\right]$. The shaded area indicates the 90 percent confidence bounds obtained by bootstrap sampling. The solid red (green) line shows aggregate and sectoral effects of the same identified government spending shock except that changes in public expenditure are implemented when the economy is in recession (expansion). Sample: 16 OECD countries, 1970-2007, annual data. 


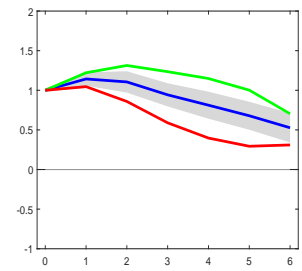

(a) Gov. spending

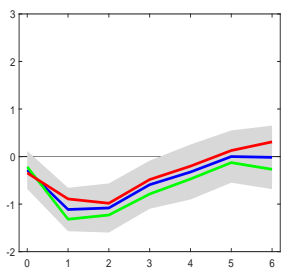

(e) Current Account

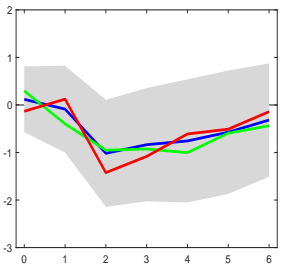

(i) $W^{T} / P_{C}$

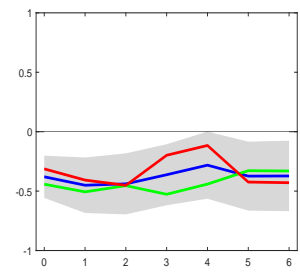

(m) $Y^{T} / Y$

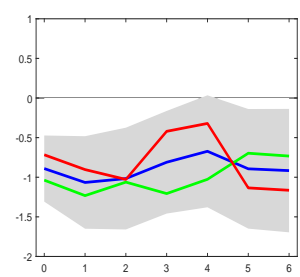

(q) $Y^{T} / Y^{N}$

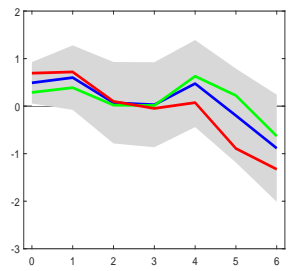

(b) $Y$

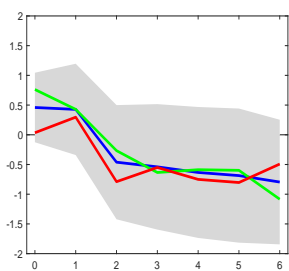

(f) $W / P_{C}$

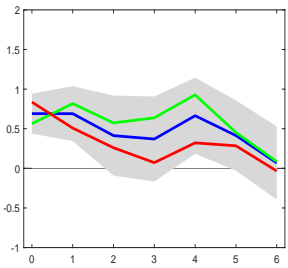

(j) $Y^{N}$

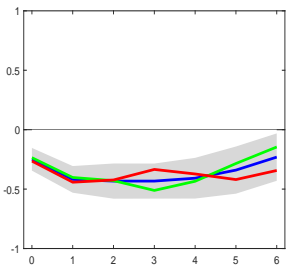

(n) $L^{T} / L$

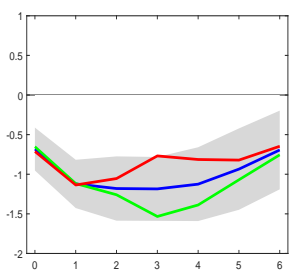

(r) $L^{T} / L^{N}$

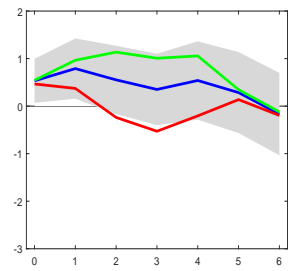

(c) $L$

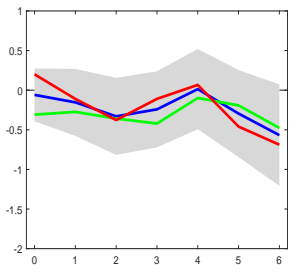

(g) $Y^{T}$

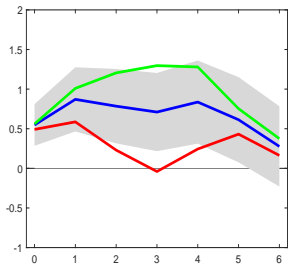

(k) $L^{N}$

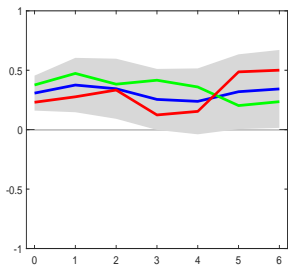

(o) $Y^{N} / Y$

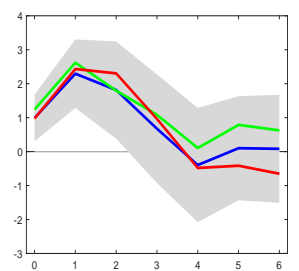

(s) $P$

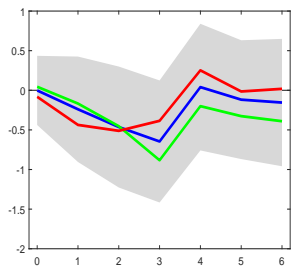

(d) Investment

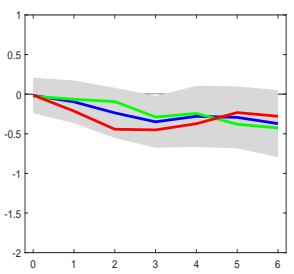

(h) $L^{T}$

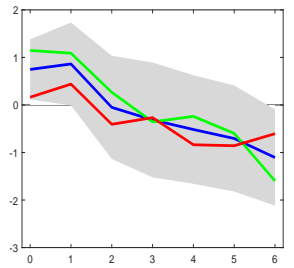

(1) $W^{N} / P_{C}$

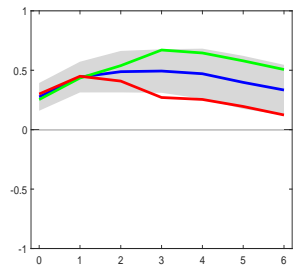

(p) $L^{N} / L$

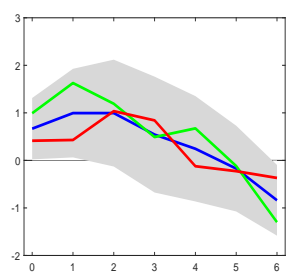

(t) $\Omega$

Figure 30: Effects of an Unanticipated Government Spending Shock: Assessing Differences between Recessions and Expansions Using Local Projection. Notes: Exogenous increase in government final consumption expenditure by $1 \%$ of GDP. The solid blue line reports the results obtained by using Jordà's [2005] local projection method to estimate impulse responses. For the baseline case, we estimate eq. (72) where the government spending shock is identified by adopting the Blanchard and Perotti [2002] assumption. The shaded area indicates the 90 percent confidence bounds. The solid red (green) line shows aggregate and sectoral effects of the same identified government spending shock except that changes in public expenditure are implemented when the economy is in recession (expansion). Sample: 16 OECD countries, 1970-2007, annual data. 
split the estimated exogenous government spending shocks depending on whether $\epsilon_{G, i t}$ has positive or negative values. For this purpose we build two dummy variables, denoted by $D U_{G, i t}^{+}$and $D U_{G, i t}^{-}$, that indicates whether the government spending shock is expansionary or contractionary:

$$
\begin{aligned}
& D U_{G, i t}^{+}=1 \text { if } \epsilon_{G, i t}>0 \text { and } 0 \text { otherwise, } \\
& D U_{G, i t}^{-}=1 \text { if } \epsilon_{G, i t}<0 \text { and } 0 \text { otherwise. }
\end{aligned}
$$

As can be seen in columns 3 and 4 of Table 9, more than half of the identified government spending shocks are contractionary. The last four columns of the Table 9 show the fraction of expansions/recessions which are associated with increases/decreases in government spending. For example, column 6 indicates that OECD countries spend, on average, 30.6 percent of the time in expansions with government spending going down. Furthermore, when the economy is in recession, government spending is going down in about 23.7 percent of the time, see column 7. All of these empirical facts are well in line with those documented by Riera-Crichton, Vegh, and Vuletin [2015]. While the authors consider a panel of 29 OECD countries and estimate state-dependent multipliers along four dimensions by using semiannual data, our own sample size prevents us from performing such an analysis; we thus estimate the same VAR model by separating increases and decreases in government spending and do not differentiate between expansions and recessions.

In the second step, the series of previously identified fiscal shocks is used to assess the dynamic effects of government spending on aggregate and sectoral macroeconomic variables of interest. Accordingly, we replicate the exercise of the previous section and consider augmented VAR and Jordà's [2005] local projection approaches. We augment each VAR model with the identified government spending shocks, ordered first, and consider the following VAR models:

$$
\begin{aligned}
z_{i t} & =\left[\epsilon_{G, i t}, g_{i t}, \operatorname{variables}_{i t}\right], \\
z_{i t}^{+} & =\left[\epsilon_{G, i t}^{+}, g_{i t}, \operatorname{variables}_{i t}\right], \\
z_{i t}^{-} & =\left[\epsilon_{G, i t}^{-}, g_{i t}, \operatorname{variables}_{i t}\right],
\end{aligned}
$$

where the shock is simply given by $\epsilon_{G, i t}$ in the baseline model, $\epsilon_{G, i t}^{+}=D U_{i t}^{+} \epsilon_{G, i t}$ when government spending is expansionary, $\epsilon_{G, i t}^{-}=D U_{i t}^{-} \epsilon_{G, i t}$ when government spending is contractionary, where $D U^{k}$ (with $k=+,-$ ) is a dummy variable that indicates whether the spending shock is positive or negative. By exploring empirically these three VAR specifications, we thus consider the same government spending shock but allow all of the coefficients of the model to vary according whether government spending increases or decreases. To have a reference point, we estimate all VAR specifications detailed in the main text and then we contrast them with those obtained when the State spends more or cuts expenditure.

Next, in order to allow for non-linearities in the response function, we alternatively adopt the Jordà method and thus estimate (72) for each horizon $h$. To differentiate between positive and negative government spending shocks, we modify our linear specification (72) by adding a dummy variable:

$$
\begin{aligned}
x_{i, t+h}^{k} & =D U_{i t}^{k} \cdot\left[\psi_{h}^{k}(L) z_{t-1}+\gamma_{h}^{k} \cdot \epsilon_{G, i t}\right] \\
& +D U_{i t}^{-k} \cdot\left[\psi_{h}^{-k}(L) z_{t-1}+\gamma_{h}^{-k} \cdot \epsilon_{G, i t}\right]+\alpha_{i, h}+\beta_{i, h} \cdot t+\nu_{i, t},
\end{aligned}
$$

where $k=+,-,-k=-,+$ and $D U^{k}$ (with $k=+,-$ ) is a dummy variable that indicates whether the shock is positive or negative. Like for the VAR approach, our aim is to estimate the coefficients of the model which are allowed to vary according to whether the government spending shocks are expansionary or contractionary.

Aggregate and Sectoral Effects. The first two columns of Figure 31 show aggregate effects of a government spending shock in the solid blue line and contrast the effects of an expansionary government spending displayed in the green line with those when the shock is contractionary. Because a decline in government spending leads to opposite effects to those triggered by increases in public purchases, for comparison purposes, we take the opposite of all impulse responses in the former case by considering a rise in government spending by $1 \%$ of GDP. As shown in the first row, decreases in government spending display a smaller magnitude than increases in $G$ but the difference is quite moderate. The second row reports the output effects of a government spending shock. Like RieraCrichton, Vegh, and Vuletin [2015], we find that the output multiplier is smaller when government spending is going down. However, as can be seen in the third row, the fiscal multiplier for hours worked is higher when the shock is contractionary. Given our normalization, it means that hours worked fall sharply when government spending is going down. We provide below an explanation to this result which is based on the asymmetry in labor mobility costs.

The last two columns of Figure 31 show the effects on output and hours worked in the traded and the non traded sector. The second row reveals that differences in the estimated effects of sectoral 
output multipliers are quite moderate if not absent. However, the responses of sectoral hours worked are quite distinct whether the shock is contractionary or expansionary (but the differences are not statistically significant). As can be seen in the third row, while the fiscal multiplier for employment in the traded sector is negative when the government spending shock is expansionary, it turns out to be positive when the shock is contractionary. This result means that traded hours decline whether government spending is going up or down. The difference is that in the latter case, the negative impact on $L^{T}$ caused by the decline in labor supply more than offsets the positive impact triggered by the reallocation of labor toward the traded sector. As discussed below, the shift of labor toward the traded sector is less when the government spending is going down since both the non tradable intensity in the government spending shock and the degree of labor mobility are lower.

Non Tradable Content of Government Spending Shocks. Figure 32 contrasts the effects of a government spending shock on its two components when the shock is expansionary (displayed in the green line) with those when the shock is contractionary (displayed in the red line). When government spending is going up, the non traded sector sector is strongly intensive in the government spending shock on impact while when government spending is going down, the non tradable content of public expenditure is lower and thus the rise in the relative size of the traded sector should be less. Because the non traded sector is less intensive in the government spending shock when the shock is contractionary, incentives to reallocate resources toward the traded sector are lower.

Sectoral Composition Effects. The first two columns of Figure 33 show the changes in the sectoral shares measured in terms of employment and real GDP as well. Evidence reveals that changes in sectoral shares of employment are less when government spending is going down. As emphasized above, there are two explanations to this result. First, the non tradable content of government spending cuts is lower than that of government spending increases. As can be seen in the third column, the change in the relative price is less pronounced when the shock is contractionary which corroborates our result related to higher intensity of government spending in traded goods when the shock is contractionary. In other words, the relative price of non tradables depreciates by a smaller amount if government expenditure are decreased. As a result, there are less incentives to shift labor toward the traded sector. Because non traded wages decline less, the real aggregate wage falls by a smaller amount. This result is also in line with our findings in Figure 31 , see the fourth row of the first two columns. The second explanation to smaller changes in sectoral shares of employment when the shock is contractionary is lower labor mobility across sectors. In line with this hypothesis, the change in the relative wage displays a much greater magnitude when the shock is contractionary. In other words, our evidence suggest that workers experience greater mobility costs when shifting hours worked from the non traded to the traded sector produces; these costs are reflected in a greater sectoral wage differential. It is worth mentioning that the differences are not statistically significant though. As explained below, these larger mobility costs can rationalize the greater response of labor supply when government spending is going down.

Labor Mobility and Asymmetry in the Response of Aggregate Labor Supply. Government spending cuts produce an excess supply in the non traded goods markets. When labor mobility costs are larger, less labor moves away from the non traded to the traded sector. As a result, the excess supply in the non traded goods market is greater which should depreciate the relative price of non tradables more. The large depreciation in the relative price of non tradables provides high incentives to shift capital toward the traded sector. The capital-labor ratio in the traded sector increases more while the capital-labor ratio in the non traded sector declines more. Thus, non traded wages decrease sharply which in turn drives down the aggregate wage and thus encourage households to supply less labor. Moreover, as a result of the greater depreciation in the relative price of non tradables, the real aggregate wage declines less than if labor mobility were higher. This chain of events can rationalize our evidence, except for the change in the relative price which is found to display a smaller magnitude when the shock is contractionary.

Local Projection. Figure 34 shows the responses obtained with the local projections methods to the three identified shocks: $\epsilon_{G, t}$ for the linear model (the solid blue line and the shaded area which indicates the 90 percent confidence bands), $\epsilon_{G, i t}^{+}$when government spending goes up (the green line) and $\epsilon_{G, i t}^{-}$when government spending goes down (the red line). By and large, the results are similar to those obtained when estimating a VAR model. Given our normalization, hours worked fall sharply when government spending is going down. Finally, less labor shifts toward the traded sector as a result of greater mobility costs when the government spending is contractionary.

\section{G Solving the Small Open Economy Model and Solutions for Temporary Government Spending Shocks}

This section presents in more details our open economy setup with imperfect mobility of labor and adjustment costs to physical capital accumulation. Then we provide the main steps for the derivation of formal solutions following a temporary government spending shock splits between non 


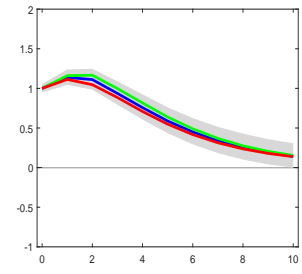

(a) Gov. spending

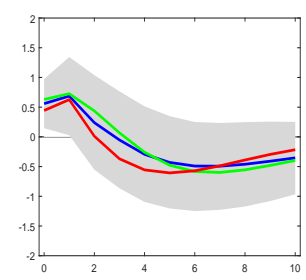

(e) $Y$

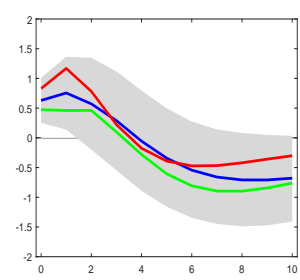

(i) $L$

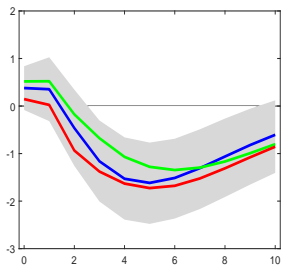

(m) $W / P_{C}$

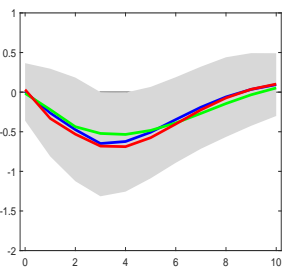

(q) Investment

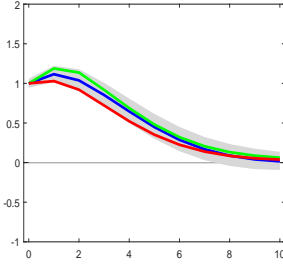

(b) Gov. spending

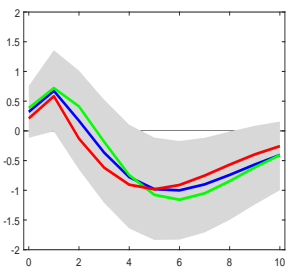

(f) $Y$

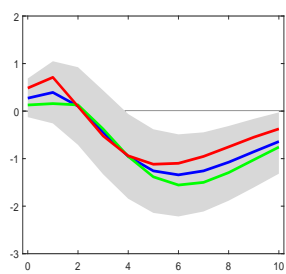

(j) $L$

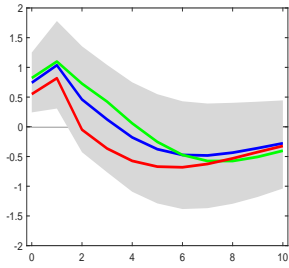

(n) $W / P_{C}$

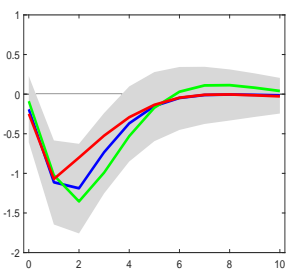

(r) Current Account

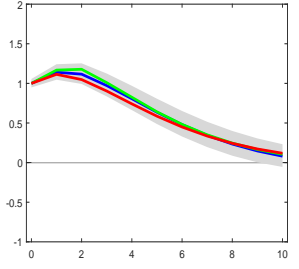

(c) Gov. spending

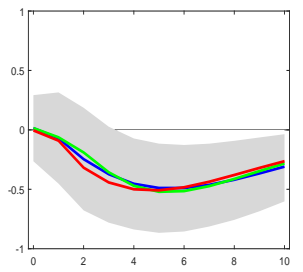

(g) $Y^{T}$

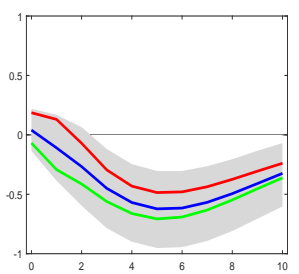

(k) $L^{T}$

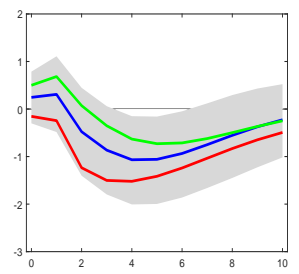

(o) $W^{T} / P_{C}$

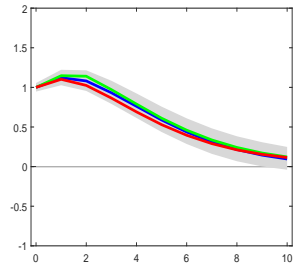

(d) Gov. spending

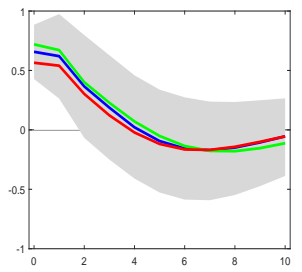

(h) $Y^{N}$

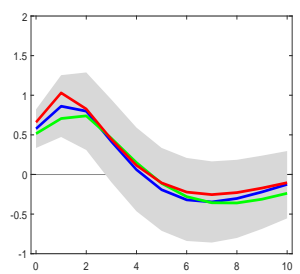

(l) $L^{N}$

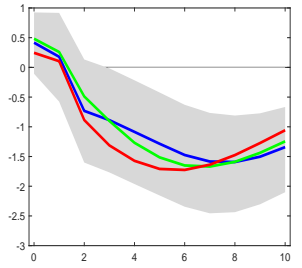

(p) $W^{N} / P_{C}$

Figure 31: Aggregate and Sectoral Effects of an Unanticipated Government Spending Shock: Assessing Differences between Expansionary and Contractionary Government Spending Shocks. Notes: Exogenous change in government final consumption expenditure by $1 \%$ of GDP. The solid blue line reports the results for VAR models which are augmented with the identified government spending shock, $\epsilon_{G, i t}$, from the first VAR model $z_{i t}=\left[g_{i t}, y_{i t}, l_{i t}, j e_{i t}, w_{C, i t}\right]$. The shaded area indicates the 90 percent confidence bounds obtained by bootstrap sampling. The solid red (green) line shows aggregate and sectoral effects of a negative (positive) government spending shock. Sample: 16 OECD countries, 1970-2007, annual data. 


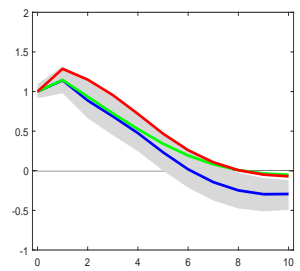

(a) Gov. spending

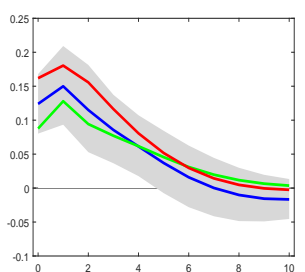

(b) $G^{T}$

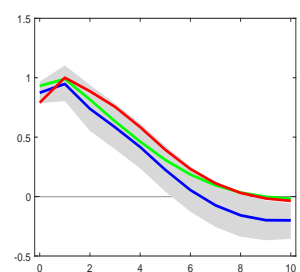

(c) $G^{N}$

Figure 32: Effects of an Unanticipated Government Spending Shock on Government Final Consumption Expenditure on Non Tradables and Tradables: Assessing Differences between Expansionary and Contractionary Government Spending Shocks. Notes: Exogenous Change in government consumption by $1 \%$ of GDP. The government spending shock is identified by estimating a VAR model that includes real government final consumption expenditure, GDP (constant prices), total hours worked, private fixed investment, and the real consumption wage. The responses of government final consumption expenditure on non tradables (i.e., $G^{N}$ ) and tradables (i.e., $G^{T}$ ) to the identified government spending shock are displayed by solid blue lines with the shaded area indicating the 90 percent confidence bounds obtained by bootstrap sampling. Sample: 13 OECD countries, 1995-2015, annual data. The solid red (green) line shows the effects of a negative (positive) government spending shock.

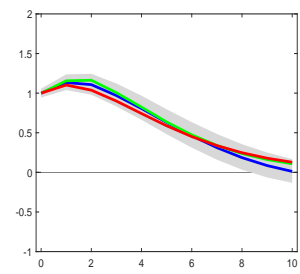

(a) Gov. spending

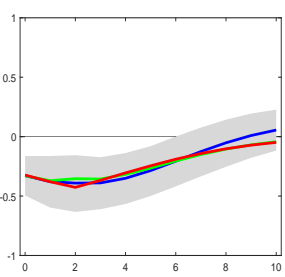

(e) $Y^{T} / Y$

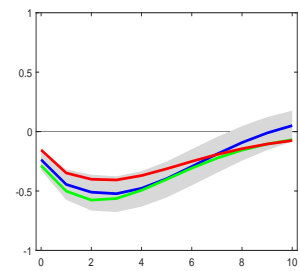

(i) $L^{T} / L$

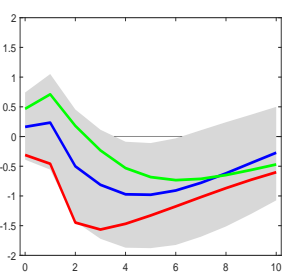

(m) $W^{T} / P_{C}$

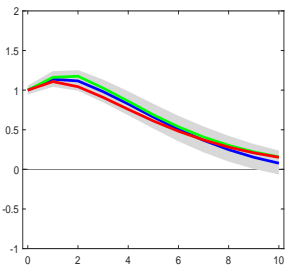

(b) Gov. spending

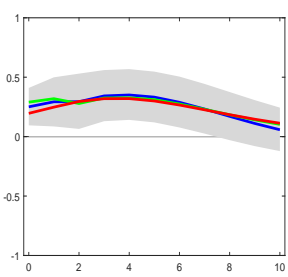

(f) $Y^{N} / Y$

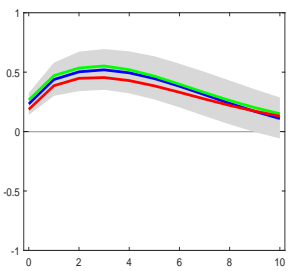

(j) $L^{N} / L$

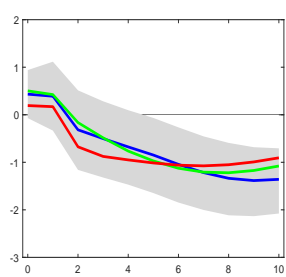

(n) $W^{N} / P_{C}$

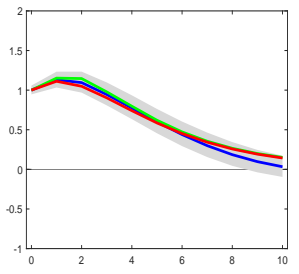

(c) Gov. spending

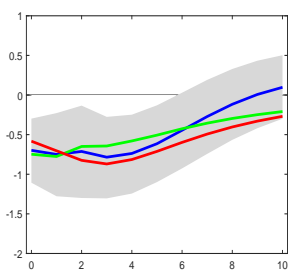

(g) $Y^{T} / Y^{N}$

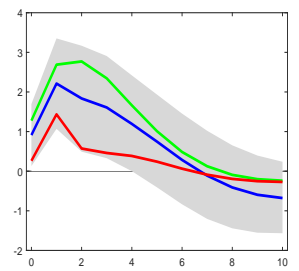

(k) $P$

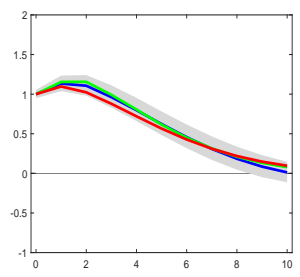

(d) Gov. spending

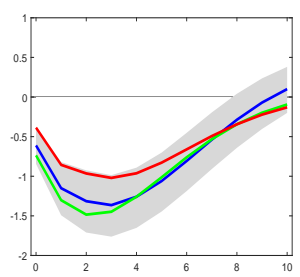

(h) $L^{T} / L^{N}$

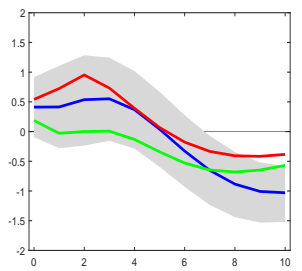

(l) $\Omega$

Figure 33: Sectoral Composition Effects of an Unanticipated Government Spending Shock: Assessing Differences between Expansionary and Contractionary Government Spending Shocks. Notes: Exogenous change in government final consumption expenditure by $1 \%$ of GDP. The solid blue line reports the results for VAR models which are augmented with the identified government spending shock, $\epsilon_{G, i t}$ from the first VAR model $z_{i t}=\left[g_{i t}, y_{i t}, l_{i t}, j e_{i t}, w_{C, i t}\right]$. The shaded area indicates the 90 percent confidence bounds obtained by bootstrap sampling. The solid red (green) line shows aggregate and sectoral effects of a negative (positive) government spending shock. Sample: 16 OECD countries, 1970-2007, annual data. 


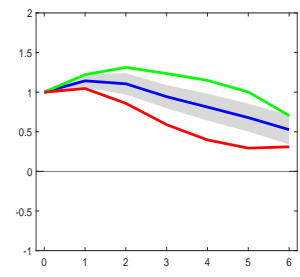

(a) Gov. spending

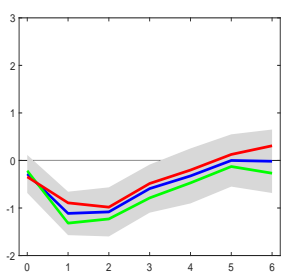

(e) Current Account

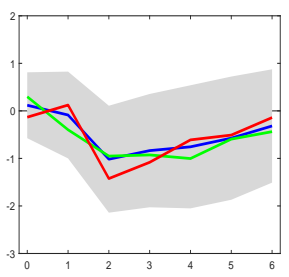

(i) $W^{T} / P_{C}$

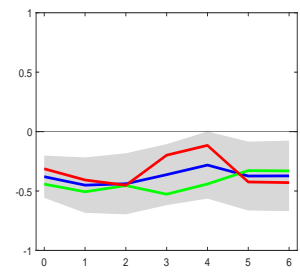

(m) $Y^{T} / Y$

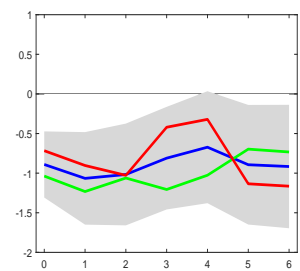

(q) $Y^{T} / Y^{N}$

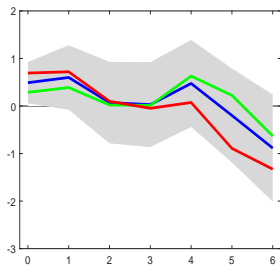

(b) $Y$

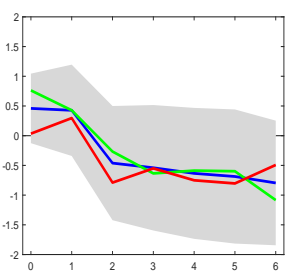

(f) $W / P_{C}$

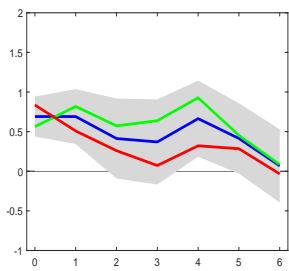

(j) $Y^{N}$

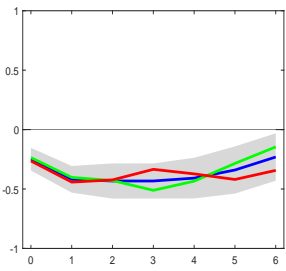

(n) $L^{T} / L$

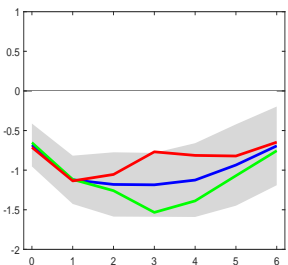

(r) $L^{T} / L^{N}$

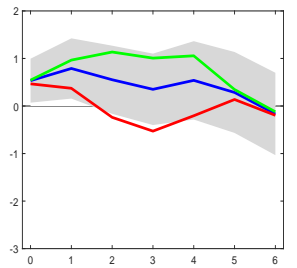

(c) $L$

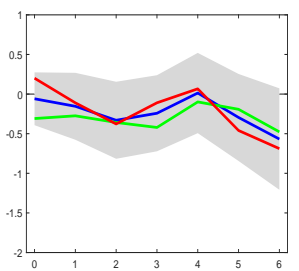

(g) $Y^{T}$

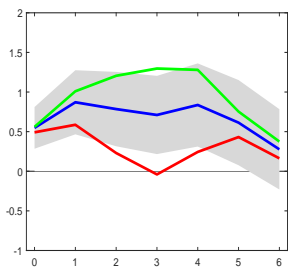

(k) $L^{N}$

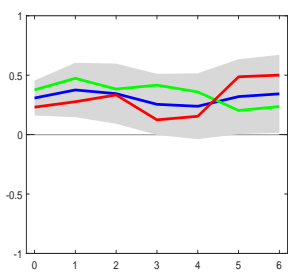

(o) $Y^{N} / Y$

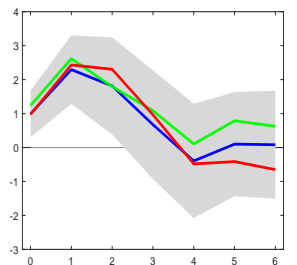

(s) $P$

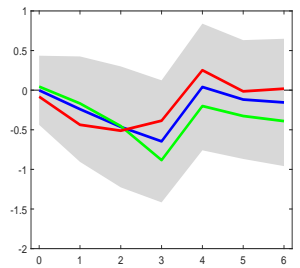

(d) Investment

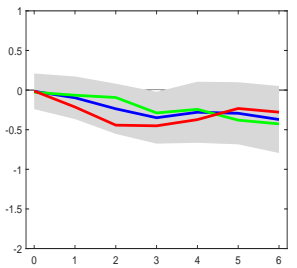

(h) $L^{T}$

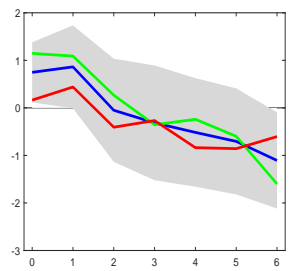

(1) $W^{N} / P_{C}$

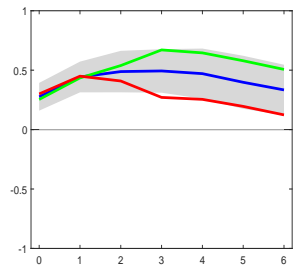

(p) $L^{N} / L$

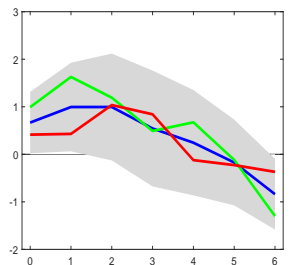

(t) $\Omega$

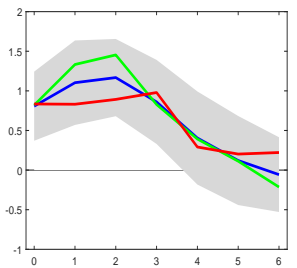

(u) $L R$

Figure 34: Effects of an Unanticipated Government Spending Shock: Assessing Differences between Expansionary and Contractionary Government Spending Shocks Using Local Projection. Notes: Exogenous increase in government final consumption expenditure by $1 \%$ of GDP. The solid blue line reports the results obtained by using Jordà's [2005] local projection method to estimate impulse responses. For the baseline case, we estimate eq. (72) where the government spending shock is identified by adopting the Blanchard and Perotti [2002] assumption. The shaded area indicates the 90 percent confidence bounds. The solid red (green) line shows aggregate and sectoral effects of contractionary (expansionary) government spending shocks. For comparison purposes, we consider an increase in government consumption in both cases which amounts to take opposite responses to impulse responses. Sample: 16 OECD countries, 1970-2007, annual data. 
tradables and tradables.

\section{G.1 First-Order Conditions}

The representative household chooses consumption, decides on labor supply, and investment that maximizes his/her lifetime utility:

$$
U=\int_{0}^{\infty}\left\{\frac{1}{1-\frac{1}{\sigma_{C}}} C(t)^{1-\frac{1}{\sigma_{C}}}-\frac{1}{1+\frac{1}{\sigma_{L}}} L(t)^{1+\frac{1}{\sigma_{L}}}\right\} e^{-\beta t} \mathrm{~d} t
$$

subject to the flow budget constraint:

$$
\dot{B}(t)=r^{\star} B(t)+R(t) K(t)+W(t) L(t)-T(t)-P_{C}(P(t)) C(t)-P_{J}(P(t)) J(t),
$$

and capital accumulation which evolves as follows:

$$
\dot{K}(t)=I(t)-\delta_{K} K(t) .
$$

We assume that capital accumulation is subject to increasing and convex cost of net investment:

$$
J(t)=I(t)+\frac{\kappa}{2}\left(\frac{I(t)}{K(t)}-\delta_{K}\right)^{2} K(t) .
$$

The first order conditions from the representative household maximization problem are:

$$
\begin{gathered}
C=\left(P_{C}(t) \bar{\lambda}\right)^{-\sigma_{C}}, \\
L=(W(t) \bar{\lambda})^{\sigma_{L}}, \\
\frac{I(t)}{K(t)}=\frac{1}{\kappa}\left(\frac{Q(t)}{P_{J}(t)}-1\right)+\delta_{K}, \\
\dot{\lambda}(t)=\lambda(t)\left(\beta-r^{\star}\right), \\
\dot{Q}(t)=\left(r^{\star}+\delta_{K}\right) Q(t)-\left\{R(t)+P_{J}(t) \frac{\kappa}{2}\left(\frac{I(t)}{K(t)}-\delta_{K}\right)\left(\frac{I(t)}{K(t)}+\delta_{K}\right)\right\},
\end{gathered}
$$

together with intratemporal decisions on allocation between tradables and non tradables

$$
\begin{gathered}
C^{N}(t)=(1-\varphi)\left(\frac{P(t)}{P_{C}(t)}\right)^{-\phi} C(t), \\
C^{T}(t)=\varphi\left(\frac{1}{P_{C}(t)}\right)^{-\phi} C(t), \\
L^{N}(t)=(1-\vartheta)\left(\frac{W^{N}(t)}{W(t)}\right)^{\epsilon} L(t), \\
L^{T}(t)=\vartheta\left(\frac{W^{T}(t)}{W(t)}\right)^{\epsilon} L(t) \\
J^{N}(t)=\frac{\alpha_{J} P_{J}(t) J(t)}{P(t)}, \\
J^{T}(t)=\left(1-\alpha_{J}\right) P_{J}(t) J(t),
\end{gathered}
$$

with consumption, investment and wage indices described by

$$
\begin{gathered}
P_{C}(t)=\left[\varphi+(1-\varphi)(P(t))^{1-\phi}\right]^{\frac{1}{1-\phi}}, \\
P_{J}(t)=P(t)^{\alpha_{J}}, \\
W(t)=\left[\vartheta\left(W^{T}(t)\right)^{\epsilon+1}+(1-\vartheta)\left(W^{N}(t)\right)^{\epsilon+1}\right]^{\frac{1}{\epsilon+1}} .
\end{gathered}
$$

In an open economy model with a representative agent who has perfect foresight, a constant rate of time preference and perfect access to world capital markets, we impose $\beta=r^{\star}$ in order to generate an interior solution. Setting $\beta=r^{\star}$ into (81d) yields $\lambda=\bar{\lambda}$.

We assume constant returns to scale technology of production. Production functions take a Cobb-Douglas form.

$$
\begin{gathered}
Y^{T}(t)=Z^{T} L^{T}(t)\left(k^{T}(t)\right)^{1-\theta^{T}}, \\
Y^{N}(t)=Z^{N} L^{N}(t)\left(k^{N}(t)\right)^{1-\theta^{N}},
\end{gathered}
$$


Both sectors are assumed to be perfectly competitive and thus choose capital and labor by taking prices as given:

$$
\max _{K^{j}, L^{j}} \Pi^{j}=\max _{K^{j}, L^{j}}\left\{P^{j} Y^{j}-W^{j} L^{j}-R K^{j}\right\} .
$$

Since capital can move freely between the two sectors, the value of marginal products in the traded and non traded sectors equalizes while costly labor mobility implies a wage differential across sectors:

$$
\begin{gathered}
Z^{T}\left(1-\theta^{T}\right)\left(k^{T}(t)\right)^{-\theta^{T}}=P(t) Z^{N}\left(1-\theta^{N}\right)\left(k^{N}(t)\right)^{-\theta^{N}} \equiv R(t), \\
Z^{T} \theta^{T}\left(k^{T}(t)\right)^{1-\theta^{T}} \equiv W^{T}(t) \\
P(t) Z^{N} \theta^{N}\left(k^{N}(t)\right)^{1-\theta^{N}} \equiv W^{N}(t),
\end{gathered}
$$

where $k^{j} \equiv K^{j} / L^{j}$ denotes the capital-labor ratio for sector $j=T, N$. Aggregating over the two sectors gives us the resource constraint for capital:

$$
K^{T}(t)+K^{N}(t)=K(t)
$$

\section{G.2 Solving the Model}

Government spending is a fixed fraction $\omega_{G}$ of GDP, $Y$. Government expenditure on non tradables and tradables are fixed fraction of government consumption at $\omega_{G}^{N}$ and $1-\omega_{G}^{N}$, respectively. To fully describe equilibrium, we impose the market clearing condition for non tradables. Using the fact that $R K+W L=Y^{T}+P Y^{N}$ and inserting the market clearing condition for non tradables into (78) gives the market clearing condition for tradables, i.e., the current account. Government spending rules, and market clearing conditions can be summarized as follows:

$$
\begin{gathered}
G(t)=\omega_{G} Y(t), \\
P G^{N}(t)=\omega_{G^{N}} G(t), \\
G^{T}(t)=\left(1-\omega_{G^{N}}\right) G(t), \\
Y^{N}(t)=C^{N}(t)+G^{N}(t)+J^{N}(t), \\
\dot{B}(t)=r^{\star} B(t)+Y^{T}(t)-J^{T}(t)-C^{T}(t)-G^{T}(t), \\
Y_{R}(t)=Y^{T}(t)+P Y^{N}(t),
\end{gathered}
$$

where $Y_{R}(t)$ is real GDP.

Inserting (81a) into (82a)-(82b) allows us to solve for consumption in non tradables and tradables, i.e., $C^{j}=C^{j}(\bar{\lambda}, P)$. Inserting (81b) into (82c)-(82d) allows us to solve for labor supply to the non traded and traded sector, i.e., $L^{j}=L^{j}\left(\bar{\lambda}, W^{T}, W^{N}\right)$. Plugging first the solutions for $L^{T}$ and $L^{N}$ into the resource constraint for capital, the system consisting of (86a)-(86c) and (87) can be solved for sectoral capital-labor ratio $k^{j}=k^{j}(\bar{\lambda}, K, P)$ and sectoral wage $W^{j}=W^{j}(\bar{\lambda}, K, P)$ (with $j=T, N)$. Inserting $k^{T}(\bar{\lambda}, K, P)$ into $R=Z^{T}\left(k^{T}\right)^{-\theta^{T}}$ allows us to solve for the return on domestic capital, i.e., $R=R(\bar{\lambda}, K, P)$. Inserting short-run solutions for sectoral capital-labor ratios and sectoral labor into production functions $(84 \mathrm{a})-(84 \mathrm{~b})$ allows us to solve for sectoral output: $Y^{j}=Y^{j}(\bar{\lambda}, K, P)$. Finally, eq. (81c) can be solved for the investment rate, i.e., $\frac{I}{K}=v\left(\frac{Q}{P_{I}(P)}\right)+\delta_{K}$, where $v()=.\frac{1}{\kappa}\left(\frac{Q}{P_{J}}-1\right)$.

Inserting first solutions for $C^{N}$ and $Y^{N}$, and substituting $J^{N}$ described by (82e) while using (83b), the non traded goods market clearing condition (88d) can be rewritten as follows:

$Y^{N}(\bar{\lambda}, K(t), P(t))=C^{N}(\bar{\lambda}, P(t))+G^{N}(t)+\alpha_{J} P(t)^{\alpha_{J}-1} K(t)\left\{v\left(\frac{Q(t)}{\left.P_{J}(t)\right)}\right)+\delta_{K}+\frac{\kappa}{2}\left[v\left(\frac{Q(t)}{P_{J}(t)}\right)\right]^{2}\right\}$.

Eq. (89) can be solved for the relative price of non tradables:

$$
P(t)=P\left(\bar{\lambda}, K(t), Q(t), G^{N}(t)\right) .
$$

Making use of (79)-(80) and (88d), the capital accumulation equation reads as follows:

$$
\dot{K}(t)=\frac{Y^{N}(t)-C^{N}(t)-G^{N}(t)}{\alpha_{J} P(t)^{\alpha_{J}-1}}-\delta_{K} K(t)-\frac{\kappa}{2}\left(\frac{I(t)}{K(t)}-\delta_{K}\right)^{2} K(t) .
$$

Inserting (90) into solutions for non traded output, consumption in non tradables, optimal investment decision, and the return of domestic capital and plugging them back into the physical capital 
accumulation equation (91) and the dynamic equation for the shadow value of capital stock (81e) and making use of $(88 \mathrm{~b})$, the adjustment of the open economy towards the steady-state is described by a dynamic system which comprises two equations that form a separate subsystem in $K$ and $Q$, i.e.,

$$
\begin{aligned}
\dot{K}(t) & \equiv \Upsilon(K(t), Q(t), G(t)) \\
\dot{Q}(t) & \equiv \Sigma(K(t), Q(t), G(t))
\end{aligned}
$$

Inserting (82f) into (88e), and using the fact that $P_{J} J=\frac{P\left(Y^{N}-C^{N}-G^{N}\right)}{\alpha_{J}}$ by combining (82f) and $(88 \mathrm{~d})$, the current account equation can be rewritten as follows:

$$
\dot{B}(t)=r^{\star} B(t)+Y^{T}(t)-C^{T}(t)-G^{T}(t)-\left(\frac{1-\alpha_{J}}{\alpha_{J}}\right) P(t)\left(Y^{N}(t)-C^{N}(t)-G^{N}(t)\right),
$$

Inserting first (90) into solutions for traded and non traded output, consumption in tradables and non tradables, optimal investment decision, plugging back them back into (93) and making use of (88b)-(88c), the accumulation equation for traded bonds reads as:

$$
\dot{B}(t) \equiv r^{\star} B+\Xi(K, Q, G)
$$

Linearizing (92a)-(92b) in the neighborhood of the steady-state, assuming saddle-path stability and denoting the eigenvalue by $\nu_{i}$, the general solutions for the capital stock and its shadow value are $K(t)-\tilde{K}=\sum_{i=1}^{2} D_{i} e^{\nu_{i} t}$ and $Q(t)-\tilde{K}=\sum_{i=1}^{2} \omega_{2}^{i} D_{i} e^{\nu_{i} t}$ where $\left(1, \omega_{2}^{i}\right)^{\prime}$ is the eigenvector associated with eigenvalue $\nu_{i}$. Linearizing (94) around the steady-state, substituting the solutions for $K(t)$ and $Q(t)$, solving and invoking the transversality condition, yields the nations's intertemporal solvency condition:

$$
\tilde{B}-B_{0}=\Psi_{1}\left(\tilde{K}-K_{0}\right)
$$

where we denote the steady-state value with a tilde, $B_{0}$ and $K_{0}$ are initial foreign asset position and the initial stock of physical capital, and $\Psi_{1}=\frac{\Xi_{K}+\Xi_{Q} \omega_{2}^{1}}{\nu_{1}-r^{\star}}$ with partial derivatives evaluated at the steady-state.

Setting $\dot{K}=\dot{Q}=\dot{B}=0$ into (79), (81e) and (88e), the initial steady-state reduces to:

$$
\begin{gathered}
Z^{T}\left(1-\theta^{T}\right)\left[k^{T}(\tilde{K}, \tilde{P}, \bar{\lambda})\right]^{-\theta^{T}}=P_{J}(\tilde{P})\left(r^{\star}+\delta\right), \\
Y^{N}(\tilde{K}, \tilde{P}, \bar{\lambda})=C^{N}(\tilde{P}, \bar{\lambda})+\alpha_{J} \tilde{P}^{\alpha_{J}-1} \delta_{K} \tilde{K}+G^{N}, \\
r^{\star} \tilde{B}+Y^{T}(\tilde{K}, \tilde{P}, \bar{\lambda})=C^{T}(\tilde{P}, \bar{\lambda})+\left(1-\alpha_{J}\right) \tilde{P}^{\alpha_{J}} \delta_{K} \tilde{K}+G^{T}, \\
\tilde{B}-B_{0}=\Psi_{1}\left(\tilde{K}-K_{0}\right) .
\end{gathered}
$$

These four equations jointly determine the values for $P, K, B$ and $\bar{\lambda}$ at the initial long-run equilibrium. Eq. (96d) shows that assumption $\beta=r^{\star}$ requires the joint determination of the transition and the steady state since the term $\Psi_{1}$ ia a function of eigenvalues and eigenvectors.

\section{G.3 Solving for Temporary Government Spending Shocks}

Because the endogenous response of government spending to an exogenous fiscal shock is humpshaped, we assume that government consumption as a percentage of GDP evolves according to the following dynamic equation:

$$
\frac{d G(t)}{Y}=\left[e^{-\xi t}-(1-g) e^{-\chi t}\right]
$$

where $g>0$ parametrizes the magnitude of the exogenous fiscal shock, $\xi>0$ and $\chi>0$ are (positive) parameters which are set in order to capture the non-monotonic endogenous response of $G(t)$. We assume that the rise in government consumption is split between non traded and traded goods in accordance with their respective shares, $\omega_{G^{N}}=\frac{P G^{N}}{G}$ and $\omega_{G^{T}}=\frac{G^{T}}{G}$, respectively. Formally, we thus have:

$$
\frac{d G(t)}{Y}=\omega_{G^{N}} \frac{d G}{\tilde{Y}}+\omega_{G^{T}} \frac{d G}{\tilde{Y}} .
$$

In line with the evidence we document in the main text and subsection B.2, $\omega_{G^{N}}$ refers to the non tradables content of government consumption and government spending shock as well.

Linearizing (92a)-(92b) in the neighborhood of the steady-state, we get in a matrix form:

$$
\left(\begin{array}{c}
\dot{K}(t) \\
\dot{Q}(t)
\end{array}\right)=\left(\begin{array}{cc}
\Upsilon_{K} & \Upsilon_{Q} \\
\Sigma_{K} & \Sigma_{Q}
\end{array}\right)\left(\begin{array}{c}
K(t)-\tilde{K} \\
Q(t)-\tilde{Q}
\end{array}\right)+\left(\begin{array}{c}
\Upsilon_{G} \\
\Sigma_{G}
\end{array}\right)\left(\begin{array}{c}
G(t)-\tilde{G} \\
G(t)-\tilde{G}
\end{array}\right)
$$


where the coefficients of the Jacobian matrix are partial derivatives evaluated at the steady-state, e.g., $\Upsilon_{X}=\frac{\partial \Upsilon}{\partial X}$ with $X=K, Q$, and the direct effects of an exogenous change in government spending on $K$ and $Q$ are described by $\Upsilon_{G}=\frac{\partial \Upsilon}{\partial G}$ and $\Sigma_{G}=\frac{\partial \Sigma}{\partial G}$, also evaluated at the steady-state.

We denote by $V=\left(V^{1}, V^{2}\right)$ the matrix of eigenvectors with $V^{i, \prime}=\left(1, \omega_{2}^{i}\right)$ and we denote by $V^{-1}$ the inverse matrix of $V$. Let us define:

$$
\left(\begin{array}{c}
X_{1}(t) \\
X_{2}(t)
\end{array}\right) \equiv V^{-1}\left(\begin{array}{c}
K(t)-\tilde{K} \\
Q(t)-\tilde{Q}
\end{array}\right) .
$$

Differentiating w.r.t. time, one obtains:

$$
\begin{aligned}
\left(\begin{array}{c}
\dot{X}_{1}(t) \\
\dot{X}_{2}(t)
\end{array}\right) & =\left(\begin{array}{cc}
\nu_{1} & 0 \\
0 & \nu_{2}
\end{array}\right)\left(\begin{array}{c}
X_{1}(t) \\
X_{2}(t)
\end{array}\right)+V^{-1}\left(\begin{array}{c}
\varepsilon_{K} d G(t) \\
\varepsilon_{Q} d G(t)
\end{array}\right) \\
& =\left(\begin{array}{c}
\nu_{1} X_{1}(t) \\
\nu_{2} X_{2}(t)
\end{array}\right)+\frac{1}{\nu_{1}-\nu_{2}}\left(\begin{array}{c}
\Phi_{1} d G(t) \\
-\Phi_{2} d G(t)
\end{array}\right)
\end{aligned}
$$

where $d G(t)=G(t)-\tilde{G}$ and we set

$$
\begin{aligned}
& \Phi_{1}=\left[\left(\Upsilon_{K}-\nu_{2}\right) \Upsilon_{G}+\Upsilon_{Q} \Sigma_{G}\right], \\
& \Phi_{2}=\left[\left(\Upsilon_{K}-\nu_{1}\right) \Upsilon_{G}+\Upsilon_{Q} \Sigma_{G}\right] .
\end{aligned}
$$

As will be useful later, in order to express solutions in a compact form, we set:

$$
\begin{gathered}
\Gamma_{1}=-\frac{\Phi_{1} Y}{\nu_{1}-\nu_{2}} \frac{1}{\nu_{1}+\xi}, \\
\Gamma_{2}=-\frac{\Phi_{2} Y}{\nu_{1}-\nu_{2}} \frac{1}{\nu_{2}+\xi}, \\
\Theta_{1}=(1-g) \frac{\nu_{1}+\xi}{\nu_{1}+\chi}, \\
\Theta_{2}=(1-g) \frac{\nu_{2}+\xi}{\nu_{2}+\chi} .
\end{gathered}
$$

Solving for $X_{1}(t)$ gives:

$$
\begin{aligned}
X_{1}(t) & =e^{\nu_{1} t}\left\{X_{1}(0)+\frac{\Phi_{1}}{\nu_{1}-\nu_{2}} \int_{0}^{t} d G(\tau) e^{-\nu_{1} \tau} d \tau\right\}, \\
& =e^{\nu_{1} t}\left\{X_{1}(0)+\frac{\Phi_{1} Y}{\nu_{1}-\nu_{2}} \int_{0}^{t}\left[e^{-\left(\xi+\nu_{1}\right) \tau}-(1-g) e^{-\left(\chi+\nu_{1}\right) \tau}\right] d \tau\right\}, \\
& =e^{\nu_{1} t} X_{1}(0)+\frac{\Phi_{1} Y}{\nu_{1}-\nu_{2}}\left[\left(\frac{e^{\nu_{1} t}-e^{-\xi t}}{\nu_{1}+\xi}\right)-(1-g)\left(\frac{e^{\nu_{1} t}-e^{-\chi t}}{\nu_{1}+\chi}\right)\right], \\
& =e^{\nu_{1} t}\left[X_{1}(0)-\Gamma_{1}\left(1-\Theta_{1}\right)\right]+\Gamma_{1}\left(e^{-\xi t}-\Theta_{1} e^{-\chi t}\right),
\end{aligned}
$$

where $\Gamma_{1}$ and $\Theta_{1}$ are given by (102a) and (102c), respectively.

Solving for $X_{2}(t)$ gives:

$$
X_{2}(t)=e^{\nu_{2} t}\left\{X_{2}(0)-\frac{\Phi_{2}}{\nu_{1}-\nu_{2}} \int_{0}^{t} d G(\tau) e^{-\nu_{2} \tau} d \tau\right\} .
$$

Because $\nu_{2}>0$, for the solution to converge to the steady-state, the term in brackets must be nil when we let $t$ tend toward infinity:

$$
\begin{aligned}
X_{2}(0) & =\frac{\Phi_{2} Y}{\nu_{1}-\nu_{2}} \int_{0}^{\infty}\left[e^{-\left(\xi+\nu_{2}\right) \tau}-(1-g) e^{-\left(\chi+\nu_{2}\right) \tau}\right] d \tau, \\
& =\frac{\Phi_{2} Y}{\nu_{1}-\nu_{2}}\left[\frac{1}{\xi+\nu_{2}}-(1-g) \frac{1}{\chi+\nu_{2}}\right], \\
& =-\Gamma_{2}\left(1-\Theta_{2}\right),
\end{aligned}
$$

where $\Gamma_{2}$ and $\Theta_{2}$ are given by (102b) and (102d), respectively.

Inserting first $X_{2}(0)$, the 'stable' solution for $X_{2}(t)$, i.e., consistent with convergence toward the steady-state when $t$ tends toward infinity, is thus given by:

$$
\begin{aligned}
X_{2}(t) & =e^{\nu_{2} t} \frac{\Phi_{2} Y}{\nu_{1}-\nu_{2}} \int_{t}^{\infty}\left[e^{-\left(\xi+\nu_{2}\right) \tau}-(1-g) e^{-\left(\chi+\nu_{2}\right) \tau}\right] d \tau, \\
& =e^{\nu_{2} t} \frac{\Phi_{2} Y}{\nu_{1}-\nu_{2}}\left[\frac{e^{-\left(\xi+\nu_{2}\right) t}}{\xi+\nu_{2}}-(1-g) \frac{e^{-\left(\chi+\nu_{2}\right) t}}{\chi+\nu_{2}}\right], \\
& =-\Gamma_{2}\left(e^{-\xi t}-\Theta_{2} e^{-\chi t}\right) .
\end{aligned}
$$


Eq. (106) corresponds to eq. (27b) in the main text.

Using the definition of $X_{i}(t)$ (with $i=1,2$ ) given by (99), we can recover the solutions for $K(t)$ and $Q(t)$ :

$$
\begin{gathered}
K(t)-\tilde{K}=X_{1}(t)+X_{2}(t), \\
Q(t)-\tilde{Q}=\omega_{2}^{1} X_{1}(t)+\omega_{2}^{2} X_{2}(t) .
\end{gathered}
$$

Eqs. (107) correspond to eqs. (26) in the main text.

Setting $t=0$ into (107a) gives $X_{1}(0)=(K(0)-\tilde{K})-X_{2}(0)$; inserting (105) leads to:

$$
X_{1}(t)=e^{\nu_{1} t}\left[(K(0)-\tilde{K})+\Gamma_{2}\left(1-\Theta_{2}\right)-\Gamma_{1}\left(1-\Theta_{1}\right)\right]+\Gamma_{1}\left(e^{-\xi t}-\Theta_{1} e^{-\chi t}\right) .
$$

Eq. (108) corresponds to eq. (27a) in the main text.

Linearizing the current account equation (94) around the steady state, substituting the solutions for $K(t)$ and $Q(t)$ given by (107), solving and invoking the transversality condition, yields the solution for traded bonds:

$$
\begin{aligned}
B(t)-\tilde{B} & =\frac{\omega_{B}^{1}}{\nu_{1}-r^{\star}} e^{\nu_{1} t}-\frac{\Xi_{G} Y}{\xi+r^{\star}}\left(e^{-\xi t}-\Theta^{\prime} e^{-\chi t}\right)-\frac{N_{1} \Gamma_{1}}{\xi+r^{\star}}\left(e^{-\xi t}-\Theta_{1}^{\prime} e^{-\chi t}\right) \\
& +\frac{N_{2} \Gamma_{2}}{\xi+r^{\star}}\left(e^{-\xi t}-\Theta_{2}^{\prime} e^{-\chi t}\right)
\end{aligned}
$$

where $\omega_{B}^{1}=\left[\Xi_{K}+\Xi_{Q} \omega_{2}^{1}\right]\left[\left(K_{0}-\tilde{K}\right)+\Gamma_{2}\left(1-\Theta_{2}\right)-\Gamma_{1}\left(1-\Theta_{1}\right)\right]$, with $\Xi_{K}=\frac{\partial \Xi}{\partial K}, \Xi_{Q}=\frac{\partial \Xi}{\partial Q}$, and $\Xi_{G}=\frac{\partial \Xi}{\partial G}$ evaluated at the steady-state, and $\Theta^{\prime}=(1-g) \frac{r^{\star}+\xi}{r^{\star}+\chi}$, and $\Theta_{i}^{\prime}=\Theta_{i} \frac{r^{\star}+\xi}{r^{\star}+\chi}$ (with $i=1,2$ ). To ultimately remain solvent, the open economy must satisfy the following condition:

$$
\tilde{B}-B_{0}=-\frac{\omega_{B}^{1}}{\nu_{1}-r^{\star}}+\frac{\omega_{B}^{2}}{\xi+r^{\star}},
$$

where $B_{0}$ is the initial stock of traded bonds and $\omega_{B}^{2}=\Xi_{G} Y\left(1-\Theta^{\prime}\right)+\left[\Xi_{K}+\Xi_{Q} \omega_{2}^{1}\right] \Gamma_{1}\left(1-\Theta_{1}^{\prime}\right)-$ $\left[\Xi_{K}+\Xi_{Q} \omega_{2}^{2}\right] \Gamma_{2}\left(1-\Theta_{2}^{\prime}\right)$. Eq. (110) corresponds to eq. (29) in the main text.

\section{H Solving Analytically the Model without Capital}

In this section, we provide the main steps to solve the two-sector model without capital accumulation. This enables us to shed some light on the implications of a difficulty in reallocating labor across sectors for the fiscal transmission. To ease the interpretation of analytical results, we set the following assumption:

Assumption 1 The elasticity of labor supply across sectors, $\epsilon$, is higher than the intertemporal elasticity of substitution for labor, $\sigma_{L}$.

In order to clearly differentiate the intertemporal from intratemporal channel, we assume that instantaneous utility for aggregate consumption takes a CARA form. The expressions derived below are identical to those shown in the main text by setting $\sigma_{C}=1$.

\section{H.1 First-Order Conditions}

The representative household chooses consumption, decides on labor supply, and investment that maximizes his/her lifetime utility:

$$
U=\int_{0}^{\infty}\left\{\frac{1}{1-\frac{1}{\sigma_{C}}} C(t)^{1-\frac{1}{\sigma_{C}}}-\frac{1}{1+\frac{1}{\sigma_{L}}} L(t)^{1+\frac{1}{\sigma_{L}}}\right\} e^{-\beta t} \mathrm{~d} t
$$

subject to the flow budget constraint:

$$
\dot{B}(t)=r^{\star} B(t)+W(t) L(t)-T(t)-P_{C}(P(t)) C(t) .
$$

Denoting the co-state variable associated with eq. (112) by $\lambda$, the first-order conditions characterizing the representative household's optimal plans are:

$$
\begin{gathered}
C=\left(P_{C}(t) \bar{\lambda}\right)^{-\sigma_{C}}, \\
L=(W(t) \bar{\lambda})^{\sigma_{L}}, \\
\dot{\lambda}(t)=\lambda(t)\left(\beta-r^{\star}\right),
\end{gathered}
$$


and the transversality condition $\lim _{t \rightarrow \infty} \bar{\lambda} B(t) e^{-\beta t}=0$. In an open economy model with a representative agent having perfect foresight, a constant rate of time preference and perfect access to world capital markets, we impose $\beta=r^{\star}$ in order to generate an interior solution. This standard assumption made in the literature implies that the marginal utility of wealth, $\lambda$, will undergo a discrete jump when individuals receive new information and must remain constant over time from thereon, i.e. $\lambda=\bar{\lambda}$.

Once aggregate consumption and labor supply have been chosen, households decide to allocate consumption expenditure and total hours worked to tradables and non tradables:

$$
\begin{gathered}
C^{N}(t)=(1-\varphi)\left(\frac{P(t)}{P_{C}(t)}\right)^{-\phi} C(t), \\
C^{T}(t)=\varphi\left(\frac{1}{P_{C}(t)}\right)^{-\phi} C(t), \\
L^{N}(t)=(1-\vartheta)\left(\frac{W^{N}(t)}{W(t)}\right)^{\epsilon} L(t), \\
L^{T}(t)=\vartheta\left(\frac{W^{T}(t)}{W(t)}\right)^{\epsilon} L(t) .
\end{gathered}
$$

where consumption and wage indices are given by (83a) and (83c) respectively.

Both the traded and non traded sectors use labor, $L^{T}$ and $L^{N}$, according to linearly homogenous production functions:

$$
Y^{j}(t)=L^{j}(t)
$$

Both sectors face a labor cost equal to the wage rate, i.e., $W^{T}$ and $W^{N}$, respectively. The traded sector and non traded sector are assumed to be perfectly competitive. The first order conditions derived from profit-maximization state that factors are paid to their respective marginal revenue:

$$
\begin{aligned}
1 & =W^{T}(t), \\
P & =W^{N}(t) .
\end{aligned}
$$

\section{H.2 Solving the Model}

Government spending rules are those described by eqs. (88a)-(88c). Market clearing conditions can be summarized as follows:

$$
\begin{gathered}
Y^{N}(t)=C^{N}(t)+G^{N}(t), \\
\dot{B}(t)=r^{\star} B(t)+Y^{T}(t)-C^{T}(t)-G^{T}(t),
\end{gathered}
$$

where we used the fact that $Y^{T}+P Y^{N}=W^{T} L^{T}+W^{N} L^{N}$ and inserted (117a) into (112) to obtain (117b). As will be clear later, it is useful to remind a number of properties and introduces some definitions:

$$
\begin{gathered}
Y(t)=Y^{T}(t)+P(t) Y^{N}(t)=W(t) L(t), \\
Y(t)=P_{C}(t) C(t)+G(t)+N X(t), \\
Y_{R}(t)=Y^{T}(t)+P Y^{N}(t), \\
\alpha_{L}(t)=\frac{W^{N}(t) L^{N}(t)}{W(t) L(t)}=\frac{P(t) Y^{N}(t)}{Y(t)}, \\
\omega_{C}(t)=\frac{P_{C}(t) C(t)}{Y(t)},
\end{gathered}
$$

where $Y(t)$ and $Y_{R}(t)$ are nominal and real GDP.

We assume that the rise in government spending is split between non tradables and tradables in accordance with their share in government spending:

$$
\frac{d G(t)}{\tilde{Y}}=\omega_{G^{N}} \frac{d G(t)}{\tilde{Y}}+\omega_{G^{T}} \frac{d G(t)}{\tilde{Y}} .
$$

Log-linearizing (117a), making use of (88b) and dividing both sides by initial GDP leads to:

$$
\alpha_{L} \hat{L}^{N}(t)=\omega_{C} \alpha_{C} \hat{C}^{N}(t)+\omega_{G^{N}} \frac{d G(t)}{Y},
$$

where we used the fact that $P d G^{N}(t)=\omega_{G^{N}} d G(t)$. Inserting first (113a) into (114a), and (113b) together with (116a)-(116b) into (114c), totally differentiating, leads to:

$$
\begin{gathered}
\hat{C}^{N}(t)=-\sigma_{C} \hat{\bar{\lambda}}-\left[\left(1-\alpha_{C}\right) \phi+\alpha_{C} \sigma_{C}\right] \hat{P}(t), \\
\hat{L}^{N}(t)=\left[\epsilon\left(1-\alpha_{L}\right)+\sigma_{L} \alpha_{L}\right] \hat{P}(t)+\sigma_{L} \hat{\bar{\lambda}} .
\end{gathered}
$$


Plugging (121a)-(121b) into (120) allows us to solve for the relative price of non tradables expressed in deviation in percentage from the initial steady-state:

$$
\hat{P}(t)=\frac{-\left[\alpha_{L} \sigma_{L}+\alpha_{C} \omega_{C} \sigma_{C}\right]}{\Psi} \hat{\bar{\lambda}}+\frac{1}{\Psi} \omega_{G}^{N} \frac{d G(t)}{Y},
$$

where we set $\Psi$

$$
\Psi=\alpha_{L}\left[\epsilon\left(1-\alpha_{L}\right)+\sigma_{L} \alpha_{L}\right]+\omega_{C} \alpha_{C}\left[\left(1-\alpha_{C}\right) \phi+\alpha_{C} \sigma_{C}\right]>0
$$

Eq. (122) corresponds to eq. (31) in the main text.

Log-linearizing the market clearing condition for tradables (117b) leads to:

$$
\frac{\dot{B}(t)}{Y}=r^{\star} \frac{d B(t)}{Y}+\left(1-\alpha_{L}\right) \hat{L}^{T}(t)-\omega_{C}\left(1-\alpha_{C}\right) \hat{C}^{T}(t)-\left(1-\omega_{G^{N}}\right) \frac{d G(t)}{Y}
$$

where we used the fact that $d G^{T}(t)=\left(1-\omega_{G^{N}}\right) d G(t)$. Inserting first (113a) into (114b), and (113b) together with (116a)-(116b) into (114d), totally differentiating, leads to:

$$
\begin{aligned}
\hat{C}^{T}(t) & =-\sigma_{C} \hat{\bar{\lambda}}+\alpha_{C}\left(\phi-\sigma_{C}\right) \hat{P}(t), \\
\hat{L}^{T}(t) & =-\alpha_{L}\left(\epsilon-\sigma_{L}\right) \hat{P}(t)+\sigma_{L} \hat{\bar{\lambda}}
\end{aligned}
$$

We set

$$
\begin{gathered}
\Upsilon_{G}^{N}=\frac{\left[\left(1-\alpha_{L}\right) \alpha_{L}\left(\epsilon-\sigma_{L}\right)+\omega_{C}\left(1-\alpha_{C}\right) \alpha_{C}\left(\phi-\sigma_{C}\right)\right]}{\Psi}>0, \\
\Upsilon_{G}=\Upsilon_{G}^{N} \omega_{G^{N}}+\left(1-\omega_{G^{N}}\right)>0 .
\end{gathered}
$$

Plugging (125a)-(125b) into (124), using the fact that $\lambda$ is constant over time, leads to:

$$
\frac{\dot{B}(t)}{Y}=r^{\star} \frac{d B(t)}{Y}-\Upsilon_{G} \frac{d G(t)}{Y}
$$

where $\Upsilon_{G}>0$ is given by $(126 \mathrm{~b})$.

To avoid unnecessary complications, we solve the model by assuming that the endogenous response to an exogenous fiscal shock is governed by the following dynamic equation:

$$
\frac{d G(t)}{Y}=g e^{-\xi t}
$$

which amounts to setting $\xi=\chi$ into eq. (97).

Substituting the law of motion of government spending (128) and solving leads to the general solution for the net foreign asset position:

$$
\frac{B(t)-\tilde{B}}{Y}=\left[\left(\frac{B_{0}-\tilde{B}}{Y}\right)-\frac{\Upsilon_{G}}{\xi+r^{\star}} g\right] e^{r^{\star} t}+\frac{\Upsilon_{G}}{\xi+r^{\star}} g e^{-\xi t} .
$$

Invoking the transversality condition gives the solution for $B(t)$ :

$$
\frac{B(t)-\tilde{B}}{Y}=\frac{\Upsilon_{G}}{\xi+r^{\star}} g e^{-\xi t},
$$

consistent with the intertemporal solvency condition

$$
\frac{\tilde{B}-B_{0}}{Y}=-\frac{\Upsilon_{G}}{\xi+r^{\star}} g .
$$

Eq. (129) corresponds to eq. (32) while eq. (130) corresponds to eq. (33) in the main text.

Plugging first (122) into (125), setting $\dot{B}=0$ while remembering that government spending is restored back toward its initial level in the long-run, and making use of (130) leads to a system that allows us to solve for the change in the equilibrium value of the marginal utility of wealth and the change in the net foreign asset position:

$$
\begin{gathered}
r^{\star} \frac{d \tilde{B}}{Y}+\frac{\Gamma}{\Psi} \hat{\bar{\lambda}}=0, \\
\frac{d \tilde{B}}{Y}=-\frac{\Upsilon_{G}}{\xi+r^{\star}} g<0 .
\end{gathered}
$$


where $(131 \mathrm{~b})$ is equivalent to (130) and we set

$$
\begin{aligned}
\Gamma & =\left[\alpha_{L} \sigma_{L}+\omega_{C} \alpha_{C} \sigma_{C}\right]\left[\omega_{C}\left(1-\alpha_{C}\right) \alpha_{C}\left(\phi-\sigma_{C}\right)+\left(1-\alpha_{L}\right) \alpha_{L}\left(\epsilon-\sigma_{L}\right)\right] \\
& +\left[\left(1-\alpha_{L}\right) \sigma_{L}+\omega_{C}\left(1-\alpha_{C}\right) \sigma_{C}\right] \Psi>0 .
\end{aligned}
$$

The two equations (131a)-(131b) jointly determine the steady-state changes for $B$ and $\bar{\lambda}$ following a government spending shock since the assumption $\beta=r^{\star}$ implies that temporary policies have permanent effects. Eq. (131a) indicates that a temporary increase in $G$ unambiguously lowers the stock of net foreign assets.

Inserting (131b) into (131a) leads to the change in the equilibrium value of the marginal utility of wealth:

$$
\hat{\bar{\lambda}}=\frac{\Psi \Upsilon_{G}}{\Gamma} \frac{r^{\star}}{\xi+r^{\star}} g>0
$$

where $\Gamma>0, \Psi>0, \Upsilon_{G}>0, \xi>0$, and $g>0$. Eq. (133) corresponds to eq. (34) in the main text. Since the marginal utility of wealth permanently increases and government spending is restored back toward its initial level, eq. (122) shows that the relative price of non tradables unambiguously depreciates in the long-run as the result as the negative wealth effect lowers expenditure on non tradables.

Before evaluating the short-run effects of the fiscal shock, it is straightforward to show that $\Gamma$ given by eq. (132) satisfies:

$$
\Gamma>\left[\alpha_{L} \sigma_{L}+\omega_{C} \alpha_{C} \sigma_{C}\right] \Upsilon_{G}^{N} \Psi
$$

which implies the following inequality

$$
0<\frac{\Psi \Upsilon_{G}^{N}}{\Gamma}\left(\alpha_{L} \sigma_{L}+\omega_{C} \alpha_{C} \sigma_{C}\right)<1
$$

where $\Gamma>0, \Psi>0$, and $\Upsilon_{G}^{N}>0$.

\section{H.3 Impact Effects of a Temporary Government Spending Shock}

Evaluating (122) at time $t=0$, inserting (133), and using the fact that $\frac{d G(0)}{Y}=g>0$ (see eq. (128)), leads to the initial response of the relative price of non tradables:

$$
\begin{aligned}
\hat{P}(0) & =\left\{\omega_{G^{N}}-\left[\alpha_{L} \sigma_{L}+\alpha_{C} \omega_{C} \sigma_{C}\right] \hat{\bar{\lambda}}\right\} \frac{g}{\Psi} \\
& =\left\{\omega_{G^{N}}-\left[\alpha_{L} \sigma_{L}+\alpha_{C} \omega_{C}\right] \frac{\Psi\left[\Upsilon_{G}^{N} \omega_{G^{N}}+\omega_{G^{T}}\right]}{\Gamma} \frac{r^{\star}}{\xi+r^{\star}}\right\} \frac{g}{\Psi} .
\end{aligned}
$$

The second line of eq. (135) corresponds to eq. (35) in the main text. When the rise in government spending, $G(t)$, is split between tradables and non tradables, the relative price of non tradables may appreciate or depreciate. For clarity purposes, let us consider two polar cases. If the government spending shock is fully biased toward non tradables, i.e., $\omega_{G^{N}}=1$, then $\omega_{G^{T}}=$ $1-\omega_{G^{N}}=0$ on the RHS of eq. (135). Due to inequality (134), i.e., $0<\frac{\Psi \Upsilon_{G}^{N}}{\Gamma}\left(\alpha_{L} \sigma_{L}+\omega_{C} \alpha_{C} \sigma_{C}\right)<1$, along with and $0<\frac{r^{\star}}{\xi+r^{\star}}<1$, a rise in $G(t)$ unambiguously appreciates the relative price of non tradables. Conversely, if the government spending shock is fully biased toward tradables, i.e., $\omega_{G^{T}}=1$, then the first term on the RHS of eq. (135) vanishes. Thus, the relative price of non tradables depreciates. Intuitively, a rise in $G^{T}$ while keeping $G^{N}$ fixed, leads to a negative wealth effect which lowers $C^{N}$. As a result, an excess supply shows up in the non traded goods market which leads to a depreciation in the relative price of non tradables. To conclude about the appreciation of the relative price on impact, $\hat{P}(0)$, we first explore its relationship with the non tradable content of the government spending shock:

$$
\frac{\partial \hat{P}(0)}{\partial \omega_{G^{N}}}=\left\{1-\frac{\left[\alpha_{L} \sigma_{L}+\alpha_{C} \omega_{C}\right]^{2}}{\Gamma} \frac{r^{\star}}{\xi+r^{\star}}\right\} \frac{g}{\Psi}>0
$$

where we used the fact that:

$$
\Upsilon_{G}^{N}-1=-\frac{\left(\alpha_{L} \sigma_{L}+\alpha_{C} \omega_{C}\right)}{\Psi}
$$

Since $\hat{P}(0)$ is monotonically increasing with $\omega_{G^{N}}$, there is a critical value $\bar{\omega}_{G^{N}}$ so that $\hat{P}(0)>0$ for $\omega_{G^{N}}>\bar{\omega}_{G^{N}}$.

Substituting the change in the equilibrium value of the marginal utility of wealth given by eq. (133) into (121b), and multiplying both sides by $\alpha_{L}$ leads to the initial reaction of non traded labor from initial steady-state in total labor units:

$$
\alpha_{L} \hat{L}^{N}(0)=\alpha_{L}\left[\epsilon\left(1-\alpha_{L}\right)+\alpha_{L} \sigma_{L}\right] \hat{P}(0)+\alpha_{L} \sigma_{L} \frac{\Psi \Upsilon_{G}}{\Gamma} \frac{r^{\star}}{\xi+r^{\star}} g>0
$$


where $\hat{P}(0)>0$ as long as $\omega_{G^{N}}>\bar{\omega}_{G^{N}}$. According to (137), a government spending shock unambiguously increases non traded labor (and thus non traded output). The change in non traded labor is the result of two reinforcing effects. First, as shown by the first term on the RHS of (137), a fiscal shock tends to increase hours worked in the non traded sector by raising the wage in this sector (remind that $W^{N}=P$ ), and all the more so the greater the elasticity of substitution between traded and non traded employment, $\epsilon$. Second, as can be seen in the second term on the RHS of (137), which is positive, the negative wealth effect causes agents to supply more labor, which raises $L^{N}$ in percent of total employment by an amount equal to $\alpha_{L}$.

Substituting the change in the equilibrium value of the marginal utility of wealth given by eq. (133) into (125b) and multiplying both sides by $1-\alpha_{L}$ leads to the initial reaction of traded labor from initial steady-state in total labor units:

$$
\left(1-\alpha_{L}\right) \hat{L}^{T}(0)=-\left(1-\alpha_{L}\right) \alpha_{L}\left(\epsilon-\sigma_{L}\right) \hat{P}(0)+\left(1-\alpha_{L}\right) \sigma_{L} \frac{\Psi \Upsilon_{G}}{\Gamma} \frac{r^{\star}}{\xi+r^{\star}} g \lessgtr 0 .
$$

According to (138), as long as $\epsilon>\sigma_{L}$, the initial reaction of traded labor to a fiscal shock is the result of two opposite effects. More precisely, the first term on the RHS of (138) captures the impact of increased non traded wages on $L^{T}$. On the one hand, a higher $W^{N}$ causes a shift of labor away from the traded sector proportional to $\epsilon$. On the other hand, the subsequent increase in the aggregate wage provides an incentive to supply more labor, and all the more so the higher the value of $\sigma_{L}$. When $\epsilon>\sigma_{L}$, the former effect more than offsets the latter. Hence, as non traded wages go up, $L^{T}$ falls. The second term on the RHS of (138) indicates that the negative wealth effect increases total hours worked, the traded sector receiving a share equal to $\left(1-\alpha_{L}\right)$. While the effect of a government spending shock on $L^{T}$ is ambiguous, traded labor falls, in line with the evidence, as long as the elasticity of labor supply, $\sigma_{L}$, is not too high.

We now investigate the impact of a government spending shock on sectoral output (or alternatively labor since $Y^{j}=L^{j}$ ) shares. To begin with, real GDP which we denote by $Y_{R}$ is equal to the sum of value added at constant prices, as described by eq. (118c). Using the fact that $Y^{j}(t)=L^{j}(t)$, totally differentiating $(118 \mathrm{c})$ gives:

$$
\hat{Y}_{R}(t)=\alpha_{L} \hat{L}^{N}(t)+\left(1-\alpha_{L}\right) \hat{L}^{T}(t) .
$$

Inserting (121b) and (125b) into (139), real GDP growth can be rewritten as follows:

$$
\hat{Y}_{R}(t)=\sigma_{L} \hat{\bar{\lambda}}+\alpha_{L} \sigma_{L} \hat{P} .
$$

According to (140), a government spending shock impinges on real GDP through two channels; first, by encouraging agents to supply more labor, the negative wealth effect pushes up real GDP; second, since the relative price of non tradables appreciates, non traded firms are encouraged to produce and thus to hire more; as workers' incur mobility costs, non traded firms have to pay higher wages which increase the aggregate wage, $W$, in proportion to the non tradable content of labor compensation, $\alpha_{L}$; consequently, agents are encouraged to supply more hours worked which further increases real GDP.

To compute the change in the sectoral output share calculated as the growth differential between sectoral output and real GDP in total output units, we divide both sides of eq. (118c) by $Y_{R}$ and log-linearize:

$$
0=\alpha_{L}\left(\hat{Y}^{N}(t)-\hat{Y}_{R}(t)\right)+\left(1-\alpha_{L}\right)\left(\hat{Y}^{T}(t)-\hat{Y}_{R}(t)\right) .
$$

The first and the second term on the RHS of eq. (141) corresponds to the response of output share in the non traded and traded sector in total output units. More precisely, the change in the sectoral output share is measured by the product of the growth differential between output of sector $j$ and real GDP and the share of sector $j$ in GDP.

Left-multiplying (140) by $\alpha_{L}$ and subtracting the resulting expression from (121b) gives the response of the output share of non tradables:

$$
\alpha_{L}\left(\hat{Y}^{N}(t)-\hat{Y}_{R}(t)\right)=\alpha_{L}\left(1-\alpha_{L}\right) \epsilon \hat{P}(t)
$$

where $\hat{P}(t)$ corresponds to the appreciation in the relative price of non tradables in percentage deviation from trend (see eq. (122)). Evaluating (142) at time $t=0$ and inserting (135) gives the response of the share of non tradables in real GDP to a government spending shock:

$$
\begin{aligned}
\alpha_{L}\left(\hat{Y}^{N}(0)-\hat{Y}_{R}(0)\right) & =\alpha_{L}\left(1-\alpha_{L}\right) \epsilon \hat{P}(0), \\
& =\frac{\alpha_{L}\left(1-\alpha_{L}\right) \epsilon}{\Psi}\left\{\omega_{G^{N}}-\left[\alpha_{L} \sigma_{L}+\omega_{C} \alpha_{C} \sigma_{C}\right] \frac{\Upsilon_{G} \Psi}{\Gamma} \frac{r^{\star}}{\xi+r^{\star}}\right\} g>0,
\end{aligned}
$$

where $\Upsilon_{G}=\Upsilon_{G}^{N} \omega_{G^{N}}+\omega_{G^{T}}>0$. The first line of eq. (143) corresponds to eq. (36) in the main text. The response of the output share of non tradables to a government spending shock is positive as long as the relative price of non tradables appreciates impact, i.e., if $\omega_{G^{N}}>\bar{\omega}_{G^{N}}$. 


\section{H.4 Output Share of Non Tradables and Labor Mobility across Sectors}

Totally differentiating the response of output share of non tradables to a government spending shock described by eq. (143) with respect to $\epsilon$ leads to:

$$
\frac{\partial \alpha_{L}\left(\hat{Y}^{N}(0)-\hat{Y}_{R}(0)\right)}{\partial \epsilon}=\alpha_{L}\left(1-\alpha_{L}\right) \epsilon \hat{P}(0)\left[1+\frac{\partial \hat{P}(0)}{\partial \epsilon} \frac{\epsilon}{\hat{P}(0)}\right]
$$

According to (144), the relationship between the positive response of output share of non tradables and the degree of labor mobility across sectors is ambiguous. On the one hand, as shown by the first term in brackets on the RHS of (144), a rise in the parameter $\epsilon$ amplifies the reallocation of labor toward the non traded sector and thus amplifies the rise in the share of non tradables. On the other hand, the rise in the degree of labor mobility also mitigates the rise in the output share as higher mobility increases further the shadow value of wealth which amplifies the crowding out of private consumption by public spending and thus moderates the excess demand in the non traded goods market. Consequently, the relative price of non tradables appreciates by a lower amount which reduces the incentive to increase non traded output. While we address this ambiguity numerically in the main text when we simulate the full model with physical capital accumulation subject to adjustment costs, we provide a formal proof below that $\frac{\partial \alpha_{L}\left(\hat{Y}^{N}(0)-\hat{Y}_{R}(0)\right)}{\partial \epsilon}>0$ in a model with labor only.

For the RHS of eq. (144) to be positive, we must have:

$$
-\frac{\partial \hat{P}(0)}{\partial \epsilon} \frac{\epsilon}{\hat{P}(0)}<1
$$

To show that inequality (144) holds, we have to make assumptions. We are able to sign expressions in two polar cases: $\xi \rightarrow \infty$ and $\xi \rightarrow 0$. The former and the latter case correspond to situations where the government spending shock is weakly persistent (i.e., $G$ increases initially and is restored back toward its initial level) and highly persistent (i.e., the fiscal shock is permanent).

The impact response of the relative price of non tradables can be rewritten as follows:

$$
\hat{P}(0)=\left.\omega_{G^{N}} \hat{P}(0)\right|_{\omega_{G^{N}}=1}-\left(1-\omega_{G^{N}}\right)\left[\alpha_{L} \sigma_{L}+\omega_{C} \alpha_{C} \sigma_{C}\right] \frac{\Psi}{\Gamma} \frac{r^{\star}}{\xi+r^{\star}} \frac{g}{\Psi} .
$$

where the first term on the RHS of eq. (146) corresponds to the initial response of the relative price of non tradables when the government spending shock is fully biased toward non tradables, i.e., $\omega_{G^{N}}$ is set to 1 :

$$
\hat{P}(0)=\left\{1-\left[\alpha_{L} \sigma_{L}+\omega_{C} \alpha_{C} \sigma_{C}\right] \frac{\Upsilon_{G}^{N} \Psi}{\Gamma} \frac{r^{\star}}{\xi+r^{\star}}\right\} \frac{g}{\Psi}>0,
$$

We first totally differentiate (146) with respect to $\epsilon$ and multiply the result by $\epsilon / \hat{P}(0)$ :

$$
\begin{aligned}
-\frac{\partial \hat{P}(0)}{\partial \epsilon} \frac{\epsilon}{\hat{P}(0)}= & \left.\frac{\left.\omega_{G^{N}} \hat{P}(0)\right|_{\omega_{G^{N}}=1}}{\hat{P}(0)}\left(-\frac{\partial \hat{P}(0)}{\partial \epsilon} \frac{\epsilon}{\hat{P}(0)}\right)\right|_{\omega_{G^{N}}=1} \\
& -\frac{1}{\hat{P}(0)}\left[\alpha_{L} \sigma_{L}+\omega_{C} \alpha_{C} \sigma_{C}\right] \frac{\left(1-\omega_{G^{N}}\right) g}{\Gamma} \frac{r^{\star}}{\xi+r^{\star}} \frac{\partial \Gamma}{\partial \epsilon} \frac{\epsilon}{\Gamma} .
\end{aligned}
$$

Before investigating whether the elasticity $-\frac{\partial \hat{P}(0)}{\partial \epsilon} \frac{\epsilon}{\hat{P}(0)}$ is smaller than 1 , we first focus on the first term on the RHS of (148), i.e., $\left.\left(-\frac{\partial \hat{P}(0)}{\partial \epsilon} \frac{\epsilon}{\hat{P}(0)}\right)\right|_{\omega_{G N}=1}$. We explore the magnitude of the elasticity of (148) when $\xi \rightarrow \infty$ and when $\xi \rightarrow 0$. The former and the latter case correspond to situations where the government spending shock is weakly persistent (i.e., $G$ increases initially and is restored back toward its initial level) and highly persistent (i.e., the fiscal shock is permanent).

As will be useful later, we have to determine the relationship between $\frac{\Psi \Upsilon_{G}^{N}}{\Gamma}$ (see the RHS of eq. (146)) as follows

$$
\frac{\Psi \Upsilon_{G}^{N}}{\Gamma}=\frac{\Upsilon_{G}^{N}}{\left[\left(1-\alpha_{L}\right) \sigma_{L}+\omega_{C}\left(1-\alpha_{C}\right) \sigma_{C}\right]+\left[\alpha_{L} \sigma_{L}+\omega_{C} \alpha_{C} \sigma_{C}\right] \Upsilon_{G}^{N}}
$$

We first explore the relationship between $\Upsilon_{G}^{N}$ described by (126a) and $\epsilon$ :

$$
\frac{\partial \Upsilon_{G}^{N}}{\partial \epsilon}=\frac{\left(1-\alpha_{L}\right) \alpha_{L}\left(\alpha_{L} \sigma_{L}+\omega_{C} \alpha_{C} \sigma_{C}\right)}{\Psi^{2}}>0
$$


where $\Psi$ is given by eq. (123). The term $\Upsilon_{G}^{N}$ can take negative values when $\epsilon$ is close to 0 , is increasing with $\epsilon$ and reaches its highest value of 1 when we let $\epsilon \rightarrow \infty$. Differentiating (149) with respect to $\epsilon$ leads to:

$$
\begin{aligned}
\frac{\partial \frac{\Psi \Upsilon_{G}^{N}}{\Gamma}}{\partial \epsilon} & =\frac{\frac{\partial \Upsilon_{G}^{N}}{\partial \epsilon}\left[\left(1-\alpha_{L}\right) \sigma_{L}+\omega_{C}\left(1-\alpha_{C}\right) \sigma_{C}\right]}{\left\{\left[\left(1-\alpha_{L}\right) \sigma_{L}+\omega_{C}\left(1-\alpha_{C}\right) \sigma_{C}\right]+\left[\alpha_{L} \sigma_{L}+\omega_{C} \alpha_{C} \sigma_{C}\right] \Upsilon_{G}^{N}\right\}^{2}}>0 \\
& =\frac{\left(1-\alpha_{L}\right) \alpha_{L}\left[\alpha_{L} \sigma_{L}+\omega_{C} \alpha_{C} \sigma_{C}\right]\left[\left(1-\alpha_{L}\right) \sigma_{L}+\omega_{C}\left(1-\alpha_{C}\right) \sigma_{C}\right]}{\Gamma^{2}}>0 .
\end{aligned}
$$

Because $\frac{\Psi \Upsilon_{G}^{N}}{\Gamma}$ and $\Psi$ are both positive and increasing with $\epsilon$ while $\lim _{\epsilon \rightarrow \infty} \frac{\Psi \Upsilon_{G}^{N}}{\Gamma}=\frac{1}{\sigma_{L}+\omega_{C} \sigma_{C}}$ and $\lim _{\epsilon \rightarrow \infty} \Psi=\infty$, the initial reaction of the relative price to a government spending shock is unambiguously decreasing with $\epsilon$; differentiating (147) with respect to $\epsilon$ leads to:

$$
\begin{aligned}
\frac{\partial \hat{P}(0)}{\partial \epsilon} & =-\frac{g}{\Psi}\left[\alpha_{L} \sigma_{L}+\omega_{C} \alpha_{C} \sigma_{C}\right] \frac{r^{\star}}{\xi+r^{\star}} \frac{\partial \frac{\Psi \Upsilon_{G}^{N}}{\Gamma}}{\partial \epsilon} \\
& -\left\{1-\left[\alpha_{L} \sigma_{L}+\omega_{C} \alpha_{C} \sigma_{C}\right] \frac{r^{\star}}{\xi+r^{\star}} \frac{\Psi \Upsilon_{G}^{N}}{\Gamma}\right\} \frac{g}{\Psi^{2}} \frac{\partial \Psi}{\partial \epsilon}<0 .
\end{aligned}
$$

A rise in $\epsilon$ mitigates the appreciation in the relative price of non tradables by amplifying the increase in the supply of non tradables and by reducing the excess of demand for non tradables. First, in countries where labor is more mobile across sectors, a government spending shock biased toward non tradables leads to a larger increase in non traded output which mitigates the appreciation in the relative price of non tradables. Second, as $\epsilon$ takes higher values, the wealth effect becomes larger so that private consumption is crowded out by a larger amount which results in a lower excess demand of non tradables.

Case $\omega_{G^{N}}=1$ : A Weakly Persistent Fiscal Shock: $\xi \rightarrow \infty$

Letting $\xi \rightarrow \infty$ into eq. (147), the initial appreciation in the relative price of non tradables reduces to:

$$
\left.\hat{P}(0)\right|_{\xi \rightarrow \infty}=\frac{g}{\Psi}>0
$$

where $\Psi$ is given by eq. (123). Differentiating (153) w.r.t. $\epsilon$ leads to:

$$
\frac{\left.\partial \hat{P}(0)\right|_{\xi \rightarrow \infty}}{\partial \epsilon}=-\frac{g \alpha_{L}\left(1-\alpha_{L}\right)}{\Psi^{2}}<0
$$

Combining (153) and (154), the elasticity (in absolute terms) of the impact response of the relative price to the degree of labor mobility is thus given by:

$$
0<-\frac{\left.\partial \hat{P}(0)\right|_{\xi \rightarrow \infty}}{\partial \epsilon} \frac{\epsilon}{\left.\hat{P}(0)\right|_{\xi \rightarrow \infty}}=\frac{\alpha_{L}\left(1-\alpha_{L}\right) \epsilon}{\Psi}<1 .
$$

Since $\Psi>\alpha_{L} \epsilon\left(1-\alpha_{L}\right)$, the elasticity is strictly smaller than one and thus the RHS of eq. (144) is unambiguously positive.

Case $\omega_{G^{N}}=1$ : A Highly Persistent Fiscal Shock

Letting $\xi \rightarrow 0$ into eq. (147), the initial appreciation in the relative price of non tradables reduces to:

$$
\left.\hat{P}(0)\right|_{\xi \rightarrow 0}=\frac{g}{\Psi}\left[1-\left(\alpha_{L} \sigma_{L}+\omega_{C} \alpha_{C} \sigma_{C}\right) \frac{\Upsilon_{G}^{N} \Psi}{\Gamma}\right] .
$$

Differentiating (156) w.r.t. $\epsilon$ leads to:

$$
\begin{aligned}
\frac{\left.\partial \hat{P}(0)\right|_{\xi \rightarrow 0}}{\partial \epsilon} & =-\frac{g \alpha_{L}\left(1-\alpha_{L}\right)}{\Psi^{2}}\left[1-\left(\alpha_{L} \sigma_{L}+\omega_{C} \alpha_{C} \sigma_{C}\right) \frac{\Upsilon_{G}^{N} \Psi}{\Gamma}\right] \\
& -\frac{g}{\Psi}\left(\alpha_{L} \sigma_{L}+\omega_{C} \alpha_{C} \sigma_{C}\right) \frac{\partial \frac{\Psi \Upsilon_{G}^{N}}{\Gamma}}{\partial \epsilon}
\end{aligned}
$$

where $\frac{\partial \frac{\Psi \Upsilon_{G}^{N}}{\Gamma}}{\partial \epsilon}$ is given by eq. (151). Computing the following term:

$$
\left[1-\left(\alpha_{L} \sigma_{L}+\omega_{C} \alpha_{C} \sigma_{C}\right) \frac{\Upsilon_{G}^{N} \Psi}{\Gamma}\right]=\frac{\Psi\left[\left(1-\alpha_{L}\right) \sigma_{L}+\omega_{C}\left(1-\alpha_{C}\right) \sigma_{C}\right]}{\Gamma}
$$

the initial reaction of the relative price (147) can be rewritten as follows:

$$
\left.\hat{P}(0)\right|_{\xi \rightarrow 0}=g \frac{\left[\left(1-\alpha_{L}\right) \sigma_{L}+\omega_{C}\left(1-\alpha_{C}\right) \sigma_{C}\right]}{\Gamma}>0 .
$$


Making use of (158) and inserting (151), eq. (157) reads as:

$$
\frac{\left.\partial \hat{P}(0)\right|_{\xi \rightarrow 0}}{\partial \epsilon}=-\frac{g \alpha_{L}\left(1-\alpha_{L}\right)\left[\left(1-\alpha_{L}\right) \sigma_{L}+\omega_{C}\left(1-\alpha_{C}\right) \sigma_{C}\right]}{\Psi \Gamma^{2}}\left[\Gamma+\left(\alpha_{L} \sigma_{L}+\omega_{C} \alpha_{C} \sigma_{C}\right)^{2}\right] .
$$

Calculating the elasticity in absolute terms of $\hat{P}(0)$ w.r.t. $\epsilon$ by combining (159) and (160), we have to show that the following inequality holds for the RHS of eq. (144) to be positive:

$$
-\frac{\left.\partial \hat{P}(0)\right|_{\xi \rightarrow 0}}{\partial \epsilon} \frac{\epsilon}{\left.\hat{P}(0)\right|_{\xi \rightarrow 0}}=\frac{\alpha_{L}\left(1-\alpha_{L}\right) \epsilon}{\Psi}\left[1+\frac{\left(\alpha_{L} \sigma_{L}+\omega_{C} \alpha_{C} \sigma_{C}\right)^{2}}{\Gamma}\right]<1 .
$$

To show (161), it is useful to write down the following properties:

$$
\begin{gathered}
\Psi=\alpha_{L}\left(1-\alpha_{L}\right)\left(\epsilon-\sigma_{L}\right)+\omega_{C} \alpha_{C}\left(1-\alpha_{C}\right)\left(\phi-\sigma_{C}\right)+\alpha_{L} \sigma_{L}+\omega_{C} \alpha_{C} \sigma_{C} \\
\Upsilon_{G}^{N} \Psi=\Psi-\left(\alpha_{L} \sigma_{L}+\omega_{C} \alpha_{C} \sigma_{C}\right) \\
\Gamma=\Psi\left(\sigma_{L}+\omega_{C} \sigma_{C}\right)-\left(\alpha_{L} \sigma_{L}+\omega_{C} \alpha_{C} \sigma_{C}\right)^{2}
\end{gathered}
$$

where we made use of (162b) to obtain (162c), i.e.,

$$
\begin{aligned}
\Gamma= & \Psi\left\{\left[\left(1-\alpha_{L}\right) \sigma_{L}+\omega_{C}\left(1-\alpha_{C}\right) \sigma_{C}\right]+\left[\alpha_{L} \sigma_{L}+\omega_{C} \alpha_{C} \sigma_{C}\right] \Upsilon_{G}^{N}\right\} \\
= & \Psi\left[\left(1-\alpha_{L}\right) \sigma_{L}+\omega_{C}\left(1-\alpha_{C}\right) \sigma_{C}\right] \\
& +\left[\alpha_{L} \sigma_{L}+\omega_{C} \alpha_{C} \sigma_{C}\right]\left[\Psi-\left(\alpha_{L} \sigma_{L}+\omega_{C} \alpha_{C} \sigma_{C}\right)\right] .
\end{aligned}
$$

Using (162c), eq. (161) can be rewritteen as follows:

$$
\frac{\left.\partial \hat{P}(0)\right|_{\xi \rightarrow 0}}{\partial \epsilon} \frac{\epsilon}{\left.\hat{P}(0)\right|_{\xi \rightarrow 0}}=\alpha_{L}\left(1-\alpha_{L}\right) \epsilon \frac{\left(\sigma_{L}+\omega_{C} \sigma_{C}\right)}{\Gamma}<1 .
$$

Thus, making use of eq. (162c), the elasticity (164) is smaller than one if the following inequality holds:

$$
\begin{aligned}
& \Gamma>\alpha_{L}\left(1-\alpha_{L}\right) \epsilon\left(\sigma_{L}+\omega_{C} \sigma_{C}\right), \\
& \Psi\left(\sigma_{L}+\omega_{C} \sigma_{C}\right)-\left(\alpha_{L} \sigma_{L}+\omega_{C} \alpha_{C} \sigma_{C}\right)^{2}>\alpha_{L}\left(1-\alpha_{L}\right) \epsilon\left(\sigma_{L}+\omega_{C} \sigma_{C}\right), \\
& \omega_{C} \sigma_{L} \sigma_{C}\left(\alpha_{L}-\alpha_{C}\right)^{2}+\left(\sigma_{L}+\omega_{C} \sigma_{C}\right) \omega_{C} \alpha_{C}\left(1-\alpha_{C}\right) \phi>0 .
\end{aligned}
$$

Since (165) holds for all range of values of parameters, we have shown that $0<\left.\left(-\frac{\partial \hat{P}(0)}{\partial \epsilon} \frac{\epsilon}{\hat{P}(0)}\right)\right|_{\omega_{G N}=1}<$ 1 is strictly smaller than one.

So far, we have been able to show that the elasticity $-\frac{\partial \hat{P}(0)}{\partial \epsilon} \frac{\epsilon}{\hat{P}(0)}$ is smaller than one in the case where the government shock is fully biased toward non tradables (see the first term on the RHS of first term on the RHS of eq. (148)). Below, we complete the proof of an elasticity smaller than one in the general case where $0<\omega_{G^{N}}<1$.

Case $0<\omega_{G^{N}}<1$ : A Weakly Persistent Fiscal Shock: $\xi \rightarrow \infty$

Letting $\xi \rightarrow \infty$ into eq. (148) leads to:

$$
0<-\frac{\left.\partial \hat{P}(0)\right|_{\xi \rightarrow \infty}}{\partial \epsilon} \frac{\epsilon}{\left.\hat{P}(0)\right|_{\xi \rightarrow \infty}}=\frac{\alpha_{L}\left(1-\alpha_{L}\right) \epsilon}{\Psi}<1 .
$$

Thus, whether we assume that the government shock is fully biased toward non tradables or is split between non tradables and tradables, the elasticity of the response of the relative price w.r.t the degree of labor mobility across sectors is identical because the wealth effect vanishes and thus a rise in $G^{T}$ has no effect on the relative price.

Case $0<\omega_{G^{N}}<1$ : A Highly Persistent Fiscal Shock: $\xi \rightarrow 0$

As shall be useful, we compute the following term:

$$
\frac{\partial \Gamma}{\partial \epsilon} \frac{\epsilon}{\Gamma}=\alpha_{L}\left(1-\alpha_{L}\right) \epsilon \frac{\left(\sigma_{L}+\omega_{C} \sigma_{C}\right)}{\Gamma}<1,
$$

where $\Gamma$ is given by eq. (132). Making use of (164), eq. (148) can be rewritten as follows:

$$
\begin{aligned}
-\frac{\partial \hat{P}(0)}{\partial \epsilon} \frac{\epsilon}{\hat{P}(0)} & =\frac{\left.\omega_{G^{N}} \hat{P}(0)\right|_{\omega_{G} N=1}-\left[\alpha_{L} \sigma_{L}+\omega_{C} \alpha_{C} \sigma_{C}\right] \frac{\omega_{G T} g}{\Gamma}}{\hat{P}(0)} \alpha_{L}\left(1-\alpha_{L}\right) \epsilon \frac{\left(\sigma_{L}+\omega_{C} \sigma_{C}\right)}{\Gamma} \\
& =\alpha_{L}\left(1-\alpha_{L}\right) \epsilon \frac{\left(\sigma_{L}+\omega_{C} \sigma_{C}\right)}{\Gamma}
\end{aligned}
$$


In sum, whether we assume $\omega_{G^{N}}=1$ or $0<\omega_{G^{N}}<1$, when $\xi$ takes intermediate values, the elasticity falls into the following range of values:

$$
-\frac{\partial \hat{P}(0)}{\partial \epsilon} \frac{\epsilon}{\hat{P}(0)} \in\left\{\frac{\alpha_{L}\left(1-\alpha_{L}\right) \epsilon}{\Psi}, \frac{\alpha_{L}\left(1-\alpha_{L}\right) \epsilon}{\Psi}\left[1+\frac{\left(\alpha_{L} \sigma_{L}+\omega_{C} \alpha_{C} \sigma_{C}\right)^{2}}{\Gamma}\right]\right\} .
$$

Finally, we show in the next section that $\alpha_{L}\left(\hat{Y}^{N}(0)-\hat{Y}_{R}(0)\right)>\left(\omega_{G^{N}}-\alpha_{L}\right) g>0$ because we need analytical results when imposing perfect mobility of labor across sectors to demonstrate this result when allowing for imperfect mobility of labor.

\section{H.5 Good-Biased Government Spending Shock and Perfect Mobility of Labor across Sectors}

When assuming perfect mobility of labor, the short-run equilibrium reduces to:

$$
\begin{gathered}
C(t)=\left(P_{C}(t) \bar{\lambda}\right)^{-\sigma_{C}}, \\
L(t)=(\bar{\lambda} W(t))^{\sigma_{L}} \\
C^{N}(t)=(1-\varphi)\left(\frac{P(t)}{P_{C}(t)}\right)^{-\phi} C(t), \\
C^{T}(t)=\varphi\left(\frac{1}{P_{C}(t)}\right)^{-\phi} C(t), \\
W^{T}=1, \\
W^{N}(t)=P(t), \\
W^{N}(t)=W^{T}(t)=W(t), \\
L(t)=L^{T}(t)+L^{N}(t), \\
Y^{N}(t)=C^{N}(t)+G^{N}(t), \\
\dot{B}(t)=r^{\star} B(t)+Y^{T}(t)-C^{T}(t)-G^{T}(t),
\end{gathered}
$$

where $Y^{N}(t)=L^{N}(t), Y^{T}(t)=L^{T}(t)$.

We now consider a rise in government spending split between non tradables and tradables in the special case of perfect mobility of labor across sectors. We restrict our attention to the main changes. Inserting (170c) into (170i) and differentiating, using the fact that $P=1$, leads to:

$$
\alpha_{L} \hat{L}^{N}(t)=-\alpha_{C} \omega_{C} \sigma_{C} \hat{\bar{\lambda}}+\omega_{G^{N}} \frac{d G(t)}{Y} .
$$

Inserting $L=\bar{\lambda}^{\sigma_{L}}$ (since $W=1$ ) into (170h), differentiating and using (171) leads to:

$$
\left(1-\alpha_{L}\right) \hat{L}^{T}(t)=\left[\sigma_{L}+\alpha_{C} \omega_{C} \sigma_{C}\right] \hat{\bar{\lambda}}-\omega_{G^{N}} \frac{d G(t)}{Y} .
$$

Inserting $L^{T}=L-L^{N}$ together with $L^{N}=C^{N}+G^{N}$ and $L=\bar{\lambda}^{\sigma_{L}}$ (since $W=1$ ) into (170j), the market clearing condition for the traded good can be written as follows:

$$
\begin{aligned}
\dot{B}(t) & =r^{\star} B(t)+L-P_{C} C-G^{T}(t)-P G^{N}(t), \\
& =r^{\star} B(t)+\bar{\lambda}^{\sigma_{L}}-\left(1-\alpha_{C}\right) P_{C}^{1-\sigma_{C}} \bar{\lambda}^{-\sigma_{C}}-P G^{N}(t)-G^{T}(t) .
\end{aligned}
$$

Using the fact that both $\bar{\lambda}$ and $P$ are constant over time, linearizing (173) in the neighborhood of the steady-state leads to:

$$
\dot{B}(t)=r^{\star} d B(t)-d G(t) .
$$

Substituting the law of motion of government spending (128) and solving leads to the general solution for the net foreign asset position as described by

$$
B(t)-\tilde{B}=\left[\left(B_{0}-\tilde{B}\right)+\frac{\tilde{Y}}{\xi+r^{\star}} g\right] e^{r^{\star} t}-\frac{\tilde{Y}}{\xi+r^{\star}} g e^{-\xi t} .
$$

Invoking the transversality condition gives the solution for $B(t)$ :

$$
\frac{B(t)-\tilde{B}}{Y}=\frac{g e^{-\xi t}}{\xi+r^{\star}},
$$


consistent with the intertemporal solvency condition

$$
\frac{\tilde{B}-B_{0}}{Y}=-\frac{g}{\xi+r^{\star}}
$$

To determine the change in the equilibrium value of the marginal utility of wealth, we have to differentiate the market clearing condition $(170 \mathrm{j})$ for the traded good evaluated at the steady-state (i.e., $\dot{B}(t)=0$ ), using the fact that government spending reverts to its initial level in the long-run (i.e., $d G(t)=0)$, inserting (172) and (125a)

$$
r^{\star} \frac{d \tilde{B}}{Y}+\left(\sigma_{L}+\omega_{C} \sigma_{C}\right) \hat{\bar{\lambda}}=0
$$

Plugging (176) into the above equation leads to the change in the equilibrium value of the marginal utility of wealth:

$$
\hat{\bar{\lambda}}=\frac{1}{\sigma_{L}+\omega_{C} \sigma_{C}} \frac{r^{\star}}{\xi+r^{\star}} g>0,
$$

where $\xi>0$ and $g>0$.

Totally differentiating the definition of real GDP (118c) and substituting both (171) and (172) leads to:

$$
\begin{aligned}
\hat{Y}_{R} & =\alpha_{L} \hat{L}^{N}+\left(1-\alpha_{L}\right) \hat{L}^{T} \\
& =\sigma_{L} \hat{\bar{\lambda}}>0
\end{aligned}
$$

Evaluating (171) at time $t=0$, pre-multiplying (178) by $\alpha_{L}$ and subtracting the latter expression from the former, and then substituting (177), the response of the output share of non tradables is given by:

$$
\begin{aligned}
\alpha_{L}\left(\hat{Y}^{N}(0)-\hat{Y}_{R}(0)\right) & =\left[\omega_{G^{N}} g-\left(\alpha_{L} \sigma_{L}+\omega_{C} \alpha_{C} \sigma_{C}\right) \hat{\bar{\lambda}}\right] \\
& =\left[\omega_{G^{N}}-\left(\frac{\alpha_{L} \sigma_{L}+\omega_{C} \alpha_{C} \sigma_{C}}{\sigma_{L}+\omega_{C} \sigma_{C}}\right) \frac{r^{\star}}{\xi+r^{\star}}\right] g \gtrless 0 .
\end{aligned}
$$

Letting $\epsilon$ tend toward infinity into eq. (143), using (177), i.e., $\lim _{\epsilon \rightarrow \infty} \frac{\Psi \Upsilon_{G}^{N}}{\Gamma}=\frac{1}{\sigma_{L}+\omega_{C} \sigma_{C}}$, and using the fact that $\lim _{\epsilon \rightarrow \infty} \frac{\Psi}{\Gamma}=\frac{1}{\sigma_{L}+\omega_{C} \sigma_{C}}$ since $\lim _{\epsilon \rightarrow \infty} \Upsilon_{G}^{N}=1$, and applying l'Hôpital's rule leads to eq. (179) since $\lim _{\epsilon \rightarrow \infty} \frac{\alpha_{L}\left(1-\alpha_{L}\right) \epsilon}{\Psi}=1$. Eq. (179) corresponds to eq. (37) in the main text.

Keeping the private demand components fixed, the response of the share of non tradables in real GDP is given by $\alpha_{L}\left(\hat{Y}^{N}(0)-\hat{Y}_{R}(0)\right)=\left(\omega_{G^{N}}-\alpha_{L}\right) \frac{d G(t)}{Y}$, where $\alpha_{L}$ refers to $\nu^{Y, N}$ in the empirical part. In a general equilibrium model, the private sector' demand components respond to a fiscal shock and thus the response of the share of non tradables in real GDP deviates from $\left(\omega_{G^{N}}-\alpha_{L}\right) \frac{d G(t)}{Y}$. To calculate the extent of the discrepancy between the response of the share of non tradables in real GDP described by eq. (179) and that when keeping private sector's demand components fixed as described by $\alpha_{L}\left(\hat{Y}^{N}(0)-\hat{Y}_{R}(0)\right)=\left(\omega_{G^{N}}-\alpha_{L}\right) \frac{d G(t)}{Y}$, we add and subtract $\alpha_{L}$ in the RHS of eq. (179):

$$
\alpha_{L}\left(\hat{Y}^{N}(0)-\hat{Y}_{R}(0)\right)=\left\{\left(\omega_{G^{N}}-\alpha_{L}\right)+\left[\alpha_{L}-\left(\frac{\alpha_{L} \sigma_{L}+\omega_{C} \alpha_{C} \sigma_{C}}{\sigma_{L}+\omega_{C} \sigma_{C}}\right) \frac{r^{\star}}{\xi+r^{\star}}\right]\right\} g .
$$

where

$$
\left[\alpha_{L}-\left(\frac{\alpha_{L} \sigma_{L}+\omega_{C} \alpha_{C} \sigma_{C}}{\sigma_{L}+\omega_{C} \sigma_{C}}\right) \frac{r^{\star}}{\xi+r^{\star}}\right]>0 .
$$

The RHS of eq. (181) is unambiguously positive since $\alpha_{L} \geq \alpha_{C}$ and $0<\frac{r^{\star}}{\xi+r^{\star}}<1$. According to (180), the share of non tradables in real GDP unambiguously rises as long as $\omega_{G^{N}}>\alpha_{L}$. As captured by the positive term (181), the share of non tradables in real GDP increases more in a general equilibrium model where demand components adjust in response to a fiscal shock because the rise in government spending triggers a fall in net exports on impact which further biases the sectoral demand shock toward non tradables.

While $\alpha_{L}\left(\hat{Y}^{N}(0)-\hat{Y}_{R}(0)\right)$ is larger than $\left(\omega_{G^{N}}-\alpha_{L}\right) g$ when $\epsilon \rightarrow \infty$ due to inequality (181), we show now that $\alpha_{L}\left(\hat{Y}^{N}(0)-\hat{Y}_{R}(0)\right)>\left(\omega_{G^{N}}-\alpha_{L}\right) g>0$ holds as well with imperfect mobility of labor across sectors. First, since $\lim _{\epsilon \rightarrow \infty} \frac{\Psi \Upsilon_{G}^{N}}{\Gamma}=\frac{1}{\sigma_{L}+\omega_{C} \sigma_{C}}$ and $\frac{\partial \frac{\Psi \Upsilon_{G}^{N}}{\Gamma}}{\partial \epsilon}>0$ (see eq. (151)), we 
have:

$$
\begin{aligned}
\frac{\Psi \Upsilon_{G}^{N}}{\Gamma} & \leq \frac{1}{\sigma_{L}+\omega_{C} \sigma_{C}} \\
\frac{\Psi \Upsilon_{G}^{N}}{\Gamma}\left(\alpha_{L} \sigma_{L}+\alpha_{C} \omega_{C} \sigma_{C}\right) & \leq \frac{\alpha_{L} \sigma_{L}+\alpha_{C} \omega_{C} \sigma_{C}}{\sigma_{L}+\omega_{C} \sigma_{C}} \\
\frac{\Psi \Upsilon_{G}^{N} \omega_{G}}{\Gamma}\left(\alpha_{L} \sigma_{L}+\alpha_{C} \omega_{C} \sigma_{C}\right) & \leq \frac{\alpha_{L} \sigma_{L}+\alpha_{C} \omega_{C} \sigma_{C}}{\sigma_{L}+\omega_{C} \sigma_{C}} \omega_{G^{N}}
\end{aligned}
$$

Second, since $\lim _{\epsilon \rightarrow \infty} \Upsilon_{G}^{N}=1$ and $\frac{\partial \Upsilon_{G}^{N}}{\partial \epsilon}>0$ (see eq. (150)), the first line of (182) implies the following inequalities:

$$
\begin{aligned}
\frac{\Psi}{\Gamma} & \leq \frac{1}{\sigma_{L}+\omega_{C} \sigma_{C}} \\
\frac{\Psi}{\Gamma}\left(\alpha_{L} \sigma_{L}+\alpha_{C} \omega_{C} \sigma_{C}\right) & \leq \frac{\alpha_{L} \sigma_{L}+\alpha_{C} \omega_{C} \sigma_{C}}{\sigma_{L}+\omega_{C} \sigma_{C}} \\
\frac{\Psi \omega_{G T}}{\Gamma}\left(\alpha_{L} \sigma_{L}+\alpha_{C} \omega_{C} \sigma_{C}\right) & \leq \frac{\alpha_{L} \sigma_{L}+\alpha_{C} \omega_{C} \sigma_{C}}{\sigma_{L}+\omega_{C} \sigma_{C}} \omega_{G^{T}} .
\end{aligned}
$$

Combining (182) and (183) leads to:

$$
\begin{aligned}
& \frac{\Psi\left[\Upsilon_{G}^{N} \omega_{G^{N}}+\omega_{G^{T}}\right]}{\Gamma}\left[\alpha_{L} \sigma_{L}+\alpha_{C} \omega_{C} \sigma_{C}\right] \leq \frac{\alpha_{L} \sigma_{L}+\alpha_{C} \omega_{C} \sigma_{C}}{\sigma_{L}+\omega_{C} \sigma_{C}}\left(\omega_{G^{N}}+\omega_{G^{T}}\right), \\
& \frac{\Psi\left[\Upsilon_{G}^{N} \omega_{G^{N}}+\omega_{G^{T}}\right]}{\Gamma}\left[\alpha_{L} \sigma_{L}+\alpha_{C} \omega_{C} \sigma_{C}\right] \leq \frac{\alpha_{L} \sigma_{L}+\alpha_{C} \omega_{C} \sigma_{C}}{\sigma_{L}+\omega_{C} \sigma_{C}},
\end{aligned}
$$

where we used the fact that $\omega_{G^{N}}+\omega_{G^{T}}=1$. From inequalities (181) and (184), we thus have:

$$
\alpha_{L}\left(\hat{Y}^{N}(0)-\hat{Y}_{R}(0)\right)>\left(\omega_{G^{N}}-\alpha_{L}\right) g
$$

whether $\epsilon \rightarrow \infty$ or $0<\epsilon<\infty$.

\section{Calibration Procedure}

In this section, we provide more details about the calibration to a representative OECD economy and to data from 16 OECD countries. Sections A-B present the source and construction of data.

\section{I.1 Initial Steady-State}

Normalizing total factor productivity (TFP henceforth) for the non traded sector $Z^{N}$ to 1 , the calibration reduces to 19 parameters: $r^{\star}, \beta, \sigma_{C}, \sigma_{L}, \epsilon, \vartheta, \phi, \varphi, \phi_{J}, \varphi_{J}, \kappa, \delta_{K}, \theta^{T}, \theta^{N}, Z^{T}, \omega_{G}$ $\left(=\frac{G}{Y}\right), \omega_{G^{N}}\left(=\frac{P G^{N}}{G}\right), \xi, \chi$, and initial conditions $B_{0}, K_{0}$.

Whilst in the main text, the aggregator function for investment inputs is assumed to take a CobbDouglas form (see eq. (14)), in the calibration procedure we consider a more general aggregator function. The investment good is (costlessly) produced using traded good and non traded good inputs according to a constant returns to scale function which is assumed to take a CES form:

$$
J(t)=\left[\varphi_{J}^{\frac{1}{\phi_{J}}}\left(J^{T}(t)\right)^{\frac{\phi_{J}-1}{\phi_{J}}}+\left(1-\varphi_{J}\right)^{\frac{1}{\phi_{J}}}\left(J^{N}(t)\right)^{\frac{\phi_{J}-1}{\phi_{J}}}\right]^{\frac{\phi_{J}}{\phi_{J}-1}},
$$

where $0<\varphi_{J}<1$ is the weight of the investment traded input and $\phi_{J}$ corresponds to the elasticity of substitution between traded good and non traded good inputs.

Since we focus on the long-run equilibrium, the tilde is suppressed for the purposes of clarity. 
The steady-state of the open economy comprises 18 equations:

$$
\begin{aligned}
& C=\left(P_{C} \bar{\lambda}\right)^{-\sigma_{C}}, \\
& L=(W \bar{\lambda})^{\sigma_{L}} \text {, } \\
& C^{N}=(1-\varphi)\left(\frac{P}{P_{C}}\right)^{-\phi} C \text {, } \\
& C^{T}=\varphi\left(\frac{1}{P_{C}}\right)^{-\phi} C, \\
& L^{N}=(1-\vartheta)\left(\frac{W^{N}}{W}\right)^{\epsilon} L, \\
& L^{T}=\vartheta\left(\frac{W^{T}}{W}\right)^{\epsilon} L \\
& I^{N}=\left(1-\varphi_{J}\right)\left(\frac{P}{P_{J}}\right)^{-\phi_{J}} I, \\
& I^{T}=\varphi_{J}\left(\frac{1}{P_{J}}\right)^{-\phi_{J}} I, \\
& I=\delta_{K} K \text {, } \\
& \frac{G}{Y}=\omega_{G}, \\
& Z^{T}\left(1-\theta^{T}\right)=P_{J}\left(r^{\star}+\delta_{K}\right), \\
& Z^{T}\left(1-\theta^{T}\right)\left(k^{T}\right)^{-\theta^{T}}=P Z^{N}\left(1-\theta^{N}\right)\left(k^{N}\right)^{-\theta^{N}} \text {, } \\
& Z^{T} \theta^{T}\left(k^{T}\right)^{1-\theta^{T}}=W^{T}, \\
& P Z^{N} \theta^{N}\left(k^{N}\right)^{1-\theta^{N}}=W^{N}, \\
& k^{T} L^{T}+k^{N} L^{N}=K, \\
& Z^{N} L^{N}\left(k^{N}\right)^{1-\theta^{N}}=C^{N}+G^{N}+I^{N}, \\
& r^{\star} B+Z^{T} L^{T}\left(k^{T}\right)^{1-\theta^{T}}-C^{T}-G^{T}-I^{T}=0,
\end{aligned}
$$

and the intertemporal solvency condition

$$
B-B_{0}=\Psi_{1}\left(K-K_{0}\right),
$$

where we used the fact that at the steady-state $I^{j}=J^{j}$ (with $j=T, N$ ), and we also have

$$
\begin{gathered}
G^{N}=\left(\omega_{G^{N}} / P\right) G, \\
G^{T}=\left(1-\omega_{G^{N}}\right) G, \\
P_{C}=\left[\varphi+(1-\varphi)(P)^{1-\phi}\right]^{\frac{1}{1-\phi}}, \\
P_{J}=\left[\varphi_{J}+\left(1-\varphi_{J}\right) P^{1-\phi_{J}}\right]^{\frac{1}{1-\phi_{J}}}, \\
W=\left[\vartheta\left(W^{T}\right)^{\epsilon+1}+(1-\vartheta)\left(W^{N}\right)^{\epsilon+1}\right]^{\frac{1}{\epsilon+1}}, \\
Y=Y^{T}+P Y^{N}=Z^{T} L^{T}\left(k^{T}\right)^{1-\theta^{T}}+P Z^{N} L^{N}\left(k^{N}\right)^{1-\theta^{N}} .
\end{gathered}
$$

Using (188), the system (187) jointly determines the following 18 variables $C, L, C^{N}, C^{T}, L^{N}, L^{T}$, $I^{N}, I^{T}, I, G, k^{T}, k^{N}, W^{T}, W^{N}, K, P, B, \bar{\lambda}$.

Some of the values of parameters can be taken directly from data, but others need to be endogenously calibrated to fit a set of an average OECD economy features. Among the 19 parameters, 4 parameters, i.e., $\varphi, \varphi_{J}, \vartheta, \delta_{K}$ together with initial conditions $\left(B_{0}, K_{0}\right)$ must be set in order to match key properties of a typical OECD economy. More precisely, the parameters $\varphi, \varphi_{J}, \vartheta, \delta_{K}$ together with the set of initial conditions are set to target $\alpha_{C}, \alpha_{J}, \alpha_{L}, v_{N X}, I / Y$. We denote by $v_{G^{j}}=G^{j} / Y^{j}$ and $v_{J^{j}}=J^{j} / Y^{j}$ the ratio of government spending and investment expenditure on good $j$ to output in sector $j$, respectively, and $v_{B}=\frac{r^{\star} B}{Y^{T}}$ the ratio of interest receipts from traded 
bonds holding to traded output. The steady-state can be reduced to the following four equations:

$$
\begin{gathered}
\frac{Y^{T}}{Y^{N}} \frac{\left(1+v_{B}-v_{J^{T}}-v_{G^{T}}\right)}{\left(1-v_{J^{N}}-v_{G^{N}}\right)}=\frac{\varphi}{1-\varphi} P^{\phi}, \\
\frac{Y^{T}}{Y^{N}}=P^{-\left\{\epsilon+(1+\epsilon)\left[\left(\frac{1-\theta_{N}}{\theta_{N}}\right)-\left(1-\varphi_{I}\right)\left(\frac{\theta_{T}-\theta_{N}}{\theta_{T^{\prime}}}\right)\right]\right\}} \Pi, \\
\left(1-\theta^{T}\right) \frac{Y^{T}}{Y}+\left(1-\theta^{N}\right) \frac{P Y^{N}}{Y}=P^{\left(1-\varphi_{I}\right)}\left(r^{\star}+\delta_{K}\right) \frac{K}{Y}, \\
v_{B}=v_{B_{0}}+r^{\star} \frac{Y}{Y^{T}} \Psi_{1}\left(\frac{K}{Y}-v_{K_{0}}\right),
\end{gathered}
$$

where $v_{K_{0}}=\frac{K_{0}}{Y}$ and $\Pi$ is a term composed of parameters described by:

$$
\begin{aligned}
& \Pi \equiv \frac{\left(Z^{T}\right)^{\frac{1+\epsilon}{\theta^{T}}}}{\left(Z^{N}\right)^{\frac{1+\epsilon}{\theta^{N}}}} \frac{\vartheta}{1-\vartheta}\left(r^{\star}+\delta_{K}\right)\left(\frac{\theta^{T}-\theta^{N}}{\theta^{T} \theta^{N}}\right)(1+\epsilon) \\
& \times {\left[\left(\theta^{T}\right)^{\epsilon \theta^{T}}\left(1-\theta^{T}\right)^{\left(1-\theta^{T}\right)(1+\epsilon)}\right]^{1 / \theta^{T}} } \\
& {\left[\left(\theta^{N}\right)^{\epsilon \theta^{N}}\left(1-\theta^{N}\right)^{\left(1-\theta^{N}\right)(1+\epsilon)}\right]^{1 / \theta^{N}} }
\end{aligned}
$$

The system (189) consisting of four equations determine $P, Y^{T} / Y^{N}, K / Y$ and $v_{B}$. The four equations (189a)-(189d) describe the goods market equilibrium, the labor market equilibrium, the resource constraint for capital, and the intertemporal solvency condition.

Dividing the market clearing condition for the traded good $(187 \mathrm{q})$ by the market clearing condition for the non traded good (187p) and equating the resulting expression with the demand of tradables in terms of non tradables obtained by calculating the ratio of $(187 \mathrm{~d})$ to $(187 \mathrm{c})$, i.e., $\frac{C^{T}}{C^{N}}=\frac{\varphi}{1-\varphi} P^{\phi}$, leads to the goods market equilibrium (189a). The derivation of the labor market equilibrium requires more steps. As mentioned below, we assume that the aggregator function for inputs of the investment good is Cobb-Douglas since data suggest that $\phi_{J}=1$. In this case, the investment price index simplifies, i.e., $P_{J}=(P)^{1-\varphi_{J}}$. First, combining (187k) and (187l) leads to:

$$
\begin{aligned}
\frac{\left(k^{N}\right)^{1-\theta^{N}}}{\left(k^{T}\right)^{1-\theta^{T}}} & =P^{\frac{1-\theta_{N}}{\theta_{N}}}\left[P_{I}\left(r^{\star}+\delta_{K}\right)\right]^{\frac{1-\theta_{T}}{\theta_{T}}-\frac{1-\theta_{N}}{\theta_{N}}} \frac{\left[Z^{N}\left(1-\theta_{N}\right)\right]^{\frac{1-\theta_{N}}{\theta_{N}}}}{\left[Z^{T}\left(1-\theta_{T}\right)\right]^{\frac{1-\theta_{T}}{\theta_{T}}}}, \\
& =P^{\left[\left(\frac{1-\theta_{N}}{\theta_{N}}\right)-\left(1-\varphi_{I}\right)\left(\frac{\theta_{T}-\theta_{N}}{\theta_{T} \theta_{N}}\right)\right]} \frac{\left[Z^{N}\left(1-\theta_{N}\right)\right]^{\frac{1-\theta_{N}}{\theta_{N}}}}{\left[Z^{T}\left(1-\theta_{T}\right)\right]^{\frac{1-\theta_{T}}{\theta_{T}}}} .
\end{aligned}
$$

Dividing (187f) by (187e) leads to the supply of hours worked in the traded sector relative to the non traded sector, i.e., $\frac{L^{T}}{L^{N}}=\frac{\vartheta}{1-\vartheta} \Omega^{-\epsilon}$. Dividing $(187 \mathrm{n})$ by $(187 \mathrm{~m})$ leads to the relative wage, i.e., $\Omega=$ $\frac{P Z^{N} \theta^{N}\left(k^{N}\right)^{1-\theta^{N}}}{Z^{T} \theta^{T}\left(k^{T}\right)^{1-\theta^{T}}}$. Inserting the latter expression into the former and using the production functions for the traded sector and non traded sectors which imply $L^{T}=\frac{Y^{T}}{Z^{T}\left(k^{T}\right)^{1-\theta^{T}}}$ and $L^{N}=\frac{Y^{N}}{Z^{N}\left(k^{N}\right)^{1-\theta^{N}}}$, one obtains:

$$
\frac{Y^{T}}{Y^{N}}=\frac{\vartheta}{1-\vartheta}\left(\frac{Z^{T}}{Z^{N}}\right)^{\epsilon+1} P^{-\epsilon}\left(\frac{\theta^{T}}{\theta^{N}}\right)^{\epsilon}\left[\frac{\left(k^{T}\right)^{1-\theta^{T}}}{\left(k^{N}\right)^{1-\theta^{N}}}\right]^{1+\epsilon}
$$

Inserting (191) into the above expression leads to the labor market equilibrium (189b) while we set $\Pi$ to eq. (190) in order to write the equation in compact form. To determine (189c), use the fact that $K^{j}=k^{j} L^{j}$, multiply both sides of (187o) by $\frac{R}{Y}$ where $R=P_{J}\left(r^{\star}+\delta_{K}\right)$ is the capital rental cost; we get:

$$
\frac{R K^{T}}{Y^{T}} \frac{Y^{T}}{Y}+\frac{R K^{N}}{P Y^{N}} \frac{P Y^{N}}{Y}=\frac{R K}{Y} .
$$

Using the fact that the capital income share $\frac{R K^{j}}{P^{j} Y^{j}}$ in sector $j$ is equal to $\left(1-\theta^{j}\right)$ and remembering that the investment price index reduces to $P_{J}=(P)^{1-\varphi_{J}}$, one obtains the resource constraint for capital described by eq. (189c). Finally, to get (189d), multiply both sides of (187r) by $\frac{r^{\star}}{Y^{T}}$, denote the ratio of interest receipts from the initial stock of traded bonds to traded output by $v_{B_{0}}=\frac{r^{\star} B_{0}}{Y^{T}}$ and the ratio of the initial capital stock to GDP by $v_{K_{0}}=\frac{K_{0}}{Y}$ leads to eq. (189d) that describes the intertemporal solvency condition.

Because the ratios we wish to target are different from the macroeconomic aggregates, i.e., $P$, $Y^{T} / Y^{N}, K / Y$ and $v_{B}$, that are jointly determined by the system of equations (189), we have to 
relate the latter ratios to the former. First, the relative price of non tradables $P$ determines the non tradable content of consumption expenditure by setting $\varphi$ :

$$
\alpha_{C}=\frac{(1-\varphi) P^{1-\phi}}{\varphi+(1-\varphi) P^{1-\phi}} .
$$

The ratio $K / Y$ along with the relative price of non tradables, $P$, determines the investment-to-GDP ratio $P_{J} I / Y$ by setting $\delta_{K}$ (see eq. (187i)):

$$
\frac{P_{J} I}{Y}=P_{J} \frac{\delta_{K} K}{Y} .
$$

The ratio of net interest receipts from traded bonds holding to traded output, i.e., $v_{B}$, determines the ratio of net exports to traded output, i.e. $v_{N X}=\frac{N X}{Y^{T}}$ with $N X=Y^{T}-C^{T}-G^{T}-J^{T}$; dividing both sides of the traded goods market clearing condition (187q) leads to:

$$
v_{N X}=-v_{B} .
$$

Finally, we show that $Y^{T} / Y^{N}$ (together with $P$ ) determines $L^{N} / L$ by setting $\vartheta$. To do so, using the definition of the aggregate wage index (83c), the ratio of the aggregate wage to the non traded wage can be rewritten as follows:

$$
\begin{aligned}
\left(\frac{W}{W^{N}}\right)^{\epsilon+1} & =\frac{\vartheta\left(W^{T}\right)^{\epsilon+1}+(1-\vartheta)\left(W^{N}\right)^{\epsilon+1}}{\left(W^{N}\right)^{\epsilon+1}}, \\
& =\vartheta\left(\frac{W^{T}}{W^{N}}\right)^{\epsilon+1}+(1-\vartheta),
\end{aligned}
$$

and by solving, we get

$$
\frac{W}{W^{N}}=\left[\vartheta\left(\frac{W^{T}}{W^{N}}\right)^{\epsilon+1}+(1-\vartheta)\right]^{\frac{1}{\epsilon+1}} .
$$

Since $\theta^{j}$ is the labor income share in sector $j$, the ratio of the traded wage to the non traded wage can be written as follows:

$$
\frac{W^{T}}{W^{N}}=\frac{\theta^{T}}{\theta^{N}} \frac{1}{P} \frac{Y^{T}}{Y^{N}} \frac{L^{N}}{L^{T}} .
$$

Dividing (187f) by (187e) leads to a positive relationship between the supply of hours worked to the traded sector relative to the non traded sector and the traded wage relative to the non traded wage, i.e., $\frac{L^{T}}{L^{N}}=\frac{\vartheta}{1-\vartheta}\left(\frac{W^{T}}{W^{N}}\right)^{\epsilon}$. Substituting the latter equation, eq. (196) can be solved for $W^{T} / W^{N}$, i.e.,

$$
\frac{W^{T}}{W^{N}}=\left[\frac{1-\vartheta}{\vartheta} \frac{\theta^{T}}{\theta^{N}} \frac{1}{P} \frac{Y^{T}}{Y^{N}}\right]^{\frac{1}{\epsilon+1}}
$$

Additionally, since $\alpha_{L}=\frac{W^{N} L^{N}}{W L}=(1-\vartheta)\left(\frac{W^{N}}{W}\right)^{\epsilon+1}$, the share of hours worked in total hours worked is governed by the following optimal rule:

$$
\begin{aligned}
\frac{L^{N}}{L} & =(1-\vartheta)\left(\frac{W^{N}}{W}\right)^{\epsilon}, \\
& =(1-\vartheta)\left(\frac{W}{W^{N}}\right)^{-\epsilon} .
\end{aligned}
$$

Inserting (197) into (195) and plugging the resulting expression into (198) gives us a relationship between the non tradable content of labor and the ratio $Y^{T} / Y^{N}$ (together with $P$ ):

$$
\begin{aligned}
\frac{L^{N}}{L} & =(1-\vartheta)\left[\vartheta\left(\frac{\theta^{T}}{\theta^{N}} \frac{1}{P} \frac{Y^{T}}{Y^{N}}\right)+(1-\vartheta)\right]^{-\frac{\epsilon}{\epsilon+1}}, \\
& =(1-\vartheta)^{\frac{1}{\epsilon+1}}\left[\frac{\theta^{T}}{\theta^{N}} \frac{1}{P} \frac{Y^{T}}{Y^{N}}+1\right]^{-\frac{\epsilon}{\epsilon+1}} .
\end{aligned}
$$

According to (199), given $Y^{T} / Y^{N}$ and $P$, setting $\vartheta$ allows us to target the ratio $L^{N} / L$ found in the data. 


\section{I.2 Calibration to a Representative OECD Economy}

To calibrate our model, we estimated a set of parameters so that the initial steady state is consistent with the key empirical properties of a representative OECD economy. This section provides more details about how we calibrate the model to match the key empirical properties of a representative OECD economy. Because we consider an open economy setup with traded and non traded goods, we calculate the non tradable content of GDP, employment, consumption, gross fixed capital formation, government spending, labor compensation and the productivity in tradables in terms of non tradables, for all countries in our sample, as summarized in Table 4. To capture the key properties a typical OECD economy which is chosen as the baseline scenario, we take unweighted average values shown in the last line of Table 4 . Columns 12-14 of Table 4 also report government spending and investment as a share of GDP along with the aggregate labor income share.

We first describe the parameters that are taken directly from the data; we start with the preference parameters shown in panel A of Table 10:

- One period in the model is a year.

- The world interest rate, $r^{\star}$, equal to the subjective time discount rate, $\beta$, is set to $4 \%$.

- We assume that utility for consumption is logarithmic and thus set the intertemporal elasticity of substitution for consumption, $\sigma_{C}$, to 1 .

- Next, we turn to the Frisch elasticity of labor supply. We set the intertemporal elasticity of substitution for labor supply $\sigma_{L}$ to 0.4 , in line with the evidence reported by Fiorito and Zanella [2012], but conduct a sensitivity analysis with respect to this parameter.

- The elasticity of labor supply across sectors, $\epsilon$, which captures the degree of labor mobility is set to 0.75 in line with the average of our estimates shown in the last column of Table $4 .{ }^{73}$ Our estimates display a wide dispersion across countries and we therefore conduct a sensitivity analysis with respect to this parameter. Excluding estimates of $\epsilon$ for Denmark and Norway which are not statistically significant at $10 \%$, estimates of $\epsilon$ range from a low of 0.22 for the Netherlands to a high of 1.39 for the United States and 1.64 for Spain. Hence, we allow for $\epsilon$ to vary between 0.22 and 1.64 in the sensitivity analysis.

- Building on our panel data estimations (see section B.3), we set the elasticity of substitution (in consumption) between traded and non traded goods to 0.77 in the baseline calibration, in line with the unweighted average value shown in the last line of column 15 of Table $4 .{ }^{74}$

- We set the elasticity of substitution, $\phi_{J}$, in investment between traded and non traded inputs to 1, in line with the empirical findings documented by Bems [2008] for OECD countries.

We also consider a more general specification for preferences which are assumed to be non separable in consumption and labor. The functional form is taken from Shimer [2011]:

$$
\frac{C^{1-\sigma} V(L)^{\sigma}-1}{1-\sigma}, \quad \text { if } \quad \sigma \neq 1, \quad V(L) \equiv\left(1+(\sigma-1) \frac{\sigma_{L}}{1+\sigma_{L}} L^{\frac{1+\sigma_{L}}{\sigma_{L}}}\right) .
$$

Setting $\sigma=1$, preferences are separable in consumption and labor, as in (77). When investigating the implications of non separability in preferences, we set $\sigma=2$ while we keep other parameters unchanged.

We pursue with the non-tradable content of consumption, investment and government expenditure, employment, along with sectoral labor income shares and relative productivity of tradables shown in the last line of Table 4 that reports the average of our estimates while panel B of Table 10 displays the value of parameters we choose to calibrate the model:

- The weight of consumption in non tradables $1-\varphi$ is set to 0.51 to target a non-tradable content in total consumption expenditure (i.e. $\alpha_{C}$ ) of $53 \%$.

- In order to target a non tradable content of labor of $67 \%$ which corresponds to the 16 OECD countries' unweighted average shown in the last line of Table 4, we set the weight of labor supply to the traded sector in the labor index $L(),. 1-\vartheta$, to 0.68 .

\footnotetext{
${ }^{73}$ Section B.3 presents the empirical strategy and contains the details of derivation of the relationship we explore empirically.

${ }^{74}$ We derive a testable equation by combining first-order conditions for relative demand and relative supply for tradables in terms of non tradables. Details of derivation of the equation we explore empirically can be found in section B.3. We explore empirically two variants of the testable equation, considering alternatively the ratio of sectoral value added or the ratio of sectoral labor compensation. Estimates of $\phi$ for Italy are negative for both variants while for Belgium, only the estimate of the elasticity of substitution in consumption between tradables and non tradables when exploring empirically the second variant of the testable equation is statistically significant (see Table 3). Excluding estimates of $\phi$ for Italy which are negative and considering a value of 0.795 for Belgium, the elasticity of substitution $\phi$ averages to 0.77.
} 
- We choose a value for the weight of non traded inputs in the investment aggregator function $J(),. 1-\varphi_{J}$, of 0.64 which allows us to obtain a non tradable content of investment expenditure of $64 \%$.

- In accordance with our estimate shown in the last line of Table 4, we choose a non tradable content of government spending, $\omega_{G^{N}}=\frac{P G^{N}}{G}$, of $90 \%$; by construction, we have a share of government consumption on tradables in total government spending, $\omega_{G^{T}}=1-\omega_{G^{N}}$, of $10 \%$.

- Columns 9 and 10 of Table 4 give the labor income share of the traded and the non traded sector for the sixteen OECD countries in our sample. Labor income shares $\theta^{T}$ and $\theta^{N}$ average respectively to 0.60 and 0.67 . Because average values suggest that the non traded sector is relatively more labor intensive than the traded sector, in the baseline calibration, we choose values for $\theta^{T}$ and $\theta^{N}$ so that $\theta^{T}<\theta^{N}$. The figures also show substantial dispersion across countries as the labor income share in the traded sector varies from a low of 0.38 in Norway to a high of 0.71 for Italy. Moreover, the labor income share in the traded sector, $\theta^{T}$, is higher than that in the non traded sector, $\theta^{N}$, for two countries, namely France and Italy. Thus, we also conduct a sensitivity analysis by considering a situation where the traded sector is more labor intensive than the non traded sector. When excluding France and Italy, the values of $\theta^{T}$ and $\theta^{N}$ average 0.58 and 0.67 , respectively. In the baseline calibration, we set $\theta^{T}$ and $\theta^{N}$ to 0.58 and 0.68 which correspond roughly to the average for countries with $k^{T}>k^{N}$ and are consistent with an aggregate labor income share of 64\%, as shown in column 14 of Table 4. Formally, the aggregate labor income share, denoted by $\theta$, is a value-weighted average of the sectoral labor income shares, i.e., $\theta=\frac{\theta^{T} Y^{T}}{Y}+\frac{\theta^{N} P Y^{N}}{Y}$. When we consider a traded sector that is relatively more labor intensive than the non traded sector, i.e., $k^{N}>k^{T}$, we use reverse but symmetric values and thus set $\theta^{T}=0.68$ and $\theta^{N}=0.58$.

- We assume that traded firms are 28 percent more productive than non traded firms in line with our estimates; we thus normalize $Z^{N}$ to 1 and set $Z^{T}$ to 1.28 .

We describe below the choice of parameters displayed in panel $\mathrm{C}$ of Table 10 characterizing macroeconomic variables such as investment, government spending and the balance of trade of a typical OECD economy:

- As shown in the last line of column 13 of Table 4, government spending as a percentage of GDP averages $20 \%$ and thus we set $\omega_{G}=\frac{G}{Y}$ to 0.2 .

- In order to target an investment-to-GDP ratio, $\omega_{J}=\frac{P_{J} I}{Y}$, of $21 \%$ as shown in the last line of column 12 of Table 4, we set the rate of physical capital depreciation, $\delta_{K}$, to $6 \%$.

- We choose the value of parameter $\kappa$ so that the elasticity of $I / K$ with respect to Tobin's q, i.e., $Q / P_{J}$, is equal to the value implied by estimates in Eberly, Rebelo, and Vincent [2008]. The resulting value of $\kappa$ is equal to $17 .{ }^{75}$

- Finally, we choose initial values for $B_{0}$ and $K_{0}$ for the ratio of net exports to traded output to be nil at the initial steady-state, i.e., $v_{N X} \simeq 0$.

Investment- and government spending-to-GDP ratios along with balanced trade endogenously determine the consumption-to-GDP ratio. More precisely, since GDP is equal to the sum if its demand components, remembering that at the steady-state $I=J$, we thus have the following accounting identity, $Y=P_{C} C+P_{J} I+G+N X$. Dividing both sides by $Y$ and remembering that net exports are nil, i.e., $N X=0$, the consumption-to-GDP ratio denoted by $\omega_{C}=\frac{P_{C} C}{Y}$ is thus equal to $59 \%$ :

$$
\omega_{C}=\frac{P_{C} C}{Y}=1-\left(\omega_{J}+\omega_{G}+\frac{N X}{Y}\right)=59 \%,
$$

where $\omega_{J}=\frac{P_{J} I}{Y}=21 \%, \omega_{G}=\frac{G}{Y}=20 \%$, and $N X=0$.

It is worthwhile mentioning that the non tradable content of GDP is endogenously determined by the non tradable content of consumption, $\alpha_{C}$, of investment, $\alpha_{J}$, and of government expenditure, $\omega_{G^{N}}$, along with the consumption-to-GDP ratio, $\omega_{C}$, the investment-to-GDP ratio, $\omega_{J}$, and government spending as a share of GDP, $\omega_{G}$. More precisely, dividing the non traded good market clearing condition (187p) by GDP, $Y$, leads to an expression that allows us to calculate the non tradable content of GDP:

$$
\frac{Y^{N}}{Y}=\omega_{C} \alpha_{C}+\omega_{J} \alpha_{J}+\omega_{G^{N}} \omega_{G}=63 \%
$$

\footnotetext{
${ }^{75}$ Eberly, Rebelo, and Vincent [2008] run the regression $I / K=\alpha+\beta \cdot \ln (q)$ and obtain a point estimate for $\beta$ of 0.06 . In our model, the steady-state elasticity of $I / K$ with respect to Tobin's $q$ is $1 / \kappa$. Equating $1 / \kappa$ to 0.06 gives a value for $\kappa$ of 17 .
} 
where $\omega_{C}=59 \%, \alpha_{C}=53 \%, \omega_{J}=21 \%, \alpha_{J}=64 \%, \omega_{G^{N}}=90 \%$, and $\omega_{G}=20 \%$. According to (202), the values we target for the non tradable content of consumption, investment and government spending along with the consumption-, investment-, and government spending-to-GDP ratios are consistent with a non tradable content of GDP of $63 \%$ found in the data, as reported in the last line of column 1 of Table 4.

In order to capture the dynamic adjustment of government consumption, we assume that the response of government consumption in percent of GDP is governed by the following dynamic equation: ${ }^{76}$

$$
\frac{d G(t)}{\tilde{Y}} \equiv \frac{G(t)-\tilde{G}}{\tilde{Y}}=\left[e^{-\xi t}-(1-g) e^{-\chi t}\right],
$$

where $g$ parametrizes the exogenous fiscal shock while $\xi>0$ and $\chi>0$ parametrize the persistence of the response of government consumption along with the pattern of its dynamic adjustment. We present below the parameters related to the endogenous response of government spending to an exogenous fiscal shock which are summarized in panel D of Table 10:

- We investigate the effects of a rise in government consumption by 1 percentage point of GDP and thus set $g$ to 0.01 .

- We choose values of $\xi$ and $\chi$ in order to account for the dynamic adjustment of government consumption. Data indicate that the endogenous response of government spending to an exogenous fiscal shock reaches a maximum at time $t=1$ :

$$
\frac{d G(1)}{\tilde{Y}} \equiv \frac{G(1)-\tilde{G}}{\tilde{Y}}=g^{\prime}=\left[e^{-\xi}-(1-g) e^{-\chi}\right] .
$$

Differentiating (203) w.r.t. time leads to:

$$
\frac{\dot{G}(t)}{\tilde{Y}}=-\left[\xi e^{-\xi t}-\chi(1-g) e^{-\chi t}\right]
$$

When government spending reaches its maximum value, we have $\dot{G}(t)=0$. Setting $t=1$ into (205) gives:

$$
\frac{\dot{G}(1)}{\tilde{Y}}=-\left[\xi e^{-\xi}-\chi(1-g) e^{-\chi}\right]=0
$$

Using the fact that $g=0.01$ and $g^{\prime}=0.01126548$, the system consisting of eq. (204) and eq. (206) jointly determine the values of $\xi$ and $\chi$ which allow us to capture the endogenous response of government spending to an exogenous fiscal shock by $g \times 100$ percentage points of GDP; we set $\xi=0.408675$ and $\chi=0.415722$.

- While government purchases both non traded goods, $G^{N}$, and traded goods, $G^{T}$, our VAR evidence suggest that the rise in government consumption is strongly biased toward non traded goods as the relative size the non traded sector rises significantly. When we simulate the model, we thus consider a rise in government consumption by 1 percentage point of GDP which is split between non tradables and tradables in accordance with their respective share in government expenditure at $90 \%$ and $10 \%$, respectively. Formally, we have:

$$
\frac{d G(t)}{\tilde{Y}}=\omega_{G^{N}} \frac{d G^{N}(t)}{\tilde{Y}}+\left(1-\omega_{G^{N}}\right) \frac{d G^{T}(t)}{\tilde{Y}}
$$

where $d G(t)=G(t)-\tilde{G}$ and $d G^{j}(t)=G^{j}(t)-\tilde{G}^{j}$.

\section{J More Numerical Results}

In this section, we provide additional numerical results which are not included in the main text for reason of space.

\section{J.1 Contrasting Empirical and Theoretical Effects on GDP and Demand Components}

We begin with the aggregate effects of a government spending shock shown in panels A and B of Table 1. Contrasting the numerical results reported in columns 2 and 6 with the evidence shown in column 1, whether we assume imperfect or perfect mobility of labor, both models tend to understate the responses of real GDP and hours worked. However, the model performance improves with imperfect

\footnotetext{
${ }^{76}$ More technical details can be found in section G.3.
} 


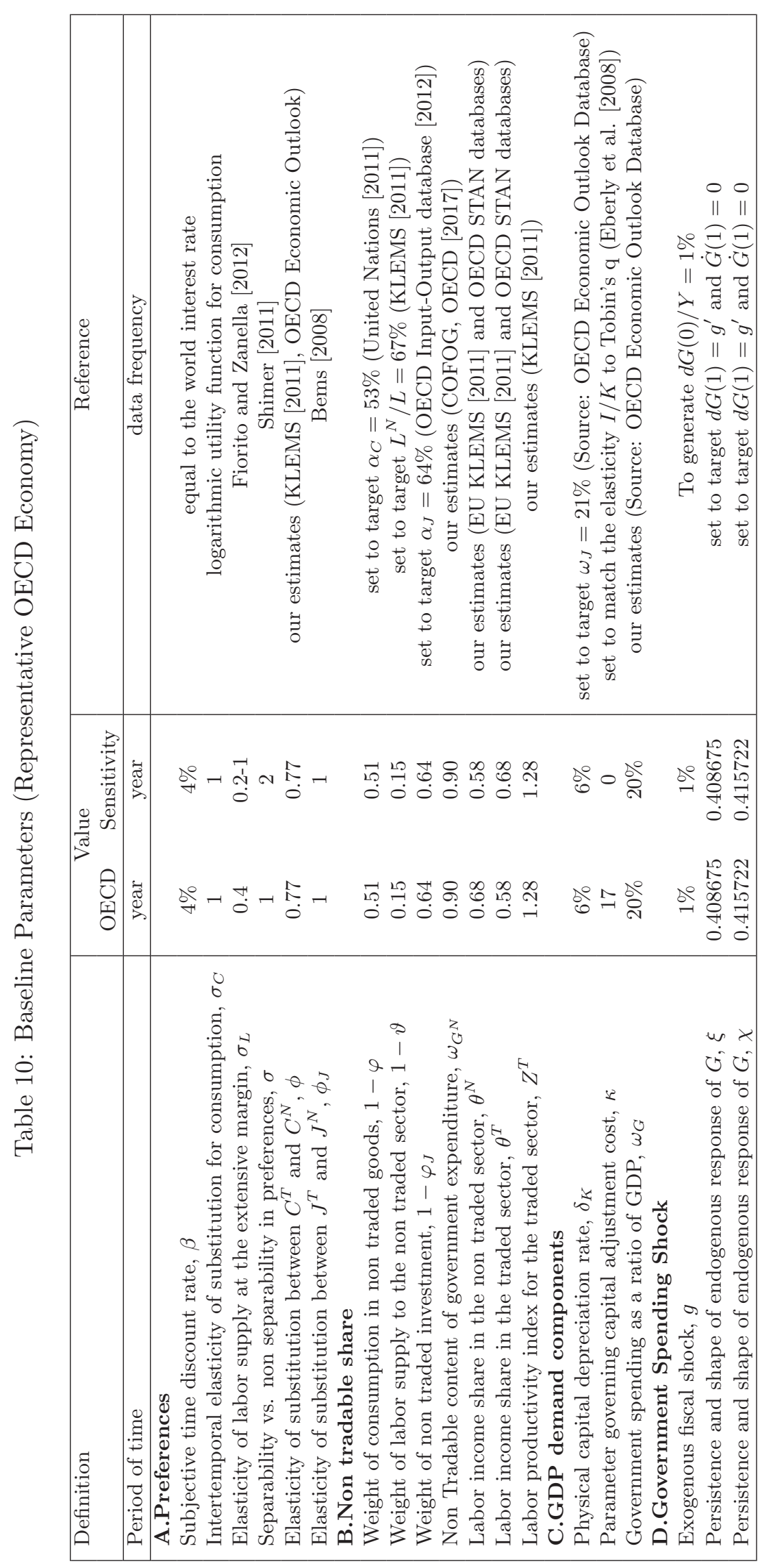


mobility of labor as the rise in GDP by $0.19 \%$ lies within the confidence interval, as shown in Figure 35(d). The reason is that with imperfect mobility of labor, the existence of workers' costs of switching sectors puts upward pressure on non traded wages and thus on the aggregate wage. This then amplifies the positive response of hours worked which increases on impact by $0.30 \%$ instead of $0.11 \%$ when the mobility cost is absent. Because agents supply more labor, real GDP rises by a larger amount as long as there is a difficulty in reallocating labor. While the real consumption wage is unaffected on impact when we let $\epsilon$ tend toward infinity, a government spending shock generates a rise in the wage rate which more than offsets the increase in the consumption price index and thus pushes up the real consumption wage by $0.07 \%$ in the baseline model where $\epsilon=0.75$.

Turning to the dynamic adjustment of investment and the current account displayed in Fig. 35(b) and 35(c), a model assuming perfect mobility and abstracting from capital installation costs dramatically overstates the decline in investment and predicts a current account surplus in the shortrun, contrary to the evidence. Because capital-labor ratios are fixed, the return on domestic capital remains unchanged as well. The substantial decline in private savings generates such a physical capital decumulation that the current account moves into surplus. In contrast, as long as we relax the assumption of perfect mobility of labor, the neoclassical model is able to produce the crowding out of investment along with the current account deficit in the short-run, as shown in column 5 of Table 1 where we abstract from capital installation costs to isolate the role of limited labor mobility. Intuitively, as long as there is a difficulty in reallocating labor across sectors, the capital-labor ratio falls in the traded sector as the workers' mobility costs moderate the shift of labor. Thus, the return on domestic capital increases, which in turn mitigates the fall in investment and produces a current account deficit. However, the model tends to overstate the crowding-out of investment and to understate the decline in the current account. In contrast, as shown in column 2, when we allow for capital installation costs along with imperfect mobility of labor, the model predicts a current account deficit of $0.34 \%$ of GDP, which accords well with our estimate, by further mitigating the decline in investment. We then ask whether both capital adjustments costs and imperfect mobility of labor are essential to account for the evidence. To answer this, column 7 considers a scenario where we assume that physical capital accumulation is subject to installation costs while hours worked are perfect substitutes across sectors. The model predicts a rise in investment instead of a decline and considerably overstates the current account deficit found in the data: while the shadow price of investment, $Q$, increases as in a model assuming imperfect mobility of labor, the rise in the investment price index, $P_{J}$, is not large enough to drive down Tobin's $q$. As will become clear below, perfect mobility of labor implies that the relative price of non tradables merely appreciates, thus hampering the increase in $P_{J}$.

Contrasting the model's predictions with VAR evidence in Fig. 35, the simulated responses lie within the confidence interval along the transitional adjustment, with the exception of the real consumption wage. Although quite stylized, the model is able to account for the time-series evidence on the aggregate effects of a government spending shock as long as we allow for both capital installation costs and a difficulty in reallocating labor.

\section{J.2 Numerical Results for a Representative OECD Economy}

Table 11 reports impact effects following a rise in government consumption by 1 percentage point of GDP. Column 1 of Tables 11 shows the effects of a government spending shock from our VAR model for comparison purposes while columns 2-14 report simulated responses. We conduct a sensitivity analysis with respect to a number of parameters, including the labor income share of sector $j, \theta^{j}$, the elasticity of labor supply across sectors, $\epsilon$, the parameter $\kappa$ that governs the magnitude of adjustment costs to capital accumulation, the Frisch elasticity of labor supply, $\sigma_{L}$, and the parameter $\sigma>0$ that determines the substitutability between consumption and leisure. We provide more details below:

- In columns 2 and 3 , we impose perfect mobility of labor across sectors, i.e., $\epsilon \rightarrow \infty$. In column 2 , we abstract from capital installation costs and thus set $\kappa=0$ while in column 3 , we consider adjustment costs to physical capital accumulation and thus sect $\kappa=17$.

- Column 4 reports results from our baseline model with imperfect mobility of labor across sectors, setting $\epsilon$ to 0.75 , while capital accumulation is assumed to be subject to adjustments costs with $\kappa=17$.

- In columns 5 and 6 , we keep unchanged $\kappa$ and investigate the effects of a government spending shock when the degree of labor mobility across sectors is low, i.e., $\epsilon$ is set to 0.22 , and when the elasticity of labor supply across sectors is high, i.e., $\epsilon$ is set to 1.64.

- In column 7, we investigate the sensitivity of our results to the Frisch elasticity of labor supply which is raised from 0.4 to 1 .

- Column 8 shows results when we allow for imperfect mobility of labor across sectors, setting $\epsilon$ to 0.75 , while we abstract from adjustment costs to capital accumulation, and thus set $\kappa$ to 


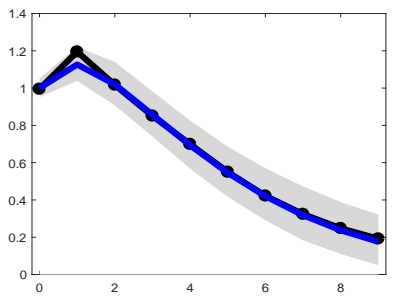

(a) Government Spending

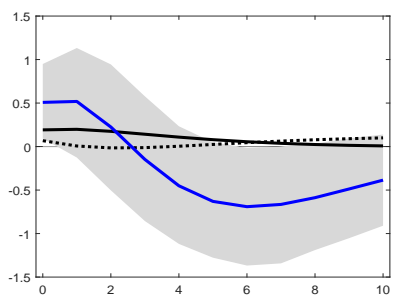

(d) Real GDP

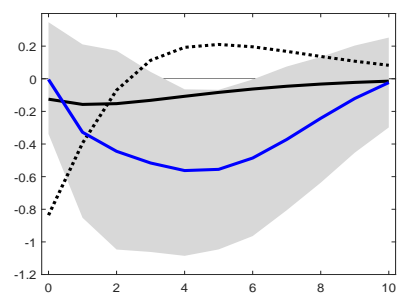

(b) Investment

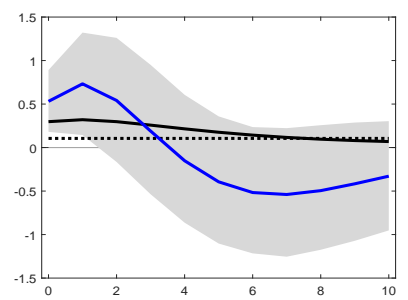

(e) Hours Worked

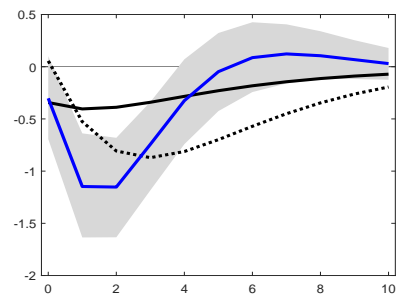

(c) Current Account

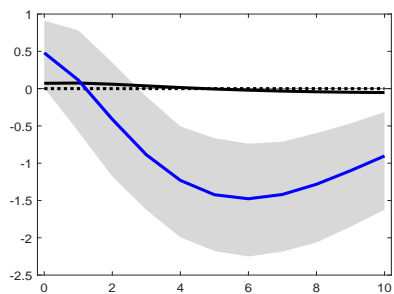

(f) Aggregate Real Wage

Figure 35: Dynamic Adjustment of Aggregate Variables to Unanticipated Government Spending Shock. Notes: Solid blue line displays point estimate of VAR model with dotted blue lines indicating $90 \%$ confidence bounds; the solid black line displays model predictions in the baseline scenario with imperfect mobility of labor across sectors $(\epsilon=0.75)$ and capital installation costs $(\kappa=17)$ while the dotted black line shows predictions of the model imposing perfect mobility of labor $(\epsilon \rightarrow \infty)$ and abstracting from capital adjustment costs $(\kappa=0)$.

0.

- Column 9 reports results when we relax the assumption of separability in preferences between consumption and labor, setting $\sigma$ to 2 .

- Columns 10 and 13 show results when we allow for imperfect mobility of both labor and capital across sectors. Implications of imperfect mobility of capital are discussed in the next section.

- While from column 2 to column 10 , we assume that the non traded sector is relatively more labor intensive than the traded sector, and thus set $\theta^{N}$ to 0.68 and $\theta^{T}$ to 0.58 , from column 11 to column 13, we explore the case where the non traded sector is relatively more capital intensive and thus choose reverse and symmetric values for the sectoral labor income shares, i.e., we set $\theta^{N}$ to 0.58 and $\theta^{T}$ to 0.68 .

- While column 12 reports our baseline model's predictions when $\theta^{T}>\theta^{N}$, in column 11 , we set $\kappa=0$ and let $\epsilon$ tend toward infinity, and in column 13 (IMK), we allow for both imperfect mobility of labor and capital across sectors, and thus set $\eta$ to 0.75 .

In column 9, we relax the assumption of separability in preferences between consumption and labor by considering a functional form which is taken from Shimer [2011]:

$$
\frac{C^{1-\sigma} V(L)^{\sigma}-1}{1-\sigma}, \quad \text { if } \quad \sigma \neq 1, \quad V(L) \equiv\left(1+(\sigma-1) \frac{\sigma_{L}}{1+\sigma_{L}} L^{\frac{1+\sigma_{L}}{\sigma_{L}}}\right) .
$$

These preferences are characterized by two crucial parameters: $\sigma_{L}$ is the Frisch elasticity of labor supply, and $\sigma>0$ determines the substitutability between consumption and leisure; if $\sigma>1$, the marginal utility of consumption increases in hours worked. In contrast, setting $\sigma=1$ implies that preferences are separable in consumption and labor, as in (11). When we investigate the implications of non separability in preferences, we set $\sigma=2$ while keeping other parameters unchanged.

Column 9 shows results when $\sigma$ is set to 2. As can be seen in column 9 , non separability in preferences between consumption and labor amplifies the rise in the real consumption wage while hours and real GDP increase less. Additionally, the open economy runs a larger current account deficit. Intuitively, because non separability in preferences between consumption and labor increases the disutility from working, agents are less willing to supply labor while demanding higher wages. Because consumption increases with the aggregate wage, agents lower their expenditure less. Thus, private savings decline further, which in turn amplifies the decline in the current account. As the crowding out of private consumption is less, the relative price of non tradables appreciates by a larger amount, thus amplifying the responses of sectoral output shares. While the extension of the baseline model to non separability in preferences somewhat improves its performance in reproducing the responses of several sectoral variables, the extended model tends to substantially overstate the contraction in the traded sector and to overpredict the rise in the relative wage. In contrast, all 
simulated impact responses from the baseline model assuming separability in preferences lie within the confidence interval.

In the last three columns of Table 11, we investigate whether our conclusions hold if we assume a non traded sector that is more capital intensive than the traded sector. While the predictions of the model are very sensitive to sectoral labor income shares if we let $\epsilon$ tend toward infinity, results are almost unaffected for the baseline model whether $\theta^{T}<\theta^{N}$ or $\theta^{T}>\theta^{N}$. As shown in column 11, the model imposing perfect mobility of labor fails to account for the evidence along a number of dimensions. In particular, the simulated responses of sectoral output shares are more than four times greater than those reported from the VAR model. The reason is that imposing perfect mobility makes labor and thus sectoral output highly sensitive to a change in relative price. Because investment is crowded in, the subsequent excess demand in the non traded goods market causes the relative price of non tradables to appreciate, thus leading to dramatic changes in the relative size of sectors. Since the model's predictions reported in column 12 are similar to those shown in column 4, they do not merit further comment.

Panels A and B of Table 11 show impact effects of a government spending shock for GDP, investment and the current account along with labor market variables such as total hours worked and the real consumption wage. Panels $\mathrm{C}$ and $\mathrm{D}$ of Table 11 summarize the theoretical responses of sectoral variables for the labor and product markets. Because the results shown in column 10 when we allow for imperfect mobility of capital across sectors do not improve the performance of the model with imperfect mobility of labor in replicating the evidence, or provide major additional information on the fiscal transmission as the conclusions are similar whether we allow or not for imperfect mobility of capital across sectors, to save space we do not present them in the main text and relegate these results in the Technical Appendix.

\section{J.3 No Capital Installation Costs vs. Perfect Mobility of Labor across Sectors}

In the main text, see section 5.2, we show that the model is successful in replicating both aggregate and sectoral effects of a government spending shock as long as we allow for both imperfect mobility of labor across sectors, captured by $\epsilon$, along with adjustment costs to capital accumulation, captured by the parameter $\kappa$. Table 1 contrasts impact effects in the baseline scenario (column 2) with a number of alternative scenarios where we impose perfect mobility of labor across sectors and abstract from capital installation costs (column 6 ), we consider capital installation costs along with perfect mobility of labor across sectors (column 7), and we allow for imperfect mobility of labor across sectors but abstract from capital installation costs (column 5). Figure 35 above and Figure 6 in the main text display the model predictions for the aggregate and sectoral effects, respectively, of a government spending shock under imperfect (solid black line with circles) and perfect mobility of labor across sectors (dashed dotted black line) together with the respective VAR evidence (solid blue line).

For reason of space, we do not contrast the dynamic adjustment of the baseline model with that obtained from a model with perfect mobility of labor while assuming capital installation costs or alternatively from a model assuming imperfect mobility of labor but abstracting from adjustment costs to physical capital accumulation. We discuss below the implications when one feature of the baseline model is shut down.

The solid black line in Figures 36 and 37 show the predictions of the baseline model while the dotted black line displays the predictions of a model with a difficulty in reallocating labor across sectors but abstracting from capital installation costs. As emphasized in the main text, the conclusion that emerges is that the model without capital adjustment costs tend to overstate the crowding out of investment in the short-run and to understate substantially the current account deficit. Because investment declines more, excess demand in the non traded goods market and thus the appreciation in the relative price of non tradables is much smaller than that found in the data. Because the model without capital installation costs underpredicts the short-run rise in $P$, it tends to understate the responses of sectoral output shares. The solid black line in Figures 38 and 39 show the predictions of the baseline model while the dotted black line displays the predictions of a model imposing perfect mobility of labor across sectors while assuming that capital accumulation is subject to installation costs. First, the model predicts a rise in investment instead of decline, in contradiction with the evidence, and tends to overstate the current account deficit. Turning 


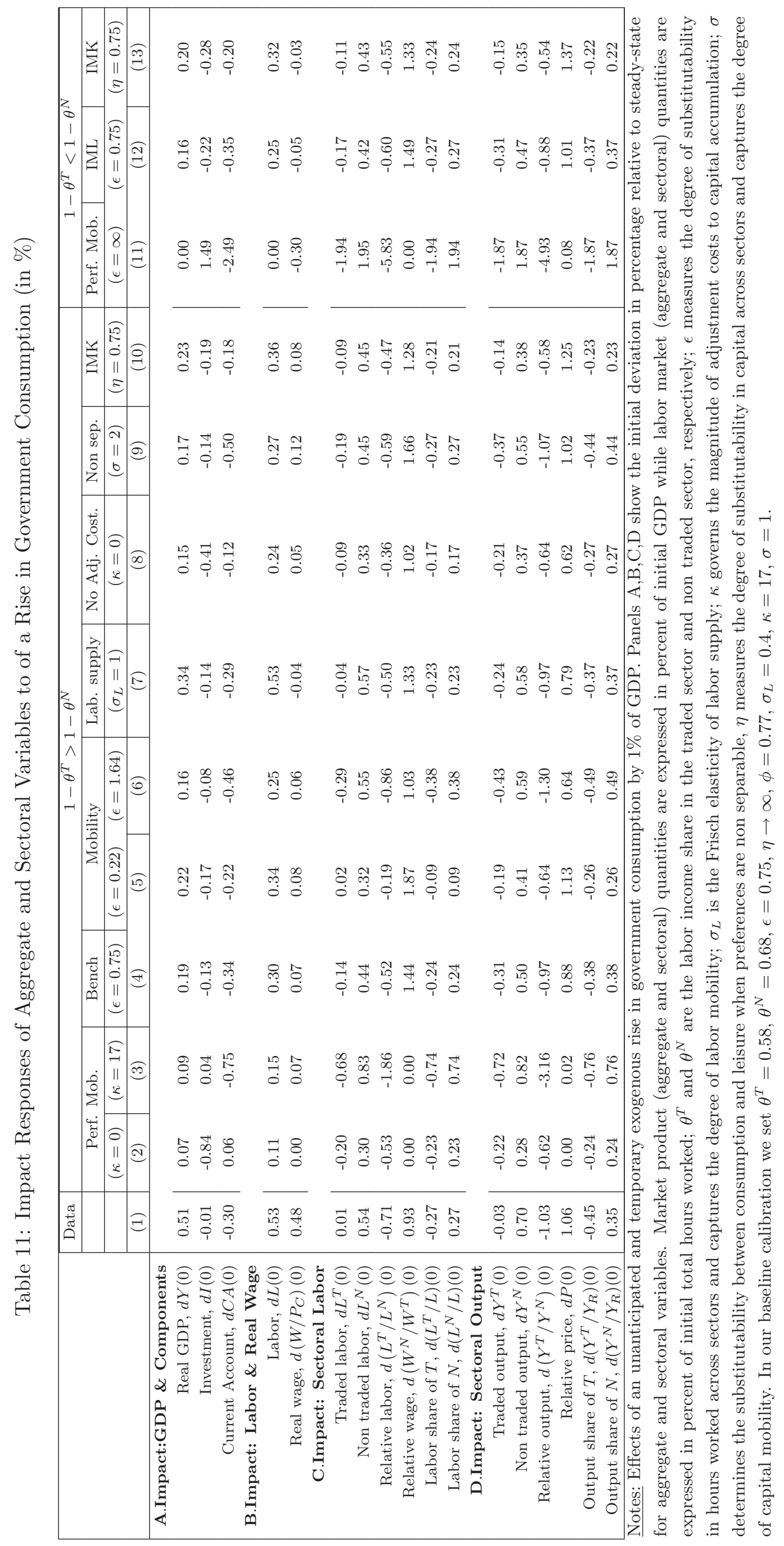




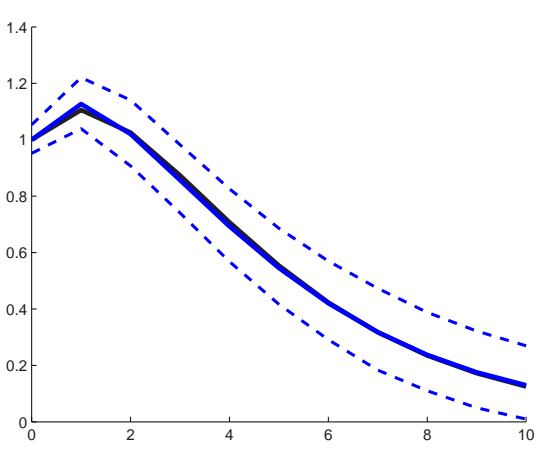

(a) Government Spending

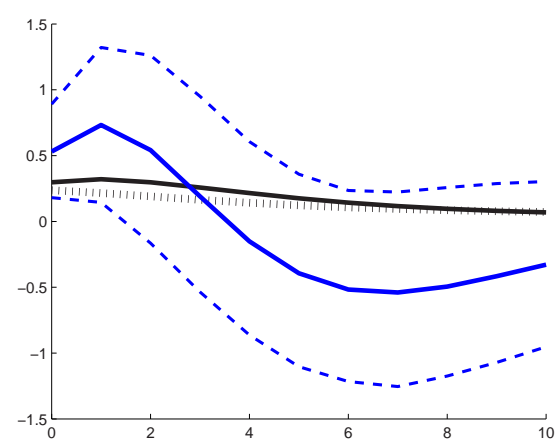

(c) Hours Worked

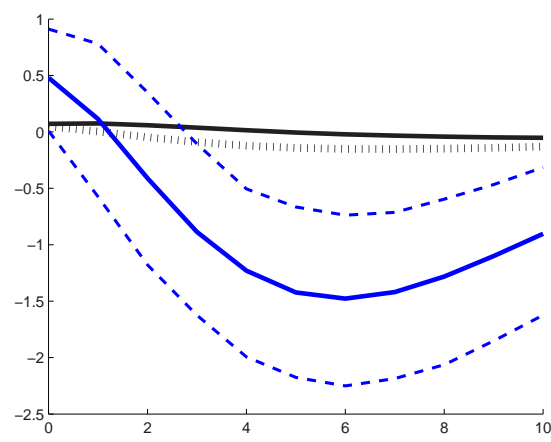

(e) Aggregate Real Wage

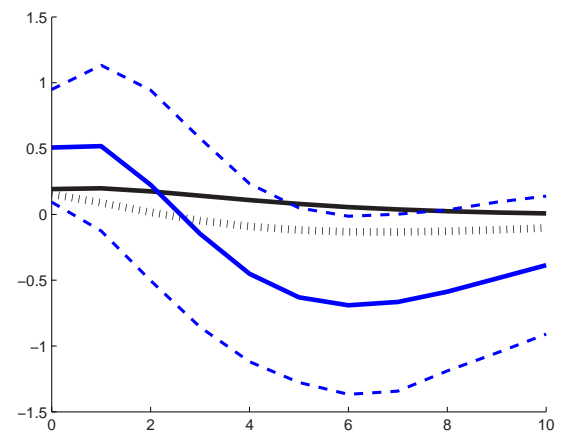

(b) GDP

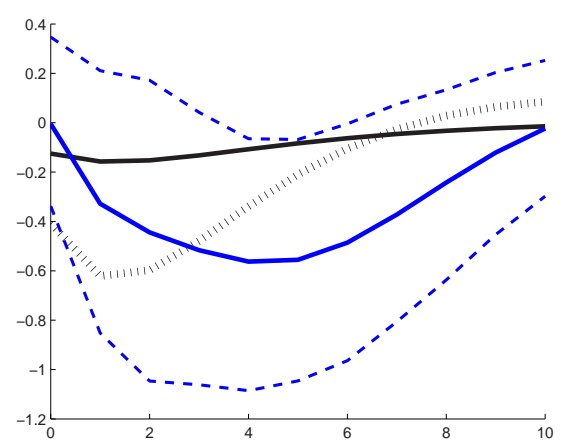

(d) Investment

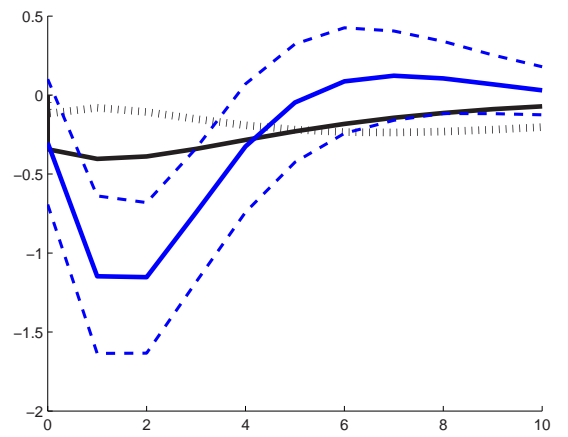

(f) Current Account

Figure 36: Dynamic Adjustment of Aggregate Variables to Unanticipated Government Spending Shock: The Role of Capital Adjustment Costs. Notes: solid blue line display point estimate of VAR with dotted blue lines indicating $90 \%$ confidence bounds; the solid black line displays model predictions in the baseline scenario with imperfect mobility of labor across sectors $(\epsilon=0.75)$ and capital installation costs $(\kappa=17)$ while the dotted black line shows results when abstracting from capital adjustment $\operatorname{costs}(\kappa=0)$.

to the sectoral effects, while assuming capital installation costs restore transitional dynamics for the relative price of non tradables, the model imposing perfect mobility considerably understates the appreciation in the relative price and cannot account for the rise in non traded wages relative to traded wages as sectoral wages equalize. Moreover, while the relative price of non tradables merely appreciates, because labor is extremely sensitive to relative price changes, subsequent changes in sectoral output shares conflict with the evidence since their magnitude are about twice what is estimated empirically,

\section{J.4 Simulated Responses of Sectoral Output Shares across Countries}

We denote by $\nu_{i}^{Y, j}(t)$ the value added $(Y)$ share of sector $j$, in country $i$ at year $t$. In terms of our model's notation, the response of the output share of sector $j$ to a government spending shock is measured in total output units and thus is calculated as the product between the growth differential between sectoral value added and GDP (both at constant 


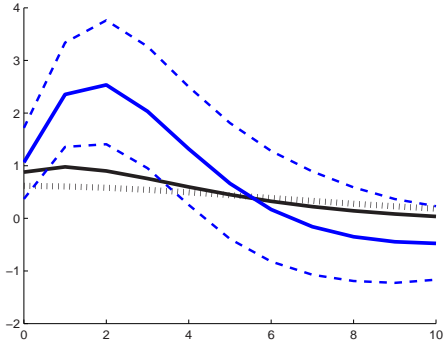

(a) Relative Price, $P$

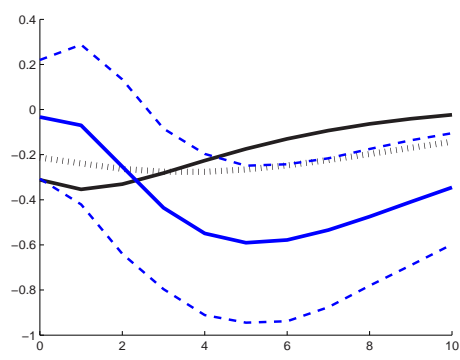

(d) Traded Output, $Y^{T}$

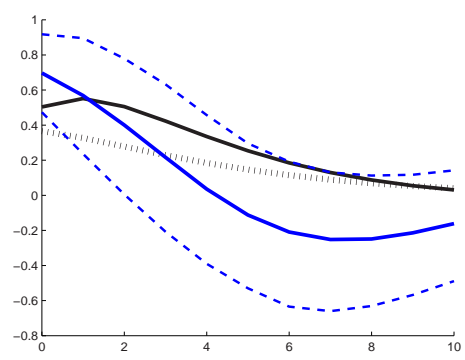

(g) Non Traded Output, $Y^{N}$

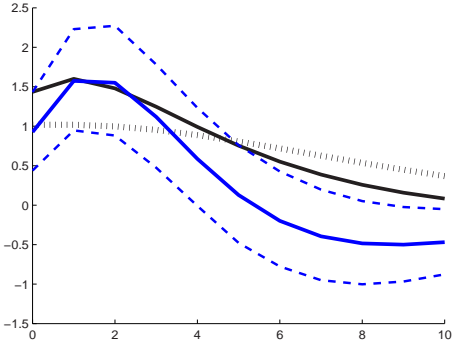

(b) Relative Wage, $W^{N} / W^{T}$

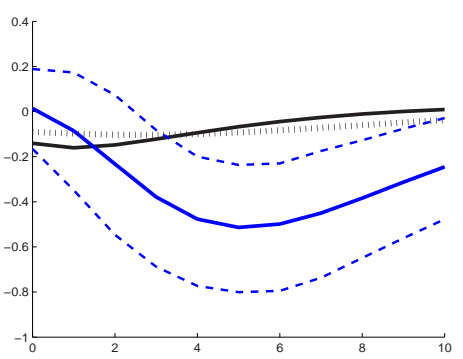

(e) Traded Labor, $L^{T}$

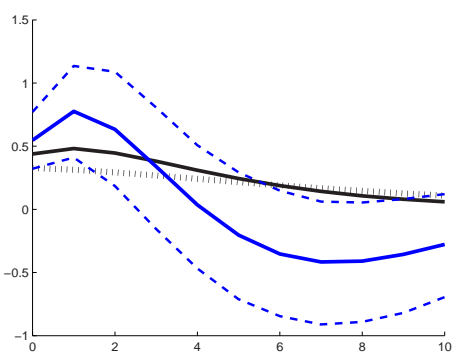

(h) Non Traded Labor, $L^{N}$

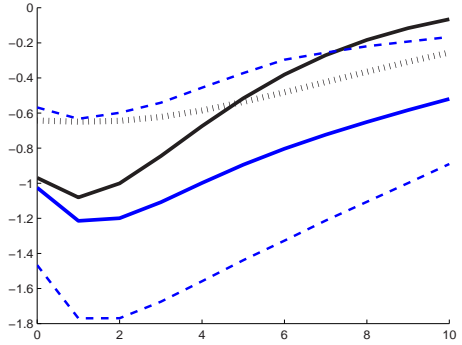

(c) Relative Output, $Y^{T} / Y^{N}$

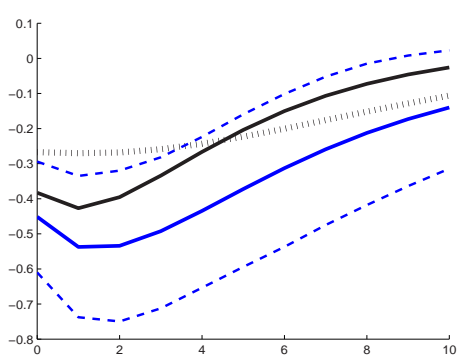

(f) Tradable share, $Y^{T} / Y$

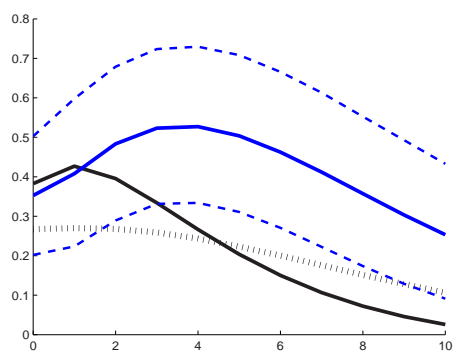

(i) Non Tradable share, $Y^{N} / Y$

Figure 37: Dynamic Adjustment of Sectoral Variables to Unanticipated Government Spending Shock: The Role of Capital Adjustment Costs. Notes: Solid blue line display point estimate of VAR with dotted blue lines indicating $90 \%$ confidence bounds; the solid black line displays model predictions in the baseline scenario with imperfect mobility of labor across sectors $(\epsilon=0.75)$ and capital installation costs $(\kappa=17)$ while the dotted black line shows results when abstracting from capital adjustment costs $(\kappa=0)$. 


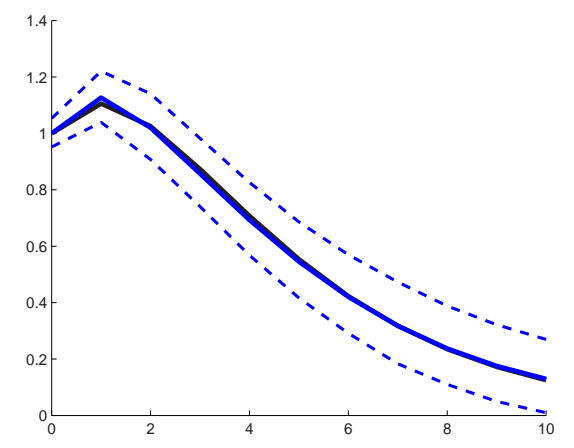

(a) Government Spending

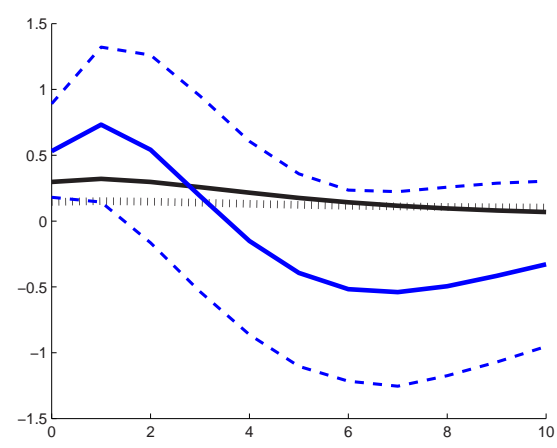

(c) Hours Worked

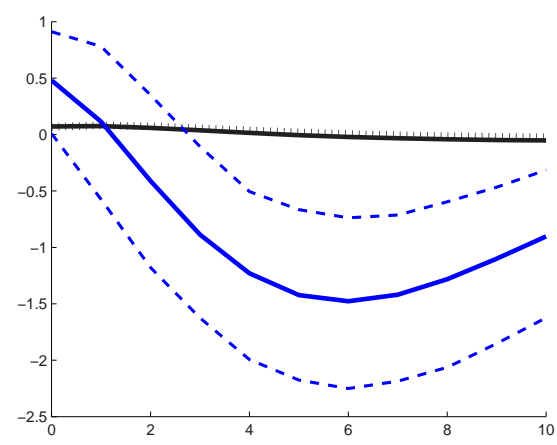

(e) Aggregate Real Wage

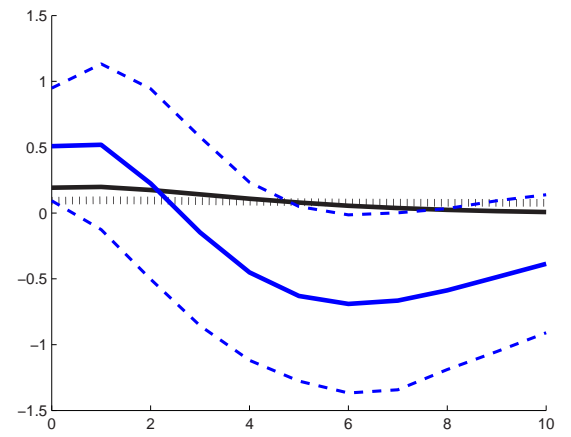

(b) GDP

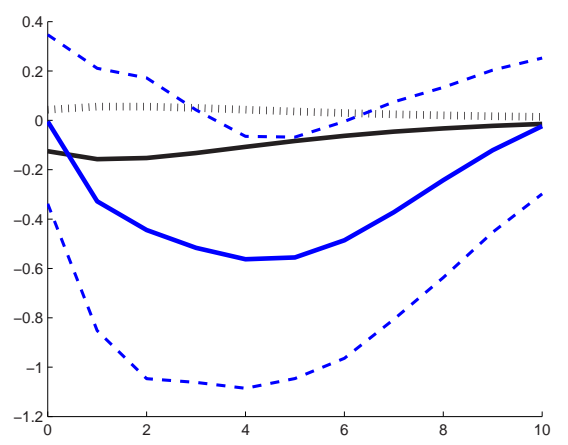

(d) Investment

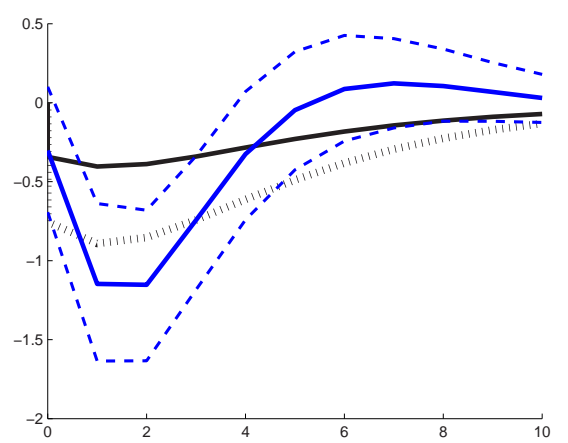

(f) Current Account

Figure 38: Dynamic Adjustment of Aggregate Variables to Unanticipated Government Spending Shock: The Role of Limited Mobility across Sectors. Notes: solid blue line display point estimate of VAR with dotted blue lines indicating $90 \%$ confidence bounds; the solid black line displays model predictions in the baseline scenario with imperfect mobility of labor across sectors $(\epsilon=0.75)$ and capital installation costs $(\kappa=17)$ while the dotted black line shows results when imposing perfect mobility of labor across sectors $(\epsilon \rightarrow \infty)$. 


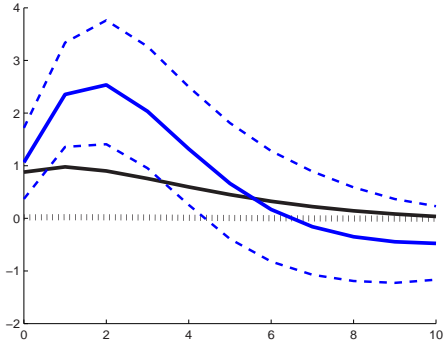

(a) Relative Price, $P$

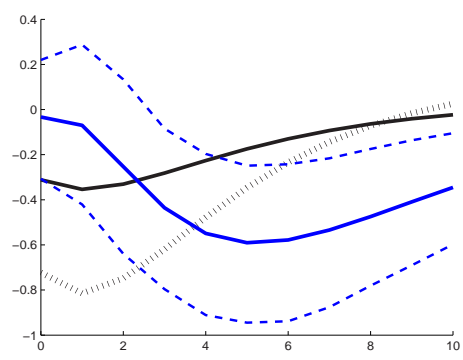

(d) Traded Output, $Y^{T}$

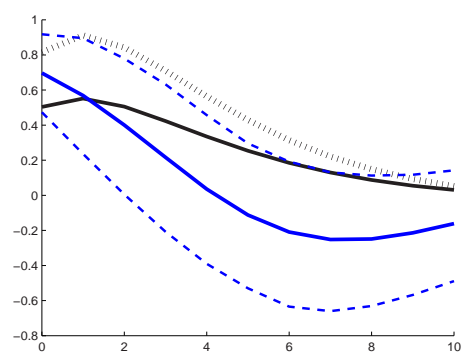

(g) Non Traded Output, $Y^{N}$

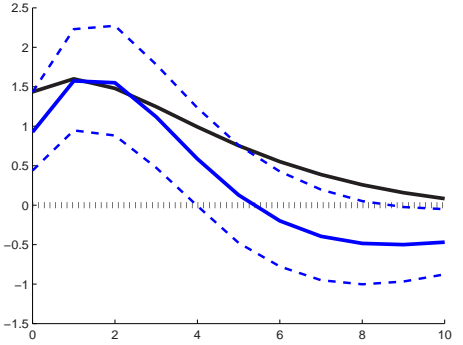

(b) Relative Wage, $W^{N} / W^{T}$

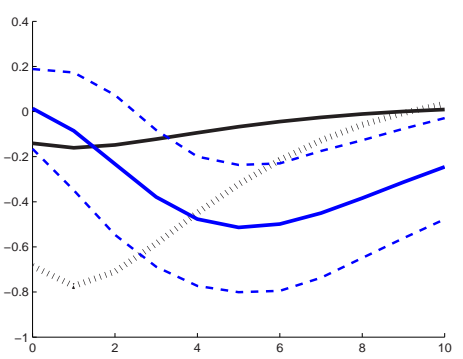

(e) Traded Labor, $L^{T}$

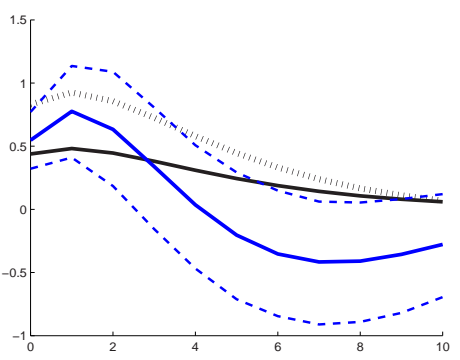

(h) Non Traded Labor, $L^{N}$

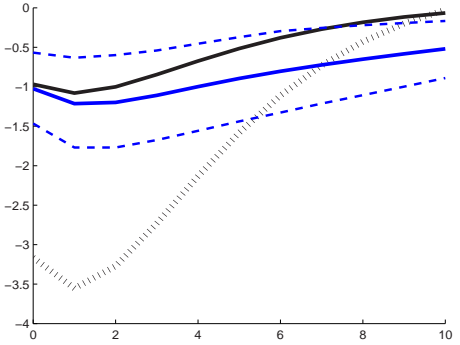

(c) Relative Output, $Y^{T} / Y^{N}$

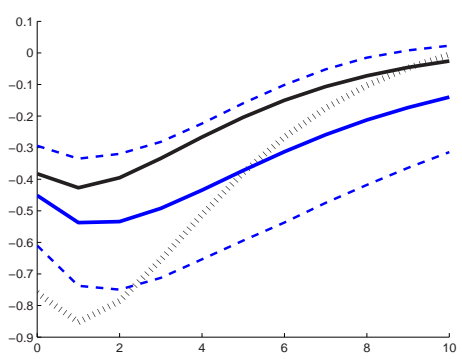

(f) Tradable share, $Y^{T} / Y$

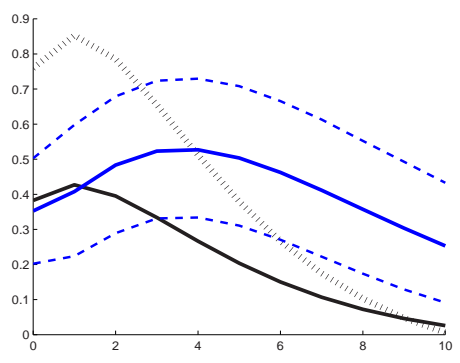

(i) Non Tradable share, $Y^{N} / Y$

Figure 39: Dynamic Adjustment of Sectoral Variables to Unanticipated Government Spending Shock: The Role of Limited Labor Mobility across Sectors. Notes: Solid blue line display point estimate of VAR with dotted blue lines indicating $90 \%$ confidence bounds; the solid black line displays model predictions in the baseline scenario with imperfect mobility of labor across sectors $(\epsilon=0.75)$ and capital installation costs $(\kappa=17)$ while the dotted black line shows results when imposing perfect mobility of labor across sectors $(\epsilon \rightarrow \infty)$. 
prices) and the share of value added in sector $j$ in real GDP. Formally, the response at year $t$ of the sectoral output share to a government spending shock reads as:

$$
d \nu_{i}^{Y, j}(t)=\frac{P_{i}^{j} Y_{i}^{j}}{P_{i} Y_{i}}\left(\hat{Y}_{i t}^{j}-\hat{Y}_{R, i t}\right) .
$$

To assess the ability of our model to account for our evidence, we calibrate the model to the data of each country in our sample, except for the world interest rate, elasticity of labor supply, and $\kappa$ that governs the magnitude of capital adjustment costs which are kept unchanged, i.e., $r^{\star}=4 \%, \sigma_{L}=0.4$, and $\kappa=17$. When numerically computing $d \nu_{i}^{Y, j}(0)$ for each country $i$, we set $\phi_{i}$ and $\epsilon_{i}$ in accordance with their empirical estimates shown the two last columns of Table 4. When we calibrate the model to the whole sample (i.e., a representative OECD economy), we set $\epsilon$ to 0.75 and $\phi$ to 0.77 which correspond to their unweighted average values.

Columns 2 and 4 of Table 12 report the simulated impact responses of the output share of tradables, $d \nu_{i}^{Y, T}(0)$, and non tradables, $d \nu_{i}^{Y, N}(0)$, respectively, to an exogenous rise in government consumption by 1 percentage point of GDP. Columns 3 and 5 report point estimates from the VAR model for $d \nu_{i}^{Y, j}(0)$ for each country and the whole sample as well. In line with our model's predictions, an increase in government consumption gives rise to a contraction in the traded sector and has an expansionary effect on the non traded sector, except for Australia and Ireland. Because in these two economies, the traded sector expands while the non traded sector shrinks, we consider a rise in government consumption by 1 percentage point of GDP triggered by an increase in public purchases on tradables while keeping $G^{N}$ fixed.

Because the time horizon of the sample is small for each country due to the annual frequency of data, the VAR estimates have to be taken with a grain of salt. More precisely, VAR estimates for $d \nu_{i}^{Y, j}(0)$ are significant at $10 \%$ for only five countries in our sample. As shown in the last line of Table 12, our model predicts remarkably well the contraction in the traded sector and the expansionary effect in the non traded sector. While our results tend to understate the changes in output shares of both sectors, the predicted values lie within the $90 \%$ confidence interval for most of the economies of our sample. More precisely, when we restrict our attention to statistically significant estimates, the model's predictions fall in the range of empirical estimates except for Canada. While we find that the model tends to understate the responses of sectoral output shares for most of the countries, in particular for Japan, Sweden, and the USA, the correlation between predicted and observed series is 0.65 for tradables and 0.69 for non tradables, as shown in the last line of Table 12, which suggests that the model can account reasonably well for cross-country differences in impact responses of sectoral output shares to a government spending shock.

To investigate the relationship between the magnitude of the sectoral impact of a fiscal shock and the degree of labor mobility across sectors, we regress the estimated sectoral output share responses, $d \nu_{i}^{Y, j}(0)$, on the elasticity of labor supply across sectors, $\epsilon_{i}$ :

$$
d \nu_{i}^{Y, j}(0)=\beta_{0}+\beta_{1} . \epsilon_{i}+\varepsilon_{i} .
$$

According to our estimates reported in Table 13, the regression coefficient, $\beta_{1}$, is negative for tradables and positive for non tradables which suggests that following a rise in government consumption, the output share of tradables falls more while the output share of non tradables rises by a larger amount in countries with a higher labor mobility across sectors. Importantly, the regression coefficients from simulated and estimated values are roughly similar.

\section{K Four Variants of Our Baseline Open Economy Setup: Ro- bustness Check Analysis}

In this section, we investigate the extent of the robustness of our theoretical results presented in the main text by considering four variants of the baseline model. In the first variant, we relax the assumption of a balanced government budget by introducing public 
Table 12: Comparison of Simulated with Estimated Values for Changes in Sectoral Output Shares

\begin{tabular}{l|c|cccc}
\hline Country & Parameter & \multicolumn{4}{|c}{ Impact responses: sectoral output shares } \\
\hline & $(1)$ & $(2)$ & $(3)$ & $(4)$ & $(5)$ \\
& Mobility $\epsilon$ & $\left(d \nu_{i}^{Y, T}(0)\right)^{\text {simul }}$ & $\left(d \nu_{i}^{Y, T}(0)\right)^{\text {estim }}$ & $\left(d \nu_{i}^{Y, N}(0)\right)^{\text {simul }}$ & $\left(d \nu_{i}^{Y, N}(0)\right)^{\text {estim }}$ \\
\hline AUS & 0.635 & $0.09^{\dagger}$ & 0.49 & $-0.09^{\dagger}$ & -0.15 \\
AUT & 0.548 & $-0.32^{\dagger}$ & -0.35 & $0.32^{\dagger}$ & 0.22 \\
BEL & 0.326 & $-0.28^{\dagger}$ & -0.12 & $0.28^{\dagger}$ & 0.12 \\
CAN & 0.454 & -0.37 & -1.03 & 0.37 & 0.94 \\
DNK & - & -0.31 & -0.77 & $0.31^{*}$ & 0.68 \\
ESP & 1.642 & $-0.49^{\dagger}$ & -0.19 & $0.49^{\dagger}$ & 0.39 \\
FIN & 0.544 & $-0.34^{*}$ & -0.81 & $0.34^{*}$ & 0.90 \\
FRA & 1.287 & $-0.40^{\dagger}$ & -0.36 & $0.40^{\dagger}$ & 0.41 \\
GBR & 1.008 & $-0.42^{\dagger}$ & -0.46 & $0.42^{\dagger}$ & 0.55 \\
IRL & 0.264 & $0.05^{\dagger}$ & 0.05 & $-0.05^{\dagger}$ & -0.07 \\
ITA & 0.686 & $-0.38^{\dagger}$ & -0.60 & $0.38^{\dagger}$ & 0.50 \\
JPN & 0.993 & $-0.41^{\dagger}$ & -0.96 & $0.41^{\dagger}$ & 0.89 \\
NLD & 0.224 & $-0.26^{\dagger}$ & -0.18 & $0.26^{\dagger}$ & 0.22 \\
NOR & - & $-0.35^{\dagger}$ & 0.03 & $0.35^{\dagger}$ & 0.09 \\
SWE & 0.443 & $-0.35^{*}$ & -0.69 & $0.35^{*}$ & 0.59 \\
USA & 1.387 & $-0.40^{*}$ & -1.21 & $0.40^{*}$ & 0.77 \\
\hline Whole & 0.746 & $-0.38^{*}$ & -0.45 & $0.38^{*}$ & 0.35 \\
\hline Corr. & & & 0.63 & & 0.67 \\
\hline
\end{tabular}

Notes: Table provides simulated (simul) and estimated (estim) responses on impact for $d \nu_{i}^{Y, j}(0)$ (with $j=T, N$ ); responses correspond to the change in sectoral value added at constant prices relative to real GDP measured in total output units; when computing the change in the share of valued added of sector $j$, we keep relative prices constant so that its change is only triggered by variations in quantities; $\epsilon$ is the elasticity of labor supply across sectors; because estimates of $\epsilon$ for Denmark and Norway are not statistically significant, their values are left blank. Predicted values for Denmark are obtained when setting $\epsilon$ to its value for the whole sample. We denote by superscripts 'simul' and 'estim' the numerically computed values and VAR estimates, respectively; $\dagger$ and ${ }^{*}$ indicate that the predicted value lies within the estimated confidence interval while ${ }^{*}$ indicates that the estimated value is significant at $10 \%$; we calculate $90 \%$ confidence intervals based on estimated standard deviations of $d \nu_{i}^{Y, j}(0)$ obtained when the VAR model is estimated, for each country and the whole sample as well; 'Corr.' refers to the correlation coefficient between simulated and estimated values. 
Table 13: Relationship between Impact Responses of Sectoral Output Shares to a Rise in Government Consumption and the Degree of Labor Mobility across Sectors (OLS estimates)

\begin{tabular}{|c|c|c|c|c|}
\hline Variable & $\beta_{0}$ & $\overline{\beta_{1}}$ & $R^{2}$ & $N$ \\
\hline$Y^{T} / Y$ & & & & \\
\hline Data & $\begin{array}{l}-0.272 \\
(-1.090)\end{array}$ & $\begin{array}{l}-0.249 \\
(-0.860)\end{array}$ & 0.058 & 14 \\
\hline Model & $\begin{array}{c}-0.156^{c} \\
(-1.904)\end{array}$ & $\begin{array}{c}-0.207^{b} \\
(-2.240)\end{array}$ & 0.295 & 14 \\
\hline$Y^{N} / Y$ & & & & \\
\hline Data & $\begin{array}{l}0.274 \\
(1.452)\end{array}$ & $\begin{array}{l}0.234 \\
(1.072)\end{array}$ & 0.087 & 14 \\
\hline Model & $\begin{array}{l}0.156^{c} \\
(1.904)\end{array}$ & $\begin{array}{l}0.207^{b} \\
(2.240)\end{array}$ & 0.295 & 14 \\
\hline
\end{tabular}

debt and distortionary labor taxation and explore the consequences of a deficit-financed government spending shock. In the second variant, we explore the potential implications of entrey/exit of firms by considering an imperfectly competitive non traded sector with endogenous markup. In the third variant, we consider a model where both labor and capital are imperfectly mobile across sectors. In the fourth variant, we relax the assumption of exogenous terms of trade by considering an open economy model which is large enough on the world goods market to influence the price of its export goods. The variants of the baseline model are laid out in section $\mathrm{M}$, section $\mathrm{N}$, and section $\mathrm{O}$.

\section{K.1 Balanced-Budget vs. Deficit-Financed Government Spending Shock}

In the main text, we consider a budget-balanced government spending shock. If alternatively the rise government spending is financed by an increase in public debt denoted by $D$ :

$$
\dot{D}+T=r^{\star} D+G .
$$

the results are identical since the Ricardian equivalence holds as long as taxes are lumpsum. Thus, whether the government budget is balanced or not affects our results neither qualitatively nor quantitatively. Conversely, if we allow labor taxation to be distortionary, a debt-financed increase in public spending requires an adjustment in the labor tax rate for the solvency condition for the government to hold so that the Ricardian equivalence no longer holds. If taxes are distorsionary, then the manner of financing higher spending could influence our results. In section $\mathrm{M}$, we lay out the model with public debt; we allow for distortionary labor taxation and consider a rise in government spending which is debt-financed. More specifically, denoting by $D(t)$ the stock of (traded) bonds issued by the government, the flow budget constraint reads as $\dot{D}(t)=r^{\star} D(t)+G(t)-T(t)$ with $T(t)=\tau(t) W(t) L(t)$ where $\tau$ is the wage tax levied on households' wage income.

To calibrate the model with public debt to a representative OECD economy, we estimate a VAR model that includes public debt, $D$, in order to determine the dynamic response of public debt to an exogenous government spending shock. More specifically, the VAR specification includes government consumption, public debt, real GDP, hours worked, nonresidential investment, and the real consumption wage. Time series for public debt as a percentage of GDP are taken from the OECD. As displayed in Figure 40(b), the endogenous response of public to an exogenous government spending shock is hump-shaped and displays high persistence. More precisely, public debt reaches a peak at time $t=6$ and then is restored back toward its initial level after 30 years. Before discussing the calibration of the model, it is convenient to repeat the equations which govern the adjustment of government 
spending, public debt, and taxes we derive in section M (see eqs. (284), (287), (288)):

$$
\begin{gathered}
\frac{d G(t)}{Y}=e^{-\xi t}-(1-g) e^{-\chi t}, \\
\frac{d D(t)}{Y}=\Theta_{D} e^{-\delta t}-\Theta_{1} e^{-\xi t}+\Theta_{2} e^{-\chi t}, \\
\frac{d T(t)}{Y}=\theta_{L} d \tau(t), \\
d \tau(t)=\Omega_{D} e^{-\delta t}-\left(\Omega 1 e^{-\xi t}-\Omega_{2} e^{-\chi t}\right),
\end{gathered}
$$

where $\tau$ is a distortive labor tax, and we impose $D_{0}=\tilde{D}$ in line with our VAR evidence, i.e., public debt is restored to its initial level; $\Theta_{i}$ and $\Omega_{i}(i=1,2, D)$ are terms which are functions of parameters (see section $\mathrm{M}$ ). To calibrate the model with public debt, we have to choose values for three new parameters, $\phi_{D}, \phi_{G}, \delta$. Since $\delta=\phi_{D}-r^{\star}$, it leaves us with only two parameters. These two parameters are chosen so as to reproduce the hump-shaped response of the public debt in percentage of GDP. Using the fact that public debt peaks at $\hat{t}=6$, we solve the system of equations below to determine the values for $\phi_{D}$ and $\phi_{G}$ :

$$
\begin{gathered}
\dot{D}(\hat{t})=-\delta \Theta_{D} e^{-\delta \hat{t}}+\xi \Theta_{1} e^{-\xi \hat{t}}-\chi \Theta_{2} e^{-\chi \hat{t}}=0, \\
\frac{d D(\hat{t})}{Y}=\Theta_{D} e^{-\delta \hat{t}}-\Theta_{1} e^{-\xi \hat{t}}+\Theta_{2} e^{-\chi \hat{t}} .
\end{gathered}
$$

Using the fact that at $\hat{t}=6$, we have $\frac{d D(\hat{t})}{Y}=1.68738$, solving yields $\phi_{G}=0.485728$ and $\phi_{D}=0.169004$.

\section{K.2 Perfect vs. Imperfect Mobility of Capital}

A shortcut to generate imperfect capital mobility is to assume limited substitutability in capital across sectors. Along the lines of Horvath [2000] who introduce limited substitutability of hours worked, we assume that capital in the traded and the non traded sectors are aggregated by means of a CES function:

$$
K\left(K^{T}, K^{N}\right)=\left[\zeta^{-\frac{1}{\eta}}\left(K^{T}\right)^{\frac{\eta+1}{\eta}}+(1-\zeta)^{-\frac{1}{\eta}}\left(K^{N}\right)^{\frac{\eta+1}{\eta}}\right]^{\frac{\eta}{\eta+1}},
$$

where $0<\zeta<1$ is the weight of capital supply to the traded sector in the aggregate capital index $K($.$) and \eta$ measures the ease with which capital in the traded and the non traded sector can be substituted for each other and thereby captures the degree of capital mobility across sectors. The case of perfect capital mobility is nested under the assumption that $\eta$ tends towards infinity; in this case, $(213)$ reduces to $K=K^{T}+K^{N}$ which implies that capital is perfectly substitutable across sectors. When $\eta<\infty$, sectoral capital goods are no longer perfect substitutes. More specifically, as $\eta$ becomes smaller, capital mobility across sectors becomes lower as investors perceive a higher cost of shifting capital and therefore become more reluctant to reallocate capital across sectors.

To calibrate the model, we keep unchanged $\epsilon=0.75, \sigma_{L}=0.4, \sigma=1, \kappa=17$ and we allow for imperfect mobility of capital across sectors, setting the elasticity of capital supply across sectors, $\eta$, to 0.75 , and the weight $1-\zeta$ of capital supply to the non traded sector in the aggregate capital index $K($.$) to 0.68$ in order to target a non tradable content of capital income of $58 \%$, in line with our estimates.

\section{K.3 Fixed vs. Endogenous Markup}

The baseline setup laid out in the main text considers perfectly competitive firms in both sectors. This assumption could be viewed as restrictive for the non traded sector which is sheltered from international competition. However, assuming an imperfectly competitive non traded sector would leave the results unchanged as long as markups are fixed. Conversely, the results could be affected if markups were endogenous. Intuitively, by creating profit opportunities and thus encouraging firm entry, a rise in $G^{N}$ produces a fall in the 


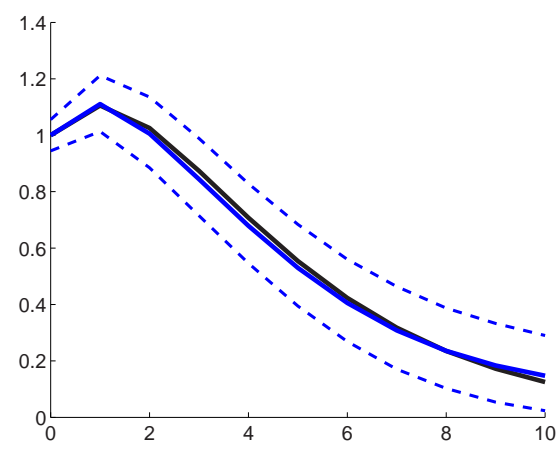

(a) Government Spending

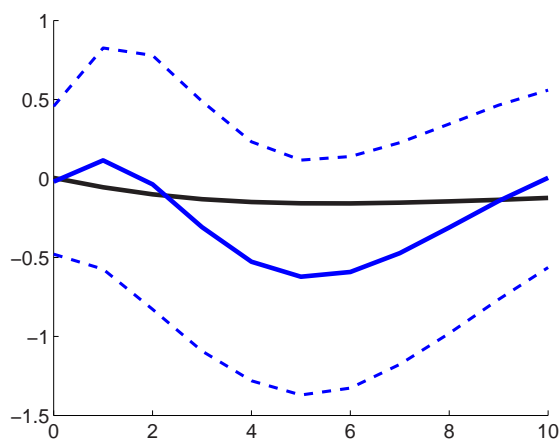

(c) Real GDP

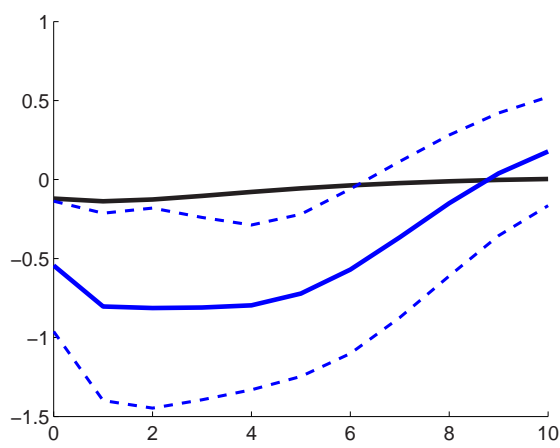

(e) Investment

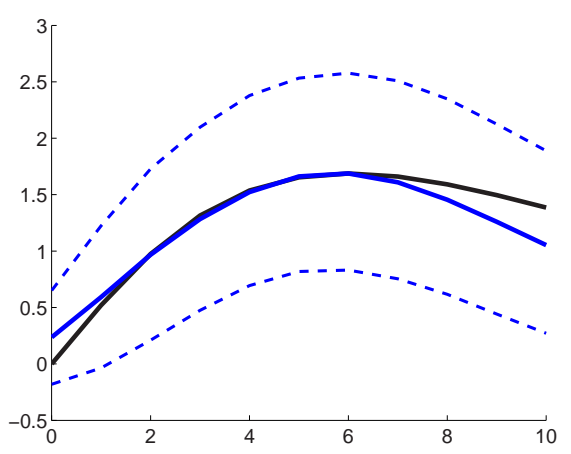

(b) Public Debt

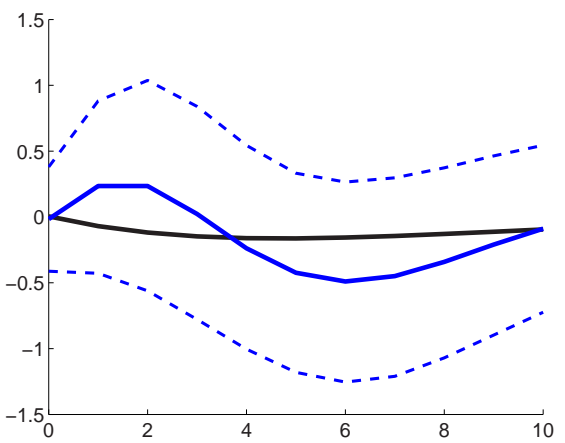

(d) Hours Worked

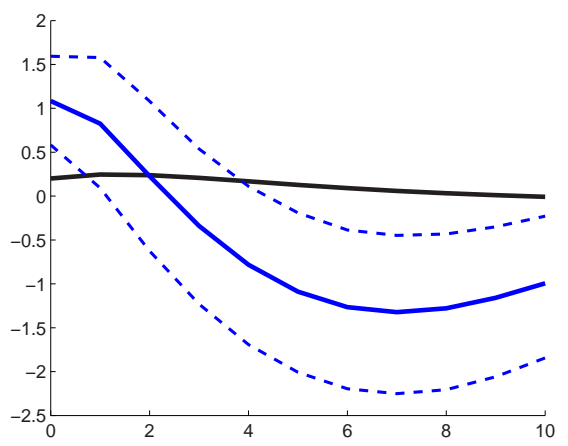

(f) Real Consumption Wage

Figure 40: Dynamic Adjustment to an Unanticipated Deficit-Financed Government Spending Shock. Notes: The solid blue line displays point estimates of the VAR model with public debt, with dotted blue lines indicating the $90 \%$ confidence bounds; the solid black line displays model predictions in the baseline scenario with imperfect mobility of labor across sectors $(\epsilon=0.75)$ and capital installation costs $(\kappa=17)$. 
markup that could potentially modify quantitatively the size of the change in the share of non tradables in real GDP. To deal with this issue, in section N, we develop an extension of the open economy model with imperfect mobility of labor by considering an imperfectly competitive non traded sector with endogenous markups.

Taking into account the fact that output of one (non traded) variety does not affect the price of final non-traded output, but influences the (non traded) price level of the industry in which the firm operates, in a symmetric equilibrium, the resulting price elasticity of demand is:

$$
e(N)=\rho-\frac{(\rho-\eta)}{N}, \quad N \in(1, \infty)
$$

Assuming that $\rho>\eta$, the price elasticity of demand faced by one single firm is an increasing function of the number of firms $N$ within a sector. Henceforth, the markup

$$
\mu(N)=\frac{e}{e-1}
$$

decreases as the number of competitors increases, i.e. $\mu_{N}<0$.

Since we consider an imperfect competitive non traded sector, we have to choose values for the elasticity of substitution between intermediate goods produced non traded industries, $\eta$, and the value for the elasticity of substitution between varieties within one non traded industry, $\rho$. Setting $\rho$ to 4 and $\eta$ to 1 yields a markup $\mu$ charged by the non-traded sector of 1.35, which is close to OECD countries' unweighted average (1970-2004) documented by Cardi and Restout [2015] for 13 OECD countries that includes all countries in our sample except for Australia, Canada, Finland. We choose a value of fixed costs $\psi$ so that the number of competitors is 20 within each non traded industry which is consistent with our assumption according to which the number of firms is large enough so that we can ignore the strategic effects but not so large that the effect of entry on the firm's demand curve is minuscule.

\section{K.4 Exogenous vs. Endogenous Terms of Trade}

Whilst in the paper, we assume exogenous terms of trade, we extend the baseline framework to endogenous terms of trade in section $\mathrm{O}$. To allow for endogenous terms of trade, we assume that the open economy is large enough on world goods market to influence the price of its export goods as reflected by a price-elastic exports function:

$$
X^{H}=\varphi_{X}\left(P^{H}\right)^{-\phi_{X}},
$$

where $\phi_{X}$ is the elasticity of exports with respect to the terms of trade, $P^{H}$, which are defined as the ratio of the price of home-produced traded goods to the price of foreignproduced traded goods. Like in the main text, households supply labor, $L$, and must decide on the allocation of total hours worked between the traded sector, $L^{H}$, and the non traded sector, $L^{N}$. They consume both traded, $C^{T}$, and non traded goods, $C^{N}$. Traded goods are now a composite of home traded goods, $C^{H}$, and foreign imported goods, $C^{F}$. Households also choose investment which is produced using inputs of the traded, $J^{T}$, and the non traded good, $J^{N}$. As for consumption, input of the traded good is a composite of home traded goods, $J^{H}$, and foreign imported goods, $J^{F}$. For simplicity purposes, we set $G^{F}=0$. The role of the price of home-produced goods in terms of foreign-produced goods or the terms of trade is to clear the home-produced traded goods market:

$$
Y^{H}=C^{H}+G^{H}+J^{H}+X^{H},
$$

The above market clearing condition along with that for non traded goods implies that net exports become price-elastic, i.e.,

$$
\dot{B}=r^{\star} B+P^{H} X^{H}-M^{F},
$$

where $X^{H}=Y^{H}-C^{H}-G^{H}-J^{H}$ are exports of home goods and we denote by $M^{F}$ consumption and investment goods imports from abroad:

$$
M^{F}=C^{F}+J^{F} .
$$


Following Backus, Kehoe and Kydland [1994], we set the elasticity of substitution, $\rho$, in consumption between home- and foreign-produced traded goods (inputs) to 1.5. The weight of consumption in home-produced traded goods $\varphi^{H}$ is set to 0.83 to target a home content in consumption expenditure in tradables (i.e. $\alpha^{H}$ ) of $78 \%$, in line with our estimates. Following Pakko [2003], we set the elasticity of substitution, $\rho_{J}$, in investment between home- and foreign-produced traded inputs to 1.5. The weight of home-produced traded investment $\iota^{H}$ is set to 0.49 to target a home content in investment expenditure in tradables (i.e. $\alpha_{J}^{H}$ ) of $42 \%$, in line with our estimates. To obtain estimates of $\alpha^{H}$ and $\alpha_{J}^{H}$, we use the Comtrade database from the United Nations [2017]. Building on structural estimates of the price elasticities of aggregate exports documented by Imbs and Mejean [2015], we set the export price elasticity, $\phi_{X}$, to 1.7 in the baseline calibration. Since we set initial conditions so that the economy starts with balanced trade, export as a share of GDP, $\omega_{X}$, is endogenously determined by the import content of consumption, $1-\alpha^{H}$, and investment expenditure, $1-\alpha_{J}^{H}$, along with the consumption-to-GDP ratio, $\omega_{C}$, and the investment-to-GDP ratio, $\omega_{J}$. More precisely, dividing the zero current account equation by GDP, $Y$, leads to an expression that allows us to calculate the GDP share of exports of final goods and services produced by the home country:

$$
\frac{P^{H} X^{H}}{Y}=\omega_{C} \alpha_{C}\left(1-\alpha^{H}\right)+\omega_{J} \alpha_{J}\left(1-\alpha_{J}^{H}\right)=10.3 \%
$$

where $\omega_{C}=59 \%, 1-\alpha^{H}=22 \%, \omega_{J}=21 \%, 1-\alpha_{J}^{H}=58 \%$. An export to GDP ratio of $10.3 \%$ corresponds exactly to the ratio found in the data over 1995-2007 (note that we consider exports of final goods and services while trade on intermediate inputs are excluded from our calculation).

\section{K.5 Robustness Check: Contrasting IRF from the Baseline Model with IRF from Four Variants of the Baseline Setup}

In this subsection, we contrast theoretical responses with empirical responses following an unanticipated government spending shock by $1 \mathrm{ppt}$ of GDP and compares theoretical IRF from the baseline model shown in the main text with those obtained by considering extensions of the benchmark setup. We consider four variants of the baseline model with imperfect mobility of labor and capital adjustment costs. Aggregate effects are displayed in Figure 41 whilst selected sectoral effects are shown in Figure 42.

First, we consider an extension of the baseline model to endogenous markups shown in the dashed dotted red line with circles. The conclusion which emerges is that entry of firms in the non traded sector does not affect our results as the theoretical responses for the baseline model with fixed markups (shown in solid black lines) cannot be distinguished from those obtained with endogenous markups. The reason is that firm entry is small so that the markup merely declines following a rise in government spending.

Second, while in the main text we investigate the effects of balanced-budget government spending shock, we alternatively explore the dynamics effects of a deficit-financed government spending shock which are shown in the dashed dotted black line. As we allow for distortionary labor taxation and since the labor tax rate must increase for the intertemporal solvency condition for the government to hold, the positive response of hours worked along with the size of the aggregate fiscal multiplier are greatly mitigated compared with the baseline. Turning to the sectoral effects of a deficit-financed spending shock, as expected, hours worked and output increase less in the non traded sector while they decline more in the traded sector as a result of the muted response of aggregate labor supply. Whilst sectoral multipliers for output and labor are substantially reduced by the increase in the labor tax, the latter merely influences the response of relative sector size along with appreciation in the relative price and the relative wage.

Third, cyan solid line with squares displays model's predictions when we allow for imperfect mobility of both capital and labor. As can be seen in Figure 42, adding imperfect mobility of capital moderates substantially changes in relative sector size, whether measured in employment or GDP units, as the difficulty in reallocating capital further mitigates the reallocation of resources toward the non traded sector. As a result, fiscal multipliers 
for labor and output in the non traded sector are less while those in the traded sector increases (i.e., turn out to be less negative). One can notice that the relative price of non tradables appreciates more since the excess demand in the non traded goods market is more pronounced as non traded output increases less.

Finally, in the fourth variant of the model displayed in dotted black line, we allow for endogenous terms of trade. While the discrepancy in estimated effects with the baseline setup is moderate, we can notice some differences though. These differences can be more easily understood by bearing in mind that a government spending shock split between tradables and non tradables produces an excess demand in both goods markets and thus improves the terms of trade (i.e., the price of home-produced traded goods in terms of imported goods) along with an appreciation in the relative price of non tradables. The increase in the relative price of tradables exerts a positive impact on the marginal revenue product of capital and labor in the traded sector and thus mitigates the shift of inputs toward the non traded sector. As a result, changes in relative sector size are less when terms of trade are endogenous.

Sectoral effects are shown in Figure 42. Whilst we can notice some differences between baseline model's predictions and its four variants, the discrepancy in the estimated effects is rather moderate across all scenarios. We can thus conclude that the results obtained in the main text are robust to the introduction of public debt, imperfect mobility of capital, endogenous terms of trade and endogenous markup. 


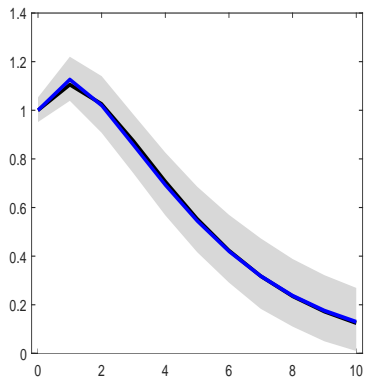

(a) Government Spending

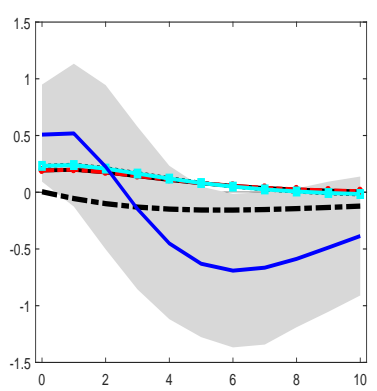

(c) Real GDP

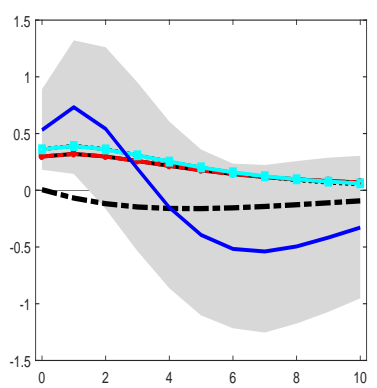

(e) Hours Worked

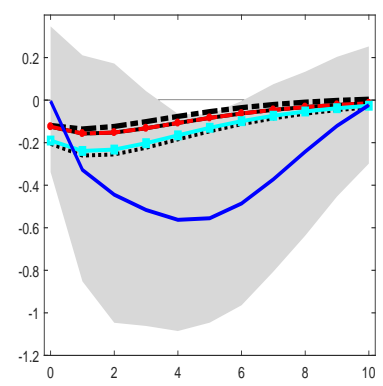

(b) Investment

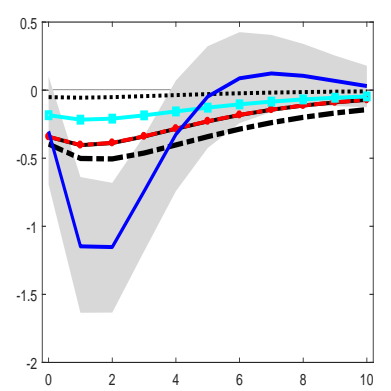

(d) Current Account

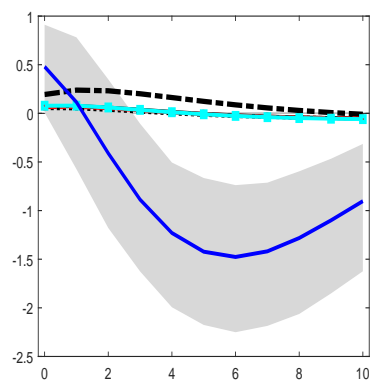

(f) Aggregate Real Wage

Figure 41: Contrasting Aggregate Effects to Unanticipated Government Spending Shock across Variants of the Baseline Model. Notes: Solid blue line displays point estimate of VAR with shaded areas indicating $90 \%$ confidence bounds; the solid black line displays model predictions in the baseline scenario with imperfect mobility of labor across sectors $(\epsilon=0.75)$ and capital installation costs $(\kappa=17)$. The dotted black line shows results for endogenous terms of trade. The dashed dotted black line displays model's predictions for a deficit-financed government spending shocks. The dashed dotted red line with circles shows results when we allow for endogenous markups in the non traded sector. The cyan solid line with squares displays model's predictions when we allow for imperfect mobility of both capital and labor. 


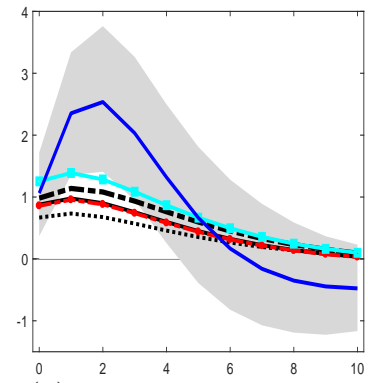

(a) Relative Price, $P$

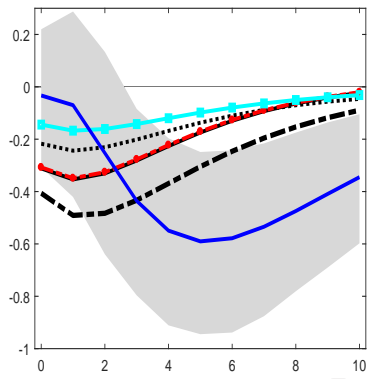

(d) Traded Output, $Y^{T}$

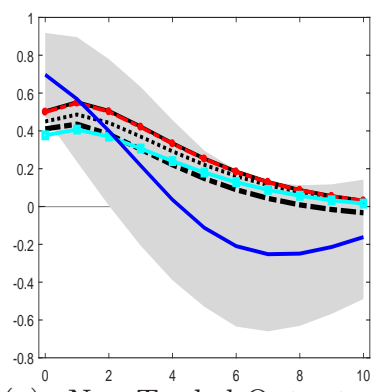

(g) Non Traded Output, $Y^{N}$

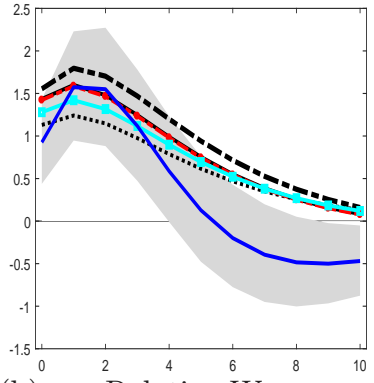

(b) Relative Wage, $W^{N} / W^{T}$

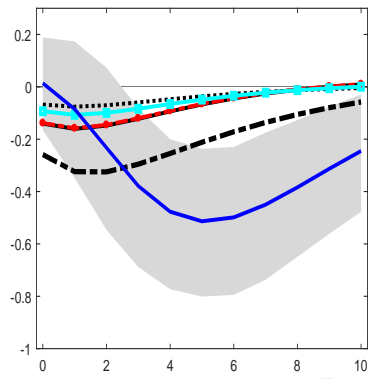

(e) Traded Labor, $L^{T}$

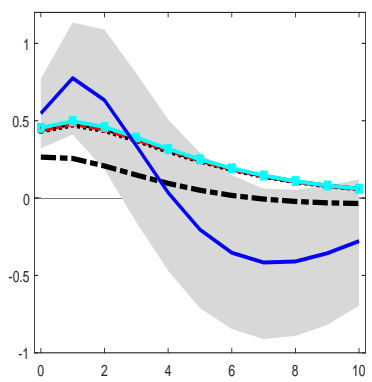

(h) Non Traded Labor, $L^{N}$

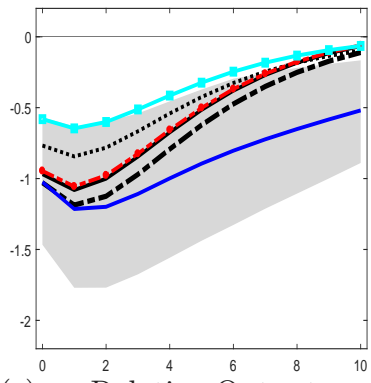

(c) Relative Output $Y^{T} / Y^{N}$

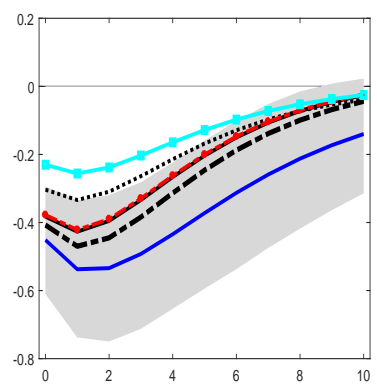

(f) Share of Tradables, $\nu^{Y, T}$

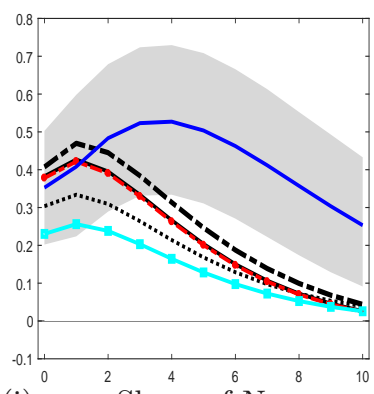

(i) Share of Non

Tradables, $\nu^{Y, N}$

Figure 42: Contrasting Sectoral Effects of Unanticipated Government Spending Shock across Variants of the Baseline Model. Notes: The solid blue line displays the point estimate of VAR with shaded areas indicating $90 \%$ confidence bounds; the solid black line displays model predictions in the baseline scenario with imperfect mobility of labor across sectors $(\epsilon=0.75)$ and capital installation costs $(\kappa=17)$. The dotted black line shows results for endogenous terms of trade. The dashed dotted black line displays the model's predictions for a deficit-financed government spending shock. The dashed dotted red line with circles shows the results when we allow for endogenous markups in the non traded sector. The cyan solid line with squares displays the model's predictions when we allow for imperfect mobility of both capital and labor. 


\section{References}

Burstein, Ariel T., João C. Neves and Sergio Rebelo (2004) Investment Prices and Exchange Rates: Some Basic Facts. Journal of the European Economic Association 2(2-3), pp. 302-309.

Mendoza, Enrique, G. (1995) The Terms of Trade, Real Exchange Rate and Economic Fluctuations. International Economic Review, 36, pp. 101-137.

Organization for Economic Cooperation and Development (2012), Input-Output Database, OECD, Paris.

Organization for Economic Cooperation and Development (2017), National Accounts: General Government Accounts, Government Expenditure by Function (COFOG), OECD, Paris.

Organization for Economic Cooperation and Development (2013), Annual National Accounts, OECD, Paris.

Pedroni, Peter (2000) Fully Modified OLS for Heterogeneous Cointegrated Panels. Advances in Econometrics, vol. 15, edited in B. Baltagi: Nonstationary Panels, Panel Cointegration and Dynamic Panels, 93-130.

Pedroni, Peter (2001) Purchasing Power Parity Tests in Cointegrated Panels. The Review of Economics and Statistics, 83(4), pp. 727-731.

Stockman Alan C. and Linda L. Tesar (1995) Tastes and Technology in a Two-Country Model of the Business Cycle: Explaining International Comovements. American Economic Review 85(1), pp. 168-185.

United Nations Statistics Division (2011) Classification of individual consumption by purpose. 


\title{
IMPERFECT MOBILITY OF LABOR ACROSS SECTORS AND FISCAL TRANSMISSION
}

\author{
Technical Appendix - Not Meant for Publication
}

Olivier CARDI, Romain RESTOUT, and Peter CLAEYS

- Section L considers a more general form for preferences by relaxing the assumption of separability in preferences in consumption and leisure.

- Appendix M introduces public debt in the setup.

- Appendix N lays out the same model as in the main text except that we allow the non traded sector to be imperfectly competitive and assume endogenous markups.

- Appendix O develops a semi-small open economy model where the terms of trade are endogenous. 


\section{Introducing Non-Separability between Consumption and Labor}

In this section, we consider a more general form for preferences taken from Shimer [2011]. Since such preferences do not affect the first-order conditions from profit maximization (see section $\mathrm{G}$ for further details), we do not repeat them and indicate major changes when solving the model.

In the baseline model, we assume that preferences are separable in consumption and leisure. We relax this assumption which implies that consumption and leisure can be substitutes. In particular, this more general specification implies that consumption can be affected by the wage rate while labor supply can be influenced by the change in the relative price of non tradables. As previously, the household's period utility function is increasing in its consumption $C$ and decreasing in its labor supply $L$, with functional form:

$$
\frac{C^{1-\sigma} V(L)^{\sigma}-1}{1-\sigma}, \quad \text { if } \quad \sigma \neq 1, \quad V(L) \equiv\left(1+(\sigma-1) \gamma \frac{\sigma_{L}}{1+\sigma_{L}} L^{\frac{1+\sigma_{L}}{\sigma_{L}}}\right)
$$

and

$$
\log C-\gamma \frac{\sigma_{L}}{1+\sigma_{L}} L^{\frac{1+\sigma_{L}}{\sigma_{L}}}, \quad \text { if } \quad \sigma=1 .
$$

These preferences are characterized by two pivotal parameters: $\sigma_{L}$ which is the Frisch elasticity of labor supply, and $\sigma>0$ that determines the substitutability between consumption and leisure; it is worth noticing that if $\sigma>1$, the marginal utility of consumption is increasing in hours worked.

The representative household maximizes lifetime utility (77) subject to the flow budget constraint (78) and the accumulation of physical capital (79). Denoting the co-state variables associated with (78) and (79) by $\lambda$ and $Q^{\prime}$, respectively, the first-order conditions characterizing the representative household's optimal plans are:

$$
\begin{gathered}
C^{-\sigma} V(L)^{\sigma}=P_{C} \lambda, \\
C^{1-\sigma} \sigma \gamma L^{1 / \sigma_{L}} V(L)^{\sigma-1}=W \lambda,
\end{gathered}
$$

along with (81c)-(81e) and transversality conditions.

First-order conditions (223a) and (223b) can be solved for consumption and labor as follows:

$$
C=C(\bar{\lambda}, P, W), \quad L=L(\bar{\lambda}, P, W) .
$$

To derive the partial derivatives, we take logarithm and totally differentiate the system which yields in matrix form:

$$
\left(\begin{array}{cc}
-\sigma & \sigma\left(\frac{1+\sigma_{L}}{\sigma_{L}}\right)\left[\frac{V(L)-1}{V(L)}\right] \\
(1-\sigma) & \left\{\frac{1}{\sigma_{L}}+(\sigma-1)\left(\frac{1+\sigma_{L}}{\sigma_{L}}\right)\left[\frac{V(L)-1}{V(L)}\right]\right\}
\end{array}\right)\left(\begin{array}{c}
\hat{C} \\
\hat{L}
\end{array}\right)\left(\begin{array}{c}
\hat{\bar{\lambda}}+\alpha_{C} \hat{P} \\
\hat{\bar{\lambda}}+\hat{W}
\end{array}\right)
$$

where we denote by a hat the deviation in percentage.

Partial derivatives are:

$$
\begin{aligned}
\frac{\hat{C}}{\hat{\bar{\lambda}}} & =\frac{\left(1+\sigma_{L}\right)}{\sigma}\left[\frac{V(L)-1}{V(L)}\right]-\frac{1}{\sigma}<0, \\
\frac{\hat{L}}{\hat{\bar{\lambda}}} & =\frac{\sigma_{L}}{\sigma}>0, \\
\frac{\hat{C}}{\hat{W}} & =\left(1+\sigma_{L}\right)\left[\frac{V(L)-1}{V(L)}\right]>0, \\
\frac{\hat{L}}{\hat{W}} & =\sigma_{L}>0, \\
\frac{\hat{C}}{\hat{P}} & =-\frac{\alpha_{C}}{\sigma}\left\{1+(\sigma-1)\left(1+\sigma_{L}\right)\left[\frac{V(L)-1}{V(L)}\right]\right\}<0, \\
\frac{\hat{L}}{\hat{P}} & =-\alpha_{C} \frac{(\sigma-1) \sigma_{L}}{\sigma}<0 .
\end{aligned}
$$


Using the fact that $W=W\left(W^{T}, W^{N}\right)$ with $\frac{\partial W}{\partial W^{T}} \frac{W^{T}}{W}=\left(1-\alpha_{L}\right)$ and $\frac{\partial W}{\partial W^{N}} \frac{W^{N}}{W}=\alpha_{L}$, we get:

$$
L=L\left(\bar{\lambda}, P, W^{T}, W^{N}\right)
$$

where

$$
\begin{aligned}
\frac{\hat{L}}{\hat{W}^{T}} & =\left(1-\alpha_{L}\right) \sigma_{L}>0, \\
\frac{\hat{L}}{\hat{W}^{N}} & =\sigma_{L} \alpha_{L}>0 .
\end{aligned}
$$

Inserting first the short-run static solution for consumption given by $(224)$ into $C^{N}=$ $P_{C}^{\prime} C$ and $C^{T}=\left[P_{C}-P P_{C}^{\prime}\right] C$, one can solve for $C^{T}$ and $C^{N}$ as follows:

$$
C^{T}=C^{T}\left(\bar{\lambda}, P, W^{T}, W^{N}\right), \quad C^{N}=C^{N}\left(\bar{\lambda}, P, W^{T}, W^{N}\right),
$$

where partial derivatives are given by:

$$
\begin{aligned}
C_{P}^{T} & =\frac{C^{T}}{P}\left(\alpha_{C} \phi+\frac{C_{P} P}{C}\right) \lessgtr 0, \\
C_{P}^{N} & =-\frac{C^{N}}{P}\left[\left(1-\alpha_{C}\right) \phi-\frac{C_{P} P}{C}\right]<0, \\
C_{W^{T}}^{T} & =\frac{C^{T}}{W^{T}}\left(1-\alpha_{L}\right) \frac{C_{W} W}{C}>0, \\
C_{W^{T}}^{N} & =\frac{C^{N}}{W^{T}}\left(1-\alpha_{L}\right) \frac{C_{W} W}{C}>0, \\
C_{W^{N}}^{T} & =\frac{C^{T}}{W^{N}} \alpha_{L} \frac{C_{W} W}{C}>0, \\
C_{W^{N}}^{N} & =\frac{C^{N}}{W^{N}} \alpha_{L} \frac{C_{W} W}{C}>0 .
\end{aligned}
$$

Inserting first the short-run solution for labor (227), into $L^{T}=\frac{\partial W\left(W^{T}, W^{N}\right)}{\partial W^{T}} L$ and $L^{N}=\frac{\partial W\left(W^{T}, W^{N}\right)}{\partial W^{N}} L$, allows us to solve for $L^{T}$ and $L^{N}$ :

$$
L^{T}=L^{T}\left(\bar{\lambda}, W^{T}, W^{N}, P\right), \quad L^{N}=L^{N}\left(\bar{\lambda}, W^{T}, W^{N}, P\right),
$$

where partial derivatives w.r.t. $P$ are:

$$
\begin{aligned}
\frac{\hat{L}^{T}}{\hat{P}} & =\frac{L^{T}}{P} \alpha_{C}(1-\sigma) \frac{\sigma_{L}}{\sigma}>0, \\
\frac{\hat{L}^{N}}{\hat{P}} & =\frac{L^{N}}{P} \alpha_{C}(1-\sigma) \frac{\sigma_{L}}{\sigma}>0 .
\end{aligned}
$$

\section{L.1 Solving the Model}

Plugging the short-run static solutions for $L^{T}$ and $L^{N}$ given by (231) into the resource constraint for capital (87), the system of four equations which comprises (86a)-(86c) and (87) can be solved for sectoral wages and sectoral capital-labor ratios. Taking logarithm and differentiating (86a)-(86c) and (87) yields in matrix form:

$$
\left(\begin{array}{cccc}
-\theta^{T} & \theta^{N} & 0 & 0 \\
\left(1-\theta^{T}\right) & 0 & -1 & 0 \\
0 & \left(1-\theta^{N}\right) & 0 & -1 \\
(1-\xi) & \xi & \Psi_{W^{T}} & \Psi_{W^{N}}
\end{array}\right)\left(\begin{array}{c}
\hat{k}^{T} \\
\hat{k}^{N} \\
\hat{W}^{T} \\
\hat{W}^{N}
\end{array}\right)=\left(\begin{array}{c}
\hat{P} \\
0 \\
-\hat{P} \\
\hat{K}-\Psi_{\bar{\lambda}} \hat{\bar{\lambda}}^{-} \Psi_{P} \hat{P}
\end{array}\right)
$$


where $\xi \equiv \frac{k^{N} L^{N}}{K}$ and

$$
\begin{aligned}
\Psi_{W^{T}} & =\left(1-\xi^{N}\right) \frac{L_{W^{T}}^{T} W^{T}}{L^{T}}+\xi^{N} \frac{L_{W^{T}}^{N} W^{T}}{L^{N}} \\
\Psi_{W^{N}} & =\left(1-\xi^{N}\right) \frac{L_{W^{N}}^{T} W^{N}}{L^{T}}+\xi^{N} \frac{L_{W^{N}}^{N} W^{N}}{L^{N}} \\
\xi^{N} & \equiv \frac{k^{N} L^{N}}{K} \\
\Psi_{\bar{\lambda}} & =\left(1-\xi^{N}\right) \sigma_{L}+\xi^{N} \sigma_{L}=\sigma_{L}
\end{aligned}
$$

along with

$$
\Psi_{P}=(1-\xi) \frac{L_{P}^{T} P}{L^{T}}+\xi \frac{L_{P}^{N} P}{L^{N}}=-\alpha_{C} \frac{(\sigma-1) \sigma_{L}}{\sigma}<0 .
$$

Only the partial derivatives w.r.t. $P$ are modified when preferences are non separable in consumption and leisure. Hence, we thus restrict attention to these partial derivatives. Short-run static solutions for sectoral wages are:

$$
W^{T}=W^{T}(\bar{\lambda}, K, P,), \quad W^{N}=W^{N}(\bar{\lambda}, K, P),
$$

with

$$
\begin{aligned}
\frac{\hat{W}^{T}}{\hat{P}} & =-\frac{\left(1-\theta^{T}\right)\left(\Psi_{W^{N}}+\theta^{N} \Psi_{P}+\xi\right)}{G}<0, \\
\frac{\hat{W}^{N}}{\hat{P}} & =-\frac{\left\{1+\left(1-\theta^{T}\right) \Psi_{W^{T}}-\left(1-\theta^{T}\right) \xi-\theta^{T}\left(1-\theta^{N}\right) \Psi_{P}\right\}}{G}>0,
\end{aligned}
$$

and sectoral capital-labor ratios:

$$
k^{T}=k^{T}(\lambda, K, P), \quad k^{N}=k^{N}(\bar{\lambda}, K, P),
$$

with

$$
\begin{aligned}
\frac{\hat{k}^{T}}{\hat{P}} & =\frac{\Psi_{W^{N}}+\xi+\theta^{N} \Psi_{P}}{G}<0 \\
\frac{\hat{k}^{N}}{\hat{P}} & =\frac{\left\{\theta^{T}\left(\Psi^{W^{N}}+\Psi_{P}\right)-\left[\left(1-\theta^{T}\right) \Psi_{W^{T}}+(1-\xi)\right]\right\}}{G}>0
\end{aligned}
$$

To solve the model, insert first short-run static solutions for sectoral wages (236) into sectoral labor (231), then substitute the resulting solutions for sectoral labor and capitallabor ratios (239), production functions can be solved for sectoral outputs. Then we solve for temporary fiscal shocks by adopting the procedure detailed in subsection G.3.

\section{Solving the Model with Public Debt}

This section extends the two-sector model with imperfect mobility of labor to public debt. In order to avoid confusion, we denote by:

- $K$ is the stock of physical capital;

- $Q K$ is the shadow value of the stock of physical capital;

- $D$ is the stock of (traded) bonds issued by the government;

- $B$ is the stock of traded bonds;

- $N=B-D$ is the net foreign asset position;

- $A=Q K+N$ is the national non human wealth equal to the shadow value of the stock of physical capital plus the net foreign asset position which gives national savings $\dot{A}$;

- $\mathcal{A}=A+D=Q K+N+D$ is non human wealth held by households which gives private savings $\dot{\mathcal{A}}$. 


\section{M.1 Government}

The government issues traded bonds, $D$, in order to finance the excess of interest payments, $r^{\star} D$, government spending, and transfers, $Z(t)$, over taxes, $T(t)$ :

$$
\dot{D}(t)=r^{\star} D(t)+G(t)+Z(t)-T(t)
$$

where we assume that the government raises taxes on labor:

$$
T(t)=\tau(t) W(t) L(t)
$$

with $\tau$ the wage tax levied on households' wage income.

\section{M.2 Households}

At each instant of time, the representative household consumes traded and non traded goods denoted by $C^{T}$ and $C^{N}$, respectively, which are aggregated by means of a CES function:

$$
C=\left[\varphi^{\frac{1}{\phi}}\left(C^{T}\right)^{\frac{\phi-1}{\phi}}+(1-\varphi)^{\frac{1}{\phi}}\left(C^{N}\right)^{\frac{\phi-1}{\phi}}\right]^{\frac{\phi}{\phi-1}},
$$

where $0<\varphi<1$ is the weight of the traded good in the overall consumption bundle and $\phi$ corresponds to the elasticity of substitution between traded goods and non traded goods.

As in De Cordoba and Kehoe [2000], the investment good is produced using inputs of the traded good and the non traded good according to a constant-returns-to-scale function which is assumed to take a CES form:

$$
J \equiv J\left(J^{T}, J^{N}\right)=\left[\varphi_{J}^{\frac{1}{\phi_{J}}}\left(J^{T}\right)^{\frac{\phi_{J}-1}{\phi_{J}}}+\left(1-\varphi_{J}\right)^{\frac{1}{\phi_{J}}}\left(J^{N}\right)^{\frac{\phi_{J}-1}{\phi_{J}}}\right]^{\frac{\phi_{J}}{\phi_{J}-1}},
$$

where $\varphi_{J}$ is the weight of the investment traded input $\left(0<\varphi_{J}<1\right)$ and $\phi_{J}$ corresponds to the intratemporal elasticity of substitution in investment between traded and non traded inputs.

Following Horvath [2000], we assume that hours worked in the traded and the non traded sectors are aggregated by means of a CES function:

$$
L=\left[\vartheta^{-1 / \epsilon}\left(L^{T}\right)^{\frac{\epsilon+1}{\epsilon}}+(1-\vartheta)^{-1 / \epsilon}\left(L^{N}\right)^{\frac{\epsilon+1}{\epsilon}}\right]^{\frac{\epsilon}{\epsilon+1}}
$$

and $0<\vartheta<1$ is the weight of labor supply to the traded sector in the labor index $L($.) and $\epsilon$ measures the ease with which hours worked can be substituted for each other and thereby captures the degree of labor mobility across sectors.

The representative household chooses consumption, decides on labor supply, and investment that maximizes his/her lifetime utility:

$$
U=\int_{0}^{\infty}\left\{\frac{1}{1-\frac{1}{\sigma_{C}}} C(t)^{1-\frac{1}{\sigma_{C}}}-\frac{1}{1+\frac{1}{\sigma_{L}}} L(t)^{1+\frac{1}{\sigma_{L}}}\right\} e^{-\beta t} \mathrm{~d} t
$$

subject to the flow budget constraint:

$$
\dot{B}(t)=r^{\star} B(t)+R(t) K(t)+W(t)(1-\tau) L(t)+Z(t)-P_{C}(P(t)) C(t)-P_{J}(P(t)) J(t),
$$

and capital accumulation which evolves as follows:

$$
\dot{K}(t)=I(t)-\delta_{K} K(t)
$$

where $I$ is investment and $0 \leq \delta_{K}<1$ is a fixed depreciation rate. The first term on the RHS of $(246) r^{\star} B(t)+R(t) K(t)+W(t)(1-\tau) L(t)+Z(t)$ is the representative household's real disposable income while the second term on the RHS $P_{C}(P(t)) C(t)+P_{J}(P(t)) J(t)$ corresponds to consumption and investment expenditure including capital installation costs. 
More specifically, we assume that capital accumulation is subject to increasing and convex cost of net investment:

$$
J(t)=I(t)+\frac{\kappa}{2}\left(\frac{I(t)}{K(t)}-\delta_{K}\right)^{2} K(t)
$$

Denoting the co-state variables associated with (246) and (247) by $\lambda$ and $Q^{\prime}$, respectively, the first-order conditions characterizing the representative household's optimal plans are:

$$
\begin{gathered}
C(t)=\left(P_{C}(t) \lambda\right)^{-\sigma_{C}}, \\
L(t)=(W(t)(1-\tau) \lambda)^{\sigma_{L}}, \\
Q(t)=P_{J}(t)\left[1+\kappa\left(\frac{I(t)}{K(t)}-\delta_{K}\right)\right], \\
\dot{\lambda}(t)=\lambda\left(\beta-r^{\star}\right), \\
\dot{Q}(t)=\left(r^{\star}+\delta_{K}\right) Q(t)-\left\{R(t)+P_{J}(t) \frac{\kappa}{2}\left(\frac{I(t)}{K(t)}-\delta_{K}\right)\left(\frac{I(t)}{K(t)}+\delta_{K}\right)\right\},
\end{gathered}
$$

and the transversality conditions $\lim _{t \rightarrow \infty} \bar{\lambda} B(t) e^{-\beta t}=0$ and $\lim _{t \rightarrow \infty} Q(t) K(t) e^{-\beta t}=0$; to derive (249c) and (249e), we used the fact that $Q(t)=Q^{\prime}(t) / \lambda(t)$.

Eq. (249c) can be solved for investment:

$$
\frac{I(t)}{K(t)}=v\left(\frac{Q(t)}{P_{J}(t)}\right)+\delta_{K}, \quad v(.)=\frac{1}{\kappa}\left(\frac{Q(t)}{P_{J}(t)}-1\right) .
$$

Once households decided on aggregate consumption, they decide on the allocation of expenditure between traded and non traded goods:

$$
\begin{gathered}
C^{N}=(1-\varphi)\left(\frac{P}{P_{C}}\right)^{-\phi} C, \\
C^{T}=\varphi\left(\frac{1}{P_{C}}\right)^{-\phi} C,
\end{gathered}
$$

where the consumption price index is:

$$
P_{C}=\left[\varphi+(1-\varphi) P^{1-\phi}\right]^{\frac{1}{1-\phi}} .
$$

As will be useful later, the percentage change in the consumption price index is proportional to the appreciation in the relative price of non tradables:

$$
\hat{P_{C}}=\alpha_{C} \hat{P}
$$

where $\alpha_{C}$ is the non tradable content of consumption expenditure.

Once households decided on aggregate investment expenditure, they decide on the allocation between traded and non traded inputs:

$$
\begin{gathered}
J^{N}=\left(1-\varphi_{J}\right)\left(\frac{P}{P_{J}}\right)^{-\phi_{J}} J, \\
J^{T}=\varphi\left(\frac{1}{P_{J}}\right)^{-\phi_{J}} J,
\end{gathered}
$$

where the investment price index is:

$$
P_{J}=\left[\varphi_{J}+\left(1-\varphi_{J}\right) P^{1-\phi_{J}}\right]^{\frac{1}{1-\phi_{J}}} .
$$

As will be useful later, the percentage change in the investment price index is proportional to the appreciation in the relative price of non tradables:

$$
\hat{P}_{J}=\alpha_{J} \hat{P},
$$


where $\alpha_{J}$ is the non tradable content of investment expenditure.

Once households decided on aggregate labor supply, they allocate hours worked to the traded and the non traded sector

$$
\begin{gathered}
L^{N}=(1-\vartheta)\left(\frac{W^{N}}{W}\right)^{\epsilon} L, \\
L^{T}=\vartheta\left(\frac{W^{T}}{W}\right)^{\epsilon} L,
\end{gathered}
$$

where the aggregate wage index is:

$$
W=\left[\vartheta\left(W^{T}\right)^{\epsilon+1}+(1-\vartheta)\left(W^{N}\right)^{\epsilon+1}\right]^{\frac{1}{\epsilon+1}} .
$$

As will be useful later, the percentage change in the aggregate wage index is a weighted average of percentage changes in sectoral wages:

$$
\hat{W}=\alpha_{L} \hat{W}^{N}+\left(1-\alpha_{L}\right) \hat{W}^{T},
$$

where $\alpha_{L}$ is the non tradable content of aggregate labor compensation.

\section{M.3 Firms}

Both the traded and non-traded sectors use physical capital, $K^{j}$, and labor, $L^{j}$, according to constant returns to scale production functions $Y^{j}=Z^{j} F\left(K^{j}, L^{j}\right)$ which are assumed to take a Cobb-Douglas form:

$$
Y^{j}=Z^{j}\left(L^{j}\right)^{\theta^{j}}\left(K^{j}\right)^{1-\theta^{j}},
$$

where $\theta^{j}$ is the labor income share in sector $j$ and $Z^{j}$ corresponds to the total factor productivity index which is introduced for calibration purposes. Both sectors face two cost components: a capital rental cost equal to $R$, and a labor cost equal to the wage rate, i.e., $W^{T}$ in the traded sector and $W^{N}$ in the non traded sector.

Both sectors are assumed to be perfectly competitive and thus choose capital and labor by taking prices as given:

$$
\max _{K^{j}, L^{j}} \Pi^{j}=\max _{K^{j}, L^{j}}\left\{P^{j} Y^{j}-W^{j} L^{j}-R K^{j}\right\} .
$$

Since capital can move freely between the two sectors, the value of marginal products in the traded and non traded sectors equalizes while costly labor mobility implies a wage differential across sectors:

$$
\begin{gathered}
Z^{T}\left(1-\theta^{T}\right)\left(k^{T}\right)^{-\theta^{T}}=P Z^{N}\left(1-\theta^{N}\right)\left(k^{N}\right)^{-\theta^{N}} \equiv R, \\
Z^{T} \theta^{T}\left(k^{T}\right)^{1-\theta^{T}} \equiv W^{T} \\
P Z^{N} \theta^{N}\left(k^{N}\right)^{1-\theta^{N}} \equiv W^{N}
\end{gathered}
$$

where $k^{j} \equiv K^{j} / L^{j}$ denotes the capital-labor ratio for sector $j=T, N$.

The resource constraint for capital is:

$$
K^{T}+K^{N}=K
$$

\section{M.4 Solving the Model}

Before linearizing, we have to determine short-run static solutions. First-order conditions (249a) and (249b) can be solved for consumption and aggregate labor supply which of course must hold at any point of time:

$$
C=C(\bar{\lambda}, P), \quad L=L\left(\bar{\lambda}, W^{T}, W^{N}, \tau\right),
$$


with partial derivatives given by

$$
\begin{gathered}
\hat{C}=-\sigma_{C} \hat{\bar{\lambda}}-\sigma_{C} \alpha_{C} \hat{P} \\
\hat{L}=\sigma_{L} \hat{\bar{\lambda}}+\sigma_{L} \alpha_{L} \hat{W}^{N}+\sigma_{L}\left(1-\alpha_{L}\right) \hat{W}^{T}-\sigma_{L} \frac{d \tau}{1-\tau} .
\end{gathered}
$$

Inserting first the solution for consumption (266) into (251) allows us to solve for $C^{T}$ and $C^{N}$ :

$$
C^{T}=C^{T}(\bar{\lambda}, P), \quad C^{N}=C^{N}(\bar{\lambda}, P),
$$

with partial derivatives given by

$$
\begin{gathered}
\hat{C}^{N}=-\left[\left(1-\alpha_{C}\right) \phi+\alpha_{C} \sigma_{C}\right] \hat{P}-\sigma_{C} \hat{\bar{\lambda}}, \\
\hat{C}^{N}=\alpha_{C}\left(\phi-\sigma_{C}\right) \hat{P}-\sigma_{C} \hat{\bar{\lambda}} .
\end{gathered}
$$

Inserting first the solution for labor (266) into (257) allows us to solve for $L^{T}$ and $L^{N}$ :

$$
L^{T}=L^{T}\left(\bar{\lambda}, W^{T}, W^{N}, \tau\right), \quad L^{N}=L^{N}\left(\bar{\lambda}, W^{T}, W^{N}, \tau\right),
$$

with partial derivatives given by:

$$
\begin{gathered}
\hat{L}^{T}=\left[\epsilon \alpha_{L}+\sigma_{L}\left(1-\alpha_{L}\right)\right] \hat{W}^{T}+\alpha_{L}\left(\sigma_{L}-\epsilon\right) \hat{W}^{N}+\sigma_{L} \hat{\bar{\lambda}}-\sigma_{L} \frac{d \tau}{1-\tau}, \\
\hat{L}^{N}=\left[\epsilon\left(1-\alpha_{L}\right)+\sigma_{L} \alpha_{L}\right] \hat{W}^{N}+\left(1-\alpha_{L}\right)\left(\sigma_{L}-\epsilon\right) \hat{W}^{T}+\sigma_{L} \hat{\bar{\lambda}}-\sigma_{L} \frac{d \tau}{1-\tau} .
\end{gathered}
$$

Plugging the short-run static solutions for $L^{T}$ and $L^{N}$ given by (268) into the resource constraint for capital (265), the system of four equations consisting of (262a)-(262c) together with $(265)$ can be solved for sectoral wages $W^{j}$ and sectoral capital-labor ratios $k^{j}$. Keeping TFPs unchanged, denoting by $\xi^{N} \equiv K^{N} / K$ the share of non traded capital in the aggregate stock of physical capital and log-differentiating (262a)-(262c) together with (265) yields in matrix form:

$$
\begin{aligned}
& \left(\begin{array}{cccc}
-\theta^{T} & \theta^{N} & 0 & 0 \\
\left(1-\theta^{T}\right) & 0 & -1 & 0 \\
0 & \left(1-\theta^{N}\right) & 0 & -1 \\
\left(1-\xi^{N}\right) & \xi^{N} & \Psi_{W^{T}} & \Psi_{W^{N}}
\end{array}\right)\left(\begin{array}{c}
\hat{k}^{T} \\
\hat{k}^{N} \\
\hat{W}^{T} \\
\hat{W}^{N}
\end{array}\right) \\
= & \left(\begin{array}{c}
\hat{P} \\
0 \\
-\hat{P} \\
\hat{K}-\Psi_{\bar{\lambda}} \hat{\bar{\lambda}}-\Psi_{\tau} \frac{d \tau}{1-\tau}
\end{array}\right),
\end{aligned}
$$

where we set:

$$
\begin{aligned}
\Psi_{W^{T}} & =\left(1-\xi^{N}\right) \frac{L_{W^{T}}^{T} W^{T}}{L^{T}}+\xi^{N} \frac{L_{W^{T}}^{N} W^{T}}{L^{N}} \\
\Psi_{W^{N}} & =\left(1-\xi^{N}\right) \frac{L_{W^{N}}^{T} W^{N}}{L^{T}}+\xi^{N} \frac{L_{W^{N}}^{N} W^{N}}{L^{N}} \\
\xi^{N} & \equiv \frac{k^{N} L^{N}}{K} \\
\Psi_{\bar{\lambda}} & =\left(1-\xi^{N}\right) \sigma_{L}+\xi^{N} \sigma_{L}=\sigma_{L} .
\end{aligned}
$$

The short-run static solutions for sectoral wages and capital-labor ratios are:

$$
W^{j}=W^{j}(\bar{\lambda}, K, P, \tau), \quad k^{j}=k^{j}(\bar{\lambda}, K, P, \tau) .
$$

Inserting first sectoral wages (272), sectoral employment (268) can be solved as functions of the shadow value of wealth, the capital stock and the relative price of non tradables:

$$
L^{j}=L^{j}(\bar{\lambda}, K, P, \tau) .
$$


Finally, plugging solutions for sectoral labor (273) and sector capital-labor ratios (272), the production functions (260) can be solved for sectoral output:

$$
Y^{j}=Y^{j}(\bar{\lambda}, K, P, \tau) .
$$

The Return on Domestic Capital, $R$

The return on domestic capital is:

$$
R=Z^{T}\left(1-\theta^{T}\right)\left(k^{T}\right)^{-\theta^{T}} .
$$

Inserting first the short-run static solution for the capital-labor ratio $k^{T}$ given by (272), eq. (275) can be solved for the return on domestic capital:

$$
R=R(\bar{\lambda}, K, P, \tau) .
$$

\section{The Relative Price of Non Tradables, $P$}

Finally, we have to solve for the relative price of non tradables by using the non traded goods market clearing condition:

$$
Y^{N}=C^{N}+G^{N}+J^{N} .
$$

Remembering that the non traded input $J^{N}$ used to produce investment goods is equal to $P_{J}^{\prime} J$, inserting solutions for $C^{N}$ and $Y^{N}$ given by (266) and (274), respectively, the non traded goods market clearing condition (277) can be rewritten as follows:

$$
Y^{N}(\bar{\lambda}, K, P, \tau)=C^{N}(\bar{\lambda}, P)+G^{N}+P_{J}^{\prime} K\left[v(.)+\delta_{K}+\frac{\kappa}{2}(v(.))^{2}\right] .
$$

Eq. (278) can be solved for the relative price of non tradables:

$$
P=P\left(\bar{\lambda}, K, Q, G^{N}, \tau\right),
$$

with partial derivatives given by:

$$
\begin{aligned}
P_{K} & =\frac{\partial P}{\partial K}=\frac{-\frac{Y_{K}^{N}}{P_{J}^{\prime}}+\frac{J}{K}}{\Psi^{P}} \lessgtr 0 \\
P_{Q} & =\frac{\partial P}{\partial Q}=\frac{K v_{Q}[1+\kappa v(.)]}{\Psi^{P}}>0 \\
P_{G^{N}} & =\frac{1}{P_{J}^{\prime} \Psi^{P}}>0 \\
P_{\tau} & =-\frac{Y_{\tau}^{N}}{P_{J}^{\prime} \Psi^{P}}>0
\end{aligned}
$$

where we set

$$
\Psi^{P}=\left[\left(Y_{P}^{N}-C_{P}^{N}\right)+\frac{J^{N} \phi_{J}\left(1-\alpha_{J}\right)}{P}\right] \frac{1}{P_{J}^{\prime}}-K v_{P}[1+\kappa v(.)]>0 .
$$

\section{M.5 Formal Solutions for public debt $D(t)$}

Like Gali, Lopez-Salido and Vallès [2007], we assume a fiscal policy rule of the (linearized) form:

$$
d T(t)=\phi_{D} d D(t)+\phi_{G} d G(t)
$$

where $d T(t)=T(t)-\tilde{T}, d D(t)=D(t)-\tilde{D}$, and $d G(t)=G(t)-\tilde{G}$. Linearizing first the government budget constraint (240), inserting the fiscal rule (282) and collecting terms yields:

$$
\begin{aligned}
\dot{D} t & =r^{\star}(D(t)-\tilde{D})+(G(t)-\tilde{G})-(T(t)-\tilde{T}), \\
& =\left(r^{\star}-\phi_{D}\right)(D(t)-\tilde{D})+\left(1-\phi_{G}\right)(G(t)-\tilde{G}) .
\end{aligned}
$$


Inserting the dynamic equation for $\frac{d G(t)}{Y}$ given by eq. (97) into (283) and solving the differential equation leads to:

$$
\frac{(D(t)-\tilde{D})}{Y}=\left[\frac{\left(D_{0}-\tilde{D}\right)}{Y}+\Theta_{D}\right] e^{-\delta t}-\left[\Theta_{1} e^{-\xi t}-\Theta_{2} e^{-\chi t}\right],
$$

where we set

$$
\begin{gathered}
\Theta_{D}=\left(1-\phi_{G}\right)\left[\frac{1}{\xi+r^{\star}-\phi_{D}}-\frac{(1-g)}{\chi+r^{\star}-\phi_{D}}\right], \\
\Theta_{1}=\frac{\left(1-\phi_{G}\right)}{\xi+r^{\star}-\phi_{D}}, \\
\Theta_{2}=\frac{\left(1-\phi_{G}\right)(1-g)}{\chi+r^{\star}-\phi_{D}}, \\
\delta=r^{\star}-\phi_{D} .
\end{gathered}
$$

We assume that initial public debt is nil, i.e., $D_{0}=0$. Since public debt is restored back toward its initial level in the long-run following a temporary rise in government spending, we have $\tilde{D}=0$ as well. Inserting (284) into (282) along with the dynamic equation for government spending (97) leads to the temporal path for taxes in percentage point of GDP:

$$
\begin{aligned}
\frac{d T(t)}{Y} & =\phi_{D} \Theta_{D} e^{-\delta t}-\phi_{D}\left[\Theta_{1} e^{-\xi t}-\Theta_{2} e^{-\chi t}\right]+\phi_{G}\left[e^{-\xi t}-(1-g) e^{-\chi t}\right] \\
& =\phi_{D} \Theta_{D} e^{-\delta t}-\left\{\left[\phi_{D} \Theta_{1}-\phi_{G}\right] e^{-\delta t}-\left[\phi_{D} \Theta_{2}-\phi_{G}(1-g)\right] e^{-\chi t}\right\} .
\end{aligned}
$$

Dividing (241) by GDP and denoting by $\theta_{L}$ the aggregate labor income share, we have:

$$
\frac{T(t)}{Y}=\theta_{L}(t) \tau(t)
$$

Because the aggregate labor income share is a weighted average of sectoral labor income shares, i.e., $\theta_{L}=\frac{P(t) Y^{N}(t)}{Y(t)} \theta^{N}+\frac{Y^{T}(t)}{Y(t)} \theta^{T}, \theta_{L}$ varies over time. In order to avoid unnecessary complications, we assume that $\theta_{L}$ is fixed, i.e., $\theta_{L}(t)=\theta_{L}$, and thus the adjustment in tax receipts is achieved through changes in the labor tax rate only. Linearizing first (287) and substituting (286), the deviation of the labor tax relative to its initial value is:

$$
\begin{aligned}
d \tau(t) & =\frac{1}{\theta_{L}} \frac{d T(t)}{Y}, \\
& =\Omega_{D} e^{-\delta t}-\left(\Omega_{1} e^{-\xi t}-\Omega_{2} e^{-\chi t}\right),
\end{aligned}
$$

where we set

$$
\begin{gathered}
\Omega_{D}=\frac{\phi_{D} \Theta_{D}}{\theta_{L}}, \\
\Omega_{1}=\frac{\phi_{D} \Theta_{1}-\phi_{G}}{\theta_{L}}, \\
\Omega_{2}=\frac{\phi_{D} \Theta_{2}-\phi_{G}(1-g)}{\theta_{L}} .
\end{gathered}
$$

\section{M.6 Formal Solutions for $K(t)$ and $Q(t)$}

Remembering that the non traded input $J^{N}$ used to produce the capital good is equal to $P_{J}^{\prime} J$, using the fact that $J^{N}=Y^{N}-C^{N}-G^{N}$ and inserting $I=\dot{K}+\delta_{K}$, the capital accumulation equation can be rewritten as follows:

$$
\dot{K}=\frac{Y^{N}-C^{N}-G^{N}}{P_{J}^{\prime}}-\delta_{K} K-\frac{\kappa}{2}\left(\frac{I}{K}-\delta_{K}\right)^{2} K .
$$


Using the fact that $\frac{\partial G^{N}}{\partial G}=\frac{\omega_{G N}}{\tilde{P}}$, inserting short-run static solutions for non traded output (274), consumption in non tradables (266), and optimal investment decision (250) into the physical capital accumulation equation (282) and the dynamic equation for the shadow value $(249 \mathrm{e})$, the dynamic system is:

$$
\begin{aligned}
\dot{K} \equiv \Upsilon(K, P(.), Q, G, \tau)= & \frac{Y^{N}(K, P(.), \bar{\lambda})-C^{N}(\bar{\lambda}, P(.))-G^{N}}{P_{J}^{\prime}(P(.))} \\
& -\delta_{K} K-\frac{K}{2 \kappa}\left[\frac{Q}{P_{J}(P(.))}-1\right]^{2}, \\
\dot{Q} \equiv \Sigma(K, P, Q, G, \tau)= & \left.\left(r^{\star}+\delta_{K}\right) Q-\left[R(K, P(.))+P_{J} \frac{\kappa}{2} v(.)\left(v(.)+2 \delta_{K}\right)\right] 2.91 \mathrm{~b}\right)
\end{aligned}
$$

The linearized system can be written in a matrix form:

$$
\left(\begin{array}{c}
\dot{K}(t) \\
\dot{Q}(t)
\end{array}\right)=\left(\begin{array}{ll}
a_{11} & a_{12} \\
a_{21} & a_{22}
\end{array}\right)\left(\begin{array}{c}
K(t)-\tilde{K} \\
Q(t)-\tilde{Q}
\end{array}\right)+\left(\begin{array}{c}
\varepsilon_{K}^{G} d G(t)+\varepsilon_{K}^{\tau} d \tau(t) \\
\varepsilon_{Q}^{G} d G(t)+\varepsilon_{Q}^{\tau} d \tau(t)
\end{array}\right)
$$

where the coefficients of the Jacobian matrix are given by

$$
\begin{gathered}
a_{11}=\Upsilon_{K}=\left(\frac{Y_{K}^{N}}{P_{J}^{\prime}}-\delta_{K}\right)+\left[\left(Y_{P}^{N}-C_{P}^{N}\right)+\frac{\tilde{I}^{N} \phi_{J}\left(1-\alpha_{J}\right)}{\tilde{P}}\right] \frac{P_{K}}{P_{J}^{\prime}} \lessgtr 0, \\
a_{12}=\Upsilon_{Q}=\left[\left(Y_{P}^{N}-C_{P}^{N}\right)+\frac{\tilde{I}^{N} \phi_{J}\left(1-\alpha_{J}\right)}{\tilde{P}}\right] \frac{P_{Q}}{P_{J}^{\prime}}>0, \\
a_{21}=\Sigma_{K}=-R_{K}-\left(R_{P}+P_{J} \kappa v_{P} \delta_{K}\right) P_{K}>0, \\
a_{22}=\Sigma_{Q}=r^{\star}-\left(R_{P}+P_{J} \kappa v_{P} \delta_{K}\right) P_{Q}>0,
\end{gathered}
$$

and the direct effects of changes in government consumption captured by the terms $\varepsilon_{K}^{G}$ and $\varepsilon_{Q}^{G}$ are described by:

$$
\begin{gathered}
\varepsilon_{K}=\left\{\left[\left(Y_{P}^{N}-C_{P}^{N}\right)+\frac{\tilde{I}^{N} \phi_{J}\left(1-\alpha_{J}\right)}{\tilde{P}}\right] \frac{P_{G^{N}}}{P_{J}^{\prime}}-\frac{1}{P_{J}^{\prime}}\right\} \frac{\omega_{G^{N}}}{\tilde{P}}, \\
\varepsilon_{Q}=-\left(R_{P}+P_{J} \kappa v_{P} \delta_{K}\right) \frac{P_{G^{N}} \omega_{G^{N}}}{\tilde{P}}
\end{gathered}
$$

The direct effects of changes in the labor tax rate on $K$ and $Q$ are described by:

$$
\begin{gathered}
\varepsilon_{K}^{\tau}=\frac{Y_{\tau}^{N}}{P_{J}^{\prime}}+\Upsilon_{P} P_{\tau}, \\
\varepsilon_{Q}^{\tau}=-R_{\tau}+\Sigma_{P} P_{\tau},
\end{gathered}
$$

where $\Upsilon_{P}=\Upsilon_{P}(\tilde{K}, \tilde{Q}, \tilde{G}, \tilde{\tau})$ and $\Sigma_{P}=\Sigma_{P}(\tilde{K}, \tilde{Q}, \tilde{G}, \tilde{\tau})$.

Denoting the negative eigenvalue by $\nu_{1}$ and the positive eigenvalue by $\nu_{2}$, the general solutions for $K$ and $Q$ can be written as follows:

$$
K(t)-\tilde{K}=X_{1}(t)+X_{2}(t), \quad Q(t)-\tilde{Q}=\omega_{2}^{1} X_{1}(t)+\omega_{2}^{2} X_{2}(t) .
$$

where $X_{1}(t)$ and $X_{2}(t)$ characterize the trajectory of physical capital and the shadow value of capital. To express these terms in compact form, we set:

$$
\begin{aligned}
& \Phi_{1}^{l}=\left[\left(a_{11}-\nu_{2}\right) \varepsilon_{K}^{l}+a_{12} \varepsilon_{Q}^{l}\right], \\
& \Phi_{2}^{l}=\left[\left(a_{11}-\nu_{1}\right) \varepsilon_{K}^{l}+a_{12} \varepsilon_{Q}^{l}\right] .
\end{aligned}
$$


where $l=G, \tau$, along with

$$
\begin{aligned}
\Gamma_{i}^{G} & =-\frac{\Phi_{i}^{G} \tilde{Y}}{\left(\nu_{1}-\nu_{2}\right)\left(\nu_{i}+\xi\right)}, \\
\Theta_{i}^{G} & =(1-g) \frac{\left(\xi+\nu_{i}\right)}{\left(\chi+\nu_{i}\right)}, \\
\Gamma_{i}^{D} & =-\frac{\Phi_{i}^{\tau} \Omega_{D}}{\left(\nu_{1}-\nu_{2}\right)\left(\nu_{i}+\delta\right)}, \\
\Gamma_{i}^{\tau} & =-\frac{\Phi_{i}^{\tau} \Omega_{1}}{\left(\nu_{1}-\nu_{2}\right)\left(\nu_{i}+\xi\right)}, \\
\Theta_{i}^{\tau} & =\frac{\Omega_{2}}{\Omega_{1}}\left(\frac{\xi+\nu_{i}}{\chi+\nu_{i}}\right) .
\end{aligned}
$$

where $i=1,2$.

Adopting the same procedure as in section G.3, solutions for $X_{1}(t)$ and $X_{2}(t)$ are given by:

$$
\begin{aligned}
X_{1}(t) & =e^{\nu_{1} t}\left\{X_{1}(0)-\Gamma_{1}^{G}\left(1-\Theta_{1}^{G}\right)-\Gamma_{1}^{D}+\Gamma_{1}^{\tau}\left(1-\Theta_{1}^{\tau}\right)\right\} \\
& +\Gamma_{1}^{G}\left(e^{-\xi t}-\Theta_{1}^{G} e^{-\chi t}\right)+\Gamma_{1}^{D} e^{-\delta t}-\Gamma_{1}^{\tau}\left(e^{-\xi t}-\Theta_{1}^{\tau} e^{-\chi t}\right), \\
X_{2}(t) & =-\Gamma_{2}^{G}\left(e^{-\xi t}-\Theta_{2}^{G} e^{-\chi t}\right)-\Gamma_{2}^{D} e^{-\delta t}+\Gamma_{2}^{\tau}\left(e^{-\xi t}-\Theta_{2}^{\tau} e^{-\chi t}\right),
\end{aligned}
$$

where

$$
X_{1}(0)=K_{0}-\tilde{K}-X_{2}(0) .
$$

\section{M.7 Formal Solutions for the Net Foreign Asset Position $N(t)$}

To determine the dynamic equation for the net foreign asset position, $N(t)$, we differentiate $N(t)=B(t)-D(t)$ w.r.t. time and substitute the dynamic equations for the stock of traded bonds (246) and for the public debt (240):

$$
\begin{aligned}
\dot{N}(t) & =\dot{B}(t)-\dot{D}(t), \\
& =r^{\star} N(t)+R(t) K(t)+W(t) L(t)-P_{C}(P(t)) C(t)-P_{J}(P(t)) J(t)-G(t)(301)
\end{aligned}
$$

Inserting the market clearing condition for non tradables (277) and remembering that $J^{T}=$ $\left(1-\alpha_{J}\right) P_{J} J$, the current account equation is given by:

$$
\begin{aligned}
\dot{N} & \equiv \Xi(N, K, Q, G), \\
& =r^{\star} N+Y^{T}-C^{T}-G^{T}-\left(1-\alpha_{J}\right) P_{J} J, \\
& =r^{\star} N+Y^{T}-C^{T}-G^{T}-\left(\frac{1-\alpha_{J}}{\alpha_{J}}\right) P\left(Y^{N}-C^{N}-G^{N}\right),
\end{aligned}
$$

where we used the fact that $P_{J}^{\prime} J=Y^{N}-C^{N}-G^{N}$.

Linearizing first the current account equation (302) in the neighborhood of the steadystate and substitute the solutions for $K(t)$ and $Q(t)$ leads to:

$$
\dot{N}(t)=r^{\star} d N(t)+N_{1} X_{1}(t)+N_{2} X_{2}(t)+\Xi_{G} d G(t)+\Xi_{\tau} d \tau(t),
$$

where $N_{i}=\Xi_{K}+\Xi_{Q} \omega_{2}^{i}$ (with $\left.i=1,2\right), \Xi_{G}=\left\{\left[\Xi_{P} P_{G^{N}}+\left(\frac{1-\alpha_{J}}{\alpha_{J}}\right) \tilde{P}\right] \frac{\omega_{G^{N}}}{\tilde{P}}-\omega_{G^{T}}\right\}$, and $\Xi_{\tau}$ reads as follows:

$$
\Xi_{\tau}=\Xi_{P} P_{\tau}+Y_{\tau}^{T}-\left(\frac{1-\alpha_{J}}{\alpha_{J}}\right) \tilde{P} Y_{\tau}^{N}
$$

with $\Xi_{P}=\left(Y_{P}^{T}-C_{P}^{T}\right)-\left(\frac{1-\alpha_{J}}{\alpha_{J}}\right) \tilde{P}\left(Y_{P}^{N}-C_{P}^{N}\right)-\phi_{J}\left(\frac{1-\alpha_{J}}{\alpha_{J}}\right) \tilde{I}^{N}<0$.

Substituting $X_{1}(t)$ given by eq. (299a ) and $X_{2}(t)$ given by eq. (299a) into (299b) leads to:

$$
\begin{aligned}
\dot{N}(t) & =r^{\star} d N(t)+\omega_{N}^{1} e^{\nu_{1} t}+N_{1} \Gamma_{1}^{G}\left(e^{-\xi t}-\Theta_{1}^{G} e^{-\chi t}\right)+N_{1} \Gamma_{1}^{D} e^{-\delta t} \\
& -N_{1} \Gamma_{1}^{\tau}\left(e^{-\xi t}-\Theta_{1}^{\tau} e^{-\chi t}\right)-N_{2} \Gamma_{2}^{G}\left(e^{-\xi t}-\Theta_{2}^{G} e^{-\chi t}\right)-N_{2} \Gamma_{2}^{D} e^{-\delta t}+N_{2} \Gamma_{2}^{\tau}\left(e^{-\xi t}-\Theta_{2}^{\tau} e^{-\chi t}\right) \\
& +\Xi_{G} \tilde{Y}\left(e^{-\xi t}-(1-g) e^{-\chi t}\right)+\Xi_{\tau} \Omega_{D} e^{-\delta t}-\Xi_{\tau}\left(\Omega_{1} e^{-\xi t}-\Omega_{2} e^{-\chi t}\right),
\end{aligned}
$$


where $\Gamma_{i}^{l}$ (with $l=G, \tau, D$, and $\left.i=1,2\right)$ is given by (298a), (298b), (298c) and we set:

$$
\begin{aligned}
\omega_{N}^{1} & =N_{1}\left[(K(0)-\tilde{K})+\Gamma_{2}^{G}\left(1-\Theta_{2}^{G}\right)+\Gamma_{2}^{D}-\Gamma_{2}^{\tau}\left(1-\Theta_{2}^{\tau}\right)\right. \\
& \left.-\Gamma_{1}^{G}\left(1-\Theta_{1}^{G}\right)-\Gamma_{1}^{D}+\Gamma_{1}^{\tau}\left(1-\Theta_{2}^{\tau}\right)\right] .
\end{aligned}
$$

Solving the differential equation (305) yields the general solution for the net foreign asset position:

$$
\begin{aligned}
N(t)-\tilde{N} & =\left\{\left(N_{0}-\tilde{N}\right)-\frac{\omega_{N}^{1}}{\nu_{1}-r^{\star}}+\frac{\Xi_{G} \tilde{Y}}{\xi+r^{\star}}\left(1-\Theta^{G, \prime}\right)+\frac{\Xi_{\tau} \Omega_{D}}{\delta+r^{\star}}-\frac{\Xi_{\tau} \Omega_{1}}{\xi+r^{\star}}\left(1-\Theta^{\tau, \prime}\right)\right. \\
& +\frac{N_{1} \Gamma_{1}^{G}}{\xi+r^{\star}}\left(1-\Theta_{1}^{G, \prime}\right)+\frac{N_{1} \Gamma_{1}^{D}}{\delta+r^{\star}}-\frac{N_{1} \Gamma_{1}^{\tau}}{\xi+r^{\star}}\left(1-\Theta_{1}^{\tau, \prime}\right) \\
& \left.-\frac{N_{2} \Gamma_{2}^{G}}{\xi+r^{\star}}\left(1-\Theta_{2}^{G, \prime}\right)-\frac{N_{2} \Gamma_{2}^{D}}{\delta+r^{\star}}+\frac{N_{2} \Gamma_{2}^{\tau}}{\xi+r^{\star}}\left(1-\Theta_{2}^{\tau, \prime}\right)\right\} e^{r^{\star} t} \\
& +\frac{\omega_{N}^{1}}{\nu_{1}-r^{\star}} e^{\nu_{1} t}-\frac{\Xi_{G} \tilde{Y}}{\xi+r^{\star}}\left(e^{-\xi t}-\Theta^{G, \prime} e^{-\chi t}\right)-\frac{\Xi_{\tau} \Omega_{D}}{\delta+r^{\star}} e^{-\delta t}+\frac{\Xi_{\tau} \Omega_{1}}{\xi+r^{\star}}\left(e^{-\xi t}-\Theta^{\tau, \prime} e^{-\chi t}\right) \\
& -\frac{N_{1} \Gamma_{1}^{G}}{\xi+r^{\star}}\left(e^{-\xi t}-\Theta_{1}^{G, \prime} e^{-\chi t}\right)-\frac{N_{1} \Gamma_{1}^{D}}{\delta+r^{\star}}+\frac{N_{1} \Gamma_{1}^{\tau}}{\xi+r^{\star}}\left(e^{-\xi t}-\Theta_{1}^{\tau, \prime} e^{-\chi t}\right) \\
& +\frac{N_{2} \Gamma_{2}^{G}}{\xi+r^{\star}}\left(1-\Theta_{2}^{G, \prime}\right)+\frac{N_{2} \Gamma_{2}^{D}}{\delta+r^{\star}}-\frac{N_{2} \Gamma_{2}^{\tau}}{\xi+r^{\star}}\left(1-\Theta_{2}^{\tau, \prime}\right),
\end{aligned}
$$

where we set:

$$
\begin{aligned}
\Theta^{G, \prime} & =(1-g) \frac{\xi+r^{\star}}{\chi+r^{\star}}, \\
\Theta_{1}^{G, \prime} & =\Theta_{1}^{G} \frac{\xi+r^{\star}}{\chi+r^{\star}}, \\
\Theta_{2}^{G, \prime} & =\Theta_{2}^{G} \frac{\xi+r^{\star}}{\chi+r^{\star}}, \\
\Theta^{\tau, \prime} & =\frac{\Omega_{2}}{\Omega_{1}} \frac{\xi+r^{\star}}{\chi+r^{\star}}, \\
\Theta_{1}^{\tau, \prime} & =\Theta_{1}^{\tau} \frac{\xi+r^{\star}}{\chi+r^{\star}}, \\
\Theta_{2}^{\tau, \prime} & =\Theta_{2}^{\tau} \frac{\xi+r^{\star}}{\chi+r^{\star}} .
\end{aligned}
$$

Invoking the transversality condition, one obtains the 'stable' solution for the stock of net foreign assets so that $N(t)$ converges toward its steady-state value $\tilde{N}$ :

$$
\begin{aligned}
N(t)-\tilde{N} & =\frac{\omega_{N}^{1}}{\nu_{1}-r^{\star}} e^{\nu_{1} t}-\frac{\Xi_{G} \tilde{Y}}{\xi+r^{\star}}\left(e^{-\xi t}-\Theta^{G, \prime} e^{-\chi t}\right)-\frac{\Xi_{\tau} \Omega_{D}}{\delta+r^{\star}} e^{-\delta t}+\frac{\Xi_{\tau} \Omega_{1}}{\xi+r^{\star}}\left(e^{-\xi t}-\Theta^{\tau, \prime} e^{-\chi t}\right) \\
& -\frac{N_{1} \Gamma_{1}^{G}}{\xi+r^{\star}}\left(e^{-\xi t}-\Theta_{1}^{G, \prime} e^{-\chi t}\right)-\frac{N_{1} \Gamma_{1}^{D}}{\delta+r^{\star}} e^{-\delta t}+\frac{N_{1} \Gamma_{1}^{\tau}}{\xi+r^{\star}}\left(e^{-\xi t}-\Theta_{1}^{\tau, \prime} e^{-\chi t}\right) \\
& +\frac{N_{2} \Gamma_{2}^{G}}{\xi+r^{\star}}\left(e^{-\xi t}-\Theta_{2}^{G, \prime} e^{-\chi t}\right)+\frac{N_{2} \Gamma_{2}^{D}}{\delta+r^{\star}} e^{-\delta t}-\frac{N_{2} \Gamma_{2}^{\tau}}{\xi+r^{\star}}\left(e^{-\xi t}-\Theta_{2}^{\tau, \prime} e^{-\chi t}\right) .
\end{aligned}
$$

Eq. (309) gives the trajectory for for $N(t)$ consistent with the intertemporal solvency condition:

$$
\left(\tilde{N}-N_{0}\right)=-\frac{\omega_{N}^{1}}{\nu_{1}-r^{\star}}+\frac{\omega_{N}^{G}}{\xi+r^{\star}}+\frac{\omega_{N}^{D}}{\delta+r^{\star}}+\frac{\omega_{N}^{\tau}}{\xi+r^{\star}},
$$

where $\omega_{N}^{1}$ is given by (306) and we set

$$
\begin{gathered}
\omega_{N}^{G}=\Xi_{G} \tilde{Y}\left(1-\Theta^{G, \prime}\right)+N_{1} \Gamma_{1}^{G}\left(1-\Theta_{1}^{G, \prime}\right)-N_{2} \Gamma_{2}^{G}\left(1-\Theta_{2}^{G, \prime}\right), \\
\omega_{N}^{D}=\Xi_{\tau} \Omega_{D}-N_{1} \Gamma_{1}^{D}+N_{2} \Gamma_{2}^{D}, \\
\omega_{N}^{\tau}=-\Xi_{\tau} \Omega_{1}\left(1-\Theta^{\tau, \prime}\right)-N_{1} \Gamma_{1}^{\tau}\left(1-\Theta_{1}^{\tau, \prime}\right)+N_{2} \Gamma_{2}^{\tau}\left(1-\Theta_{2}^{\tau, \prime}\right) .
\end{gathered}
$$


Differentiating (309) w.r.t. time gives the trajectory for the current account along the transitional path when government spending follows the temporal path given by eq. (97) and the labor tax rate is governed by the dynamic equation (288)

$$
\begin{aligned}
\dot{N}(t) & =\nu_{1} \frac{\omega_{N}^{1}}{\nu_{1}-r^{\star}} e^{\nu_{1} t}+\frac{\Xi_{G} \tilde{Y}}{\xi+r^{\star}}\left(\xi e^{-\xi t}-\chi \Theta^{G, \prime} e^{-\chi t}\right)+\delta \frac{\Xi_{\tau} \Omega_{D}}{\delta+r^{\star}} e^{-\delta t}-\frac{\Xi_{\tau} \Omega_{1}}{\xi+r^{\star}}\left(\xi e^{-\xi t}-\chi \Theta^{\tau, \prime} e^{-\chi t}\right) \\
& +\frac{N_{1} \Gamma_{1}^{G}}{\xi+r^{\star}}\left(\xi e^{-\xi t}-\chi \Theta_{1}^{G, \prime} e^{-\chi t}\right)+\delta \frac{N_{1} \Gamma_{1}^{D}}{\delta+r^{\star}} e^{-\delta t}-\frac{N_{1} \Gamma_{1}^{\tau}}{\xi+r^{\star}}\left(\xi e^{-\xi t}-\chi \Theta_{1}^{\tau, \prime} e^{-\chi t}\right) \\
& -\frac{N_{2} \Gamma_{2}^{G}}{\xi+r^{\star}}\left(\xi e^{-\xi t}-\chi \Theta_{2}^{G, \prime} e^{-\chi t}\right)+\frac{N_{2} \Gamma_{2}^{D}}{\delta+r^{\star}} e^{-\delta t}+\frac{N_{2} \Gamma_{2}^{\tau}}{\xi+r^{\star}}\left(\xi e^{-\xi t}-\chi \Theta_{2}^{\tau, \prime} e^{-\chi t}\right) .
\end{aligned}
$$

\section{M.8 Formal Solution for the Stock of Non Human Wealth, $A(t)$}

Remembering that the stock of national non human wealth $A(t)$ is equal to $N(t)+Q(t) K(t)$, differentiating w.r.t. time, i.e., $\dot{A}(t)=\dot{B}(t)-\dot{D}(t)+\dot{Q}(t) K(t)+Q(t) \dot{K}(t)$, plugging the dynamic equation for the shadow value of capital $(249 \mathrm{e})$, inserting the accumulation equations for physical capital (247), traded bonds (246), traded bonds issued by the government (240) and using the specification of capita adjustment costs (248) along with the first order condition (249d) yields the accumulation equation for the stock of national non human wealth or the dynamic equation for national savings:

$$
\dot{A}(t)=r^{\star} A(t)+W(t) L(t)-P_{C}(P(t)) C(t)-G(t) .
$$

We first determine short-run static solutions for aggregate labor supply and aggregate wage index. Inserting solutions for sectoral wages (272) into the solution for aggregate labor supply (266), one can solve for total hours worked:

$$
L=L(\bar{\lambda}, K, P, \tau)
$$

where partial derivatives are given by

$$
\begin{aligned}
L_{K} & \equiv \frac{\partial L}{\partial K}=L_{W^{T}} W_{K}^{T}+L_{W^{N}} W_{K}^{N} \\
L_{P} & \equiv \frac{\partial L}{\partial P}=L_{W^{T}} W_{P}^{T}+L_{W^{N}} W_{P}^{N} \\
L_{\tau} & \equiv \frac{\partial L}{\partial \tau}=L_{W^{T}} W_{\tau}^{T}+L_{W^{N}} W_{\tau}^{N}
\end{aligned}
$$

Substituting solutions for sectoral wages (272) into the aggregate wage index $W \equiv W\left(W^{T}, W^{N}\right)$, we can solve for the aggregate wage index:

$$
W=W(\bar{\lambda}, K, P, \tau),
$$

where partial derivatives are given by

$$
\begin{aligned}
W_{K} & \equiv \frac{\partial W}{\partial K}=W_{W^{T}} W_{K}^{T}+W_{W^{N}} W_{K}^{N}, \\
W_{P} & \equiv \frac{\partial W}{\partial P}=W_{W^{T}} W_{P}^{T}+W_{W^{N}} W_{P}^{N}, \\
W_{\tau} & \equiv \frac{\partial W}{\partial P}=W_{W^{T}} W_{\tau}^{T}+W_{W^{N}} W_{\tau}^{N},
\end{aligned}
$$

with $W_{W^{T}}=\left(W / W^{T}\right)\left(1-\alpha_{L}\right)$ and $W_{W^{N}}=\left(W / W^{N}\right) \alpha_{L}$.

Inserting solutions for aggregate labor supply (314), plugging the solutions for aggregate wage index (316) and for consumption (266) into the accumulation equation of financial wealth (313), linearizing around the steady-state leads to:

$$
\dot{A}(t)=r^{\star} d A(t)+\Lambda_{K} d K(t)+\Lambda_{Q} d Q(t)+\Lambda_{G} d G(t)+\Lambda_{\tau} d \tau(t),
$$


where partial derivatives evaluated at the steady-state are given by

$$
\begin{aligned}
\Lambda_{P} & =\left(W_{P} \tilde{L}+\tilde{W} L_{P}\right)-\left(\tilde{C}^{N}+P_{C} C_{P}\right), \\
\left.\Lambda_{K}\right|_{\text {P fixed }} & =W_{K} \tilde{L}+\tilde{W} L_{K}, \\
\left.\Lambda_{G}\right|_{\text {P fixed }} & =-1, \\
\left.\Lambda_{\tau}\right|_{\text {P fixed }} & =W_{\tau} \tilde{L}+\tilde{W} L_{\tau} .
\end{aligned}
$$

Substituting the solutions for $K(t)$ and $Q(t)$ into (318) leads to:

$$
\dot{A}(t)=r^{\star} d A(t)+M_{1} X_{1}(t)+M_{2} X_{2}(t)+\Lambda_{G} d G(t)+\Lambda_{\tau} d \tau(t),
$$

where $M_{i}=\Lambda_{K}+\Lambda_{Q} \omega_{2}^{i}$ (with $i=1,2$ ).

Substituting the equation that governs the endogenous response of government consumption to an exogenous fiscal shock (97) along with the equation that governs the endogenous response of the labor tax rate (288) into (320) and solving yields the general solution for the stock of national non human wealth:

$$
\begin{aligned}
A(t)-\tilde{A} & =\left\{\left(A_{0}-\tilde{A}\right)-\frac{\omega_{A}^{1}}{\nu_{1}-r^{\star}}+\frac{\Lambda_{G} \tilde{Y}}{\xi+r^{\star}}\left(1-\Theta^{G, \prime}\right)+\frac{\Lambda_{\tau} \Omega_{D}}{\delta+r^{\star}}-\frac{\Lambda_{\tau} \Omega_{1}}{\xi+r^{\star}}\left(1-\Theta^{\tau, \prime}\right)\right. \\
& +\frac{M_{1} \Gamma_{1}^{G}}{\xi+r^{\star}}\left(1-\Theta_{1}^{G, \prime}\right)+\frac{M_{1} \Gamma_{1}^{D}}{\delta+r^{\star}}-\frac{M_{1} \Gamma_{1}^{\tau}}{\xi+r^{\star}}\left(1-\Theta_{1}^{\tau, \prime}\right) \\
& \left.-\frac{M_{2} \Gamma_{2}^{G}}{\xi+r^{\star}}\left(1-\Theta_{2}^{G, \prime}\right)-\frac{M_{2} \Gamma_{2}^{D}}{\delta+r^{\star}}+\frac{M_{2} \Gamma_{2}^{\tau}}{\xi+r^{\star}}\left(1-\Theta_{2}^{\tau, \prime}\right)\right\} e^{r^{\star} t} \\
& +\frac{\omega_{A}^{1}}{\nu_{1}-r^{\star}} e^{\nu_{1} t}-\frac{\Lambda_{G} \tilde{Y}}{\xi+r^{\star}}\left(e^{-\xi t}-\Theta^{G,{ }^{\prime}} e^{-\chi t}\right)-\frac{\Lambda_{\tau} \Omega_{D}}{\delta+r^{\star}} e^{-\delta t}+\frac{\Lambda_{\tau} \Omega_{1}}{\xi+r^{\star}}\left(e^{-\xi t}-\Theta^{\tau, \prime} e^{-\chi t}\right) \\
& -\frac{M_{1} \Gamma_{1}^{G}}{\xi+r^{\star}}\left(e^{-\xi t}-\Theta_{1}^{G, \prime} e^{-\chi t}\right)-\frac{M_{1} \Gamma_{1}^{D}}{\delta+r^{\star}}+\frac{M_{1} \Gamma_{1}^{\tau}}{\xi+r^{\star}}\left(e^{-\xi t}-\Theta_{1}^{\tau, \prime} e^{-\chi t}\right) \\
& +\frac{M_{2} \Gamma_{2}^{G}}{\xi+r^{\star}}\left(1-\Theta_{2}^{G, \prime}\right)+\frac{M_{2} \Gamma_{2}^{D}}{\delta+r^{\star}}-\frac{M_{2} \Gamma_{2}^{\tau}}{\xi+r^{\star}}\left(1-\Theta_{2}^{\tau, \prime}\right),
\end{aligned}
$$

where we set:

$$
\omega_{A}^{1}=M_{1}\left[\left(K_{0}-\tilde{K}\right)-X_{2}(0)-\Gamma_{1}^{G}\left(1-\Theta_{1}^{G}\right)-\Gamma_{1}^{D}+\Gamma_{1}^{\tau}\left(1-\Theta_{1}^{\tau}\right)\right] .
$$

Invoking the transversality condition, one obtains the 'stable' solution for the stock of national non human wealth so that $A(t)$ converges toward its steady-state value $\tilde{A}$ :

$$
\begin{aligned}
A(t)-\tilde{A} & =\frac{\omega_{A}^{1}}{\nu_{1}-r^{\star}} e^{\nu_{1} t}-\frac{\Lambda_{G} \tilde{Y}}{\xi+r^{\star}}\left(e^{-\xi t}-\Theta^{G, \prime} e^{-\chi t}\right)-\frac{\Lambda_{\tau} \Omega_{D}}{\delta+r^{\star}} e^{-\delta t}+\frac{\Lambda_{\tau} \Omega_{1}}{\xi+r^{\star}}\left(e^{-\xi t}-\Theta^{\tau, \prime} e^{-\chi t}\right) \\
& -\frac{M_{1} \Gamma_{1}^{G}}{\xi+r^{\star}}\left(e^{-\xi t}-\Theta_{1}^{G, \prime} e^{-\chi t}\right)-\frac{M_{1} \Gamma_{1}^{D}}{\delta+r^{\star}} e^{-\delta t}+\frac{M_{1} \Gamma_{1}^{\tau}}{\xi+r^{\star}}\left(e^{-\xi t}-\Theta_{1}^{\tau, \prime} e^{-\chi t}\right) \\
& +\frac{M_{2} \Gamma_{2}^{G}}{\xi+r^{\star}}\left(e^{-\xi t}-\Theta_{2}^{G, \prime} e^{-\chi t}\right)+\frac{M_{2} \Gamma_{2}^{D}}{\delta+r^{\star}} e^{-\delta t}-\frac{M_{2} \Gamma_{2}^{\tau}}{\xi+r^{\star}}\left(e^{-\xi t}-\Theta_{2}^{\tau, \prime} e^{-\chi t}\right) .
\end{aligned}
$$

Eq. (323) gives the trajectory for for $N(t)$ consistent with the intertemporal solvency condition:

$$
\left(\tilde{A}-A_{0}\right)=-\frac{\omega_{A}^{1}}{\nu_{1}-r^{\star}}+\frac{\omega_{A}^{G}}{\xi+r^{\star}}+\frac{\omega_{A}^{D}}{\delta+r^{\star}}+\frac{\omega_{A}^{\tau}}{\xi+r^{\star}},
$$

where $\omega_{A}^{1}$ is given by (322) and we set

$$
\begin{gathered}
\omega_{A}^{G}=\Lambda_{G} \tilde{Y}\left(1-\Theta^{G, \prime}\right)+M_{1} \Gamma_{1}^{G}\left(1-\Theta_{1}^{G, \prime}\right)-M_{2} \Gamma_{2}^{G}\left(1-\Theta_{2}^{G, \prime}\right), \\
\omega_{A}^{D}=\Lambda_{\tau} \Omega_{D}-M_{1} \Gamma_{1}^{D}+M_{2} \Gamma_{2}^{D}, \\
\omega_{A}^{\tau}=-\Lambda_{\tau} \Omega_{1}\left(1-\Theta^{\tau, \prime}\right)-M_{1} \Gamma_{1}^{\tau}\left(1-\Theta_{1}^{\tau, \prime}\right)+M_{2} \Gamma_{2}^{\tau}\left(1-\Theta_{2}^{\tau, \prime}\right) .
\end{gathered}
$$


Differentiating (323) w.r.t. time gives the trajectory for the national non human wealth along the transitional path when government spending follows the temporal path given by eq. (97) and the labor tax rate is governed by the dynamic equation (288)

$$
\begin{aligned}
\dot{A}(t) & =\nu_{1} \frac{\omega_{A}^{1}}{\nu_{1}-r^{\star}} e^{\nu_{1} t}+\frac{\Lambda_{G} \tilde{Y}}{\xi+r^{\star}}\left(\xi e^{-\xi t}-\chi \Theta^{G, \prime} e^{-\chi t}\right)+\delta \frac{\Lambda_{\tau} \Omega_{D}}{\delta+r^{\star}} e^{-\delta t}-\frac{\Lambda_{\tau} \Omega_{1}}{\xi+r^{\star}}\left(\xi e^{-\xi t}-\chi \Theta^{\tau, \prime} e^{-\chi t}\right) \\
& +\frac{M_{1} \Gamma_{1}^{G}}{\xi+r^{\star}}\left(\xi e^{-\xi t}-\chi \Theta_{1}^{G, \prime} e^{-\chi t}\right)+\delta \frac{M_{1} \Gamma_{1}^{D}}{\delta+r^{\star}} e^{-\delta t}-\frac{M_{1} \Gamma_{1}^{\tau}}{\xi+r^{\star}}\left(\xi e^{-\xi t}-\chi \Theta_{1}^{\tau, \prime} e^{-\chi t}\right) \\
& -\frac{M_{2} \Gamma_{2}^{G}}{\xi+r^{\star}}\left(\xi e^{-\xi t}-\chi \Theta_{2}^{G, \prime} e^{-\chi t}\right)+\frac{M_{2} \Gamma_{2}^{D}}{\delta+r^{\star}} e^{-\delta t}+\frac{M_{2} \Gamma_{2}^{\tau}}{\xi+r^{\star}}\left(\xi e^{-\xi t}-\chi \Theta_{2}^{\tau, \prime} e^{-\chi t}\right) .
\end{aligned}
$$

\section{N Solving the Model with Endogenous Markups}

This section extends the two-sector model with imperfect mobility of labor to an imperfectly competitive non traded sector with endogenous markups. We maintain the assumption of capital installation costs. There are two sectors. A traded sector produced a good that can be consumed by the private, $C^{T}$, and the public sector, $G^{T}$, invested, $J^{T}$, or exported. A non traded sector produces a good for domestic absorption only. The non traded good can be consumed by the private, $C^{N}$, and the public sector, $G^{N}$, or invested, $J^{N}$. The final non-traded output, $Y^{N}$, is produced in a competitive retail sector with constant-returns-toscale production which aggregates a continuum measure one of sectoral non-traded goods. We denote the elasticity of substitution between any two different sectoral non traded goods by $\eta>0$. In each industry, there are $N>1$ firms producing differentiated goods that are aggregated into a sectoral non-traded good. The elasticity of substitution between any two varieties within an industry is denoted by $\rho>0$, and we assume that this is higher than the elasticity of substitution across non traded industries, i.e. $\rho>\eta$ (see Jaimovich and Floetotto [2008]). The number of firms is large enough so that we can ignore the strategic effects but not so large that the effect of entry on the firm's demand curve is minuscule. Consequently, the price elasticity of demand faced by a single firm is no longer constant and equal to the elasticity of substitution between any two varieties, but rather a function of the number of firms $N$. We further assume instantaneous entry, which implies that the producers make zero profits. Since the household's maximization problem is identical to that described in section 2, we restrict our attention to the firms' maximization problem. More technical details can be found in the working paper version of the paper by Cardi and Restout [2014], [2015].

\section{N.1 Introducing Endogenous Markups}

Within each industry, there is monopolistic competition; each firm that produces one variety is a price setter. Output $\mathcal{X}_{i, j}$ of firm $i$ in industry $j$ is produced using capital and labor, i.e. $\mathcal{X}_{i, j}=H\left(\mathcal{K}_{i, j}, \mathcal{L}_{i, j}\right)$. Each firm chooses capital and labor by equating markup-adjusted marginal products to the marginal cost of inputs, i. e. $P H_{K} / \mu=R$, and $P H_{L} / \mu=W^{N}$, where $\mu$ is the markup over the marginal costs. At a symmetric equilibrium, non-traded output is equal to $Y^{N}=N \mathcal{X}=H\left(K^{N}, L^{N}\right)$ where $L_{N}=N \mathcal{L}_{N}$ and $K_{N}=N \mathcal{K}_{N}$.

Taking into account the fact that output of one variety does not affect the price of final non-traded output, but influences the sectoral price level, in a symmetric equilibrium, the resulting price elasticity of demand is:

$$
e(N)=\rho-\frac{(\rho-\eta)}{N}, \quad N \in(1, \infty)
$$

Assuming that $\rho>\eta$, the price elasticity of demand faced by one single firm is an increasing function of the number of firms $N$ within a sector:

$$
\frac{\partial e}{\partial N}=\frac{\rho-\eta}{N^{2}}>0
$$

where the positive sign of the partial derivative follows from the assumption $\rho>\eta$. Henceforth, the markup defined as follows

$$
\mu(N)=\frac{e}{e-1}
$$


decreases as the number of competitors increases, i.e. $\mu_{N}<0$.

We assume instantaneous entry, which implies that the zero-profit condition holds at each instant of time:

$$
\begin{aligned}
\pi^{N} & =H\left(\mathcal{K}^{N}, \mathcal{L}^{N}\right)-R \mathcal{K}^{N}-W^{N} \mathcal{L}^{N}-P \psi \\
& =P\left[\frac{Y^{N}}{N}\left(1-\frac{1}{\mu}\right)-\psi\right]=0
\end{aligned}
$$

where we denote fixed costs by $\psi$; we used the fact that $\frac{P}{\mu} \frac{\partial \mathcal{X}}{\partial \mathcal{K}^{N}}=R$ and $\frac{P}{\mu} \frac{\partial \mathcal{X}}{\partial \mathcal{L}^{N}}=W^{N}$ and $\frac{\partial \mathcal{X}}{\partial \mathcal{K}^{N}} \mathcal{K}^{N}+\frac{\partial \mathcal{X}}{\partial \mathcal{L}^{N}} \mathcal{L}^{N}=\mathcal{X}$. The zero-profit condition $\pi^{N}=0$ can be solved for the number of firms.

Since capital can move freely between the two sectors while the shift of labor across sectors is costly, only marginal products of capital in the traded and the non traded sector equalize:

$$
\begin{gathered}
Z^{T}\left(1-\theta^{T}\right)\left(k^{T}\right)^{-\theta^{T}}=\frac{P}{\mu} Z^{N}\left(1-\theta^{N}\right)\left(k^{N}\right)^{-\theta^{N}} \equiv R, \\
Z^{T} \theta^{T}\left(k^{T}\right)^{1-\theta^{T}} \equiv W^{T}, \\
\frac{P}{\mu} Z^{N} \theta^{N}\left(k^{N}\right)^{1-\theta^{N}} \equiv W^{N},
\end{gathered}
$$

where the capital-labor ratio for sector $j=T, N$ is denoted by $k^{j} \equiv K^{j} / L^{j}$. These static efficiency conditions state that the value of the marginal product of labor in sector $j$ is equal to the labor cost $W^{j}$ while the value of the marginal product of capital in the traded and the non traded sector must be equal to the capital rental cost, $R$.

Aggregating over the two sectors gives us the resource constraint for capital:

$$
K^{T}+K^{N}=K
$$

\section{N.2 Solving the Model with Endogenous Markups}

Plugging the short-run static solutions for $L^{T}$ and $L^{N}$ (see section $\mathrm{G}$ ) into the resource constraint for capital (332), the system of four equations consisting of (331a)-(331c) together with (332) can be solved for the sectoral wage rates $W^{j}$ and sectoral capital-labor ratios $k^{j}$. Keeping TFPs unchanged, and differentiating (331a)-(331c) together with (332) yields in matrix form:

$$
\begin{aligned}
& \left(\begin{array}{cccc}
-\frac{\theta^{T}}{k^{T}} & \frac{\theta^{N}}{k^{N}} & 0 & 0 \\
\frac{\left(1-\theta^{T}\right)}{k^{T}} & 0 & -\frac{1}{W^{T}} & 0 \\
0 & \frac{\left(1-\theta^{N}\right)}{k^{N}} & 0 & -\frac{1}{W^{N}} \\
L^{T} & \Psi_{W^{T}} & \Psi_{W^{N}}
\end{array}\right)\left(\begin{array}{c}
d k^{T} \\
d k^{N} \\
d W^{T} \\
d W^{N}
\end{array}\right) \\
= & \left(\begin{array}{c}
\frac{d P}{P}-\frac{d \mu}{\mu} \\
0 \\
-\frac{d P}{P}+\frac{d \mu}{\mu} \\
d K-\Psi_{\bar{\lambda}} d \bar{\lambda}
\end{array}\right),
\end{aligned}
$$

where we set:

$$
\begin{aligned}
\Psi_{W^{T}} & =k^{T} L_{W^{T}}^{T}+k^{N} L_{W^{T}}^{N}, \\
\Psi_{W^{N}} & =k^{T} L_{W^{N}}^{T}+k^{N} L_{W^{N}}^{N}, \\
\Psi_{\bar{\lambda}} & =k^{T} L_{\bar{\lambda}}^{T}+k^{N} L_{\bar{\lambda}}^{N} .
\end{aligned}
$$

The short-run static for sectoral wages and sectoral capital-labor ratios are:

$$
W^{j}=W^{j}(\bar{\lambda}, K, P, \mu), \quad k^{j}=k^{j}(\bar{\lambda}, K, P, \mu) .
$$


Inserting first solutions for sectoral wages (335) into $L^{j}=L^{j}\left(\bar{\lambda}, W^{T}, W^{N}\right)$, sectoral hours worked can be solved as functions of the shadow value of wealth, the capital stock, the relative price of non tradables and the markup

$$
L^{j}=L^{j}(\bar{\lambda}, K, P, \mu) .
$$

We repeat production functions for convenience:

$$
Y^{j}=Z^{j} L^{j}\left(k^{j}\right)^{1-\theta^{j}}, \quad j=T, N .
$$

Inserting first short-run static solutions for sectoral capital-labor ratios (335) and sectoral labor (336) into the production functions yields:

$$
Y^{j}=Y^{j}(\bar{\lambda}, K, P, \mu) .
$$

It is worth noticing that a rise in the markup $\mu$ produces opposite effects to those induced by an appreciation in $P$.

The Return on Domestic Capital, $R$

The return on domestic capital is:

$$
R=Z^{T}\left(1-\theta^{T}\right)\left(k^{T}\right)^{-\theta^{T}} .
$$

Inserting first the short-run static solution for the capital-labor ratio $k^{T}$ given by (335), eq. (339) can be solved for the return on domestic capital:

$$
R=R(\bar{\lambda}, K, P, \mu) .
$$

Optimal Investment Decision, $I / K$

Eq. (81c) can be solved for the investment rate:

$$
\frac{I}{K}=v\left(\frac{Q}{P_{I}(P)}\right)+\delta_{K}
$$

where

$$
v(.)=\frac{1}{\kappa}\left(\frac{Q}{P_{J}}-1\right),
$$

The Number of Firms within each Non Traded Industry, $N$

Substituting the short-run solution for non traded output (338) and using the fact that $\mu=\mu(N)$ (see (327)-(329)), the zero-profit condition (330) can be rewritten as:

$$
Y^{N}(\bar{\lambda}, K, P, \mu(N))\left(1-\frac{1}{\mu(N)}\right)=N \psi .
$$

Solving yields the short-run solution for the number of firms:

$$
N=N(\bar{\lambda}, K, P),
$$

where partial derivatives are given by:

$$
N_{x} \equiv \frac{\partial N}{\partial x}=-\frac{Y_{x}^{N}\left(1-\frac{1}{\mu}\right)}{\chi} \gtrless 0,
$$

where $x=K, P, \bar{\lambda}$ and we set

$$
\chi=\frac{\mu_{N}}{\mu}\left\{\left[Y_{\mu}^{N}(\mu-1)+\frac{Y^{N}}{\mu}\right]-\psi\right\} .
$$

Inspection of (346) shows that $\chi<0$ since $\mu_{N}=\frac{\partial \mu}{\partial N}<0$ if $Y_{\mu}^{N}=\frac{\partial Y^{N}}{\partial \mu}<0$ is not too large. This implies that an input inflow in the non-traded sector that raises $Y^{N}$ and thereby leads to profit opportunities results in firm entry (i.e, $N$ increases) which lowers the markup, $\mu$.

Solutions for Sectoral Production Variables 
Since sectoral wages, sectoral capital labor-ratios, sectoral labor and sectoral output depend on the markup and thus on the number of firms, we have to plug back (344) into (335), (336), and (338) in order get the solutions for sectoral wages, sectoral capital laborratios, sectoral labor and sectoral output:

$$
\begin{aligned}
W^{j} & =W^{j}\{\bar{\lambda}, K, P, \mu[N(.)]\} \equiv W^{j}(\bar{\lambda}, K, P), \\
k^{j} & =k^{j}\{\bar{\lambda}, K, P, \mu[N(.)]\} \equiv W^{j}(\bar{\lambda}, K, P), \\
L^{j} & =L^{j}\{\bar{\lambda}, K, P, \mu[N(.)]\} \equiv W^{j}(\bar{\lambda}, K, P), \\
Y^{j} & =Y^{j}\{\bar{\lambda}, K, P, \mu[N(.)]\} \equiv W^{j}(\bar{\lambda}, K, P),
\end{aligned}
$$

where $Y_{X}^{j}=\frac{\partial Y^{j}}{\partial X}+\frac{\partial Y^{j}}{\partial \mu} \mu_{N} N_{X}$ with $X=\bar{\lambda}, K, P$. The same logic applies to $W^{j}, k^{j}, L^{j}$.

Sectoral Government Spending, $G^{j}$

Making use of (5), the budget constraint can be solved for government expenditure in good $j=T, N$ can be solved for overall government consumption as follows:

$$
G^{N}(t)=\mathrm{G}^{N}(G(t)), \quad G^{T}=\mathrm{G}^{T}(G(t)),
$$

where $\frac{\partial G^{N}}{\partial G}=\frac{\omega_{G} N}{P}$ and $\frac{\partial G^{T}}{\partial G}=\omega_{G^{T}}$ with $\omega_{G^{j}}$ corresponding to the share of expenditure on good $j$ in total government spending.

The Relative Price of Non Tradables, $P$

Finally, we have to solve for the relative price of non tradables by using the non traded goods market clearing condition:

$$
Y^{N}=C^{N}+G^{N}+J^{N} .
$$

Remembering that the non traded input $J^{N}$ used to produce investment goods is equal to $P_{J}^{\prime} J$, inserting short-run static solutions for $C^{N}$ and $Y^{N}$, substituting $J=K\left[v()+.\delta_{K}+\frac{\kappa}{2}(v(.))^{2}\right]$, and inserting the solution for the number of firms described by (344) into the markup, i.e., $\mu=\mu[N(\bar{\lambda}, K, P)]$, the non traded goods market clearing condition (349) can be rewritten as follows:

$$
\frac{Y^{N}[\bar{\lambda}, K, P, \mu(N(.))]}{\mu(N(.))}=C^{N}(\bar{\lambda}, P)+G^{N}+P_{J}^{\prime} K\left[v(.)+\delta_{K}+\frac{\kappa}{2}(v(.))^{2}\right] .
$$

Using eq. (348), eq. (350) can be solved for the relative price of non tradables:

$$
P=P(\bar{\lambda}, K, Q, G),
$$

with partial derivatives given by:

$$
\begin{aligned}
P_{K} & =\frac{\partial P}{\partial K}=\frac{\left(-\frac{Y_{K}^{N}}{\mu}+\frac{Y^{N}}{\mu} \frac{\mu_{N}}{\mu} N_{K}\right) \frac{1}{P_{J}^{\prime}}+\frac{J}{K}}{\Psi^{P, I}} \lessgtr 0, \\
P_{Q} & =\frac{\partial P}{\partial Q}=\frac{K v_{Q}[1+\kappa v(.)]}{\Psi^{P, \prime}}>0, \\
P_{G} & =\frac{\omega_{G^{N}}}{P P_{J}^{\prime} \Psi^{P, \prime}}>0,
\end{aligned}
$$

where we set

$$
\Psi^{P, \prime}=\left[\left(\frac{Y_{P}^{N}}{\mu}-C_{P}^{N}\right)+\frac{J^{N} \phi_{J}\left(1-\alpha_{J}\right)}{P}-\frac{Y^{N}}{\mu} \frac{\mu_{N}}{\mu} N_{P}\right] \frac{1}{P_{J}^{\prime}}-K v_{P}[1+\kappa v(.)]>0 .
$$

with $\mu_{N}<0$ and $N_{P}>0$.

\section{N.3 Equilibrium Dynamics}

Remembering that the non traded input $J^{N}$ used to produce the capital good is equal to $P_{J}^{\prime} J$, using the fact that $J^{N}=Y^{N}-C^{N}-G^{N}$ and inserting $I=\dot{K}+\delta_{K} K$, the capital accumulation equation can be rewritten as follows:

$$
\dot{K}=\frac{\frac{Y^{N}}{\mu}-C^{N}-G^{N}}{P_{J}^{\prime}}-\delta_{K} K-\frac{\kappa}{2}\left(\frac{I}{K}-\delta_{K}\right)^{2} K .
$$


Inserting short-run solutions for non traded output (347d), consumption in non tradables, optimal investment decision (342), and the number of firms (344) into the physical capital accumulation equation (354), and inserting the solution for the return on domestic capital (340) into the dynamic equation for the shadow value of capital stock (81e), the dynamic system reads as follows:

$$
\begin{aligned}
\dot{K} \equiv \Upsilon(K, P, Q, G)= & \frac{\frac{Y^{N}[K, P(.), \bar{\lambda}]}{\mu[N(.)]}-C^{N}(\bar{\lambda}, P(.))-\mathrm{G}^{N}(G)}{P_{J}^{\prime}(P(.))} \\
& -\delta_{K} K-\frac{K}{2 \kappa}\left[\frac{Q}{P_{J}(P(.))}-1\right]^{2} \\
\dot{Q} \equiv \Sigma(K, P, Q, G)= & \left(r^{\star}+\delta_{K}\right) Q-\left[R(K, P(.))+P_{J} \frac{\kappa}{2} v(.)\left(v(.)+2 \delta_{K}\right)\right] .
\end{aligned}
$$

where we have inserted the solution for the number of firms (344) into (340) in order to solve for the domestic return of physical capital, i.e., $R=R\{\bar{\lambda}, K, P, \mu[N()].\} \equiv R(\bar{\lambda}, K, P)$.

As will be useful, let us denote by $\Upsilon_{K}, \Upsilon_{Q}$, and $\Upsilon_{P}$ the partial derivatives evaluated at the steady-state of the capital accumulation equation w.r.t. $K$ and $Q$ (for given $P$ ), respectively, and $P$ :

$$
\begin{aligned}
\left.\Upsilon_{K}\right|_{\text {P fixed }} & \left.\equiv \frac{\partial \dot{K}}{\partial K}\right|_{\text {P fixed }}=\left(\frac{Y_{K}^{N}}{\mu}-\frac{Y^{N}}{\mu} \frac{\mu_{N}}{\mu} N_{K}\right) \frac{1}{P_{J}^{\prime}}-\delta_{K}>0 \\
\Upsilon_{P} & \equiv \frac{\partial \dot{K}}{\partial P}=\left[\left(\frac{Y_{P}^{N}}{\mu}-\frac{Y^{N}}{\mu} \frac{\mu_{N}}{\mu} N_{P}-C_{P}^{N}\right)+\frac{\tilde{I}^{N} \phi_{J}\left(1-\alpha_{J}\right)}{\tilde{P}}\right] \frac{1}{P_{J}^{\prime}}>0 \\
\left.\Upsilon_{Q}\right|_{\text {P fixed }} & \left.\equiv \frac{\partial \dot{K}}{\partial Q}\right|_{\text {P fixed }}=0
\end{aligned}
$$

where we used the fact that in the long-run, $\tilde{J}^{N}=\tilde{I}^{N}$ and $\tilde{Q}=P_{J}(\tilde{P})$.

Remembering that $J^{T}=\left(1-\alpha_{J}\right) P_{J} J$, the current account equation is given by:

$$
\begin{aligned}
\dot{B} \equiv \Xi(B, K, Q, G) & =r^{\star} B+Y^{T}-C^{T}-G^{T}-\left(1-\alpha_{J}\right) P_{J} J \\
& =r^{\star} B+Y^{T}-C^{T}-G^{T}-\left(\frac{1-\alpha_{J}}{\alpha_{J}}\right) P\left(\frac{Y^{N}}{\mu}-C^{N}-G^{N}\right)
\end{aligned}
$$

where we used the fact that $P_{J}^{\prime} J=Y^{N}-C^{N}-G^{N}$. As will be useful, let us denote by $\Xi_{K}$ and $\Xi_{P}$ the partial derivatives of the accumulation equation for traded bonds w.r.t. $K$ (for given $P$ ) and $P$ :

$$
\begin{aligned}
\left.\Xi_{K}\right|_{\mathrm{P} \text { fixed }} \equiv & \left.\frac{\partial \dot{B}}{\partial K}\right|_{\mathrm{P} \text { fixed }}=Y_{K}^{T}-\left(\frac{1-\alpha_{J}}{\alpha_{J}}\right) \tilde{P}\left(\frac{Y_{K}^{N}}{\mu}-\frac{Y^{N}}{\mu} \frac{\mu_{N}}{\mu} N_{K}\right) \geq 0, \\
\Xi_{P} \equiv & \frac{\partial \dot{B}}{\partial P}=\left(Y_{P}^{T}-C_{P}^{T}\right)-\left(\frac{1-\alpha_{J}}{\alpha_{J}}\right) \tilde{P}\left(\frac{Y_{P}^{N}}{\mu}-\frac{Y^{N}}{\mu} \frac{\mu_{N}}{\mu} N_{P}-C_{P}^{N}\right) \\
& -\phi_{J}\left(\frac{1-\alpha_{J}}{\alpha_{J}}\right) \tilde{I}^{N}<0,
\end{aligned}
$$

where we used the fact that $\frac{\partial\left(\frac{1-\alpha_{J}}{\alpha_{J}}\right)}{\partial P}=-\frac{1}{P}\left[\left(\frac{1-\alpha_{J}}{\alpha_{J}}\right)-\phi_{J}\left(\frac{1-\alpha_{J}}{\alpha_{J}}\right)\right]$ and at the steady-state, we have $\tilde{J}^{N}=\tilde{I}^{N}$ since capital installation costs are absent in the long run. The steps for the derivation of solutions for a temporary government shock are identical to those detailed in section G.3.

\section{O Semi-Small Open Economy Model}

This section puts forward an open economy version of the neoclassical model with tradables and non tradables, imperfect mobility of labor across sectors, capital adjustment costs and endogenous terms of trade. This section illustrates in detail the steps we follow in solving 
this model. Households supply labor, $L$, and must decide on the allocation of total hours worked between the traded sector, $L^{H}$, and the non traded sector, $L^{N}$. They consume both traded, $C^{T}$, and non traded goods, $C^{N}$. Traded goods are a composite of home traded goods, $C^{H}$, and foreign imported goods, $C^{F}$. Households also choose investment which is produced using inputs of the traded, $J^{T}$, and the non traded good, $J^{N}$. As for consumption, input of the traded good is a composite of home traded goods, $J^{H}$, and foreign imported goods, $J^{F}$. The numeraire is the foreign good whose price, $P^{F}$, is thus normalized to one.

\section{O.1 Households}

At each instant of time, the representative household consumes traded and non traded goods denoted by $C^{T}$ and $C^{N}$, respectively, which are aggregated by means of a CES function:

$$
C=\left[\varphi^{\frac{1}{\phi}}\left(C^{T}\right)^{\frac{\phi-1}{\phi}}+(1-\varphi)^{\frac{1}{\phi}}\left(C^{N}\right)^{\frac{\phi-1}{\phi}}\right]^{\frac{\phi}{\phi-1}},
$$

where $0<\varphi<1$ is the weight of the traded good in the overall consumption bundle and $\phi$ corresponds to the elasticity of substitution between traded goods and non traded goods. The index $C^{T}$ is defined as a CES aggregator of home-produced traded goods, $C^{H}$, and foreign produced traded goods, $C^{F}$ :

$$
C^{T}=\left[\left(\varphi^{H}\right)^{\frac{1}{\rho}}\left(C^{H}\right)^{\frac{\rho-1}{\rho}}+\left(1-\varphi_{H}\right)^{\frac{1}{\rho}}\left(C^{F}\right)^{\frac{\rho-1}{\rho}}\right]^{\frac{\rho}{\rho-1}},
$$

where $0<\varphi_{H}<1$ is the weight of the home-produced traded good in the overall consumption bundle and $\rho$ corresponds to the elasticity of substitution between home-produced traded goods goods and foreign produced traded goods.

As in De Cordoba and Kehoe [2000], the investment good is produced using inputs of the traded good and the non traded good according to a constant-returns-to-scale function which is assumed to take a CES form:

$$
J \equiv J\left(J^{T}, J^{N}\right)=\left[\iota^{\frac{1}{\phi_{J}}}\left(J^{T}\right)^{\frac{\phi_{J}-1}{\phi_{J}}}+(1-\iota)^{\frac{1}{\phi_{J}}}\left(J^{N}\right)^{\frac{\phi_{J}-1}{\phi_{J}}}\right]^{\frac{\phi_{J}}{\phi_{J}-1}},
$$

where $\iota$ is the weight of the investment traded input $(0<\iota<1)$ and $\phi_{J}$ corresponds to the intratemporal elasticity of substitution in investment between traded and non traded inputs. The index $J^{T}$ is defined as a CES aggregator of home-produced traded inputs, $J^{H}$, and foreign produced traded inputs, $J^{F}$ :

$$
J^{T}=\left[\left(\iota_{H}\right)^{\frac{1}{\rho_{J}}}\left(J^{H}\right)^{\frac{\rho_{J}-1}{\rho_{J}}}+\left(1-\iota_{H}\right)^{\frac{1}{\rho_{J}}}\left(J^{F}\right)^{\frac{\rho_{J}-1}{\rho_{J}}}\right]^{\frac{\rho_{J}}{\rho_{J}-1}},
$$

where $0<\iota_{H}<1$ is the weight of the home-produced traded good in the overall consumption bundle and $\rho_{J}$ corresponds to the elasticity of substitution between home-produced traded inputs and foreign-produced traded inputs.

Following Horvath [2000], we assume that hours worked in the traded and the non traded sectors are aggregated by means of a CES function:

$$
L=\left[\vartheta^{-1 / \epsilon}\left(L^{H}\right)^{\frac{\epsilon+1}{\epsilon}}+(1-\vartheta)^{-1 / \epsilon}\left(L^{N}\right)^{\frac{\epsilon+1}{\epsilon}}\right]^{\frac{\epsilon}{\epsilon+1}},
$$

where $0<\vartheta<1$ is the weight of labor supply to the traded sector in the labor index $L($.) and $\epsilon$ measures the ease with which hours worked can be substituted for each other and thereby captures the degree of labor mobility across sectors.

The representative household chooses consumption, decides on labor supply, and investment that maximizes his/her lifetime utility:

$$
U=\int_{0}^{\infty}\left\{\frac{1}{1-\frac{1}{\sigma_{C}}} C(t)^{1-\frac{1}{\sigma_{C}}}-\frac{1}{1+\frac{1}{\sigma_{L}}} L(t)^{1+\frac{1}{\sigma_{L}}}\right\} e^{-\beta t} \mathrm{~d} t
$$


subject to the flow budget constraint:

$$
\dot{B}(t)=r^{\star} B(t)+R(t) K(t)+W(t) L(t)-T(t)-P_{C}\left(P^{T}(t), P^{N}(t)\right) C(t)-P_{J}\left(P^{T}(t), P^{N}(t)\right) J(t),
$$

and capital accumulation which evolves as follows:

$$
\dot{K}(t)=I(t)-\delta_{K} K(t)
$$

where $I$ is investment and $0 \leq \delta_{K}<1$ is a fixed depreciation rate. The first term on the RHS of $(365) r^{\star} B(t)+R(t) K(t)+W(t) L(t)-T(t)$ is the representative household's real disposable income while the second term on the RHS, i.e., $P_{C}\left(P^{T}(t), P^{N}(t)\right) C(t)+$ $P_{J}\left(P_{J}^{T}(t), P^{N}(t)\right) J(t)$, corresponds to consumption and investment expenditure including capital installation costs. More specifically, we assume that capital accumulation is subject to increasing and convex cost of net investment, $I(t)-\delta_{K} K(t)$ :

$$
J(t)=I(t)+\Psi(I(t), K(t)) K(t),
$$

where $\Psi$ (.) is increasing (i.e., $\Psi^{\prime}()>$.0 ), convex (i.e., $\Psi^{\prime \prime}()>$.0 ), is equal to zero at $\delta_{K}$ (i.e., $\Psi\left(\delta_{K}\right)=0$ ), and has first partial derivative equal to zero as well at $\delta_{K}$ (i.e., $\Psi^{\prime}\left(\delta_{K}\right)=0$ ). We suppose the following functional form for the adjustment cost function:

$$
\Psi(I(t), K(t))=\frac{\kappa}{2}\left(\frac{I(t)}{K(t)}-\delta_{K}\right)^{2} .
$$

Using (368), partial derivatives of total investment expenditure are:

$$
\begin{aligned}
\frac{\partial J(t)}{\partial I(t)} & =1+\kappa\left(\frac{I(t)}{K(t)}-\delta_{K}\right) \\
\frac{\partial J(t)}{\partial K(t)} & =-\frac{\kappa}{2}\left(\frac{I(t)}{K(t)}-\delta_{K}\right)\left(\frac{I(t)}{K(t)}+\delta_{K}\right) .
\end{aligned}
$$

Denoting the co-state variables associated with (365) and (366) by $\lambda$ and $Q^{\prime}$, respectively, the first-order conditions characterizing the representative household's optimal plans are:

$$
\begin{gathered}
C(t)=\left(P_{C}(t) \lambda\right)^{-\sigma_{C}}, \\
L(t)=(W(t) \lambda)^{\sigma_{L}}, \\
Q(t)=P_{J}(t)\left[1+\kappa\left(\frac{I(t)}{K(t)}-\delta_{K}\right)\right], \\
\dot{\lambda}(t)=\lambda\left(\beta-r^{\star}\right), \\
\dot{Q}(t)=\left(r^{\star}+\delta_{K}\right) Q(t)-\left\{R(t)+P_{J}(t) \frac{\kappa}{2}\left(\frac{I(t)}{K(t)}-\delta_{K}\right)\left(\frac{I(t)}{K(t)}+\delta_{K}\right)\right\},
\end{gathered}
$$

and the transversality conditions $\lim _{t \rightarrow \infty} \bar{\lambda} B(t) e^{-\beta t}=0$ and $\lim _{t \rightarrow \infty} Q(t) K(t) e^{-\beta t}=0$; to derive (370c) and (370e), we used the fact that $Q(t)=Q^{\prime}(t) / \lambda(t)$.

Given the above consumption indices, we can derive appropriate price indices. With respect to the general consumption index, we obtain the consumption-based price index $P_{C}$ :

$$
P_{C}=\left[\varphi\left(P^{T}\right)^{1-\phi}+(1-\varphi)\left(P^{N}\right)^{1-\phi}\right]^{\frac{1}{1-\phi}},
$$

where the price index for traded goods is:

$$
P^{T}=\left[\varphi_{H}\left(P^{H}\right)^{1-\rho}+\left(1-\varphi_{H}\right)\right]^{\frac{1}{1-\rho}} .
$$

Given the consumption-based price index (371), the representative household has the following demand of traded and non traded goods:

$$
\begin{gathered}
C^{T}=\varphi\left(\frac{P^{T}}{P_{C}}\right)^{-\phi} C, \\
C^{N}=(1-\varphi)\left(\frac{P^{N}}{P_{C}}\right)^{-\phi} C .
\end{gathered}
$$


Given the price indices (371) and (372), the representative household has the following demand of home-produced traded goods and foreign-produced traded goods:

$$
\begin{gathered}
C^{H}=\varphi\left(\frac{P^{T}}{P_{C}}\right)^{-\phi} \varphi_{H}\left(\frac{P^{H}}{P^{T}}\right)^{-\rho} C, \\
C^{F}=\varphi\left(\frac{P^{T}}{P_{C}}\right)^{-\phi}\left(1-\varphi_{H}\right)\left(\frac{1}{P_{T}}\right)^{-\rho} C .
\end{gathered}
$$

As will be useful later, the percentage change in the consumption price index is a weighted average of percentage changes in the price of traded and non traded goods in terms of foreign goods:

$$
\begin{gathered}
\hat{P}_{C}=\left(1-\alpha_{C}\right) \hat{P}^{T}+\alpha_{C} \hat{P}^{N}, \\
\hat{P}^{T}=\alpha^{H} \hat{P}^{H},
\end{gathered}
$$

where $\alpha_{C}$ is the non tradable content of overall consumption expenditure and $\alpha^{H}$ is the home-produced goods content of consumption expenditure on traded goods:

$$
\begin{gathered}
1-\alpha_{C}=\varphi\left(\frac{P^{T}}{P_{C}}\right)^{1-\phi}, \\
\alpha_{C}=(1-\varphi)\left(\frac{P^{N}}{P_{C}}\right)^{1-\phi}, \\
\alpha^{H}=\varphi_{H}\left(\frac{P^{H}}{P^{T}}\right)^{1-\rho}, \\
1-\alpha^{H}=\left(1-\varphi_{H}\right)\left(\frac{1}{P^{T}}\right)^{1-\rho} .
\end{gathered}
$$

Given the CES aggregator functions above, we can derive the appropriate price indices for investment. With respect to the general investment index, we obtain the investmentbased price index $P_{J}$ :

$$
P_{J}=\left[\iota\left(P_{J}^{T}\right)^{1-\phi_{J}}+(1-\iota)\left(P^{N}\right)^{1-\phi_{J}}\right]^{\frac{1}{1-\phi_{J}}}
$$

where the price index for traded goods is:

$$
P_{J}^{T}=\left[\iota^{H}\left(P^{H}\right)^{1-\rho_{J}}+\left(1-\iota^{H}\right)\right]^{\frac{1}{1-\rho_{J}}} .
$$

Given the investment-based price index (377), we can derive the demand for inputs of the traded good and the non traded good:

$$
\begin{gathered}
J^{T}=\iota\left(\frac{P_{J}^{T}}{P_{J}}\right)^{-\phi_{J}} J, \\
J^{N}=(1-\iota)\left(\frac{P^{N}}{P_{J}}\right)^{-\phi_{J}} J .
\end{gathered}
$$

Given the price indices (377) and (378), we can derive the demand for inputs of homeproduced traded goods and foreign-produced traded goods:

$$
\begin{gathered}
J^{H}=\iota\left(\frac{P_{J}^{T}}{P_{J}}\right)^{-\phi_{J}} \iota^{H}\left(\frac{P^{H}}{P_{J}^{T}}\right)^{-\rho_{J}} J \\
J^{F}=\iota\left(\frac{P_{J}^{T}}{P_{J}}\right)^{-\phi_{J}}\left(1-\iota^{H}\right)\left(\frac{1}{P_{J}^{T}}\right)^{-\rho_{J}} J .
\end{gathered}
$$

As will be useful later, the percentage change in the investment price index is a weighted average of percentage changes in the price of traded and non traded inputs in terms of foreign inputs:

$$
\begin{gathered}
\hat{P}_{J}=\left(1-\alpha_{J}\right) \hat{P}_{J}^{T}+\alpha_{J} \hat{P}^{N}, \\
\hat{P}_{J}^{T}=\alpha_{J}^{H} \hat{P}^{H},
\end{gathered}
$$


where $\alpha_{J}$ is the non tradable content of overall investment expenditure and $\alpha_{J}^{H}$ is the home-produced goods content of investment expenditure on traded goods:

$$
\begin{gathered}
1-\alpha_{J}=\iota\left(\frac{P_{J}^{T}}{P_{J}}\right)^{1-\phi_{J}}, \\
\alpha_{J}=(1-\iota)\left(\frac{P^{N}}{P_{J}}\right)^{1-\phi_{J}}, \\
\alpha_{J}^{H}=\iota^{H}\left(\frac{P^{H}}{P_{J}^{T}}\right)^{1-\rho_{J}}, \\
1-\alpha_{J}^{H}=\left(1-\iota^{H}\right)\left(\frac{1}{P_{J}^{T}}\right)^{1-\rho_{J}} .
\end{gathered}
$$

The aggregate wage index, $W(t)$, associated with the labor index defined above (363) is:

$$
W=\left[\vartheta\left(W^{H}\right)^{\epsilon+1}+(1-\vartheta)\left(W^{N}\right)^{\epsilon+1}\right]^{\frac{1}{\epsilon+1}},
$$

where $W^{H}$ and $W^{N}$ are wages paid in the traded and the non traded sectors, respectively.

Given the aggregate wage index, we can derive the allocation of aggregate labor supply to the traded and the non traded sector:

$$
\begin{gathered}
L^{H}=\vartheta\left(\frac{W^{H}}{W}\right)^{\epsilon} L, \\
L^{N}=(1-\vartheta)\left(\frac{W^{N}}{W}\right)^{\epsilon} L .
\end{gathered}
$$

As will be useful later, the percentage change in the aggregate wage index is a weighted average of percentage changes in sectoral wages:

$$
\hat{W}=\left(1-\alpha_{L}\right) \hat{W}^{H}+\alpha_{L} \hat{W}^{N},
$$

where $\alpha_{L}$ is the non tradable content of aggregate labor compensation:

$$
\begin{gathered}
1-\alpha_{L}=\vartheta\left(\frac{W^{H}}{W}\right)^{1+\epsilon}, \\
\alpha_{L}=(1-\vartheta)\left(\frac{W^{N}}{W}\right)^{1+\epsilon} .
\end{gathered}
$$

\section{O.2 Firms}

Both the home traded and non traded sectors use physical capital, $K^{j}$, and labor, $L^{j}$, according to constant returns to scale production functions $Y^{j}=Z^{j} F^{j}\left(K^{j}, L^{j}\right)$ which are assumed to take a Cobb-Douglas form:

$$
Y^{j}=Z^{j}\left(L^{j}\right)^{\theta^{j}}\left(K^{j}\right)^{1-\theta^{j}}, \quad j=H, N
$$

where $\theta^{j}$ is the labor income share in sector $j$ and $Z^{j}$ corresponds to the total factor productivity index which is introduced for calibration purposes. Both sectors face two cost components: a capital rental cost equal to $R$, and a labor cost equal to the wage rate, i.e., $W^{H}$ in the traded sector and $W^{N}$ in the non traded sector.

Both sectors are assumed to be perfectly competitive and thus choose capital and labor by taking prices as given:

$$
\max _{K^{j}, L^{j}} \Pi^{j}=\max _{K^{j}, L^{j}}\left\{P^{j} Y^{j}-W^{j} L^{j}-R K^{j}\right\} .
$$

Since capital can move freely between the two sectors, the value of marginal products in the traded and non traded sectors equalizes while costly labor mobility implies a wage 
differential across sectors:

$$
\begin{gathered}
P^{H} Z^{H}\left(1-\theta^{H}\right)\left(k^{H}\right)^{-\theta^{H}}=P^{N} Z^{N}\left(1-\theta^{N}\right)\left(k^{N}\right)^{-\theta^{N}} \equiv R, \\
P^{H} Z^{H} \theta^{H}\left(k^{H}\right)^{1-\theta^{H}} \equiv W^{H}, \\
P^{N} Z^{N} \theta^{N}\left(k^{N}\right)^{1-\theta^{N}} \equiv W^{N},
\end{gathered}
$$

where $k^{j} \equiv K^{j} / L^{j}$ denotes the capital-labor ratio for sector $j=H, N$.

The resource constraint for capital is:

$$
K^{H}+K^{N}=K \text {. }
$$

\section{O.3 Short-Run Solutions}

\section{Consumption and Labor}

Before linearizing, we have to determine short-run solutions. First-order conditions (370a) and (370b) can be solved for consumption and aggregate labor supply which of course must hold at any point of time:

$$
C=C\left(\bar{\lambda}, P^{N}, P^{H}\right), \quad L=L\left(\bar{\lambda}, W^{H}, W^{N}\right),
$$

with partial derivatives given by

$$
\begin{gathered}
\hat{C}=-\sigma_{C} \hat{\bar{\lambda}}-\sigma_{C}\left(1-\alpha_{C}\right) \alpha^{H} \hat{P}^{H}-\sigma_{C} \alpha_{C} \hat{P}^{N}, \\
\hat{L}=\sigma_{L} \hat{\bar{\lambda}}+\sigma_{L} \alpha_{L} \hat{W}^{N}+\sigma_{L}\left(1-\alpha_{L}\right) \hat{W}^{H},
\end{gathered}
$$

where we used (385) and (375).

Inserting first the solution for consumption (391) into (373a)-(374b) allows us to solve for $C^{N}, C^{H}$, and $C^{F}$ :

$$
C^{N}=C^{N}\left(\bar{\lambda}, P^{N}, P^{H}\right), \quad C^{H}=C^{H}\left(\bar{\lambda}, P^{N}, P^{H}\right), \quad C^{F}=C^{F}\left(\bar{\lambda}, P^{N}, P^{H}\right),
$$

with partial derivatives given by

$$
\begin{aligned}
\hat{C}^{N} & =-\phi \hat{P}^{N}+\left(\phi-\sigma_{C}\right) \hat{P}_{C}-\sigma_{C} \hat{\bar{\lambda}} \\
& =-\left[\left(1-\alpha_{C}\right) \phi+\alpha_{C} \sigma_{C}\right] \hat{P}^{N}+\left(\phi-\sigma_{C}\right)\left(1-\alpha_{C}\right) \alpha^{H} \hat{P}^{H}-\sigma_{C} \hat{\bar{\lambda}} \\
\hat{C}^{H} & =-\left[\rho\left(1-\alpha^{H}\right)+\phi \alpha_{C} \alpha^{H}+\sigma_{C}\left(1-\alpha_{C}\right) \alpha^{H}\right] \hat{P}^{H}+\alpha_{C}\left(\phi-\sigma_{C}\right) \hat{P}^{N}-\sigma_{C} \hat{\bar{\lambda}},(39) \\
\hat{C}^{F} & =\alpha^{H}\left[\rho-\phi \alpha_{C}-\sigma_{C}\left(1-\alpha_{C}\right)\right] \hat{P}^{H}+\alpha_{C}\left(\phi-\sigma_{C}\right) \hat{P}^{N}-\sigma_{C} \hat{\bar{\lambda}}
\end{aligned}
$$

Inserting first the solution for labor (391) into (384a)-(385) allows us to solve for $L^{H}$ and $L^{N}$ :

$$
L^{H}=L^{H}\left(\bar{\lambda}, W^{H}, W^{N}\right), \quad L^{N}=L^{N}\left(\bar{\lambda}, W^{H}, W^{N}\right),
$$

with partial derivatives given by:

$$
\begin{gathered}
\hat{L}^{H}=\left[\epsilon \alpha_{L}+\sigma_{L}\left(1-\alpha_{L}\right)\right] \hat{W}^{H}-\alpha_{L}\left(\epsilon-\sigma_{L}\right) \hat{W}^{N}+\sigma_{L} \hat{\bar{\lambda}}, \\
\hat{L}^{N}=\left[\epsilon\left(1-\alpha_{L}\right)+\sigma_{L} \alpha_{L}\right] \hat{W}^{N}-\left(1-\alpha_{L}\right)\left(\epsilon-\sigma_{L}\right) \hat{W}^{H}+\sigma_{L} \hat{\bar{\lambda}} .
\end{gathered}
$$

\section{Sectoral Wages and Capital-Labor Ratios}

Plugging the short-run solutions for $L^{H}$ and $L^{N}$ given by (395) into the resource constraint for capital (390), the system of four equations consisting of (389a)-(389c) together with (390) can be solved for sectoral wages $W^{j}$ and sectoral capital-labor ratios $k^{j}$. Denoting by $\xi^{N} \equiv K^{N} / K$ the share of non traded capital in the aggregate stock of physical capital and log-differentiating (389a)-(389c) together with (390) yields in matrix form:

$$
\begin{aligned}
& \left(\begin{array}{cccc}
-\theta^{H} & \theta^{N} & 0 & 0 \\
\left(1-\theta^{H}\right) & 0 & -1 & 0 \\
0 & \left(1-\theta^{N}\right) & 0 & -1 \\
\left(1-\xi^{N}\right) & \xi^{N} & \Psi_{W^{H}} & \Psi_{W^{N}}
\end{array}\right)\left(\begin{array}{c}
\hat{k}^{H} \\
\hat{k}^{N} \\
\hat{W}^{H} \\
\hat{W}^{N}
\end{array}\right) \\
= & \left(\begin{array}{c}
\hat{P}^{N}-\hat{P}^{H} \\
-\hat{P}^{H} \\
-\hat{P}^{N} \\
\hat{K}-\Psi_{\bar{\lambda}} \hat{\bar{\lambda}}
\end{array}\right),
\end{aligned}
$$


where we set:

$$
\begin{aligned}
\Psi_{W^{j}} & =\left(1-\xi^{N}\right) \frac{L_{W^{j}}^{H} W^{j}}{L^{H}}+\xi^{N} \frac{L_{W^{j}}^{N} W^{j}}{L^{N}} \\
\xi^{N} & \equiv \frac{k^{N} L^{N}}{K} \\
\Psi_{\bar{\lambda}} & =\left(1-\xi^{N}\right) \sigma_{L}+\xi^{N} \sigma_{L}=\sigma_{L} .
\end{aligned}
$$

The short-run solutions for sectoral wages and capital-labor ratios are:

$$
W^{j}=W^{j}\left(\bar{\lambda}, K, P^{N}, P^{H}\right), \quad k^{j}=k^{j}\left(\bar{\lambda}, K, P^{N}, P^{H}\right) .
$$

Inserting first sectoral wages (399), sectoral employment (395) can be solved as functions of the shadow value of wealth, the capital stock, the price of non traded goods in terms of foreign goods, $P^{N}$, and the terms of trade:

$$
L^{j}=L^{j}\left(\bar{\lambda}, K, P^{N}, P^{H}\right)
$$

Finally, plugging solutions for sectoral labor (400) and sector capital-labor ratios (399), the production functions (387) can be solved for sectoral output:

$$
Y^{j}=Y^{j}\left(\bar{\lambda}, K, P^{N}, P^{H}\right)
$$

where

$$
\hat{Y}^{j}=\sum_{X} \frac{\partial L^{j}}{\partial X} \frac{X}{L^{j}}+\left(1-\theta^{j}\right) \frac{\partial k^{j}}{\partial X} \frac{X}{k^{j}},
$$

where $X=\bar{\lambda}, K, P^{N}, P^{H}$.

The Return on Domestic Capital, $R$

The return on domestic capital is:

$$
R=P^{H} Z^{H}\left(1-\theta^{H}\right)\left(k^{H}\right)^{-\theta^{H}} .
$$

Inserting first the short-run static solution for the capital-labor ratio $k^{H}$ given by (399), eq. (403) can be solved for the return on domestic capital:

$$
R=R\left(\bar{\lambda}, K, P^{N}, P^{H}\right),
$$

where partial derivatives are

$$
\hat{R}=\sum_{X} \frac{\partial k^{H}}{\partial X} \frac{X}{k^{H}},
$$

where $X=\bar{\lambda}, K, P^{N}, P^{H}$.

Optimal Investment Decision, $I / K$

Eq. (370c) can be solved for the investment rate:

$$
\frac{I}{K}=v\left(\frac{Q}{P_{I}\left(P^{T}, P^{N}\right)}\right)+\delta_{K}
$$

where

$$
v(.)=\frac{1}{\kappa}\left(\frac{Q}{P_{J}}-1\right)
$$

with

$$
\begin{gathered}
v_{Q}=\frac{\partial v(.)}{\partial Q}=\frac{1}{\kappa} \frac{1}{P_{J}}>0 \\
v_{P^{H}}=\frac{\partial v(.)}{\partial P^{H}}=-\frac{1}{\kappa} \frac{Q}{P_{J}} \frac{\left(1-\alpha_{J}\right) \alpha_{J}^{H}}{P^{H}}<0 \\
v_{P^{N}}=\frac{\partial v(.)}{\partial P^{N}}=-\frac{1}{\kappa} \frac{Q}{P_{J}} \frac{\alpha_{J}}{P^{N}}<0
\end{gathered}
$$


Inserting (406) into (367), investment including capital installation costs can be rewritten as follows:

$$
\begin{aligned}
J & =K\left[\frac{I}{K}+\frac{\kappa}{2}\left(\frac{I}{K}-\delta_{K}\right)^{2}\right], \\
& =K\left[v(.)+\delta_{K}+\frac{\kappa}{2}(v(.))^{2}\right] .
\end{aligned}
$$

Eq. (409) can be solved for investment including capital installation costs:

$$
J=J\left(K, Q, P^{N}, P^{H}\right),
$$

where

$$
\begin{gathered}
J_{K}=\frac{\partial J}{\partial K}=\frac{J}{K}, \\
J_{X}=\frac{\partial J}{\partial X}=\kappa v_{X}(1+\kappa v(.))>0,
\end{gathered}
$$

with $X=Q, P^{H}, P^{N}$.

Substituting (411) into (379b), (380a), and (380b) allows us to solve for the demand of non traded, home-produced traded, and foreign inputs:

$$
J^{N}=J^{N}\left(K, Q, P^{N}, P^{H}\right), \quad J^{H}=J^{H}\left(K, Q, P^{N}, P^{H}\right), \quad J^{F}=J^{F}\left(K, Q, P^{N}, P^{H}\right),
$$

with partial derivatives given by

$$
\begin{aligned}
\hat{J}^{N} & =-\left(1-\alpha_{J}\right) \phi_{J} \hat{P}^{N}+\phi_{J}\left(1-\alpha_{J}\right) \alpha_{J}^{H} \hat{P}^{H}+\hat{J}, \\
& =\frac{Q}{P_{J}} \frac{(1+\kappa v(.))}{J} \hat{Q}-\left[\left(1-\alpha_{J}\right) \phi_{J}+\frac{Q}{P_{J}} \frac{(1+\kappa v(.))}{J} \alpha_{J}\right] \hat{P}^{N} \\
& +\left(1-\alpha_{J}\right) \alpha_{J}^{H}\left[\phi_{J}-\frac{Q}{P_{J}} \frac{(1+\kappa v(.))}{J}\right] \hat{P}^{H}+\hat{K}, \\
\hat{J}^{H} & =-\left[\rho_{J}\left(1-\alpha_{J}^{H}\right)+\alpha_{J}^{H} \phi_{J} \alpha_{J}\right] \hat{P}^{H}+\phi_{J} \alpha_{J} \hat{P}^{N}+\hat{J}, \\
& =-\left\{\left[\rho_{J}\left(1-\alpha_{J}^{H}\right)+\alpha_{J}^{H} \phi_{J} \alpha_{J}\right]+\left(1-\alpha_{J}\right) \alpha_{J}^{H} \frac{Q}{P_{J}} \frac{(1+\kappa v(.))}{J}\right\} \hat{P}^{H} \\
& +\alpha_{J}\left[\phi_{J}-\frac{Q}{P_{J}} \frac{(1+\kappa v(.))}{J}\right] \hat{P}^{N}+\frac{Q}{P_{J}} \frac{(1+\kappa v(.))}{J} \hat{Q}+\hat{K}, \\
\hat{J}^{F} & =\alpha_{J}^{H}\left(\rho_{J}-\phi_{J} \alpha_{J}\right) \hat{P}^{H}+\phi_{J} \alpha_{J} \hat{P}^{N}+\hat{J}, \\
& =\alpha_{J}^{H}\left\{\left(\rho_{J}-\phi_{J} \alpha_{J}\right)-\left(1-\alpha_{J}\right) \frac{Q}{P_{J}} \frac{(1+\kappa v(.))}{J}\right\} \hat{P}^{H} \\
& +\alpha_{J}\left[\phi_{J}-\frac{Q}{P_{J}} \frac{(1+\kappa v(.))}{J}\right] \hat{P}^{N}+\frac{Q}{P_{J}} \frac{(1+\kappa v(.))}{J} \hat{Q}+\hat{K},
\end{aligned}
$$

where use has been made of (411), i.e.,

$$
\begin{aligned}
\hat{J}= & \hat{K}+\frac{Q}{P_{J}} \frac{(1+\kappa v(.))}{J} \hat{Q}-\frac{Q}{P_{J}} \frac{(1+\kappa v(.))}{J} \alpha_{J} \hat{P}^{N} \\
& -\left(1-\alpha_{J}\right) \alpha_{J}^{H} \frac{Q}{P_{J}} \frac{(1+\kappa v(.))}{J} \hat{P}^{H} .
\end{aligned}
$$

\section{O.4 Market Clearing Conditions}

Finally, we have to solve for the relative price of non traded goods and the terms of trade.

\section{Market Clearing Condition for Non Tradables}

The role of the price of non tradables in terms of foreign goods is to clear the non traded goods market:

$$
Y^{N}=C^{N}+G^{N}+J^{N}
$$


Inserting solutions for $C^{N}, J^{N}, Y^{N}$ given by (393), (410), (401), respectively, the non traded goods market clearing condition (414) can be rewritten as follows:

$$
Y^{N}\left(\bar{\lambda}, K, P^{N}, P^{H}\right)=C^{N}\left(\bar{\lambda}, P^{N}, P^{H}\right)+G^{N}+J^{N}
$$

Eq. (415) can be solved for the relative price of non tradables:

$$
P^{N}=\Psi^{N}\left(K, Q, P^{H}, G^{N}, \bar{\lambda}\right),
$$

with partial derivatives given by:

$$
\begin{aligned}
\Psi_{K}^{N} & =\frac{\partial \Psi^{N}}{\partial K}=-\frac{\left(Y_{K}^{N}-J_{K}^{N}\right)}{\Delta^{N}}<0, \\
\Psi_{Q}^{N} & =\frac{\partial \Psi^{N}}{\partial Q}=\frac{J_{Q}^{N}}{\Delta^{N}}>0, \\
\Psi_{P^{H}}^{N} & =\frac{\partial \Psi^{N}}{\partial P^{H}}=-\frac{\left(Y_{P^{H}}^{N}-C_{P^{H}}^{N}-J_{P^{H}}^{N}\right)}{\Delta^{N}}>0, \\
\Psi_{G^{N}}^{N} & =\frac{\partial \Psi^{N}}{\partial G^{N}}=\frac{1}{\Delta^{N}}>0,
\end{aligned}
$$

where we set

$$
\Delta^{N}=\left(Y_{P^{N}}^{N}-C_{P^{N}}^{N}-J_{P^{N}}^{N}\right)>0 .
$$

\section{Market Clearing Condition for Home-Produced Traded Goods}

The role of the price of home-produced goods in terms of foreign-produced goods or the terms of trade is to clear the home-produced traded goods market:

$$
Y^{H}=C^{H}+G^{H}+J^{H}+X^{H},
$$

where $X^{H}$ stands for exports which are negatively related to the terms of trade:

$$
X^{H}=\varphi_{X}\left(P^{H}\right)^{-\phi_{X}},
$$

where $\phi_{X}$ is the elasticity of exports with respect to the terms of trade.

Inserting solutions for $C^{H}, J^{H}, Y^{H}$ given by (393), (410), (401), respectively, the traded goods market clearing condition (419) can be rewritten as follows:

$$
Y^{H}\left(\bar{\lambda}, K, P^{N}, P^{H}\right)=C^{H}\left(\bar{\lambda}, P^{N}, P^{H}\right)+G^{H}+J^{H}+X^{H}\left(P^{H}\right) .
$$

Eq. (421) can be solved for the terms of trade:

$$
P^{H}=\Psi^{H}\left(K, Q, P^{N}, G^{H}, \bar{\lambda}\right),
$$

with partial derivatives given by:

$$
\begin{aligned}
\Psi_{K}^{H} & =\frac{\partial \Psi^{H}}{\partial K}=-\frac{\left(Y_{K}^{H}-J_{K}^{H}\right)}{\Delta^{H}}<0, \\
\Psi_{Q}^{H} & =\frac{\partial \Psi^{H}}{\partial Q}=\frac{J_{Q}^{H}}{\Delta^{H}}>0, \\
\Psi_{P^{N}}^{H} & =\frac{\partial \Psi^{H}}{\partial P^{N}}=-\frac{\left(Y_{P^{N}}^{H}-C_{P^{N}}^{H}-J_{P^{N}}^{H}\right)}{\Psi^{N}}>0, \\
\Psi_{G^{H}}^{H} & =\frac{\partial \Psi^{H}}{\partial G^{H}}=\frac{1}{\Delta^{H}}>0,
\end{aligned}
$$

where we set

$$
\Delta^{H}=\left(Y_{P^{H}}^{H}-C_{P^{H}}^{H}-J_{P^{H}}^{H}-X_{P^{H}}^{H}\right)>0,
$$

where $X_{P^{H}}^{H}=\frac{\partial X^{H}}{\partial P^{H}}<0$. 


\section{O.5 Solving the Model}

In our model, there is one state variable, namely $K$, and one control variable, $Q$. To solve the model, we have to express all variables in terms of state and control variables. Plugging first eq. (422) into (416) allows us to solve for the relative price of non tradables:

$$
P^{N}=P^{N}\left(K, Q, G^{H}, G^{N}, \bar{\lambda}\right),
$$

where partial derivatives (with respect to $X=K, Q, Z^{H}, Z^{N}$ ) are given by

$$
P_{X}^{N}=\frac{\partial P^{N}}{\partial X}=\frac{\Psi_{X}^{N}+\Psi_{P^{H}}^{N} \Psi_{X}^{H}}{\Delta^{N}+\Psi_{P^{H}}^{N} \Psi_{P^{N}}^{H}}
$$

with $P_{K}^{N}<0, P_{Q}^{N}>0, P_{G^{H}}^{N}>0, P_{G^{N}}^{N}>0$.

Plugging first eq. (425) into (422) allows us to solve for the terms of trade:

$$
P^{H}=P^{H}\left(K, Q, Z^{H}, Z^{N}, \bar{\lambda}\right),
$$

where partial derivatives (with respect to $X=K, Q, Z^{H}, Z^{N}$ ) are given by

$$
P_{X}^{H}=\frac{\partial P^{H}}{\partial X}=\Psi_{X}^{H}+\Psi_{P^{N}}^{H} P_{X}^{N}
$$

with $P_{K}^{H}<0, P_{Q}^{H}>0, P_{G^{H}}^{H}>0, P_{G^{N}}^{H}>0$.

Substituting solutions for the relative price of non tradables (425) and the terms of trade (427) into solutions for consumption (393), sectoral output (401), the return on domestic capital (404), and the optimal investment decision (406) yields:

$$
\begin{aligned}
C^{j} & =C^{j}\left(K, Q, G^{H}, G^{N}, \bar{\lambda}\right), \\
Y^{j} & =Y^{j}\left(K, Q, G^{H}, G^{N}, \bar{\lambda}\right), \\
R & =R\left(K, Q, G^{H}, G^{N}, \bar{\lambda}\right), \\
v & =v\left(K, Q, G^{H}, G^{N}, \bar{\lambda}\right) .
\end{aligned}
$$

To keep things simple, we assume $G^{F}=0$. Thus $G^{N}=\omega_{G^{N}} G$ and $G^{H}=\omega_{G^{T}} G$. Using the fact $G^{j}(G)$ with $\frac{\partial G^{N}}{\partial G}=\frac{\omega_{G N}}{P^{N}}>0$ and $\frac{\partial G^{H}}{\partial G}=\frac{\omega_{G T}}{P^{H}}>0$, we can express all variables in terms of government final consumption expenditure:

$$
D=D(K, Q, G, \bar{\lambda}),
$$

where $D=C^{j}, J^{j}, L^{j}, W^{j}, P^{j}, Y^{j}, k^{j}, R, v, P, X^{H}, M^{F}$ with $P=P^{N} / P^{H}$.

Remembering that the non traded input $J^{N}$ used to produce the capital good is equal to $(1-\iota)\left(\frac{P^{N}}{P_{J}}\right)^{-\phi_{J}} J$ (see eq. $\left.(379 \mathrm{~b})\right)$ with $J=I+\frac{\kappa}{2}\left(\frac{I}{K}-\delta_{K}\right)^{2} K$, using the fact that $J^{N}=Y^{N}-C^{N}-G^{N}$ and inserting $I=\dot{K}+\delta_{K}$, the capital accumulation equation reads as follows:

$$
\dot{K}=\frac{Y^{N}-C^{N}-G^{N}}{(1-\iota)\left(\frac{P^{N}}{P_{J}}\right)^{-\phi_{J}}}-\delta_{K} K-\frac{\kappa}{2}\left(\frac{I}{K}-\delta_{K}\right)^{2} K .
$$

Inserting short-run solutions for non traded output (429b) and for consumption in non tradables (430), substituting optimal investment decision (429d) into the physical capital accumulation equation (431), and plugging the short-run solution for the return on domestic capital (429c) into the dynamic equation for the shadow value of capital stock (370e), the dynamic system reads as follows: ${ }^{77}$

$$
\begin{aligned}
\dot{K} \equiv \Upsilon(K, Q, G)= & \frac{Y^{N}(K, Q, G)-C^{N}(K, Q, G)-G^{N}}{(1-\iota)\left\{\frac{P^{N}(.)}{P_{J}\left[P^{H}(.) P^{N}(.)\right]}\right\}^{-\phi_{J}}} \\
& -\delta_{K} K-\frac{K}{2 \kappa}\left\{\frac{Q}{P_{J}\left[P^{H}(.), P^{N}(.)\right]}-1\right\}^{2}, \\
\dot{Q} \equiv \Sigma(K, Q, G)= & \left(r^{\star}+\delta_{K}\right) Q-[R(K, Q, G) \\
+ & \left.P_{J}\left[P^{H}(.), P^{N}(.)\right] \frac{\kappa}{2} v(.)\left(v(.)+2 \delta_{K}\right)\right],
\end{aligned}
$$

\footnotetext{
${ }^{77}$ We omit the shadow value of wealth from short-run solutions for clarity purposes as $\lambda$ remains constant over time.
} 
where $P^{N}($.$) and P^{H}($.$) are given by (425) and (427).$

To facilitate the linearization, it is useful to break down the capital accumulation into two components:

$$
\hat{K}=J-\delta_{K} K-\frac{\kappa}{2}\left(\frac{I}{K}-\delta_{K}\right)^{2} K
$$

The first component is $J$. Using the fact that $J=\frac{J^{N}}{(1-\iota)\left(\frac{P^{N}}{P_{J}}\right)^{-\phi_{J}}}$ and log-linearizing gives:

$$
\hat{J}=\hat{J}^{N}+\phi_{J}\left(1-\alpha_{J}\right) \hat{P}^{N}-\phi_{J}\left(1-\alpha_{J}\right) \alpha_{J}^{H} \hat{P}^{H}
$$

where we used the fact that $\hat{P}_{J}=\left(1-\alpha_{J}\right) \alpha_{J}^{H} \hat{P}^{H}+\alpha_{J} \hat{P}^{N}$. Using (433) and the fact that $J^{N}=Y^{N}-C^{N}-G^{N}$, linearizing (433) in the neighborhood of the steady-state gives:

$$
\begin{aligned}
\dot{K} & =\frac{J}{J^{N}}\left[d Y^{N}(t)-d C^{N}(t)\right]+\phi_{J} \frac{J}{P^{N}}\left(1-\alpha_{J}\right) d P^{N}(t) \\
& -\phi_{J} \frac{J}{P^{H}}\left(1-\alpha_{J}\right) \alpha_{J}^{H} d P^{H}(t)-\delta_{K} d K(t),
\end{aligned}
$$

where $J=I=\delta_{K} K$ in the long-run.

As will be useful, let us denote by $\Upsilon_{K}, \Upsilon_{Q}$, and $\Upsilon_{G}$ the partial derivatives evaluated at the steady-state of the capital accumulation equation w.r.t. $K, Q$, and $G$, respectively. Using (429) and (435), these elements of the Jacobian matrix are given by:

$$
\begin{aligned}
& \Upsilon_{K} \equiv \frac{\partial \dot{K}}{\partial K}=\frac{J}{J^{N}}\left(Y_{K}^{N}-C_{K}^{N}\right)+\left(1-\alpha_{J}\right) \phi_{J} J\left(\frac{P_{K}^{N}}{P^{N}}-\alpha_{J}^{H} \frac{P_{K}^{H}}{P^{H}}\right)-\delta_{K} \gtrless 0, \\
& \Upsilon_{Q} \equiv \frac{\partial \dot{K}}{\partial Q}=\frac{J}{J^{N}}\left(Y_{Q}^{N}-C_{Q}^{N}\right)+\left(1-\alpha_{J}\right) \phi_{J} J\left(\frac{P_{Q}^{N}}{P^{N}}-\alpha_{J}^{H} \frac{P_{Q}^{H}}{P^{H}}\right)>0 \\
& \Upsilon_{G} \equiv \frac{\partial \dot{K}}{\partial G}=\frac{J}{J^{N}}\left(Y_{G}^{N}-C_{G}^{N}-G_{G}^{N}\right)+\left(1-\alpha_{J}\right) \phi_{J} J\left(\frac{P_{G}^{N}}{P^{N}}-\alpha_{J}^{H} \frac{P_{G}^{H}}{P^{H}}\right)
\end{aligned}
$$

where $J=\delta_{K} K$ in the long run.

Let us denote by $\Sigma_{K}, \Sigma_{Q}$, and $\Sigma_{G}$ the partial derivatives evaluated at the steady-state of the dynamic equation for the marginal value of an additional unit of capital w.r.t. $K$, $Q$, and $G$, respectively:

$$
\begin{aligned}
\Sigma_{K} & \equiv \frac{\partial \dot{Q}}{\partial K}=-R_{K}-P_{J} \kappa v_{K} \delta_{K}>0 \\
\Sigma_{Q} & \equiv \frac{\partial \dot{Q}}{\partial Q}=\left(r^{\star}+\delta_{K}\right)-P_{J} \kappa v_{Q} \delta_{K}=r^{\star}>0 \\
\Sigma_{G} & \equiv \frac{\partial \dot{Q}}{\partial G}=-R_{G}-P_{J} \kappa v_{G} \delta_{K} .
\end{aligned}
$$

Assuming that the saddle-path stability condition is fulfilled, and denoting the negative eigenvalue by $\nu_{1}$ and the positive eigenvalue by $\nu_{2}$, the general solutions for $K$ and $Q$ are:

$$
K(t)-\tilde{K}=D_{1} e^{\nu_{1} t}+D_{2} e^{\nu_{2} t}, \quad Q(t)-\tilde{Q}=\omega_{2}^{1} D_{1} e^{\nu_{1} t}+\omega_{2}^{2} D_{2} e^{\nu_{2} t},
$$

where $K_{0}$ is the initial capital stock and $\left(1, \omega_{2}^{i}\right)^{\prime}$ is the eigenvector associated with eigenvalue $\nu_{i}$ :

$$
\omega_{2}^{i}=\frac{\nu_{i}-\Upsilon_{K}}{\Upsilon_{Q}}
$$

Because $\nu_{1}<0, \Upsilon_{K}>0$ and $\Upsilon_{Q}>0$, we have $\omega_{2}^{1}<0$, regardless of sectoral capital intensities, which implies that the shadow value of investment and the stock physical capital move in opposite direction along a stable path (i.e., $D_{2}=0$ ). 


\section{O.6 Current Account Equation and Intertemporal Solvency Condition}

To determine the current account equation, we use the following identities and properties:

$$
\begin{gathered}
P_{C} C=P^{H} C^{H}+C^{F}+P^{N} C^{N}, \\
P_{J} J=P^{H} J^{H}+J^{F}+P^{N} J^{N}, \\
T=G=P^{H} G^{H}+G^{F}+P^{N} G^{N}, \\
W L+R K=\left(W^{H} L^{H}+R K^{H}\right)+\left(W^{N} L^{N}+R K^{N}\right)=P^{H} Y^{H}+P^{N} Y^{N},
\end{gathered}
$$

where (440d) follows from Euler theorem. Using (440d), inserting (440a)-(440c) into (365) and invoking market clearing conditions for non traded goods (414) and home-produced traded goods (419) yields:

$$
\begin{aligned}
\dot{B} & =r^{\star} B+P^{H}\left(Y^{H}-C^{H}-G^{H}-J^{H}\right)-\left(C^{F}+J^{F}+G^{F}\right), \\
& =r^{\star} B+P^{H} X^{H}-M^{F},
\end{aligned}
$$

where $X^{H}=Y^{H}-C^{H}-G^{H}-J^{H}$ stands for exports of home goods and we denote by $M^{F}$ imports of foreign consumption and investment goods:

$$
M^{F}=C^{F}+G^{F}+J^{F} .
$$

Substituting first solutions for $P^{N}$ and $P^{H}$ given by (425) and (427), respectively, into (412) and (420) allows us to express the demand for input of foreign-produced traded goods, $J^{F}$, and exports of home goods, $X^{H}$ :

$$
\begin{aligned}
J^{F} & =J^{F}(K, Q, G, \bar{\lambda}), \\
X^{H} & =X^{H}(K, Q, G, \bar{\lambda}) .
\end{aligned}
$$

Inserting (443a)-(443b) into(441) allows us to write the current account equation as follows:

$$
\begin{aligned}
\dot{B} & \equiv r^{\star} B+\Xi(K, Q, G), \\
& =r^{\star} B+P^{H}(K, Q, G) X^{H}(K, Q, G)-M^{F}(K, Q, G) .
\end{aligned}
$$

Let us denote by $\Xi_{K}, \Xi_{Q}$, and $\Xi_{G}$ the partial derivatives evaluated at the steady-state of the dynamic equation for the current account w.r.t. $K, Q$, and $G$, respectively:

$$
\begin{aligned}
\Xi_{K} & \equiv \frac{\partial \dot{B}}{\partial K}=\left(1-\phi_{X}\right) X^{H} P_{K}^{H}-M_{K}^{F} \\
\Xi_{Q} & \equiv \frac{\partial \dot{B}}{\partial Q}=\left(1-\phi_{X}\right) X^{H} P_{Q}^{H}-M_{Q}^{F} \\
\Xi_{G} & \equiv \frac{\partial \dot{B}}{\partial G}=\left(1-\phi_{X}\right) X^{H} P_{G}^{H}-M_{G}^{F}
\end{aligned}
$$

where we used the fact that $P^{H} X^{H}=\varphi_{X}\left(P^{H}\right)^{1-\phi_{X}}$ (see eq. (420)).

Linearizing (444) in the neighborhood of the steady-state, making use of (445a) and (445b), inserting solutions for $K(t)$ and $Q(t)$ given by (438) and solving yields the general solution for the net foreign asset position:

$$
B(t)=\tilde{B}+\left[\left(B_{0}-\tilde{B}\right)-\Psi_{1} D_{1}-\Psi_{2} D_{2}\right] e^{r^{\star} t}+\Psi_{1} D_{1} e^{\nu_{1} t}+\Psi_{2} D_{2} e^{\nu_{2} t},
$$

where $B_{0}$ is the initial stock of traded bonds and we set

$$
\begin{aligned}
N_{i} & =\Xi_{K}+\Xi_{Q} \omega_{2}^{i}, \\
\Psi_{i} & =\frac{N_{i}}{\nu_{i}-r^{\star}} .
\end{aligned}
$$

Invoking the transversality condition leads to the linearized version of the nations's intertemporal solvency condition:

$$
\tilde{B}-B_{0}=\Psi_{1}\left(\tilde{K}-K_{0}\right),
$$

where $K_{0}$ is the initial stock of physical capital. 


\section{O.7 Derivation of the Accumulation Equation of Non Human Wealth}

Remembering that the stock of financial wealth $A(t)$ is equal to $B(t)+Q(t) K(t)$, differentiating w.r.t. time, i.e., $\dot{A}(t)=\dot{B}(t)+\dot{Q}(t) K(t)+Q(t) \dot{K}(t)$, plugging the dynamic equation for the marginal value of capital (370e), inserting the accumulation equations for physical capital (366) and traded bonds (365), yields the accumulation equation for the stock of financial wealth or the dynamic equation for private savings:

$$
\dot{A}(t)=r^{\star} A(t)+W(t) L(t)-T(t)-P_{C}(t) C(t) .
$$

where we assume that the government levies lump-sum taxes, $T$, to finance purchases of foreign-produced, home-produced and non traded goods, i.e., $T=G=\left(G^{F}+P^{H}(.) G^{H}+P^{N}(.) G^{N}\right)$.

We first determine short-run solutions for aggregate labor supply and aggregate wage index. Inserting first short-run solutions for the relative price of non tradables (425) and the terms of trade (427) into (383) allows us to solve for sectoral wages, $W^{j}=W^{j}(K, Q, G, \bar{\lambda})$. Then inserting sectoral wages into (383) and (391) allows us to solve for aggregate wage, aggregate labor supply and consumption:

$$
\begin{aligned}
W & =W(K, Q, G, \bar{\lambda}), \\
L & =L(K, Q, G, \bar{\lambda}), \\
C & =C(K, Q, G, \bar{\lambda}) .
\end{aligned}
$$

Inserting (450a)-(450c) into (441) allows us to write the current account equation as follows:

$$
\begin{aligned}
\dot{A} & \equiv r^{\star} A+\Lambda(K, Q, G) \\
& =r^{\star} A+W(K, Q, G) L(K, Q, G)-G-P_{C}\left[P^{H}(.), P^{N}(.)\right] C(K, Q, G),
\end{aligned}
$$

where $P^{N}$ and $P^{H}$ are given by (425) and (427), respectively.

Let us denote by $\Lambda_{K}, \Lambda_{Q}$, and $\Lambda_{G}$ the partial derivatives evaluated at the steady-state of the dynamic equation for the non human wealth w.r.t. $K, Q$, and $G$, respectively:

$$
\begin{aligned}
\Lambda_{K} & \equiv \frac{\partial \dot{A}}{\partial K}=\left(W_{K} L+W L_{K}\right)-G_{K}-\left(\frac{\partial P_{C}}{\partial K} C+P_{C} C_{K}\right), \\
\Lambda_{Q} & \equiv \frac{\partial \dot{A}}{\partial Q}=\left(W_{Q} L+W L_{Q}\right)-G_{Q}-\left(\frac{\partial P_{C}}{\partial Q} C+P_{C} C_{Q}\right), \\
\Lambda_{G} & \equiv \frac{\partial \dot{A}}{\partial G}=\left(W_{G} L+W L_{G}\right)-1-\left(\frac{\partial P_{C}}{\partial G} C+P_{C} C_{G}\right) .
\end{aligned}
$$

Linearizing (451) in the neighborhood of the steady-state, making use of (452a) and (452b), inserting solutions for $K(t)$ and $Q(t)$ given by (438) and solving yields the general solution for the stock of non human wealth:

$$
A(t)=\tilde{A}+\left[\left(A_{0}-\tilde{A}\right)-\Delta_{1} D_{1}-\Delta_{2} D_{2}\right] e^{r^{\star} t}+\Delta_{1} D_{1} e^{\nu_{1} t}+\Delta_{2} D_{2} e^{\nu_{2} t},
$$

where $A_{0}$ is the initial stock of financial wealth and we set

$$
\begin{aligned}
M_{i} & =A_{K}+A_{Q} \omega_{2}^{i}, \\
\Delta_{i} & =\frac{M_{i}}{\nu_{i}-r^{\star}} .
\end{aligned}
$$

The linearized version of the representative household's intertemporal solvency condition is:

$$
\tilde{A}-A_{0}=\Delta_{1}\left(\tilde{K}-K_{0}\right)
$$

where $A_{0}$ is the initial stock of non human wealth. 


\section{O.8 The Steady-State}

Below, we characterize the whole steady-state and use tilde to denote long-run values. Setting $\dot{K}=\dot{Q}=\dot{B}=0$ into (366), (370e) and (441), and inserting short-run static solutions for $k^{N}, Y^{N}$ and $Y^{H}, C^{N}, J^{N}, C^{H}, J^{H}, M^{F}$ derived above, the steady-state can be summarized by five equations:

$$
\begin{gathered}
Z^{H}\left(1-\theta^{H}\right)\left[k^{H}\left(\tilde{K}, \tilde{P}^{H}, \tilde{P}^{N}, G, \bar{\lambda}\right)\right]^{-\theta^{H}}=P_{J}\left(\tilde{P}^{H}, \tilde{P}^{N}\right)\left(r^{\star}+\delta_{K}\right), \\
Y^{N}\left(\tilde{K}, \tilde{P}^{H}, \tilde{P}^{N}, G, \bar{\lambda}\right)=C^{N}\left(\tilde{P}^{H}, \tilde{P}^{N}, \bar{\lambda}\right)+\left(1-\alpha_{J}\right) P_{J}\left(\tilde{P}^{H}, \tilde{P}^{N}\right) \delta_{K} \tilde{K}+\omega_{G^{N}} G, \\
Y^{H}\left(\tilde{K}, \tilde{P}^{H}, \tilde{P}^{N}, G, \bar{\lambda}\right)=C^{H}(\tilde{K}, \tilde{Q}, G, \bar{\lambda})+\alpha_{J} \alpha_{J}^{H} P_{J}\left(\tilde{P}^{H}, \tilde{P}^{N}\right) \delta_{K} \tilde{K}+G^{H}+X^{H}\left(\tilde{P}^{H}\right), \\
r^{\star} \tilde{B}+\tilde{P}^{H} X^{H}\left(\tilde{P}^{H}\right)=M^{F}\left(\tilde{K}, \tilde{P}^{H}, \tilde{P}^{N}, \bar{\lambda}\right) \\
\tilde{B}-B_{0}=\Psi_{1}\left(\tilde{K}-K_{0}\right) .
\end{gathered}
$$

These five equations jointly determine $\tilde{P}^{N}, \tilde{P}^{H}, \tilde{K}, \tilde{B}$ and $\bar{\lambda}$.

To solve for temporary fiscal shocks, we follow the procedure detailed in subsection G.3. 


\section{References}

Artuç, Erhan, Shubham Chaudhuri, and John McLaren (2010) Trade Shocks and Labor Adjustment: A Structural Empirical Approach. American Economic Review, 100(3), pp. 1008-45.

Auerbach, Alan, and Yuriy Gorodnichenko (2012) Measuring the Output Responses to Fiscal Policy. American Economic Journal: Economic Policy, 4, 1-27

Auerbach, Alan, and Yuriy Gorodnichenko (2013) Output Spillovers from Fiscal Policy. American Economic Review Papers and Proceedings 103, 141-146.

Auerbach, Alan, and Yuriy Gorodnichenko (2013) Fiscal Multipliers in Recession and Expansion. In Fiscal Policy After the Financial Crisis, edited by Alberto Alesian and Francesco Giavazzi, pp. 63-98. University of Chicago Press.

Backus, David K, Patrick J, Kehoe, Finn E. Kydland (1994) Dynamics of the Trade Balance and the Terms of Trade: The J-Curve? American Economic Review, 84(1), pp. 84-103.

Barnichon, Regis, and Christian Matthes (2018) Understanding the Size of the Government Spending Multiplier: Itss in the Sign. Mimeo.

Beetsma, Roel and Massimo Giuliodori (2011) The Effects of Government Purchases Shocks: Review and Estimates for the EU. Economic Journal, 121(550), pp. 4-32.

Blanchard, Olivier J., and Roberto Perotti (2002) An Empirical Characterization of the Dynamic Effects of Changes in Government Spending and Taxes on Output. Quarterly Journal of Economcis 177, pp. 1329-1368.

Born, Benjamin, and Gernot Müller (2012) Government Spending Shocks in Quarterly and Annual Time Series. Journal of Money, Credit, and Banking 44(2), pp. 507-517.

Brinca, Pedro, Hans A. Holter, Per Krusell and Laurence Malafry (2016) Fiscal Multipliers in the 21st Century. Journal of Monetary Economics, 77, pp. 53-69.

Brückner, Markus, and Evi Pappa (2012) Fiscal Expansions, Unemployment, And Labor Force Participation: Theory And Evidence. International Economic Review, 53(4), pp. 1205-1228,

Burstein, Ariel T., João C. Neves and Sergio Rebelo (2004) Investment Prices and Exchange Rates: Some Basic Facts. Journal of the European Economic Association 2(2-3), pp. 302-309.

Canzoneri, Matthew, Fabrice Collard, Harris Dellas, and Behzad Diba (2016) Fiscal Multipliers in Recessions. Economic Journal 126 (590), pp. 75-108.

Cardi Olivier and Romain Restout (2015) Fiscal Shocks in a Two Sector Open Economy with Endogenous Markups. Macroeconomic Dynamics, vol. 19 (8), pp. 1839-1865.

Cardi, Olivier and Romain Restout (2014) Unanticipated vs. Anticipated Tax Reforms in a Two-Sector Open Economy. Open Economies Review, 25(2), pp. 373-406.

Cashin, Paul and John C. McDermott (2003) Intertemporal Substitution and Terms-of-Trade Shocks. Review of International Economics, 11(4), pp. 604-618.

Christiano, Lawrence, Martin Eichenbaum, and Sergio Rebelo When is the Government Spending Multiplier is Large? Journal of Political Economy, 119(1), pp. 78-121.

Corsetti, Giancarlo, André Meier, and Gernot Müller (2012) What Determines Government Spending Multipliers? Economic Policy, 72, pp. 523-564.

Corsetti, Giancarlo, André Meier, and Gernot J. Müller (2012) Fiscal Stimulus with Spending Reversals. The Review of Economics and Statistics, 94(4), pp. 878-895.

Cordoba (de), Gonzalo Fernandez and Timothy J. Kehoe (2000) Capital Flows and Real Exchange Rate Fluctuations Following Spain's Entry into the European Community. Journal of International Economics, 51(1), 49-78.

Dix-Carneiro, Rafael (2014) Trade Liberalization and Labor Market Dynamics. Econometrica, 82(3), pp. 825-885.

Engle Robert F., David F. Hendry and Jean-François Richard (1983) Exogeneity. Econometrica, 51, pp. 277-304.

Galí, Jordi, J. David López-Salido and J. Vallés (2007) Understanding the Effects of Government Spending on Consumption. Journal of the European Economic Association 5, pp. 227-270.

Granger Clive W.J. (1969) Investigating Causal Relations by Econometrics Models and CrossSpectral Methods. Econometrica, 37, pp. 424-438.

Guajardo, Jaime, Daniel Leigh, and Andrea Pescatori (2014) Expansionary Austerity? International Evidence. Journal of the European Economic Association, 12(4), pp. 949-968. 
Hadri, Kaddour (2000) Testing for Unit Roots in Heterogeneous Panel Data. Econometrics Journal, 3, pp. 148-161.

Ilzetzki, Ethan, Enrique G., Mendoza and Carlos A. Végh, (2013) How big (small?) are fiscal multipliers. Journal of Monetary Economics, 60(2), pp. 239-254.

Imbs, Jean, and Isabelle Mejean (2015) Elasticity Optimism. American Economic Journal: Macroeconomics, 7(3), pages 43-83.

Jaimovich, Nir and Joseph Floetotto (2008) Firm Dynamics, Markup Variations and the Business Cycle. Journal of Monetary Economics, 55, pp. 1238-1252.

Jordà, Òscar (2005) Estimation and Inference of Impulse Responses by Local Projections. American Economic Review, 95(1), pp. 161-182.

Kambourov, Gueorgui (2009) Labour Market Regulations and the Sectoral Reallocation of Workers: The Case of Trade Reforms. The Review of Economic Studies, 76, pp. 1321-1358.

Kilian, Lutz and Helmut Lütkepohl (2017) Structural Vector Autoregressive Analysis. Cambridge University Press. Forthcoming.

Lee, Donghoon and Kenneth I. Wolpin (2006) Intersectoral Labor Mobility and the Growth of the Service Sector. Econometrica, 74, pp. 1-46.

Morshed, Mahbub A. K. M., and Stefen J. Turnovsky (2004) Sectoral Adjustment Costs and Real Exchange Rate Dynamics in a Two-Sector Dependent Economy. Journal of International Economics 63, pp. 147-177.

Nekarda, Christopher J. and Valerie A. Ramey (2011) Industry Evidence on the Effects of Government Spending. American Economic Journal: Macroeconomics, 3(1), pp. 36-59.

Newey, Whitney K and Kenneth D. West (1987) A Simple Positive Semi-Definite, Heteroskedasticity and Autocorrelation Consistent Covariance Matrix. Econometrica, 51, 703-708.

Ostry, Jonathan, and Carmen M. Reinhart (1992) Private Saving and Terms of Trade Shocks: Evidence from Developing Countries, IMF Staff Papers 39(3), pp. 495-517.

Owyang, Michael, Valerie Ramey and Sarah Zubairy (2013) Are Government Spending Multipliers Greater During Periods of Slack? Evidence from 20th Century Historical Data. AER: Papers and Proceedings, 103(3), 129-134.

Pakko, Michael R. (2003) Substitution Elasticities and Investment Dynamics in Two-Country Business Cycle Models. The B.E. Journal of Macroeconomics, 3(1), pp. 1-20.

Pappa, Evi (2009) The Effects of Fiscal Shocks on Employment and the Real Wage. International Economic Review 50, pp. 217-244.

Pedroni, Peter (2001) Purchasing Power Parity Tests in Cointegrated Panels. The Review of Economics and Statistics, 83(4), pp. 727-731.

Pedroni, Peter (2004) Panel Cointegration: Asymptotic and Finite Sample Properties of Pooled Time Series Tests with an Application to the PPP Hypothesis. Econometric Theory, 20, pp. 597-625.

Ramey, Valerie A. (2011) Identifying Government Spending Shocks: It's All in the Timing Quarterly Journal of Economics, 126(1), pp. 1-50.

Ramey, Valerie (2013) Government Spending and Private Activity, published in 'Fiscal Policy After the Financial Crisis' eds. Alberto Alesina and Francesco Giavazzi, University of Chicago Press.

Ramey, Valerie and Sarah Zubairy (2017) Government Spending Multipliers in Good Times and in Bad: Evidence from U.S. Historical Data. Journal of Political Economy, forthcoming.

Riera-Crichton, Daniel, Carlos A. Vegh, and Guillermo Vuletin (2015) Procyclical and Countercyclical Fiscal Multipliers: Evidence from OECD countries. Journal of International Money and Finance, 52(C), pp. 15-31.

Rodrik, Dani (1998) Why Do More Open Economies Have Bigger Governments? Journal of Political Economy, 106(5), pp. 997-1032.

Schubert, Stefan F., and Stephen J. Turnovsky (2002) The Dynamics of Temporary Policies in a Small Open Economy. Review of International Economics 10(4), 604-622.

Shimer, Robert (2011) Wage and Price Rigidities. Mimeo. http://www.eief .it/files/2011/ 03/wage-price-rigidities.pdf

Stockman Alan C. and Linda L. Tesar (1995) Tastes and Technology in a Two-Country Model of the Business Cycle: Explaining International Comovements. American Economic Review 85(1), pp. 168-185. 
Wacziarg, Romain and Jessica S. Wallack (2004) Trade Liberalization and Intersectoral Labor Movements. Journal of International Economics, 64, pp. 411-439.

Yang Shu-Chun Susan (2007) Tentative Evidence of Tax Foresight. Economics Letters, 96, pp. 30-7.

United Nations Comtrade Database (2017) Classification of Broad Economic Categories. 